\title{
What Farmers Read and Like
}




\section{WHAT FARMERS READ AND LIKE}

A record of experiments with readership on Wallaces Farmer and Wisconsin Agriculturist, 1938-1961

\section{DONALD R. MURPHY}

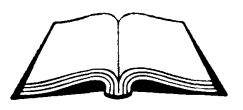

lowa State University Press, Ames, lowa 
DONALD R. MURPHy joined the staff of Wallaces Farmer (Des Moines, Iowa) in 1919. He was acting editor 193346 , in the period when Henry A. Wallace in Washington, D.C. was carried on the masthead as "Editor on leave of absence." Murphy continued to serve as editor, 19461955. After retirement as editor in 1955 , he became director of editorial research, $1955-60$ and later contributing editor, 1961-. He was also, 1940-57, director of editorial research for Wisconsin Agriculturist (Racine, Wisconsin). Iowa State University gave him an award for "distinguished service to technical journalism" in 1955. In 1957, the American Association of Agricultural College Editors gave him the Reuben Brigham Award "for meritorious service to journalism." His articles on readership have appeared in Journalism Quarterly, Printers' Ink and Advertising Age. From 1945 to 1955, he was chairman of the agriculture committee of the National Planning Association and vice-chairman since 1955 .

(C) 1962 by The Iowa State University Press,

Composed and printed at Ames, Iowa, U.S.A. 
$1 N 4784.43$

$\left.M{ }^{2}\right)$ SW

To

Henry A. Wallace

A farm paper editor who, by example,

taught his staff to test hunches by experiments 
$\therefore$ 


\section{Introduction}

The magazine world is a hazardous one. A sure path to failure is to publish the same magazine this year that pleased last year's readers. Not only do needs and interests change, the audience itself changes as old readers depart and new ones take their place.

What every magazine seeks is a path of reason - neither a strict traditionalism nor a nervous pattern of change for its own sake.

Is there a place for research in this unending quest? Can cold statistics and experimentation be used without crippling that spirit of originality that a lively, living magazine must have? Don Murphy believes they can, and he has done much to prove his point.

Murphy's consuming interest in research as an editorial tool dates back to the early 'thirties. His regular readership and opinion polls began at Wallaces Farmer in 1938 and at Wisconsin Agriculturist in 1940. They are the oldest sample surveys in the farm magazine field, and some of the oldest for any newspaper or magazine.

Critics of editorial research claim that readership 
studies necessarily look to the past instead of the future. For the most part they are used to tell which of several alternatives is least desirable. They cannot by themselves create or invent new and better choices.

These are criticisms I am sure Don Murphy and his colleagues would readily accept. Surveys and experiments can give the skilled editor a particular kind of tested information to supplement his other resources. They cannot tell him how to be creative.

Yet Murphy has, in fact, been strikingly creative. The magazines under his influence have developed an extremely effective writing style - clear, simple, and direct. They use larger and more open type faces. Layouts are clearer and more straightforward. There is increased recognition of a kind of article that before did not even have a name - "dirt copy," which tackles head-on the urgent and immediate problems of farm families.

In two remarkable ways Murphy has shown his concern for the values and methods of the true scholar.

First, he has continuously developed his competence and knowledge of research techniques and has applied them ruthlessly to his own ideas and hopes. Preconceptions have not shaped his results, and he has not been afraid to say "I was wrong" or "I don't know."

Second, he has followed a policy rare in modern commercial journalism: the results of his work have been published freely and openly. Competitors are free to examine his methods, his reasoning, and his conclusions. The result has been a wholesome and continuing discussion of editorial research among his fellow farm magazine editors for nearly thirty years. 
Don Murphy believes that this book highlights the important aspects of his work. In fact, the report is quite incomplete without a look at the two farm magazines with which he worked so closely. Besides the other visible marks of his presence, he has left them a valuable tradition of using research creatively and imaginatively.

Another chapter missing from this book must be read in the other American farm magazines - Murphy's competitors, if you will. His influence upon them is indisputable. His own earnest spirit of inquiry, and his willingness to share his ideas with others, have stirred up among farm magazines a refreshing spirit of selfscrutiny and a heightened concern about the reader and his needs. The credit is not Murphy's alone, but he has been an unfailing source of encouragement and support.

It is a pleasure to pay tribute to such a worthwhile service.

BRYANT E. KEARL

Chairman, Department of

Agricultural Journalism,

College of Agriculture,

University of Wisconsin 



\section{What This Book Is About}

On Wallaces Farmer and Wisconsin Agriculturist, we've been testing readership for over 20 years. We started in Iowa (Wallaces Farmer) in 1938; in Wisconsin (Wisconsin Agriculturist) in 1940.

Opinion measurement on current affairs (Gallup and Roper style) started at the same time.

In over 20 years, what have we learned about farm response to editorial and advertising copy? This book is a summary of some of the high points of this experience.

The book was designed in the first place as a legacy from the author to his associates on Wallaces Farmer, Wisconsin Agriculturist and Prairie Farmer. The experiments may also interest editors of other publications, advertisers, advertising agencies, students of journalism and marketing and any others who deal with farm audiences in the Middle West.

I hope this publication may also stimulate others to write down and publish results of their own experiments. Much more work is being done in this field than is generally recognized, but far too little gets into a permanent record. Research men are busy; editors are loaded down with other chores and sometimes publishers feel that it is unwise to give away what they think are trade secrets. 
For details on survey methods and reports, turn to Chapters 15 and 16. When sources are not given in the notes, the data reported come from the files of the Research Department, Wallaces Farmer and Wisconsin Agriculturist.

Two cautions are stressed throughout the book. They are repeated here for emphasis:

1. These experiments deal with farm audiences in Iowa and Wisconsin. We have no data of our own on other readers. However, experiments in other states indicate that most Middle Western farmers and many non-farmers respond in somewhat the same way as do Iowa and Wisconsin farm people.

2. Tastes change. What was true of copy in 1940 may not be true in 1960. Emphasis in the book is therefore given to fairly recent experiments.

In 20 years, we have reported frequently on results of editorial research. Other publications have used our results; we have borrowed from others. The art - or science - of communication has thus been advanced.

While the author has been in charge of editorial research on both Wallaces Farmer and Wisconsin Agriculturist from 1938 through 1960, the contributions of others have been great. Clifford Gregory, then associate publisher of Wallaces Farmer, made the policy decision in 1938 that started this work. On the Wisconsin Agriculturist, David Klinger, W. C. Voskuil, Ralph S. Yohe, Douglas Sorenson, and Rosemary Reid have, at different times, contributed much to these experiments. On Wallaces Farmer, Arthur T. Thompson, Richard Pommrehn, Richard Albrecht, Leon Thompson, and David Bryant have been active in this field. Jean Ginsberg and 
Dorothy Taylor, editorial assistants at Wallaces Farmer, kept the records which made this report possible. Clara Bucka's work on the index was invaluable.

Looking ahead, Richard Pommrehn, director of research for the three papers, will continue this experimental work. Richard Albrecht, editor of Wallaces Farmer, and Ralph Yohe, editor of Wisconsin Agriculturist, will continue to contribute to the research program.

We owe a great deal to professional workers in the field of research. Special thanks go to Norman Strand, Arnold King and Raymond Jessen of the Statistical Laboratory, Iowa State University at Ames. We are indebted also to many workers in schools of journalism, particularly Robert Jones of the University of Minnesota, Charles Swanson, formerly of the University of Iowa, Ralph O. Nafziger and Bryant Kearl of the University of Wisconsin, Wilbur Schramm of Stanford University and Kenneth Marvin, Rodney Fox and Harry Heath of the Iowa State University at Ames. Dr. Louis Bean's advice has often stimulated our research. Our friends in the Association for Public Opinion Research and the Association for Education in Journalism have also been helpful.

This manuscript has been helped by critical reading and suggestions by several of those named above, principally Pommrehn, Albrecht, Yohe, Sorenson and Miss Reid. I have also profited by the suggestions of Dr. D. B. Murphy. The errors that remain are, of course, mine.

DONALD R. MURPhY 



\section{Table of Contents}

Introduction - Bryant E. Kearl . . . . . 1

What This Book Is About . . . . . . . . . . 5

1. Using Research in Farm Publications . . . . 11

2. Front Covers That Attract Readers . . . . . 29

3. Does a Second Color Help? . . . . . . . . . 43

4. What Kind of Illustration? . . . . . . . 61

5. Page Position and Readership . . . . . . . 85

6. Heads That Pull In Readers . . . . . . . 95

7. More Experiments in Readership . . . . . 107

8. What Kind of Folks Read Your Ad or Article? . 124

9. The Problem of the Non-Reader . . . . . . 143

10. Opinion Polls and Readership . . . . . . 150

11. Subjects That Appeal . . . . . . . . . 161

12. Just Getting Read Isn't Enough . . . . . . 170

13. Research in the Future . . . . . . . . . 188

14. What Kind of Editor? . . . . . . . . 200

Survey Methods . . . . . . . . . . . 209

Survey Report - examples . . . . . . . 222

Notes to Citations . . . . . . . . . . . . . . 237

Books To Read . . . . . . . . . . . . . . 241

Index . . . . . . . . . . . . . . . 243 



\section{1.}

\section{Using Research in Farm Publications}

How doEs A FARM PAPER happen to get started on research in the field of readership? Probably because a farm paper editor is likely to think in terms of experiments. Experiment station data on corn yields and hog feeding are the editor's daily diet. Why not apply the same methods to readers?

The only surprising thing about readership surveys in farm papers is that they came so late. It has been said, "Without readership surveys a farm paper editor is like a farmer who throws feed through a hole in the fence to hogs he never sees. He doesn't know whether they eat the feed or reject it. He doesn't know whether the hogs are gaining or losing."

Henry A. Wallace, from 1904 until he left Wallaces Farmer for Washington in 1933, was continually running tests on different strains of corn. Why not use similar methods on readership?

"We must get at it," said Wallace. But the actual work came after his time. What Wallace had done was 
to make the staff alert to the experimental approach to any problem.

"Ted" Gallup, working in Des Moines on readership surveys in the 'twenties, started many people thinking about experiments of this kind. The Gallup and Roper opinion surveys in the election of 1936 helped to emphasize these possibilities.

It was 1938 before Wallaces Farmer started the Wallaces Farmer Poll and began to report on farm attitudes on elections and - more important to the paper - about farm reading habits.

Some editors insisted that readership surveys were not needed and that letters to the editor would give a picture of farm response to copy. We checked this several times. For instance, we asked farm people through the poll about their views on social security for farmers. A big majority approved. At the same time, we checked the letters on the subject. The letters only gave a 50-50 break to social security.

Ballots printed in the paper and sent in by readers also proved to be misleading. Prairie Farmer ran an experiment along this line and checked mailed-in-ballots against a personal interview survey. The two failed to match.

What Wallaces Farmer did, therefore, was to set up a polling system using a sample of around 400 interviews (200 men and 200 women) to check readership. The sample was distributed over the state according to the economic regions as defined by the U.S. Department of Agriculture. Interviews were made by farm women trained by the Wallaces Farmer staff.

What do we mean by readership? If the respondent (any adult on a farm into whose mailbox the publica- 
tion is delivered) said that he remembered reading the issue in question and could identify one or more items as having been read, he was classified as a reader.

After a respondent was identified as a reader, the key question by the interviewer on each page of the issue was, "Did you HAPPEN to see or read anything on this page?" The word HAPPEN is stressed to support the interviewer's opening statement that there is nothing especially virtuous about readership. We do not want the non-reader of an article to feel guilty about being a non-reader.

The respondent's answer on any page is likely to fall into one or more of the classes below. In the first place, he will have a page score. Either he read or saw nothing on the page, or he did notice something. If he did notice something, he is given a score for "Any This Page."

Some possible reports on advertisements and articles are listed below:

\section{Advertisement}

1. Nothing

2. "Any This Ad" - Respondent has seen or read one or more features of this particular advertisement

3. "S e e n" - Respondent h a s looked at a picture or a head

4. "Read $S$ o $\mathrm{m}$ e" - Respondent has read less than $h$ llf of a particular piece of copy

5. "Read M o s t" - Respondent has read half or more of a particular piece of copy
Article

1. Nothing

2. "A n y Th is Article" - Re spondent has looked at head, picture, or read something in the article

3. "S e e n"-Respondent $h$ a s looked at picture or head

4. "Read Some"-Respondent has read less than half of article

5. "R e a d Most" - Respondent has read half or more of article

An advertisement, therefore, might have one score for "Any This Ad;" another for "Seen" on the head; another "Seen" on the illustration; another score for 
"Read Some" on a block of sales copy; another for "Read Most" on the same block of sales copy. Scores for men and women are always reported separately.

In the tables that follow, the figures given are always percentages of the sample used. When the men's sample is 200 cases, a score of 50 per cent, of course, means that 100 men responded in the way indicated. In split runs the A sample and the B sample each includes 100 men and 100 women. A score of 50 per cent means that 50 cases responded in the way indicated.

On opinion polks, the sample is larger and not so constant. On breakdowns of readership surveys, the sub-samples are smaller; and they vary. In each case, however, when there are exceptions to the rule noted in the paragraph above, the sample size is given.

While readership surveys (except in a few early surveys) always use a constant sample of 200 men and 200 women, opinion polls vary in size. The opinion sample ranges from 400 to 700 interviews in each state.

Opinion polls, of course, deal with a sample of all the farm men and women in each state. Readership surveys deal with a sample of the subscribers in each state.

One of the hazards of setting up your own survey machinery is that your interviewers may show a bias in favor of the paper that hires them. We tried to offset this in training sessions to point out necessity for keeping absolutely impartial approaches and comments.

We also checked our survey results against surveys made by independent operators. The Continuing Study of Farm Papers, conducted by the Advertising Research Foundation, ran a survey in the September 20, 1947 issue of Wallaces Farmer. (1)

Our survey crews checked the same issue independ- 
ently. Was the Wallaces Farmer Poll getting higher readership scores than the Continuing Study? At our request, Professor Roscoe Giffin of Iowa State University went over the results and found that with men, in six cases our scores were higher than the Continuing Study. In 49 cases our scores were lower. In one case, they were exactly the same. With women, in eight cases our scores were higher than the Continuing Study and in 54 cases, lower. In one case, the score was the same.

Starch makes regular checks on readership of Wallaces Farmer and Wisconsin Agriculturist. Starch scores, as a rule, tend to run a little higher than ours, especially on ads. There is some difficulty in comparison because surveys are made in different months. In 1959, however, we had a readership survey of Wisconsin Agriculturist in October, and Starch had one of the same magazine in November.

Of 11 editorial departments, the Read Most scores compared as follows:

OUR SURVEY

Read Most

Men Women

Average of

11 departments . . $\quad 34 \% \quad 36 \% \quad 38.3 \% \quad 34.0 \%$

This seems a reasonably close fit. On the whole, it does not seem that the readership scores in our surveys are biased because our interviewers do the work. It may help impartiality that our interviewers are trained in pre-election polls and know that errors from bias will show up.

A series of surveys by the Statistical Laboratory of Iowa State University at Ames gave us further information. These surveys, in 1947, 1951 and 1955, told where 
farmers go to get information on different subjects. (2) They gave us a better picture of our subscribers, what they were like, and what kind of subjects interested them.

It should be kept in mind that throughout this book, the readership scores are given with readers of the issue as a base. Non-readers are also measured but, of course, in a different way.

A reader, as noted above, is any adult in the subscriber sample, who recalls one or more items in the issue. A non-reader is any adult in the sample of subscriber homes who reported that he or she had read nothing in the current issue.

While readership studies are built around readers of the current issue, the non-reader is also important. Professor Bryant Kearl, head of the Department of Agricultural Journalism at the University of Wisconsin, said, "A description of non-readers could be one of the most useful parts of a readership survey." (3) Chapter 9 goes into this.

What did we learn from the early readership surveys? Perhaps the first thing was to avoid jumps. We found that when an article started on page 10 and jumped to page 50 , many readers were lost.

This seems obvious enough now. Since 1938, most publications in our field have abolished the jump. It is still used in magazines which use extra-long articles or stories. In these cases, however, the opening page or spread, featuring a big illustration and not much type, is really only an expanded plug. 
In our early experiments, we found that we lost about 30 per cent of our readers when we had a sizable jump. If the jump were dressed up with a cut and a strong head, the loss was cut down.

In March, 1944, we ran another test. An article starting on page one scored 61.1 for men there; the runover on page 21 scored 49.7. Somewhat later, we tried starting an article on the right-hand page and continuing it on the following left-hand page. This lost readers, too.

A detailed report on this point came from the University of Iowa in 1958. Six articles in one publication started on the right-hand page and were continued on the following left-hand page. These runovers lost, on the average, 49 per cent with men and 25 per cent with women.

The answer, so far as we were concerned, seemed plain enough back in 1940. Complete every article on the page on which it starts. If the article is longer, let it run from a left-hand page to a right-hand one - but no farther. This policy, of course, meant more editing and more rewriting. But most farm publications, including ours, don't do as much desk work on copy as they should anyway.

Readership scores were helpful in showing us which kind of copy was likely to be read and whether an article appealed to young readers, to old readers, to men, to women, to big farmers, to small farmers, to owners, to tenants, and so on.

What these surveys lacked was a definite comparison between different layouts, uses of color, styles of 
cuts, placements of copy and other points. We could say that Ad A, in January, scored 40 per cent Noted with men, and that Ad B, in March, on the same kind of product, scored 30 per cent Noted with men. But did that mean Ad A was any better? A snow storm in March, a thaw in January, might have changed reader response to the two issues.

To give a fair test to editorial copy or to ads, it seemed necessary to expose this copy to readers at exactly the same time. This meant using what we called a "split run."

The term "split run" has since changed its meaning for many. Now it often indicates that Magazine A will run special copy in, for example, Illinois and Indiana. The same pages will carry special and different copy for Ohio and Pennsylvania.

Our "split run" goes back instead to the practice of newspapers with mail-order ads. With newspapers, every other one that came off the press would have different copy. Ad A would go to half the readers; Ad $B$ to the other half. The results were measured by coupon return.

This worked well for mail-order ads. It was no help to other kinds of advertisers, to whom coupon returns were not important.

What we did was to set up two samples in each state. Think of Iowa, with its 99 counties, as a checkerboard. We sent A copies to the red counties, and B copies to the black counties.

Actually, we never used this big a sample. Ordinarily, we interviewed in about $20 \mathrm{~A}$ counties and $20 \mathrm{~B}$ counties. The interviews in the A counties were distri- 
buted proportionately among the five economic regions of the state. The same was done in the B counties. We ended up with two samples, closely matched - 100 interviews with men and 100 interviews with women in the A counties and the same number in the B counties.

We tried our first split in 1946 to test readability levels. When Rudolph Flesch published his doctoral dissertation at Columbia on the subject back in 1944, we got one of the copies and began to wonder about its applicability to our problems. With his Art of Plain Talk (Harpers, 1946) we settled down to test his theories.

The Flesch hypothesis was that copy with short sentences, short words (few affixes) and "personal" words would attract and hold more readers than copy with longer sentences, longer words and fewer "personal" words.

In the March 1, 1946 issue of Wallaces Farmer, we ran three splits based on the Flesch formula. The main thing we learned from this was that we were shooting too high. We moved - in Flesch's words - from a seventh grade level to a sixth grade level. Our readers didn't notice the difference.

Only when we moved to a much simpler level did the new copy take hold. The Flesch index of 1.5 seemed to increase readership. What did this mean? The copy would average around 12 words per sentence, 20 affixes for 100 words and 10 personal references per 100 words.

In November, 1946, we tried again. This time we split three men's articles and one woman's article.

Remember that nothing was changed except the 
style. The head, the illustration and the theme had not been altered. The copy was edited only to get different levels of readability in terms of the Flesch index.

In the four splits, the low Flesch copy ranged from 1.11 to 1.76 . The high Flesch counts ranged from 2.48 to 4.27 .

Of the eight comparisons (using men and women for each split), we couldn't use three. On two pieces of copy designed for men, the women's score was too low to provide any answers. On one piece of copy the men's scores were too low for us to use.

Of the five split comparisons, where the number of readers was fairly high, one piece of men's copy showed a loss of 9.4 per cent for the low Flesch score. With the other four, increases ranged from 7.3 to 66 per cent for the low Flesch score over the high score. (4)

We have since tried similar splits in Wisconsin $A g$ riculturist and in later issues of Wallaces Farmer. Experiments at the University of Iowa made another check. (5) The results seemed clear enough. Other things being equal, simple language scored high.

Does this mean we try to write for morons? Not at all. An experiment at Iowa State University at Ames threw some light on this delusion. A split, using Flesch scores, was tried out on faculty members and students. Presumably the faculty members were the intellectuals. Yet the simpler Flesch copy did better with the faculty than with the students.

Why? The copy was in a field of more interest to the students than to the faculty. When readers are excited about a subject, they'll read difficult copy, printed in small type. When their feelings are neutral, they'll 
respond better to readable copy. If you can pick subjects of overwhelming interest, you can write badly and get away with it. Nobody is that good a picker. It is better to assume that some of your readers may be indifferent.

As members of our staff promptly pointed out, you can write very bad copy that has a good Flesch score. "I see a cat. Do you see a cat?" scores well on the Flesch index.

To avoid disasters like this, our rule was to write the copy as well as we could. Remember what the teacher said in English 1 -short, easily understood words, action verbs and not too many adjectives, specific and colorful descriptions, questions and names.

After writing - and often after publishing - we went over the copy with the Flesch index. The staff noted the scores and sometimes remembered them next time.

The extent of improvement in style may be measured in this way. Before we started testing, we took our usual copy (around 3.5 Flesch) and edited to bring it down to 1.5. After some months of education, we found that our usual copy was around 1.5 Flesch. To get a split, we had to edit to bring one version up to 3.5 .

One source of confusion in using the Flesch index is the fact that the author changed his measuring device. In the earlier Flesch scoring system the low score (note 1.5 above) was the best. In The Art of Readable Writing Flesch uses a measuring stick called "Reading Ease." (6) Here the high score is the best. The Reading Ease score is based on syllables per 100 and on words per sentence. 
A meritorious Reading Ease score would be 80 (much like the old Flesch index of 1.5). This would mean 12 words per sentence and 134 syllables per 100 words. A "difficult" Reading Ease score might be around 40 with 20 words per sentence and 173 syllables per 100 words.

Just to see if readability (in Flesch terms) was still important, we ran a split in Wallaces Farmer for January 16, 1960 on the article entitled "USDA Studies Soil Acidity" (Figures 1.2 and 1.3). Following is the Reading Ease Index and the resulting scores for men:

\begin{tabular}{|c|c|c|}
\hline & A (Difficult) & B (Easy) \\
\hline Words per sentence . & & \\
\hline Syllables per 100 words & 170 & 141 \\
\hline Reading Ease Index . & $\mathbf{5 6 . 0}$ & 74.6 \\
\hline Read Some on copy . & $32.0 \%$ & $47.0 \%$ \\
\hline Read Most . . . & $30.0 \%$ & $43.0 \%$ \\
\hline
\end{tabular}

It may help to show what happened here if we quote the lead from each version of the copy: (A was a USDA release)

Version A - 56 Reading Ease

The strong trend to heavier nitrogen fertilization, coupled with reduced use of lime over the past decade, is making our nation's soil more acid. That's why USDA has expanded its research into the problem of acidity.
Version B - 74 Reading Ease

Are you planning to put a lot of nitrogen fertilizer on your fields this spring? If you are, make sure also that you've spread enough lime on these same fields.

How do you determine "Reading Ease," according to Flesch? His Art of Readable Writing has a timesaving chart. The Flesch formula - if you don't use the chart - goes like this:

Multiply the average sentence length by 1.015 ; 
Multiply the number of syllables per 100 words by 0.846 ;

Subtract the sum of the two items above from 206.835.

What is left is Reading Ease.

It is a good deal easier to remember that you can get a Reading Ease score of 75 - which is pretty good - in the following ways:

15 words per sentence and 138 syllables per 100 words

\section{or}

12 words per sentence and 142 syllables per 100 words

\section{or}

18 words per sentence and 134 syllables per 100 words.

On the other hand, if your Reading Ease score falls below 50, you are probably losing readers. A score of 50 can be obtained in the following ways:

18 words per sentence and 164 syllables per 100 words

$$
\text { or }
$$

20 words per sentence and 162 syllables per 100 words

$$
\text { or }
$$

25 words per sentence and 156 syllables per 100 words.

It is still a good idea to get a copy of the book and use the Flesch chart.

If you are hitting somewhere between 60 and 80 on the Reading Ease Index, you are doing fairly 
well. But, note that we have had very high scoring copy-Read Most scores of 60 per cent or betterthat had a Flesch rating of 65 . And we have had low scoring copy - Read Most of 30 per cent or less - that had a Flesch rating of 80.

All this means is that subject matter is always more important than style. A hog article, in Iowa, will always outscore a sheep article. But a sheep article with a Flesch index of 80 will usually outscore another sheep article with a Flesch index of 55 or less.

There are, of course, other methods, and excellent ones, of scoring readability. We have stuck to Flesch because we happened to start with it and because it has stood up under split-run testing.

This was our start in split-run testing. I have reported it in some detail because it illustrates the methods used in many later experiments. The splitrun device has thrown light on many problems in advertising and editorial customs.

Each split-run reader-interest survey for some years has had five to seven splits with ads and the same number or more with editorial matter. Some of these proved that the differences we expected did not exist. Some showed a sharp reader response to a change of layout or copy.

Succeeding chapters go into detail on some of the things that advertisers and editors learned. 
Figure 1.1

\section{Editorial Page}

Page Score

\section{5\% Men}

\section{$\mathbf{5 5 . 0} \%$ Women}

\section{Who Reads Editorials?}

Do subscribers read the editorial page? What kind of subscribers?

Above is the first editorial page (Wallaces runs a spread of two) in a fall issue of Wallaces Farmer. Men read more editorials than women. As you might expect, the men's first choice was the editorial on hog prices, with a Read Most of 54.5 per cent.

Young men (21-34 years) read about as much as older men (50 and up). Farm men with gross incomes of $\$ 10,000$ a year read more than men with smaller incomes. 


\section{USDA studies soil acidity}

Research is intended to show how acidity can cut yields

Figure 1.2

THE smoxo tread to heswier

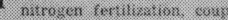
led with reduced ate oil lime

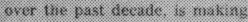

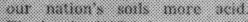
That's why L SDA liki expandien

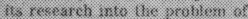
aciulity

while these expormonis use

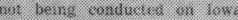

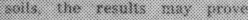

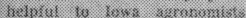

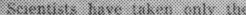

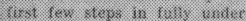

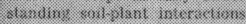

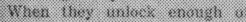

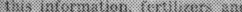

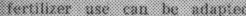

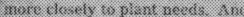
plant: cain lo bred to make

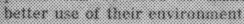
More than so freld expent ments on 23 agriculturally tant portant soil types are arw binto conducted in ecosperstion with state experiment stations to fil in the gaps of our understandin of how acidity decterses yeld These same sonls are alloo studhed under uniform enwiransnental conditions in greenhouse and laboratory to learn why they he hove as they do.

Altho this research is only in its second year, it has already wiven some interesting leads. For example, allatia was srown in the greenhouse on two siti loams that showed the same lime requirement when tested by sccepted soil tests

When limed, ane soil gave a 400-percent increase in yietd but the other gave mily a. 25 percent increase. $1 \mathrm{n}$. derstanding the reasan for such differanters to hehasion

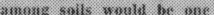
of the kers to accurate predistime of linse require. monis.

Toxic conicentristinns ot mant ganese and miminum are proth

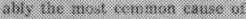
pont plant arowlit in andi smik

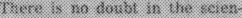

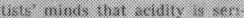

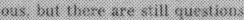

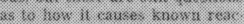
$72085:$

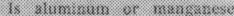

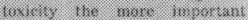
qurobilim:

Whotr what conditions sind hos

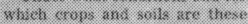
insiotices of partimition sismit cance:

What are the twientctions ot nutrients: susch as phio phorut:

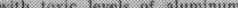
and minganese?

lins and to what extent does oxganic matter allesi. ate the loxieity of these ele. ate the toxicity of these ele ments? What are the critieal
levels of these elements in important erops?

Sini scidity is a serious soil management problem in the cornbell, says AfS soil scientist R. W. Pearson

From 1947 to 1957, the use of nutrogen fertilizer over the nax tion jumped from less than a million tons to 2.3 miltion lons a year. fut the use of limestone drompend over a third from 28 minis

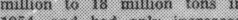
back to 22 million by 1953, Some back to 22 million by 1952 . Some
60 milion lons sre extimated to be needed innually to maintain oprimum soil resetion
Read Most

\section{Men 30\%}

\section{No, They Aren't the Same!}

The two articles here look alike, but they score differently. They have the same head, the same theme and the same structure. But they differ in the number of long words and long sentences.

In a series of splits, of which this is the most recent, copy with short sentences and short words has been shown to help readership. 
Figure 1.3 Soil acidity

Research is intended to show
how acidity can cut yields

ARe yov plannins to pur a A lot of nitrogen tertilizer on your ticlds this spring? li you are, make aure also that you ve spread enough line on these same tidids

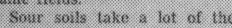

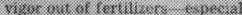

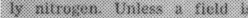
linsed. you wont

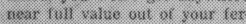

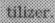

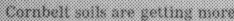

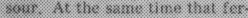

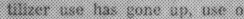

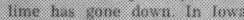

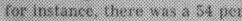

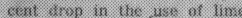

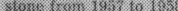

intionully, the same thin: is

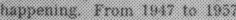

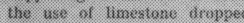
oret a lird At the sume lime the use of hitionsen fertitios more than dowblect

To keep the nation's solit sweet, farmers need to spread arousd si million tons of limesteme a year in 1958, only 22 million tons were spread.

Hest farmers know that sout soils make it harder to get stand of legumes. Not all reatis that the vatue of their fertilsu may be cut heavily when sppliec to sour sents.

To find out just what lakgpens to crops in sour soils, a number ot experiments nte beins ewr ried on ower the nation. as different field experiment: are besng carnied wi with 23 soi types:

nome of the answers 89 ,

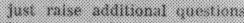
in one greeninuse experiment two sill hami were tested. Ay

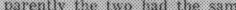
limu resumeanents. But the whint happenexis

When lined, one soll gave 3. thi perceni inscreiste is yieli. The otber zawi waly a 28 percemil. Nobudi yel is sure why.

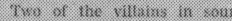

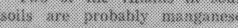

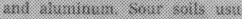

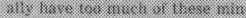

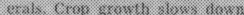

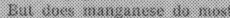

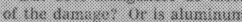
is in:is or culprit:

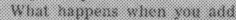

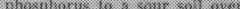
1.:30 : louded with mangamesce "mad

Does it lielp smat soil of thit kind to plow under grens ma nure or to add a lat of barnyared manuter" or does such action make lhing wrorse?

These are ssine of the ques tivns sclentists are axking them selves No linal answers have been detwrnimed yet.

In the meantime, il does seem certain lawi sour solls dion' get the bis bemetit: out of nitroset fertinzer. When you blan your program for 1060 erops you may want to was lime as well as nitrogen.

Tho the research is only in its second veat many interesting leads have already been pro. duced. in the futuris this re

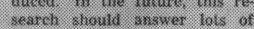
questions on soll icidity.

Here is the difference in the two pieces of copy:

A

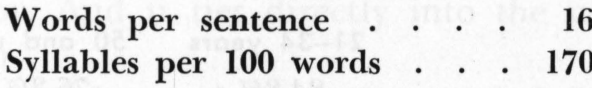

B

13

Editing A copy to the B standard raised the Read Most score for men fom 30 in A to 43 in B. Read Some scores showed a similar gain.

Wallaces Farmer, January 16, 1960 


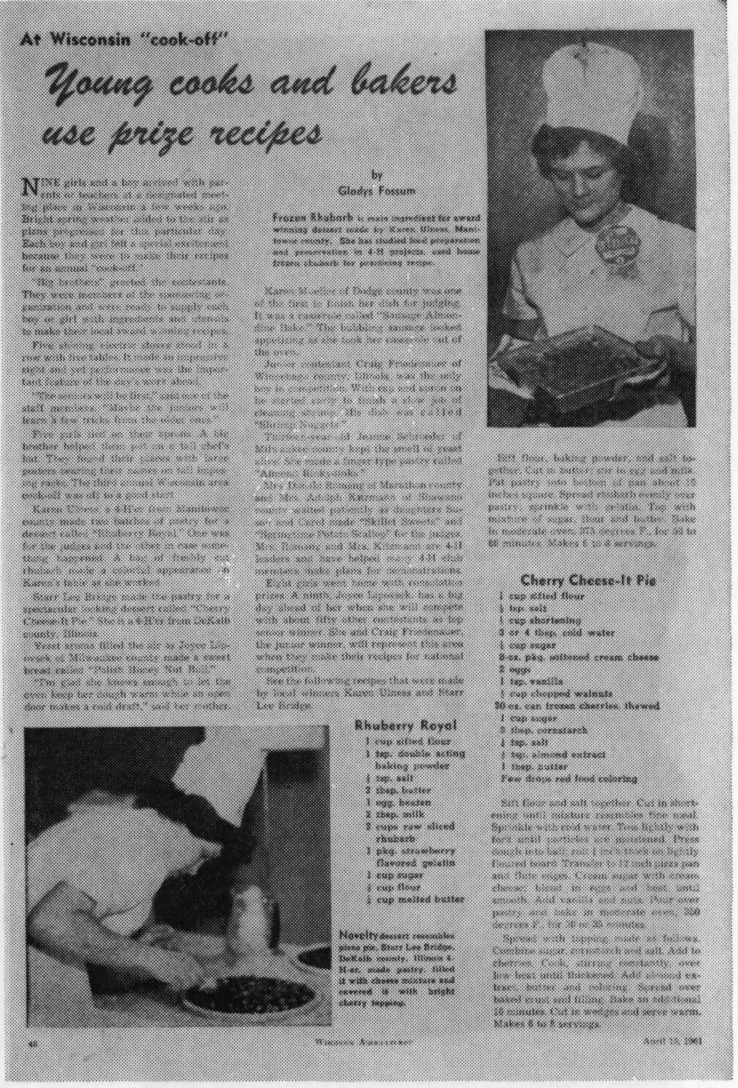

Figure 1.4

\section{Food Page}

Page Score

\section{Women 90.5\%}

\section{Recipes Pull Women In}

Farm women continue to read food copy, especially if there is a local angle. This Home Department lead page addressed to "Young Cooks" actually scored almost as well with older women as it did with younger ones.

$$
\text { Read Most . . . . } \begin{array}{cc}
21-34 \text { years } & 50 \text { and up } \\
84.8 \% & 76.3 \%
\end{array}
$$

The photo (upper right) of the Wisconsin farm girl, Karen Ulness of Manitowoc County, drew the attention of 90 per cent of the women readers of the issue. 


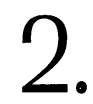

\section{Front Covers That Attract Readers}

A FARM PAPER EDITOR is in some ways like the publisher of a picture magazine who tries to build up his newsstand sales. But the farm paper's newsstand is the table in the front room where the mail is dumped. Which paper or which magazine in that collection will catch the eye of the possible reader?

We have to keep in mind that in Iowa half of the farm homes take four or more farm publications and three or more general non-farm magazines. Wisconsin farmers read a little less avidly, but the competition is still severe. And in both states, almost everybody takes a newspaper and has a radio and a television set.

The non-reader problem is a major one for an editor. And it ties directly into the use of the front cover.

How do we define a non-reader? He is any adult who lives in a family where the paper is received and who doesn't read the issue being surveyed.

Farm papers are not the only ones that have trouble. 
A good co-op newspaper, the Midland Cooperator, surveyed by the U. S. Department of Agriculture, had 44 per cent of its possible men readers in the non-reader class, and 33 per cent of the women. (1) A well-edited house organ of a feed company reported one internal survey which showed a non-reader problem of somewhat the same nature.

If page one demands attention, the potential nonreader may pick up the copy. If the bait is good enough, he may open up the paper and read something inside.

When you look over the score for non-readers, you realize how important page one is. Wallaces Farmer, for instance, has a 20 issue mean of 14.5 per cent men non-readers and 17.9 per cent women non-readers. The Wisconsin Agriculturist has a mean over 19 issues of 16.8 per cent men non-readers and 16.1 per cent women non-readers.

Remember that a 20 per cent non-reader figure does not mean that 20 per cent of the households on the subscription list sample had no readers of the issue surveyed. The non-reader figure deals with individuals, not with households. In visiting 10 households, one of our interviewers may find 16 readers and four nonreaders (20 per cent non-readers), but he may also find that the 16 readers are so distributed that there is, at least, one reader in every household.

The Advertising Research Foundation in its "Continuing Study of Farm Publications" found that Wallaces Farmer had 1.76 readers per copy in spite of the fact that the non-reader percentage for that issue was fairly high. (2)

One way to try to find out which cover is doing 
the job is to check non-readers. Wallaces Farmer did best with men in March 1954 and March 1952. In the 1954 issue, the non-reader score was 6.8 per cent. In the 1952 issue, the non-reader score was 9.2. What kind of cover was used in each case?

Each had a timely theme appropriate to the month and the season, a big head playing up this theme, a picture to illustrate it and a caption written in article style. In each case, plugs were added.

In March 1954, the page scored 94 with men; the copy scored 75 per cent Read Most for men; the head, not scored, was "Got Manure Hauled?" Four plugs, ‘all aimed at men, scored Read Some 63 for men and 32 for women.

Did these two covers score high because they were effective or because farmers do more reading in March? There is some evidence that these March covers did not score high simply because they were in March. We have had some low March scores. As reported later, we have had high scores in September, April and November.

Yet this does illustrate the value of the split run. Any effect of the season on the score is wiped out when we have a cover split. On the November 6, 1954 issue of Wisconsin Agriculturist the shift from a dairy cover (A) to a farm family cover (B) showed a marked difference among women in favor of B. November weather made no difference. $\mathrm{A}$ and $\mathrm{B}$ were affected the same.

In Wisconsin, we find that the lowest (therefore best) three non-reader scores for men appeared in the following issues: 
March 3, 1951 (non-reader score 9.7 per cent)

November 2, 1957 (non-reader score 12 per cent)

April 2, 1960 (non-reader score 10.7 per cent on $A$ copy).

Of these, the 1957 issue used the standard head above the cut and a somewhat weaker caption than some of our other good-scoring pages. The page score was 93 for men. The caption scored 70 for men.

The 1951 issue used a strong head also, but mortised it in the lower part of the cut. The caption was written in article style. Men scored 91 on the page and 79 on the copy.

Of these issues with a low non-reader score, only the April 2, 1960, A version broke the pattern. It had no head, a short caption, and fairly strong plugs. Score for the page was 90 for men, for the plugs 52 and for the caption 51 .

This question always comes up, "Why don't we get a 100 per cent score on a cover among readers of the issue? Doesn't a farmer notice the cover when he picks it up?"

Sometimes he doesn't. A farmer may turn directly to a special department like "What's Ahead." A woman may turn to the homemaking section. Each recognizes, by the different cover, that it is a new issue, but that is as much as some respondents will report.

In the listing above, women's scores on the cover have not been given. Mostly they were poor and for a good reason. The cover often did not have anything of interest for women.

There are some exceptions. In Wallaces Farmer (January 7, 1959), the theme was planning gardens. 
In the $\mathrm{B}$ version, the women's score was 89 per cent for the cover.

Another issue (January 18, 1958) had farm records as the theme with a man and woman in the picture. Scores for the picture were 85 per cent for men and also for women.

Shifting to Wisconsin Agriculturist, we find the April 5, 1958 issue had one of the high scoring covers. Here color was used on a dairy picture, and plugs played up with plenty of white space were put in the upper right hand corner of the picture. (It might be noted that a Wallaces Farmer cover using plugs in about the same position also got good plug results on this placing.)

The Wisconsin Agriculturist cover scored for the picture, 85 for men and 84 for women; for the plugs, 69 for men and 51 for women.

Two more Wallaces Farmer covers also might be noted. In March 16, 1957, there was a big head overprinted "When Neighbors Stop To Chat." The picture score was 91 and 86; the caption 74 and 59. Here the caption was mortised in the lower part of the cut.

In the September 20, 1958 issue, the head was overprinted "You Helped Buy Them," a reference to a campaign to buy gilts for flood-hit farmers. The picture scored 90.5 for men and 74.5 for women. A split on this issue showed that an expanded plug set like a caption and crowded with too little white space produced a low score.

What good are plugs? We are fairly sure that they do not help the score of the article plugged. Splits have seemed to prove this. That is why we now leave off the 
page number on the plug. What the plug does - if we are smart enough - is to pull readers into the issue.

An example is Wisconsin Agriculturist, October 3, 1959. On the cover split, we used "Harvest Time Comes to Wisconsin" as the A plug and "What Farmers Think of Khrushchev's Visit . . Page 20" as the B plug.

The article on page 20 scored 58 per cent Read Most for men in $\mathrm{A}$ and 59 in $\mathrm{B}$. For women, 45 in $\mathrm{A}$ and 45 in $\mathrm{B}$.

What kind of material goes best on page one? After going over reader-interest surveys for a number of years in both states, there seems a fairly strong case for the following ingredients:

1. Use a timely theme for picture, head and copy. If the theme deals with a subject likely to be on the farmer's mind at the time he gets the paper, he will probably look at the issue. This is standard editorial policy for planning timely articles.

EXAMPLE: On the October 5, 1957 Wallaces Farmer is a picture of a man greasing a combine. The head (below picture) is "Keep It Greased." The copy - handled like a short article - talks about soybean combining. Plugs also play up soybeans. The score for the page was 92 for men; 77 for women (Figure 2.6).

It might be noted also that the non-reader score for men in the October 5, 1957 Wallaces Farmer was 14.4, and for women 20.5. Yet, there was nothing on the cover for women readers. Another good cover was the September 15, 1956, Wallaces Farmer with the head "Feeders Moving Fast" below the cut. Copy, handled like a short article, dealt with late news on feeder shipments. Plugs hit other subjects. 
2. A strong head, 42-point or bigger, seems desirable to emphasize the cover theme. This head can either be overprinted on part of the cut (provided it's that kind of a picture) or better - played up heavily under the cut.

3. The caption should be handled like a short articlelarge type and enough detail to stress the theme.

4. Plugs should include some references to women's copy, and should be lively enough to qualify as good bait.

5. Change the cover style from issue to issue in order to make sure that the reader knows he is getting a fresh copy. A big head can help on this - so can changes in layout.

\section{NOTES ON COVER PAGES}

Pick out the major theme for the issue, the most timely, the most important. Use a photograph that illustrates this theme and put it on page one. An example is the November 5, 1949 issue of Wallaces Farmer. Corn had blown down early in the fall and there was the big job of picking up fallen ears. The cover played this up and got a page score of 96.4 per cent for men and 86.7 per cent for women. The same theme was used on page five, where men had a Read Most score of 65.1 and a page score of 89.2.

A caption under the cover picture should not be too long or too tight. In the A version of the January 17, 1959 Wallaces Farmer, a four-line caption (Vogue 12point) was stretched out to 47 picas. It scored badly, especially with women, against a caption set in 12point Corona, with short lines (14 picas). The score with women in A was 49; B, 70. This was women's gardening copy. 
Women and children, in a good picture, will draw men as well as women. The November 5, 1955, Wisconsin Agriculturist cover had a school scene in a close-up of children and teacher with a reverse head across top "How Well Can Johnny Read." There was no caption (probably a mistake) and plugs. Men scored 85.2 per cent and women 81.5 per cent for the page (Figure 2.1).

Another problem is the dirt picture vs. human interest picture. The November 6, 1954 Wisconsin Agriculturist ran a split of different covers. In A was a dairy picture (Bang's test) with a head "Blood Will Tell" and expanded caption. In B, was a farm family at the store buying clothes with a head "Sure Sign of Winter" and expanded caption. Both pictures did well; women gave B a little preference. Each had a big head, expanded caption and plugs. Each was timely.

\begin{tabular}{|c|c|c|c|c|c|}
\hline \multirow{2}{*}{ Any This } & \multirow[b]{2}{*}{ Page } & \multicolumn{2}{|c|}{ Men } & \multicolumn{2}{|c|}{ Women } \\
\hline & & $\stackrel{\text { A }}{93.4 \%}$ & $\stackrel{\text { B }}{95.3 \%}$ & $818^{A} \%$ & B ${ }^{B}$ \\
\hline Picture & $\log ^{\circ}$ & 92.0 & 92.9 & 80.9 & 90.7 \\
\hline Plugs . & . & 50.0 & 54.1 & 38.2 & 56.5 \\
\hline Caption & . & 79.2 & 65.9 & 55.4 & 69.4 \\
\hline
\end{tabular}

If you want women to read the issue, play to them on the cover. In October 5, 1955 Wallaces Farmer, the A issue of the split had a picture of a Master Farm Homemaker. B did not have a picture of a woman. The score for the page was 96 per cent for A with women, 62 per cent for $B$. 
Figure 2.1

\section{Cover Page}

Page Score

Men $\mathbf{8 5 . 2 \%}$

Women $\mathbf{8 1 . 5 \%}$

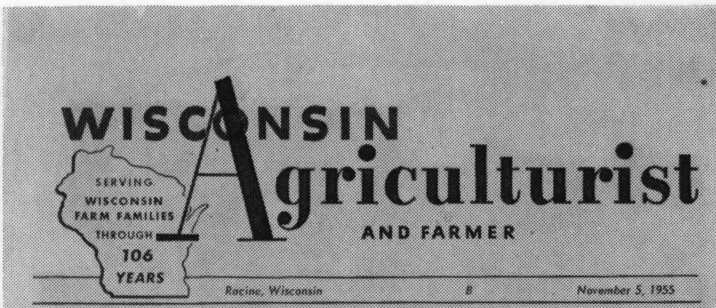

\section{How Well CAN Johnny Read?}

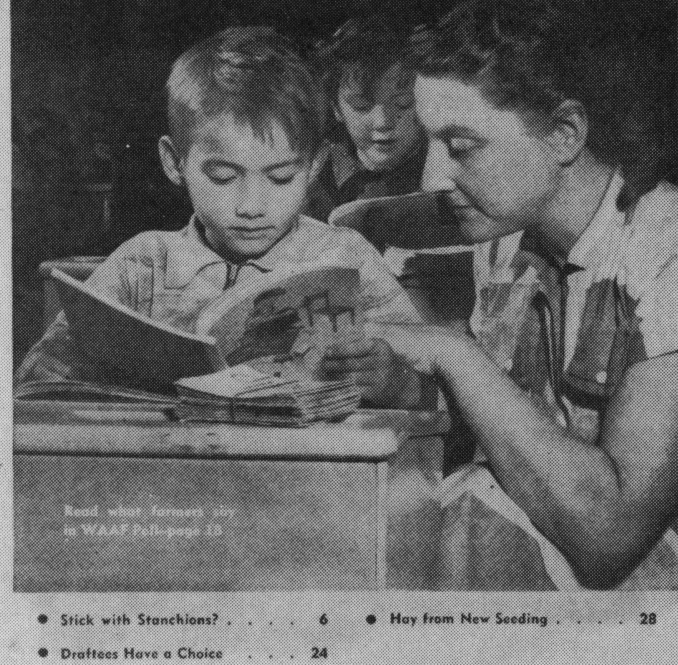

\section{Covers That Pull Readers}

Not every reader of an issue really looks at the cover. Some turn directly to the department they usually read. But an attractive cover can draw the attention of men and women who might otherwise be non-readers.

This Wisconsin Agriculturist cover did well with both men and women. It also built up an audience for the article on page 18 that was plugged by the cover and the caption. That article on Johnny and his reading habits scored 59.5 Read Most with women.

Wisconsin Agriculturist, November 5, 1955 


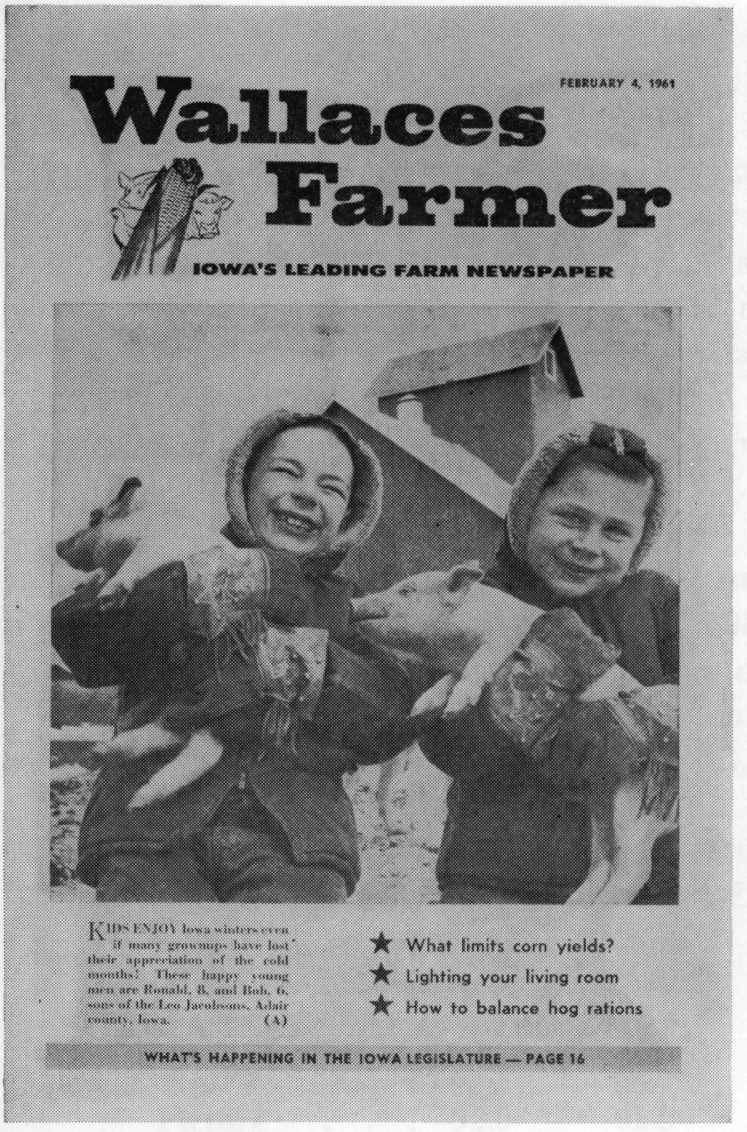

Figure 2.2

\section{Cover Split A}

Page Score

Men $97 \%$

Women $91 \%$

\section{Close-up Does Better}

In this cover split on Wallaces Farmer, both the closeup A version and the long shot B version did well with both men and women. However, the close-up A picture not only scored higher with readers, but also had fewer non-readers among those exposed to the issue.

This cover did an unusually good job in pulling women into the issue without scaring off men. Farm children in Adair (or Pocahontas) County, Iowa, appeal to farm men and women in Iowa. 
Figure 2.3

Cover Split B

\section{Wallaces}

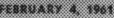

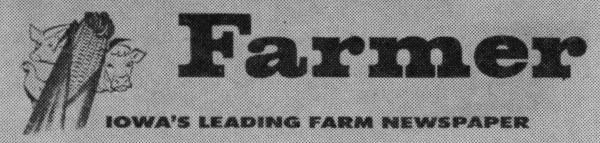

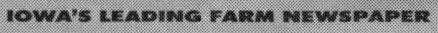

Page Score

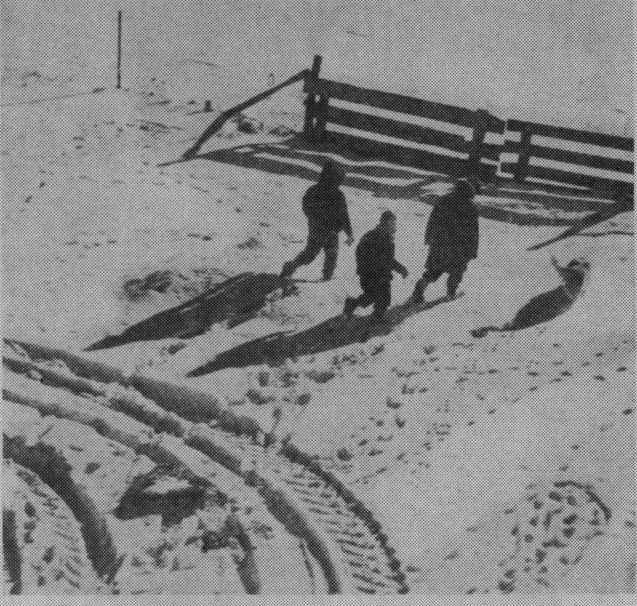

\section{Men 86\%}

\section{Women $\mathbf{8 1} \%$}

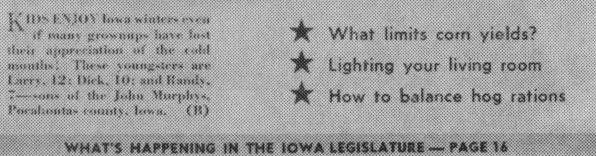

Scores for A and B follow. Note that readership held up fairly well down through the plugs at the bottom of the page.

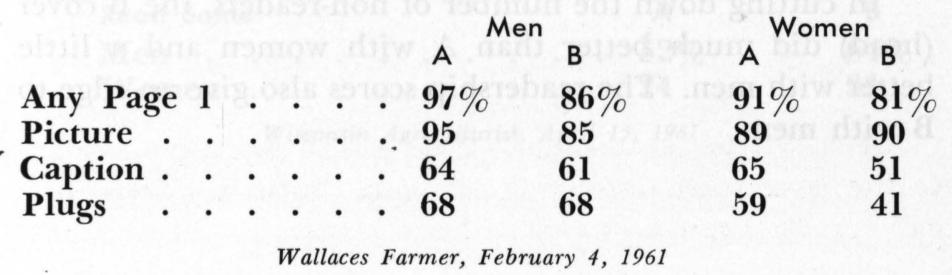




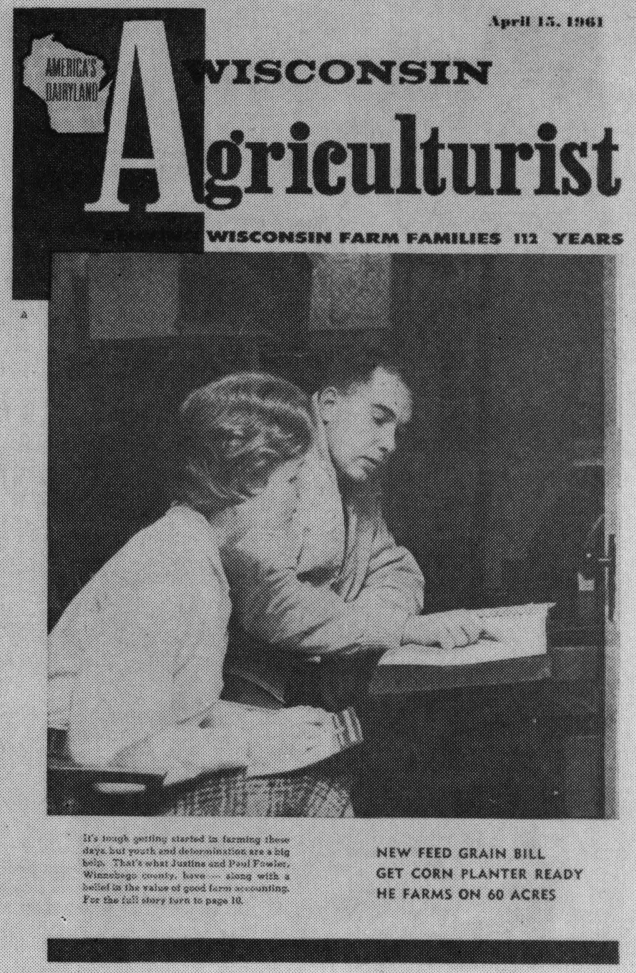

Figure 2.4

\section{Cover Split A}

Page Score

Men 86\%

Women 85\%

\section{The Headline Helped}

Does it pay to use a strong head on the cover? In this Wisconsin split, the A version uses no head; the B version uses a head. This is the only difference.

In cutting down the number of non-readers, the $\mathrm{B}$ cover (head) did much better than A with women and a little better with men. The readership scores also give an edge to B with men. 
Figure 2.5

\section{Cover Split B}

Page Score

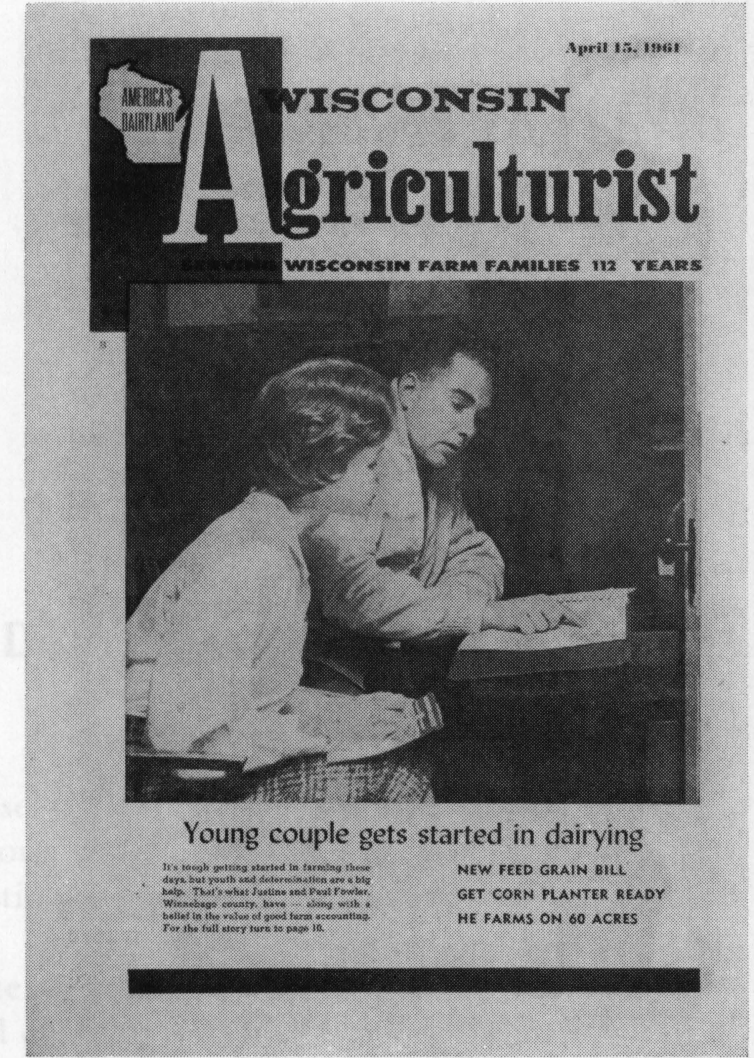

Men 94\%

\section{Women $83 \%$}

The head in B also pulled up the score for the caption in B. Men's scores were 52 for the caption in A and 70 in B.

The combination of picture, head and caption directed interest toward the article plugged. On page 10, this article showed a higher score in B for both men and women.

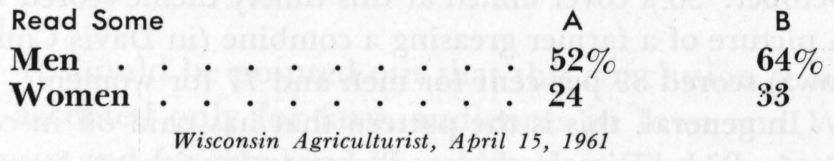




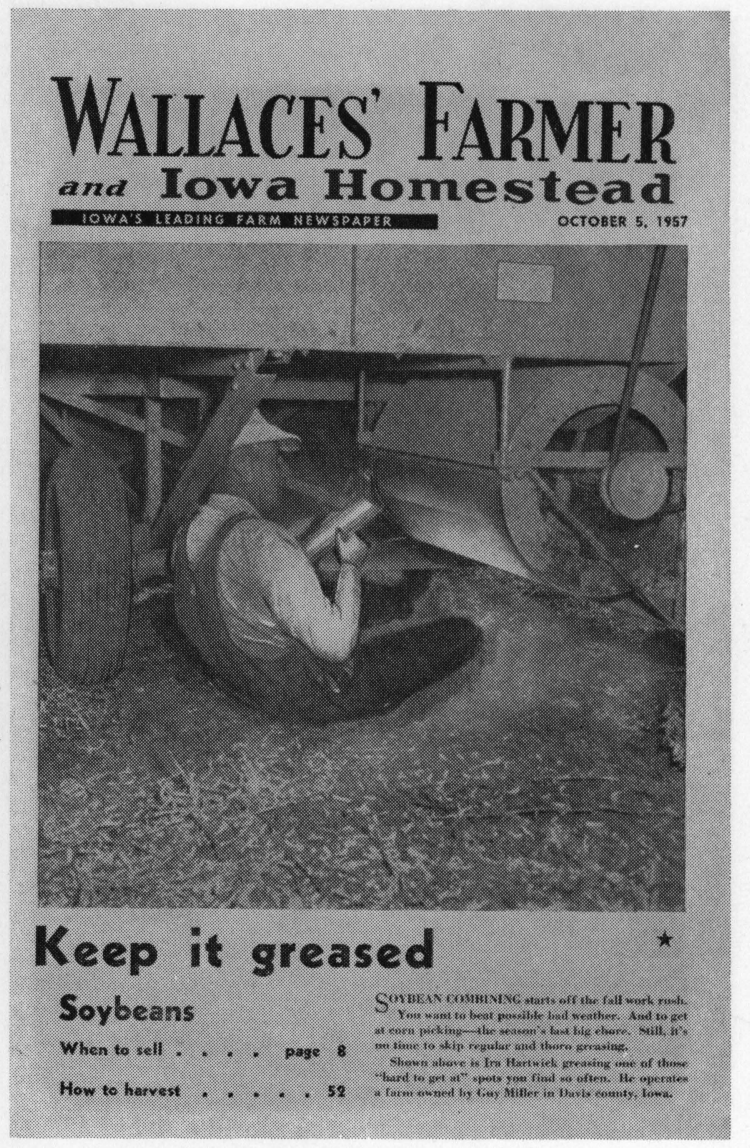

Figure 2.6

\section{Cover Page}

Page Score

Men 92\%

Women $\mathbf{7 7 \%}$

\section{Timely Theme Pays Off}

Soybean harvesting reaches a peak in Iowa in early October. So a cover aimed at this timely theme scored well. A picture of a farmer greasing a combine (in Davis County, Iowa) scored 89 per cent for men and 77 for women.

In general, this is the pattern that has paid off in cover scores. Pick a timely theme, illustrate it with an Iowa (or Wisconsin) farmer doing something appropriate and use headline and caption to emphasize the topic. 


\section{3.}

\section{Does a Second Color Help?}

Does IT PAy to use a second color (yellow, red, green, orange) on a layout for editorial matter or for advertising? This question has been the subject of over 30 splits.

The answers tend to run in one direction. Most of the time, a second color - in Wallaces Farmer and Wisconsin Agriculturist - doesn't do much to help readership.

This conclusion has exasperated all of us in the office. We like the looks of a second color. We think readers should like it. Unfortunately, it appears as if they don't. We keep thinking we'll yet find a color combination that will do something substantial for readership. Perhaps we will eventually, but we haven't yet.

It should be pointed out that this conclusion should be accepted only for farm audiences in Iowa and Wisconsin and for our kind of publication. The fact is that a second color is no treat to our readers. Our papers are full of second colors - especially red. If fewer ads 
used a second color, the ones that do use it might show up better.

To detail all the color splits would take too much space. Following are some high points:

White letters on red. This was used by Quaker Oats in Wisconsin Agriculturist (November 7, 1953, page 41) in the A version. B had the same head, but black letters on white, with a red line around the head (Figures $3.7,3.8)$.

\begin{tabular}{|c|c|c|c|c|}
\hline Women & & & (Reverse) & B (Black) \\
\hline Hea & & & $23.3 \%$ & $52.0 \%$ \\
\hline Sales Copy & (Read Most) & 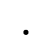 & 12.9 & 31.0 \\
\hline
\end{tabular}

The reverse head (as in A above) has been tested by many researchers. Their conclusions, in general, agree with ours.

Head in color. This split, probably because it is easy to handle, has been tried by us more than any other.

Typical is the Nutrena ad in the Wisconsin Agriculturist (November 7, 1953, page 21). A put the head in red; B in black.

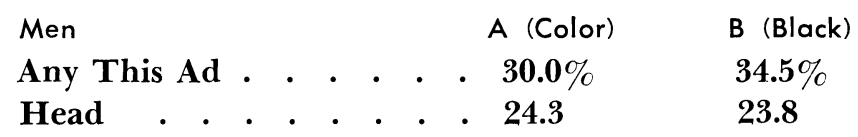

This has been the usual experience. There is no measurable gain through using a head in color. On some splits, it seemed that the black head scored a little better.

Overprint. We have used black letters on a red screen; black on a yellow screen or a yellow solid, etc. 
We did not have much luck with this, but a ferr splits seemed to hold some hope. Here is one:

Overprint (black on yellow) was tried in Wallaces Farmer (March 1, 1947). The head, "Why Work Hard at Chores" was black on yellow for A and black on white for B.

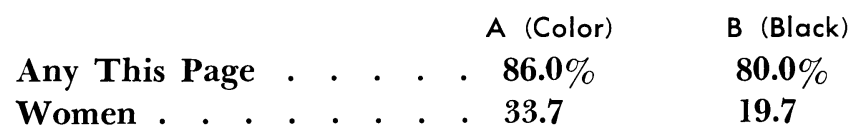

There is no difference for men, but with women, the difference is significant. Men, more interested in the article, were not impressed by the color. Women, not so much interested in the article, apparently responded to color.

This same tendency has showed up in other splits. The readers who were less interested in the copy might be lured by color or some other layout gadget. Those more interested in the copy paid no attention.

If we are trying for a dual purpose score (good with both men and women) and the article is aimed at men, color may help the women's score. If the article is aimed at women, color may help the men's score.

Does this tentative rule work with ads? Once in a while. But the evidence is stronger for editorial copy.

It makes a difference, of course, whether the overprint is imposed on a solid color or a screen. We haven't had much luck with solids; there is a tendency to smear. With red or green, the screen range has been from 40 to 60 . On the whole, 50 has been the best. With yellow, a heavy screen (70) has looked the best, though we have gone as low as 50 . A 50 screen with yellow, how- 
ever, tends to fade out. There have been no readership splits on the different screens.

What about an overprint of black on red? In the Wisconsin Agriculturist (November 3, 1951, page 9), a one-column, two-line head was overprinted in black on red in B; black on white in A.
Men
A
B (Color)
Read Some
$41.1 \%$
$36.1 \%$

Unchanged copy on the same page gave the edge to $\mathrm{B}$.

A heavy red border around the head was used in Wisconsin Agriculturist (February 20, 1954, page 6) for A. The color was taken off for B.
Men
A (Color)
B
Any This Page . . . . 93.3\%
93.2\%

For a test split, this copy was too attractive. It was a dairy story and pulled almost all the readers. Color made no difference here. It might have made some difference if the article had dealt with sheep or hogs, less popular than cows in Wisconsin.

Studies of 11 splits in Wallaces Farmer where color was used with ads were made by R. J. Pommrehn. This report deals with a variety of uses of color. None made any significant difference in the scores, except that in a few cases low scores for women on ads addressed to men were pulled up a little by color. (1)

Cornell University reports an experiment in a somewhat different field. A sample of New York dairymen were sent a leaflet on early and late cut hay and silage. 
Half of the sample got this leaflet (an advance print from Successful Farming) in black and white; half, in four color. (2)

Apparently the black and white had as much effect as the four color. The bulletin adds this caution:

It must be recognized that the test article used in this study had a high degree of attraction for the dairyman, since it directly affected profit. Consequently it might be expected that it would be read regardless of whether it was presented in color or in black and white. Possibly color is more important for attracting and holding attention among those for whom the item has less possibility of affecting profit.

This matches the experience of Wallaces Farmer and Wisconsin Agriculturist.

A yellow screen was tried out behind black type of "What's Ahead" in Wallaces Farmer (September 20, 1958) .

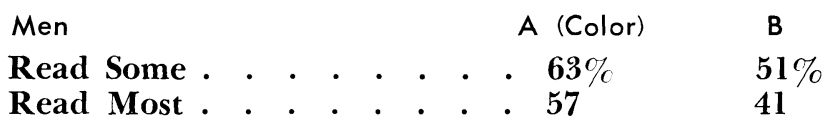

This made black on yellow look hopeful. But two later splits with black charts on yellow showed no advantage. We are inclined to say that black type on a yellow screen probably has some advantages but that the point needs further testing.

Red screen as background for department heads was tried out several times. The best showing was with “Country Air" Wallaces Farmer (September 20, 1958).

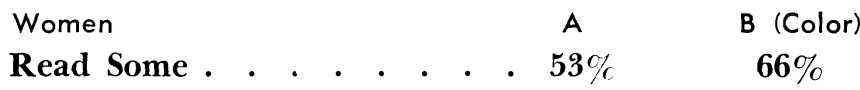


This and similar tests indicate the possibility that this use of color in a department head on a spread with no other color may show good results. Further experiments along this line are now being tried.

We tried in Wallaces Farmer (October 5, 1957) a standard layout, black and white, in B; in A, art decorations in red. The same copy was used - the same illustration and the same head. This was designed to answer questions about art work as well as color (Figures 3.9, $3.10)$.

\begin{tabular}{|c|c|c|c|c|c|c|c|}
\hline & & & A (Color) & B & A & $\begin{array}{l}\text { Women } \\
\text { (Color) }\end{array}$ & B \\
\hline Any Thi & is Pag & e & . $75 \%$ & $78 \%$ & & $53 \%$ & $\mathbf{5 6} \%$ \\
\hline Picture & . . & . & . 65 & 56 & & 37 & 42 \\
\hline Caption & . . & . & . 57 & 61 & & 28 & 42 \\
\hline Head . & . . & . . & . 66 & 70 & & 33 & 43 \\
\hline \multirow[t]{2}{*}{ Copy } & Read & Some & . 63 & 73 & & 39 & 49 \\
\hline & Read & Most & . 55 & 62 & & 29 & 40 \\
\hline
\end{tabular}

In this case, as in all splits, we take a look at unchanged copy on nearby pages. If there is a difference in A and B scores on unchanged copy, especially if this copy is on the same theme as the tested copy, we make allowance for this. In this case, unchanged copy on nearby pages had A scores running 5 to 10 percentage points higher than B. Allowing for this, the B copy, without color or decorations, seemed to be making a better showing than A.

Possibly the article was too popular to make a good test. An article with a score of 40 Read Some would give more weight to the value of the color and art work.

We were hopeful about a feed ad in Wisconsin $\mathrm{Ag}$ - 
riculturist (April 4, 1959). Here was functional color; the Duroc hog was entitled to be red. In A color was used on the picture, on the head and on the feed bag. Ad B was black and white (Figures 3.1, 3.2).

\begin{tabular}{|c|c|c|c|c|c|}
\hline & A & $\begin{array}{c}\text { Men } \\
\text { (Color) }\end{array}$ & B & $\begin{array}{c}\text { Women } \\
\text { A (Color) }\end{array}$ & B \\
\hline Any This Ad & . & $32 \%$ & $33 \%$ & $14 \%$ & $21 \%$ \\
\hline Picture . . & . & 31 & 33 & 14 & 21 \\
\hline Head . . & . & 20 & 19 & 4 & 8 \\
\hline \multicolumn{6}{|l|}{ Sales Copy } \\
\hline Read Some & . & 19 & 19 & 2 & 7 \\
\hline Read Most & . . & 14 & 10 & 2 & 2 \\
\hline Company nam & , etc & 19 & 16 & 6 & 6 \\
\hline
\end{tabular}

Color was skillfully used in this ad, but apparently made no difference in the response. 


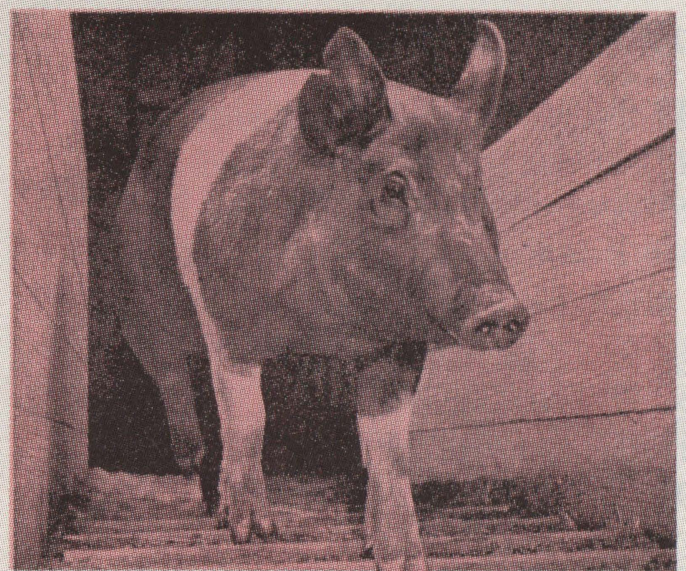

Cut cash outlay for feed to only $\$ 500$ per hog with Murphy's

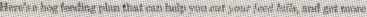

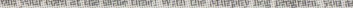

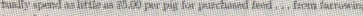
to raliekser

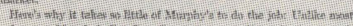

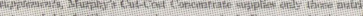

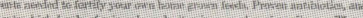

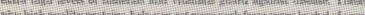

Phat ton Thenta Yunction

CUT YOUR FEED BILLS WITH MURPHY'S
Figure 3.1

\section{Red}

A

Any This Ad

Men 32\%

\section{Red Color on a Red Hog}

Splashing color around on heads and decorations hadn't done too well. More hope was attached to "functional" use of color. This can mean a red color on a picture of farm machinery when that farm machine habitually uses red. Or it can mean a red color on a red Duroc hog.

We tried a split with A showing the hog in color on a tinted background.

B was black and white. 
Figure 3.2

\section{Black}

B

Any This Ad

\section{Men 33\%}

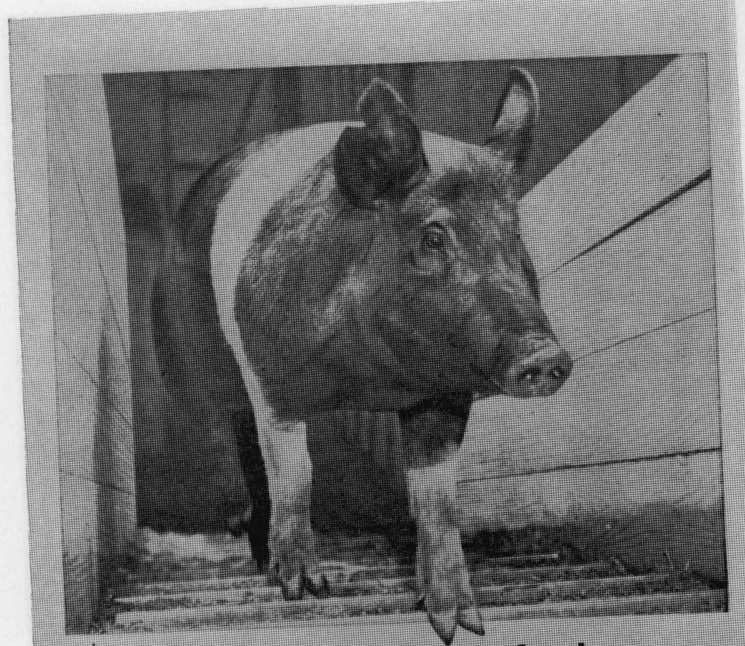

Cut cash outlay for feed to only \$ 500 per hog with Murphy's

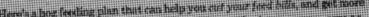

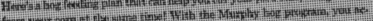

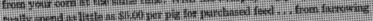
Rialy pen

masket.

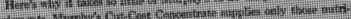

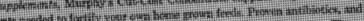

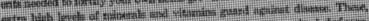

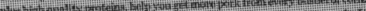

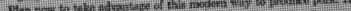

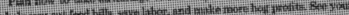
con tirs,

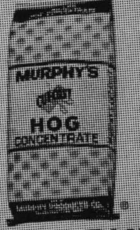

(2) Whoontin

MURFHY PRODUCVO COMFAR

Men's scores on the split follow. Women were less interested in hog feed. With both men and women, the color made no real difference:
A (Color)
B (Black)

$32 \%$

Any This Ad.

31

Picture .

Head

Sales Copy

Read Some

Read Most

Company Name

Wisconsin Agriculturist, April 4, 1959 $33 \%$

33

33

19

10

16 


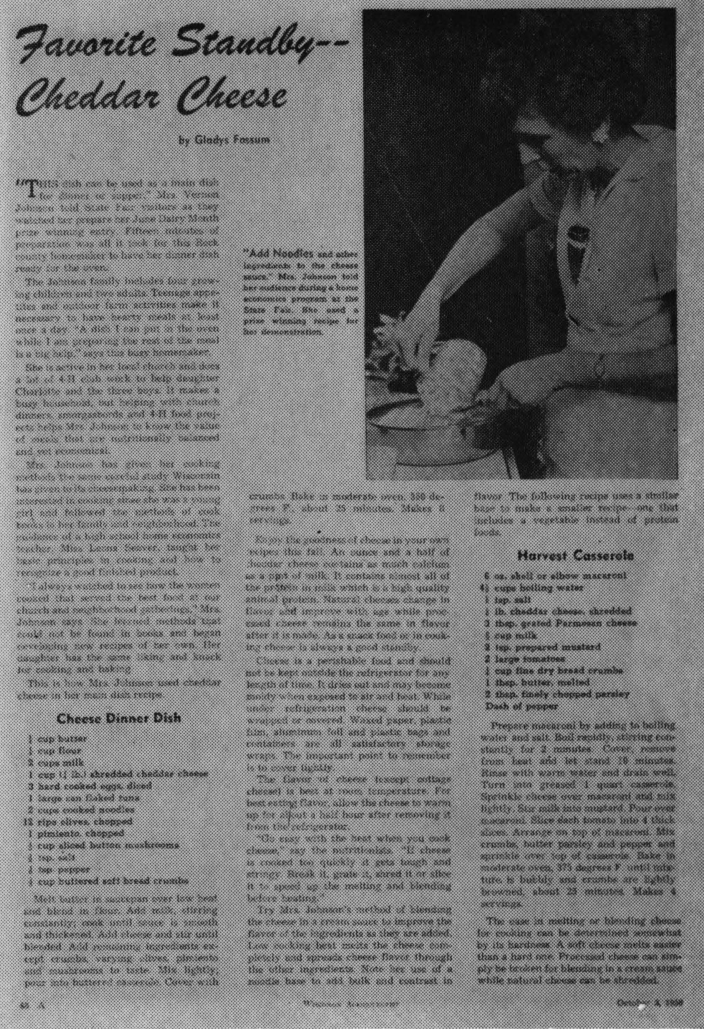

Figure 3.3

\section{Black}

A

Any This Page

Women $\mathbf{9 0} \%$

\section{Using Color in Heads}

Repeated splits which use color heads against black have come out like the experiment on this page. The color does not seem to help or to hurt.

Here are the women's scores:

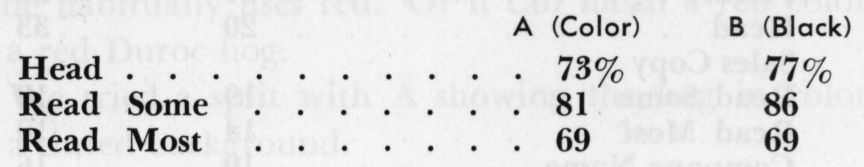




\section{Red}

B

Any This Page

\section{Women 91\%}

\section{Favorite Standby- Cheddar Cheese}

by Gishtif fousute

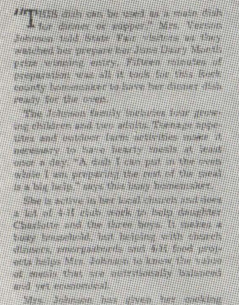

Hot

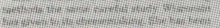

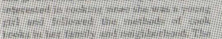

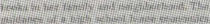

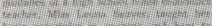
Aret $y^{2}$

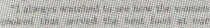
Hite

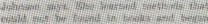

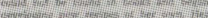
the

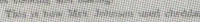

Chesse Dinner Dish

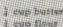

1. cus Alpit

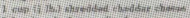

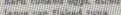

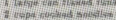

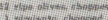

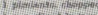

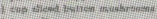

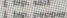

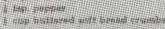
A He

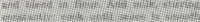

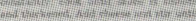
thet

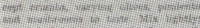
is

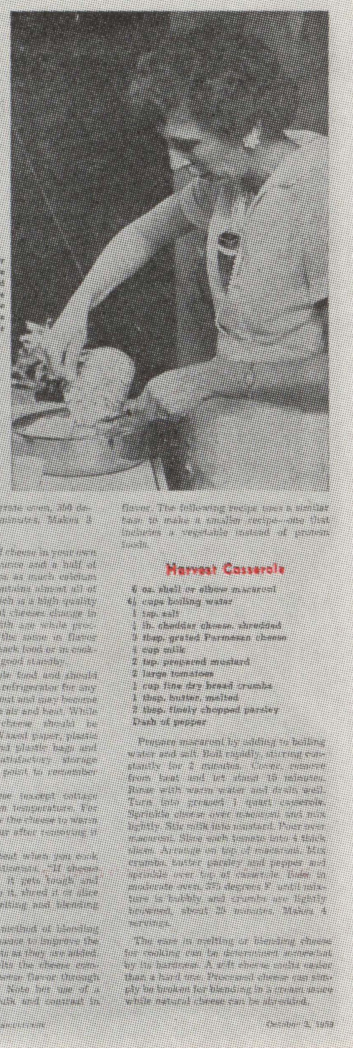

Men read very little on this page, but those who did read showed a preference for the black head (12 per cent to 4 per cent).

A few experiments using black type on a yellow background have given a slight edge to this combination as against black on white.

The over-all lesson of many splits, however, is that a head in color makes little if any difference in readership.

Wisconsin Agriculturist, October 3, 1959 


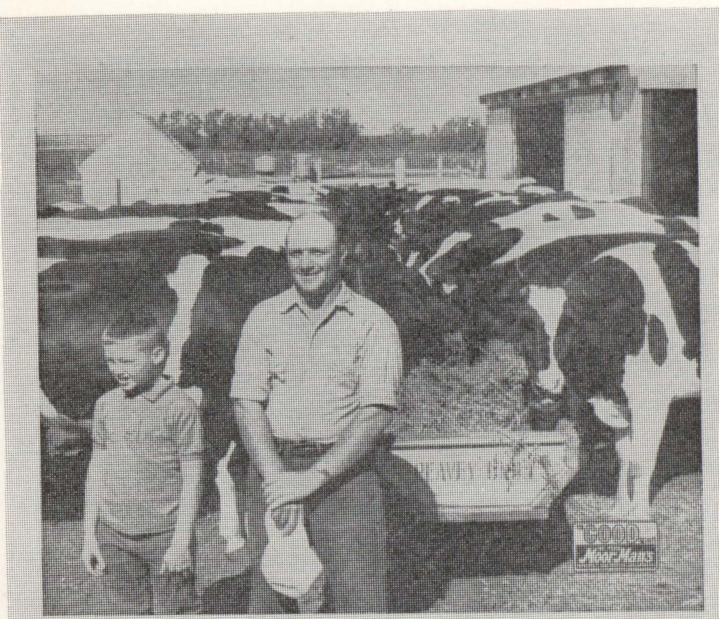

12,712 lbs. of milk... feed cost only \$131.66 per cow
Figure 3.5

\section{Red}

A

Any This Ad

Men 44\%

\section{Another Split on Head Color}

Farm men made up the principal audience in this split. As in similar experiments, the head in color seemed to do nothing for the page.

Men's scores:

\begin{tabular}{|c|c|c|c|c|c|c|c|}
\hline & & & & & A & (Color) & B (Black) \\
\hline Picture and & Head & & & & 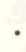 & $40 \%$ & $48 \%$ \\
\hline Read Some & . . & . & . & . & . & 18 & 20 \\
\hline Read Most & . & . & & . & . & 8 & 14 \\
\hline
\end{tabular}


Figure 3.6
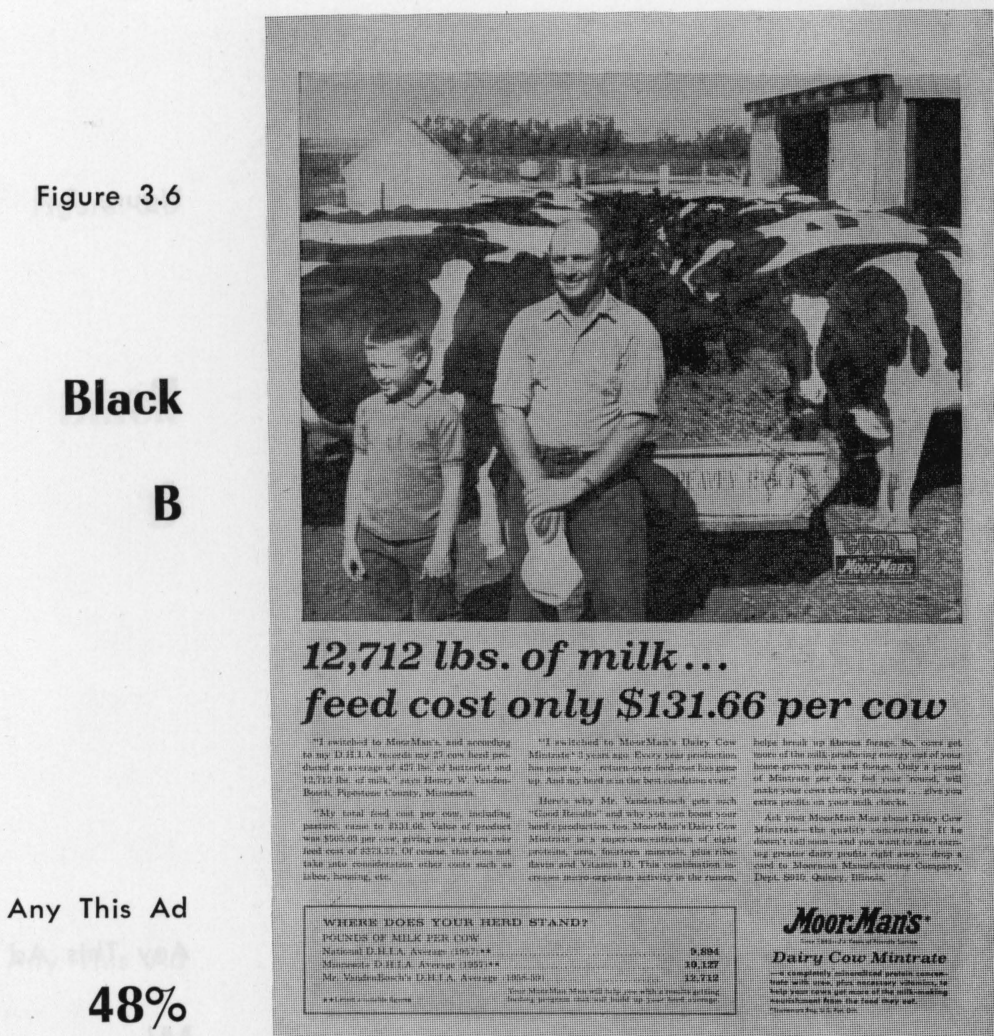

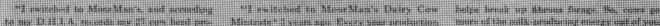

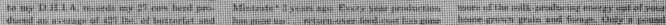

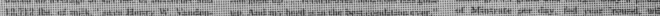

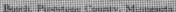

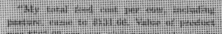
(1)

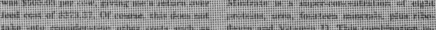

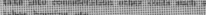

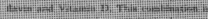

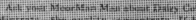

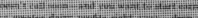

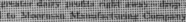

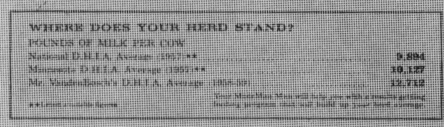

NoorNans.

Dairy Cow Mintrate

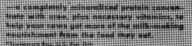

Women were less interested in the ad, and the difference between A and B was slight. (Any This Ad 23 per cent for A and 16 per cent for B.)

Farmers who were milking 20 or more cows showed a slight preference for B (black).

Wisconsin Agriculturist, October 3, 1959 


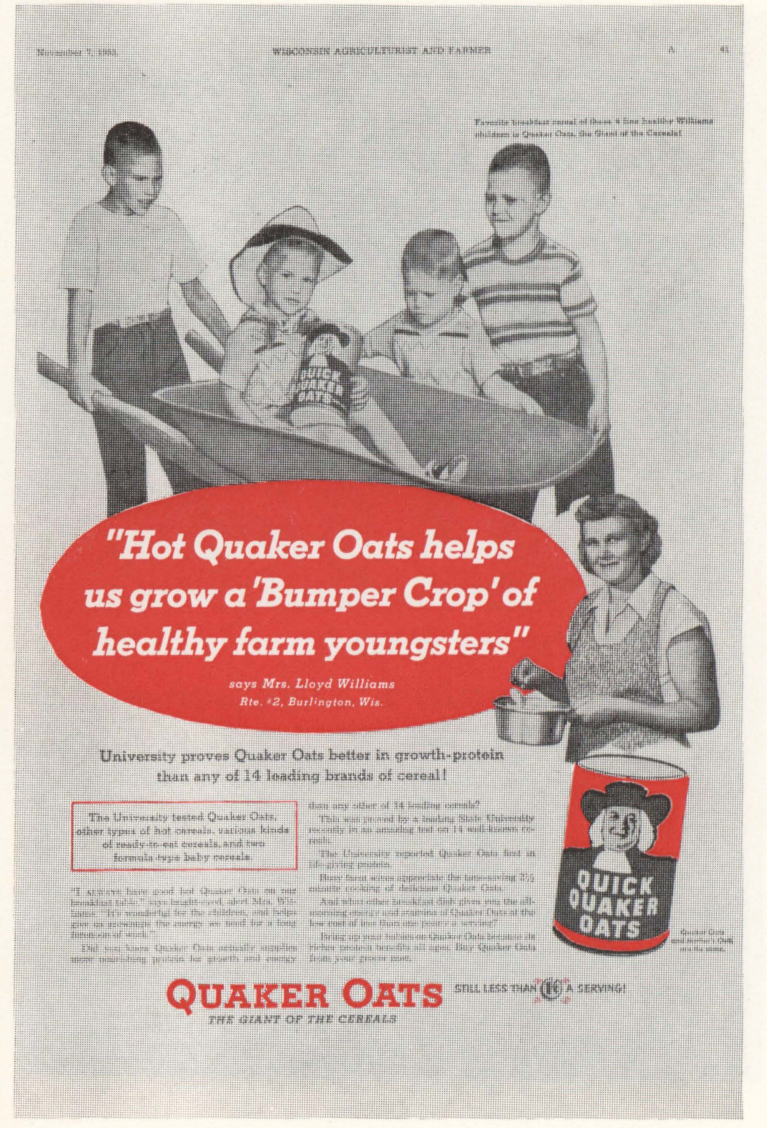

Figure 3.7

\section{Red}

A

Any This Ad

\section{Women $37.2 \%$}

\section{Reverse on Red Loses Readers}

In this case, the use of a reverse head on red apparently lost readers. Scores by women follow:

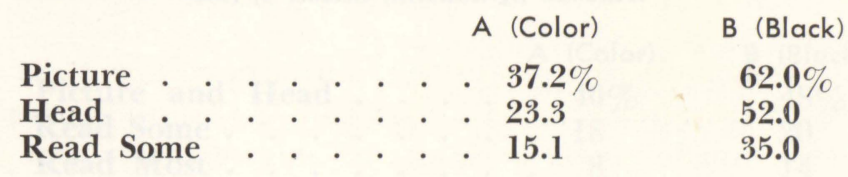


Figure 3.8

Black

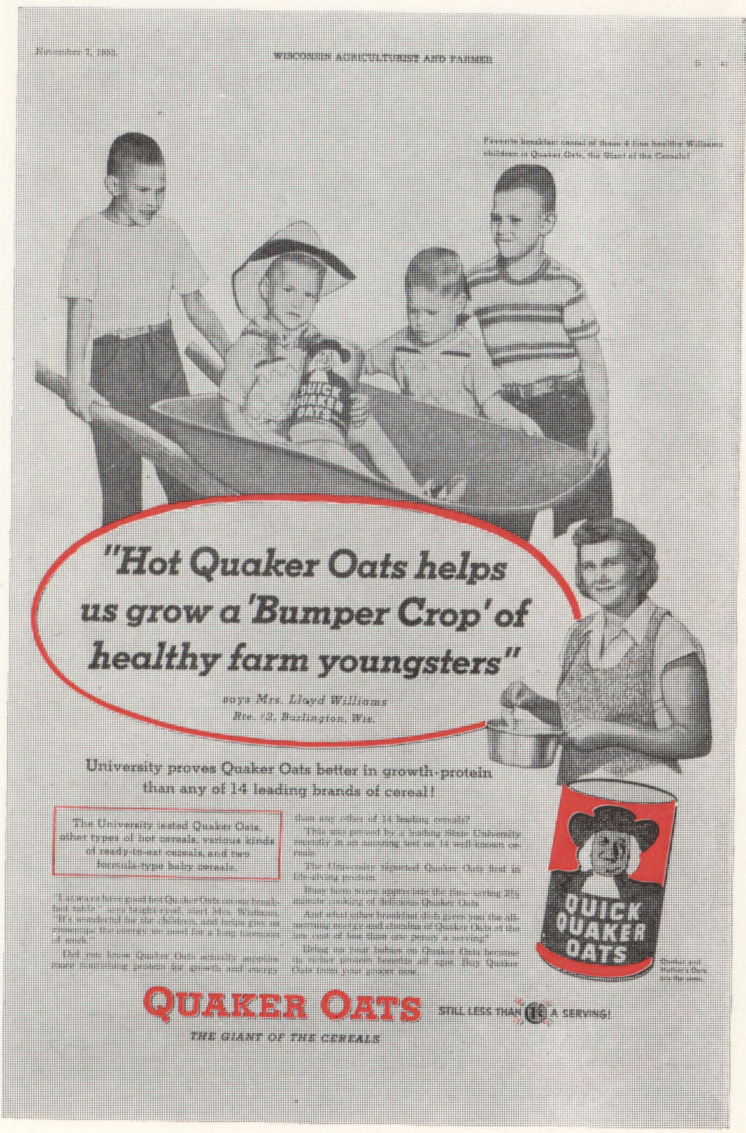

\section{Women 64\%}

The head in black (perhaps the red circle around it gets some credit) pulled up the unchanged part of the ad for women. Men had low scores with no difference between $\mathrm{A}$ and $\mathrm{B}$.

Women who had families of four or more gave B (black) a big Read Most vote (35.3 for B and 15.1 for A). The ad as a whole made a good showing with this important group of big families. 


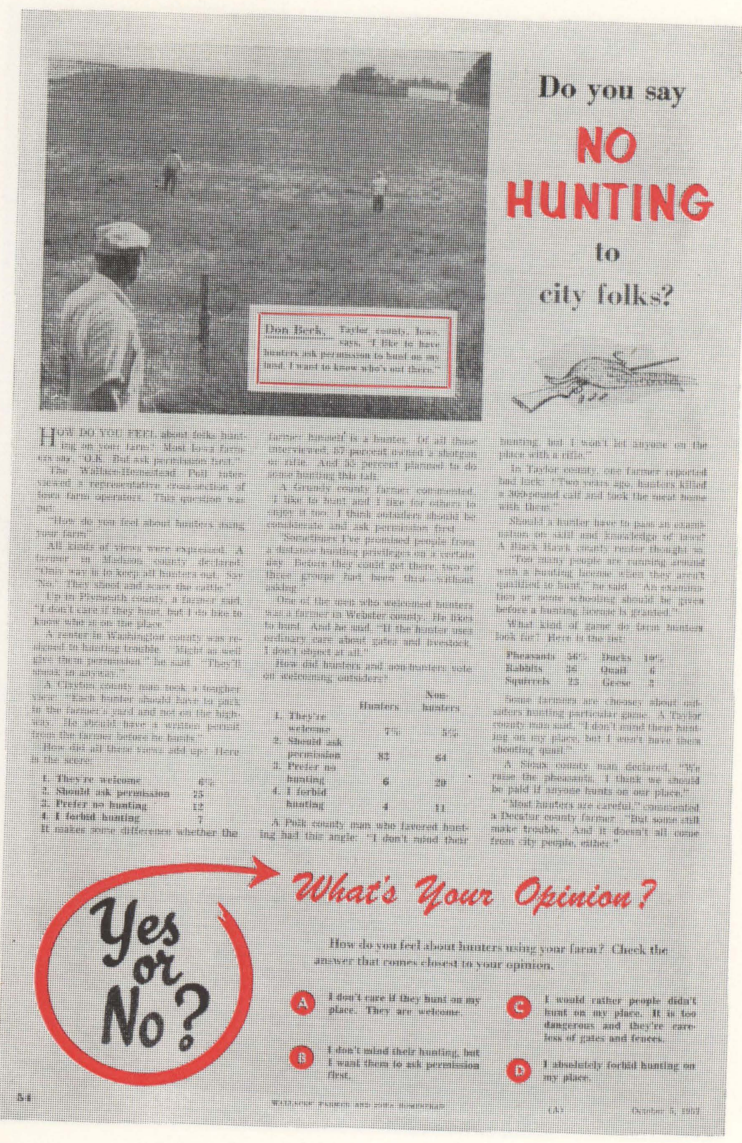

Figure 3.9

\section{Red}

A

Any This Page

Men $\mathbf{7 5 \%}$

\section{Women 53\%}

\section{Decorations and Color}

This was a combination split to see if some art work in color would help the article. Here are the principal scores for men:

\begin{tabular}{|c|c|c|c|c|c|c|}
\hline & & & & & A (Color) & B (Black) \\
\hline Picture & & & & & $65 \%$ & $56 \%$ \\
\hline Head · & - & • & & . & 66 & 70 \\
\hline $\begin{array}{l}\text { Read Some } \\
\text { Read Most }\end{array}$ & - & • & & . & 63 & 73 \\
\hline Read Most & . & • & & . & 55 & 62 \\
\hline
\end{tabular}


Figure 3.10

\section{Black}

B

Any This Page

Men $\mathbf{7 8} \%$

Women 56\%

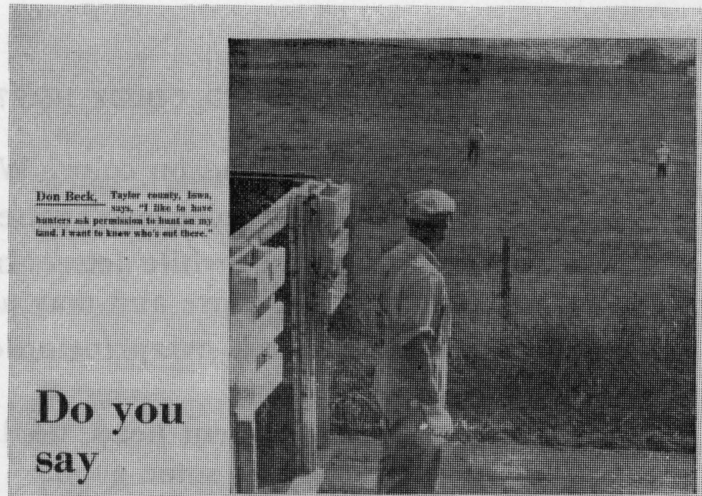

\section{"No Hunting" to city folks?}

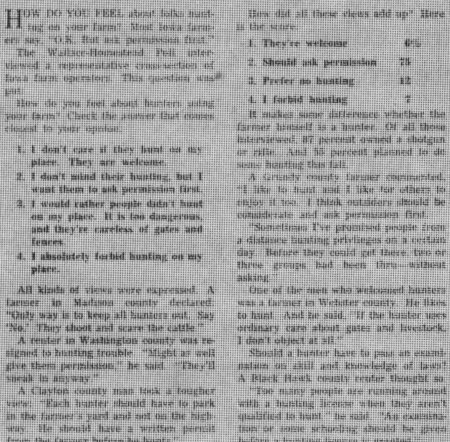

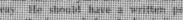

A WALTACE-HONISTYAD POL,

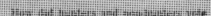

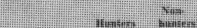

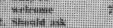
pernasion at 4. it intiot (1)

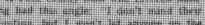
Hare sith a rite"

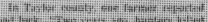

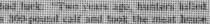

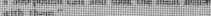

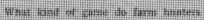

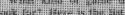

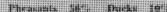

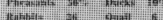

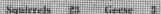

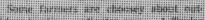

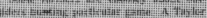

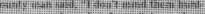

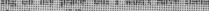

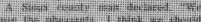

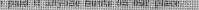

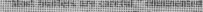

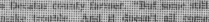

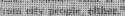

Women gave more of an edge to B. Read Some was 39 per cent for A and 49 per cent for B.

The editors liked A better. But the readers didn't agree. There was no real difference.

Wallaces Farmer, October 5, 1957 
Where does this leave us on color? We are inclined to say: 1. A head printed in color won't raise the readership score.

2. A head in reverse (white letters on color background) will not raise the score and may actually lower it.

3. A head using black overprint on color may work once in a while.

4. Color on a department head, used on a spread without other color, may do some good.

5. Decorative art work in color doesn't usually work.

6. Functional color - red hog, orange farm machinery (actual color of machine) - doesn't seem to make any difference.

7. An overprint of black type on yellow may do some good.

8. Color may pull in a few readers who are indifferent to the theme of the copy. For instance, color on a farm machinery ad may attract a few more women, but it isn't likely to make any difference with men.

9. A second color is a long shot. If used, try it on a section of the book where color is scarce. 


\section{4.}

\section{What Kind of Illustration?}

IN THE EARLY DAYS of farm papers, the problem of illustration was no problem at all. Hardly any photographs or drawings were used by the editors. Advertisers relied on stiff drawings that often looked like bad wood cuts.

There have been marked changes in the use of illustrations over the years. More cuts, bigger cuts and more local farm shots are used now.

Take, for example, the third and fourth issues of March, 1930, Wallaces Farmer (March 15, 68 pages and March 22, 42 pages). At that time, the paper came out every week. These issues can be contrasted with the second issue in March, 1960 (March 19, 104 pages).

In 1930, we ran seven Iowa farm pictures, with a total area of 82.75 square inches or 11.82 square inches per cut. In 1960, we ran 22 Iowa farm pictures with a total of 369 square inches and an average of 16.8 square inches per cut.

These figures do not include the cover. Neither do they include pictures that did not meet the test of being taken on Iowa farms. In 1930, for instance, there was 
a picture page of the editor's visit to Hungary. There were also unidentified pictures of livestock and crops.

The most striking change probably is the use in 1960 of one big illustration on a page article. In 1930 and earlier, several small cuts often would be strung together.

A check of the November, 1930 and November, 1960 issues shows much the same results.

When we began readership testing, farm pictures were still enough of a novelty that almost any kind of photograph got attention. Today, the farm public is used to pictures. Many take Look and Life. Competition for attention is keener. A poor illustration isn't noticed as readily.

What makes a good illustration for a state farm paper? One farm woman gave this clue, "The first thing I do is to look through the paper and see if I know anybody in the pictures."

What she wants is a picture of somebody she can recognize. If she finds Cousin Jack Smith of Decatur County pictured in one photograph, she is pleased. If she has relatives in Calhoun County and sees a picture of some farmer, unknown to her, from that county she may say to herself, "He lives near Aunt.Martha's. She probably knows him."

This local angle is pointed up by a question asked of a sample of Iowa readers by Starch in March, 1960. "Have you ever seen (in Wallaces Farmer) an article or a photograph about someone you know?" And 72.5 per cent said, "Yes."

How important is this local angle on photographs to advertisers? We have run tests in both Iowa and 
Wisconsin to see whether readers respond better to a photograph of a home state farmer than to a photograph of an outlander.

One advertiser gives this answer, "If you have a testimonial and photograph of a farmer in Iowa, play up the address to the Iowa audience. If the photograph and testimonial belong to a farmer in Illinois, play down the address to an Iowa audience."

Our splits indicate that a local address helps a little. But, the main thing is to have the person photographed doing something that makes sense in terms of the state where the ad appears. An Illinois hog farmer, shown with his herd of hogs, will do well in Iowa. But a wheat picture from South Dakota will not impress an Iowa audience.

Another old rule still holds! Men look at pictures of men, and women look at pictures of women.

This is one reason why we like family shots when we can find a reasonable pose. Fortunately, women are around the farm frequently, and it isn't too hard to find an excuse for getting a woman into a man's picture.

How do we rank cartoons and drawings in editorial or advertising copy? Editorially, we use cartoons to slow up readers as they go through the book. But, we don't use cartoon treatment of illustrations of articles. The exception is the cartoon used on the editorial page of Wisconsin Agriculturist (Figure 4.12). This seems to have some value in pulling younger readers into the editorial page.

A few advertising splits using cartoons versus photographs indicate that farming is serious business. The photograph usually wins. 
What about drawings? We have used sketches instead of photographs in layouts of editorial copy and each time wished we hadn't.

This is also true for ads. A photograph ordinarily outpulls a drawing. The one notable exception was a John Deere ad in Wallaces Farmer (September 30, 1958). Here the drawing scored 47 for men against the photograph's 39. Note, however, that the drawing used heavy lines and came closer to the weight of a photograph than the usual drawing.

Another test of photograph versus drawing came in the Starch scores in the October 17, 1959 issue of Wallaces Farmer. Of three page hog feed ads, one used drawings of the two farmers whose experiences were quoted. The other two used the standard photograph of the farmer quoted.

Noted, Men Read Most, Men

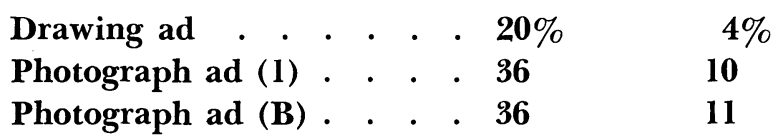

Is one big picture better than several small ones? The answer is what you would expect. For example, a Certified Alfalfa Seed Council ad in Wallaces Farmer (January 16, 1960) showed one big picture versus five small ones. For men, scores were 32 for the ad with the big picture against nine for the ad with the five small pictures.

A slightly different approach was used on a cover in Wallaces Farmer (March 1, 1947). We played up a picture of a farm family going to the movies and accompanied it with a small picture on a different theme. In the $B$ version, we used four pictures of equal size. 
The $B$ version did not do as well as A. Men's page score for A was 76.1 and for B, 67.7. The principal lesson however was that neither cover did especially well. Probably if we had left out the small picture in A and concentrated on one photograph - it happened to be a good one - the cover would have made more impression.

We tried a page layout illustrating the theme "How Iowa Farmers Vote" in Wallaces Farmer (November 4, 1950). Eight pictures were used-all about the same size - and not much text. The page score was 62.5 for men and 62 for women. It seemed clear that we would have done better to play up the most interesting photograph and to give the design a center.

Should a feed company run a picture of its president, or a picture of a hog eating its feed? Another possibility is to have the president on all fours eating the hog feed, but nobody yet has managed to get that kind of copy approved. It still happens that the ego of a company head (or the flattery of an agency) leads to the kind of copy where the principal illustration is a photo or drawing of President John K. Doe looking important.

We had a good example of this some years ago. The score for the page ad was 18.6 for men, which established some kind of record. This same company, using more rational copy in 1959, pulled 42 per cent for men on a page ad.

Does the composition of a picture help reader response? It probably does, but we have done little testing. One inadvertent test came in Wallaces Farmer (November 19, 1960). The cover split showed different arrangements of the same picture (Figures 4.6, 4.7). 
In $\mathrm{A}$ was a close-up of a farmer in the hog lot, with hogs also prominent. In B was a close-up of hogs, with the farmer in background. Since the A arrangement was the conventional one, we wanted to see whether a shift away from the farmer toward the livestock would help.

Results were ambiguous. On the non-reader basis, $\mathrm{B}$ was better; that is, it attracted more readers. On score by readers, there was a little difference but $\mathrm{A}$ got the edge.

Professor Rodney Fox of the Department of Technical Journalism at Iowa State University at Ames commented:

The hogs were played up about the same in both pictures. The play given the man was the only real variable.

There may be one factor you didn't consider. In A, the man and the hogs compete for attention. The resulting tension is somewhat unpleasant.

In $B$, the man has been subordinated to the hogs. The resulting effect is not disturbing - in short, I think B has more pleasing composition.

It would be interesting to know how readers would have reacted had the man dominated the picture in A with the hogs subordinated to a weak background position function. And it would be interesting to know how the readers would have reacted had the hogs dominated the picture with the man even more subordinated than he is in $\mathrm{B}$.

And it would be interesting to know how a non-farm audience with only the most casual interest in hogs might react.

I would have expected A to make a better showing than it did because I'm so deeply convinced of the interest of people in people. Can it be that composition is a quite important factor even in news type pictures? (1)

Editors at times mutilate a big cut by overprinting a head, cutting out a chunk to permit use of a caption, etc.

Advertisers fall into the same trap. In Wallaces 
Farmer (November 3, 1951) Moorman ran a page ad on hog feed. In the B version, the picture filled the page, but a big area in the middle of the lower center of the cut was cut out and copy inserted. In the A version, an unmutilated three-column cut was used with sales copy running in the fourth column.

The A picture outscored the $\mathrm{B}$ picture with men 54 to 41 . The page as a whole (Any This Ad) scored 59 for A, 42 for B.

The advertiser threw away some of the benefits of this good start, however, by putting the sales copy column on the left instead of next to the gutter and by using type that was too small on the sales copy. As a result, the Read Most scores of A and B were almost even. (2)

What value are thumbnail cuts? Wallaces Farmer (November 21, 1959) ran a two-column article on corn, with no illustrations, against the same article illustrated by thumbnails of four farmers quoted in the article (Figures 4.8, 4.9). Men scored like this:

$$
\begin{aligned}
& \text { No cuts } \quad 4 \text { cuts } \\
& \begin{array}{llllll}
\text { Any Page . . . . . . . . . } & \mathbf{6 5} \% & \mathbf{8 2} \%
\end{array} \\
& \text { Read Most . . . . . . . . } 54 \quad 72
\end{aligned}
$$

This outcome wasn't difficult to predict. A tougher problem in the same issue dealt with a two-column article which started on the left-hand page, had one twocolumn cut and ran over in a column on the right-hand page.

It did not help to add a thumbnail to the left-hand page which already had an illustration. But, the thumbnail on the runover against no cut at all on the runover apparently helped women's readership. 
The monotony of the standard two-column layout probably needs relief. We tried one way by getting more depth on the cut. In A, it was four inches deep; in $\mathrm{B}$, six inches. There was no other change. This experiment in Wallaces Farmer (January 16, 1960) indicated a modest gain for the deeper cut (Men $60 \mathrm{~A}$, $72 \mathrm{~B})$.

Wisconsin experiments on whether to put the head above or below the two-column cut at the top of page also may be related to monotony. The head above the two-column cut did better than the head below. Since most of the articles used the second style, this may be a tribute to change.

On page copy, we got a somewhat different response. Here the conventional style of ads and editorial matter is to put a big cut at the top of the page. Yet an ad in Wallaces Farmer (September 20, 1958) gave a better score to copy at the top of page and cut at the bottom than to the reverse layout.

Another attempt to break the monotony of the standard two-column article was to set copy in 10point, 22 picas wide, instead of two columns of 9-point each 12 picas wide. Only a slight gain for the 10-point was indicated. Yet we suspect that the change of pace may have made the book as a whole look more attractive.

"Cook's Corner," with recipes, always scores high and therefore probably needs no help. Yet we tried in Wisconsin Agriculturist (November 7, 1953) an A version with illustrations set into the recipes; $\mathrm{B}$ was all type. There was no difference in score.

For a two-column cut, should the print be trimmed 
down to the principal figures or should a good deal of background be permitted? Splits on this came out as one would expect. The picture cut down to the essentials always won. A cut 24 picas wide is too small to permit much background. The same thing is more emphatically true of a 12 pica cut.

Does "What's Ahead" (the economic outlook department) need help from an illustration? Wallaces Farmer (January 16, 1960) found that adding the illustration made no difference. Wisconsin Agriculturist, in earlier tests, found the illustration helped and changed layout accordingly.

For outside comment, note the following from the Research Department, Curtis Publishing Company. (3)

"Whenever possible, it is better to use photographs rather than sketches to illustrate an article.

"Art-work illustrations seem most successful in attracting readers when they are clear and realistic, as nearly photographic in quality as possible.

"While cartoons as separate features are immensely popular, using them to illustrate a piece seems to result in lower readership than the use of the conventional photographic treatment does."

Our own summary (we agree with the Curtis statement above) might add these points:

1. Use pictures of farm men and farm women in working clothes occupied in farm or household chores. (Getting women to act as subjects without prettying up as if for a trip to town is a hazard for the photographer.)

2. A big picture is worth three small ones.

3. Every picture used should be identified - "This is John 
Smith who farms 200 acres in Blank County, Iowa. He thinks hog prices are going down." Put the caption under the cut.

4. Farmers aren't always farming. Human interest pictures of farm families at play, on vacation, at the fair, give variety.

5. Never line up the officers of an organization in a row and take their pictures. Such photographs bring low scores.

6. Take three or four times as many good pictures as can possibly be used in the paper. Then sort for the best. (4) 
Figure 4.1

Page Score

\section{Men $\mathbf{8 6} \%$}

\section{Women 57\%}

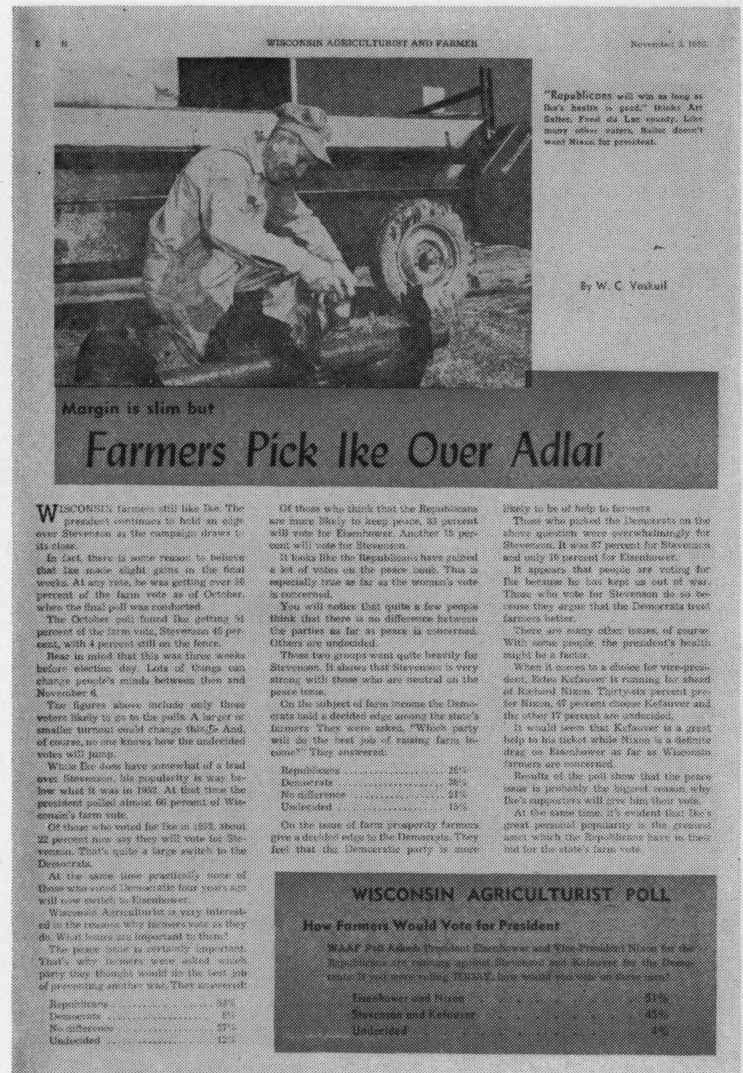

\section{How Farm People Vote}

Before every election, Wallaces Farmer and Wisconsin Agriculturist sample rural-farm townships and interview farm people. This page scored well because:

1. The theme was timely, and the election was only a few days away.

2. One big picture dominated the page.

3. Black head and black box on yellow background drew some eyes.

This survey, incidentally, indicated that Eisenhower would get 53 per cent of the farm vote in Wisconsin. In the actual tally; he got 55 per cent.

Wisconsin Agriculturist, November 3, 1956 


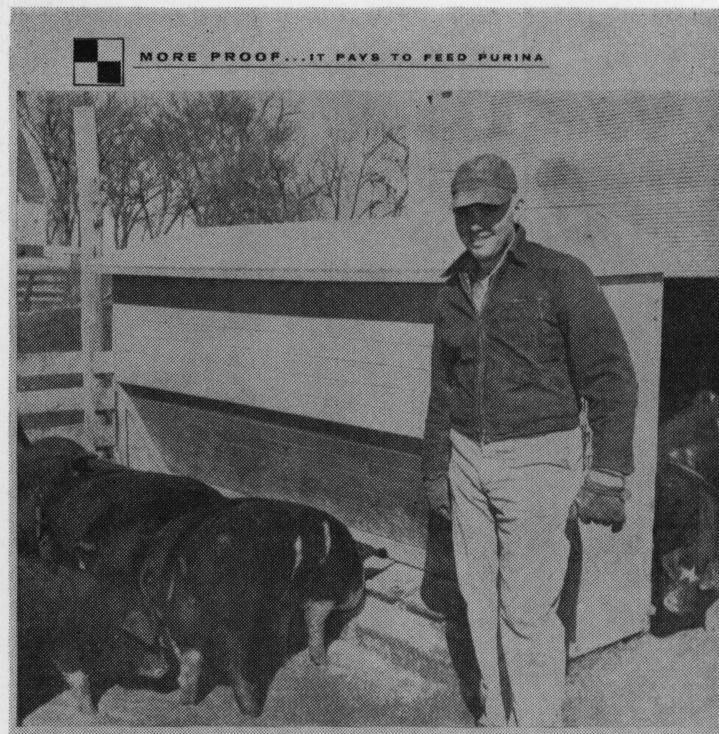

Figure 4.2

\section{Page Split A}

Langwarthy, lowa, Purina feeder

Galen Helgens produces pork for ${ }^{5} 915$ per $\mathrm{cwt}$

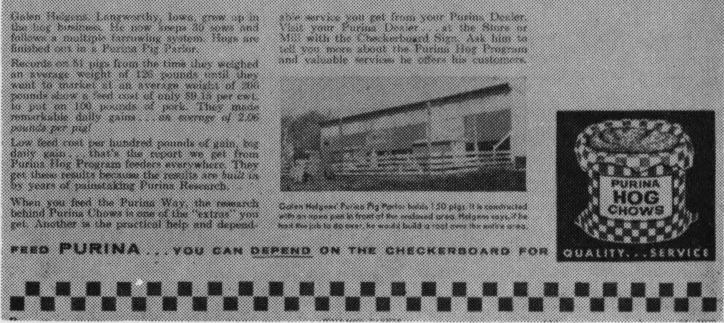

Page Score

Men 47\%

Women $42 \%$

\section{Photograph Outscores Drawing}

The sketch in B pulled down the over-all page score with both men and women. Other experiments show the - same results. A photograph almost always outpulls a drawing.

But notice something else. Moving the sales copy in B to the upper left, where the eye is apt to look first, made up for the damage done by the sketch. 
Figure 4.3

\section{Page Split B}

Page Score

\section{Men 28\%}

\section{Women $16 \%$}

Languorthy, lowa.

Purina forder

\section{Galen} Helgens produces pork for "915 per cwt. 2inisis.

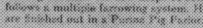

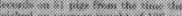

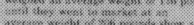

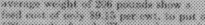

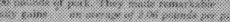

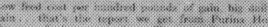

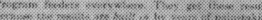

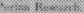

it:

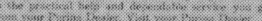

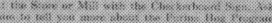

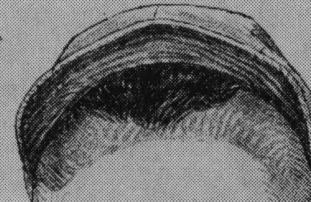

10
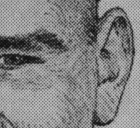


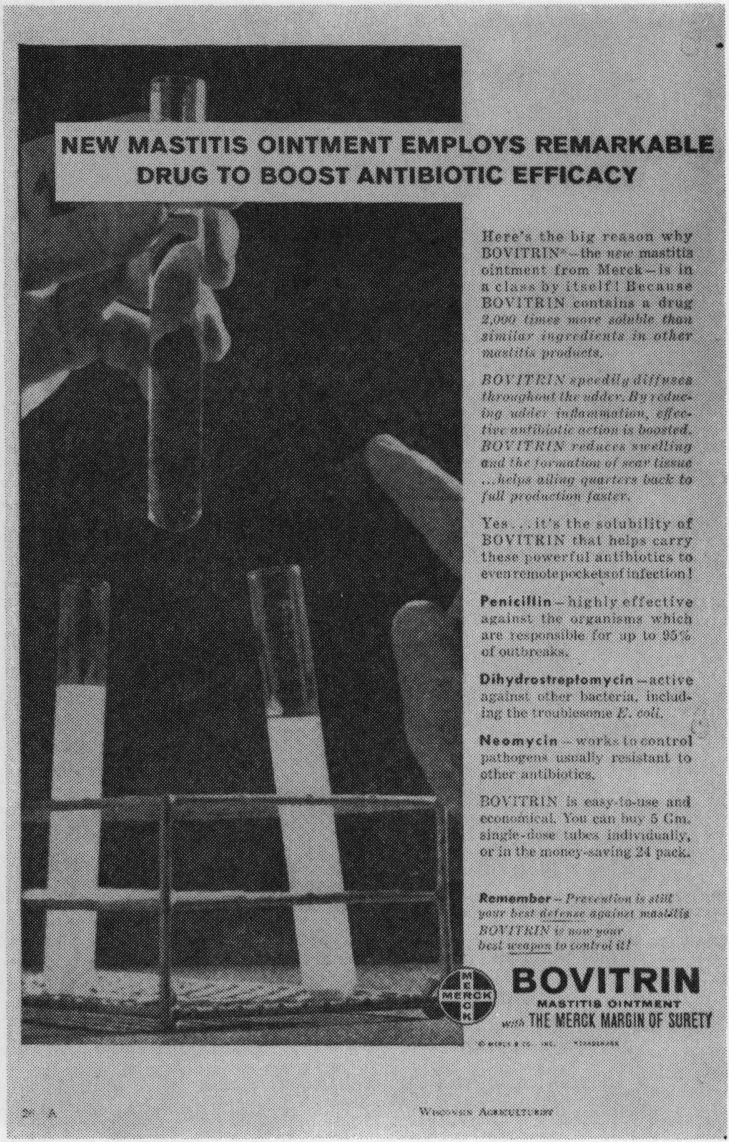

Figure 4.4

\title{
Split Page A
}

\author{
Ad Score
}

Men $\mathbf{2 0} \%$

Women $7 \%$

\section{Cow Versus Test Tube}

The cow won. And the superiority for B helped other parts of the ad:

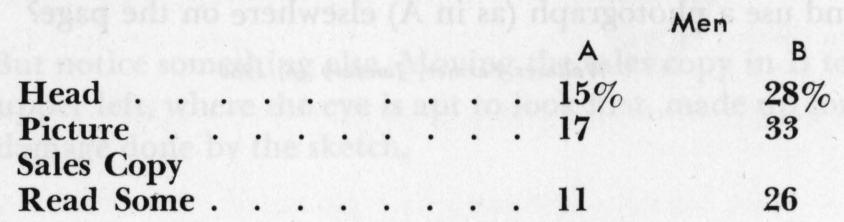


Figure 4.5

\section{Split Page B}

Ad Score

\section{Men 32\%}

\section{Women $7 \%$}

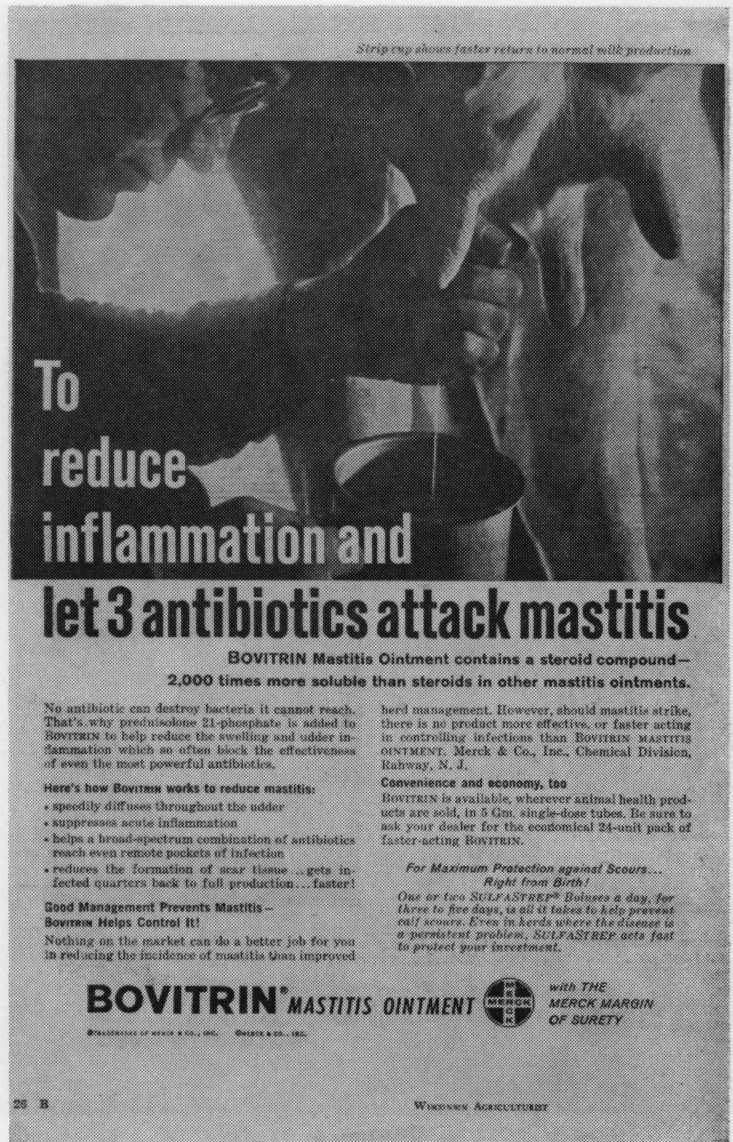

Of farmers who were having trouble with mastitis in their herds, 41.2 per cent Read Some of the B copy. Of those with NO trouble with mastitis, only 11.1 per cent Read Some of the A copy.

Of farmers with big herds (30 cows and up), 21.4 per cent Read Some of the B copy. Only 5.3 per cent had Read Some of the A copy.

Full details on this split appear in Chapter 16, pages 223-27. 


\section{Wallaces 1. Farmex \\ IOWA's UEADING FARM NEWSPAPER}

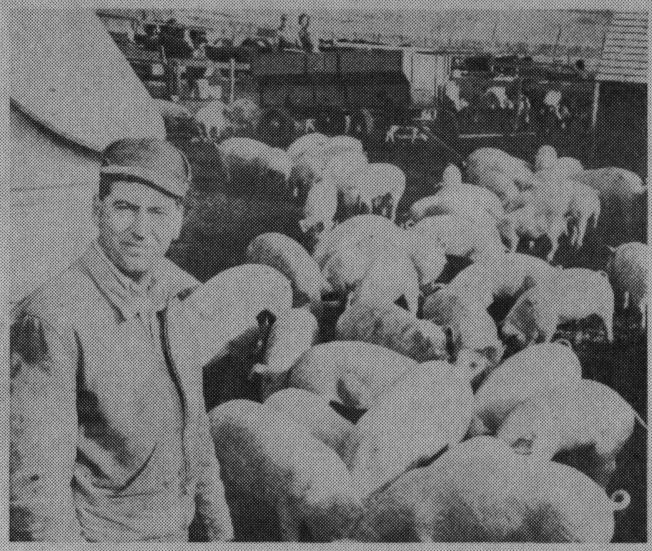

Corn programs to help hogs

W"10

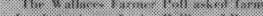

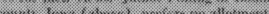

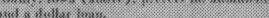

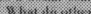

(19:15)

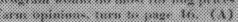

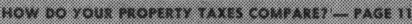

Figure 4.6

\section{Cover Split A}

Men 97\%

\section{Women $86 \%$}

\section{Man Versus Hogs}

Sometimes farmers who are hog raisers are more interested in hogs than in people. But here we found a slight edge for the cover that played up the farmer. What would have happened if we had played up a hog in B and had left the farmer out of the photograph?

Read Some scores on sales copy also gave A (man) the advantage:

Men . . . . . . . . . . $80 \%$

Women . . . . . . . . . 43 
Figure 4.7

\section{Cover Split B}

Page Score

\section{Wallaces}

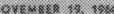

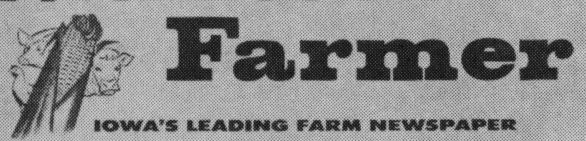

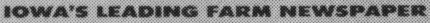

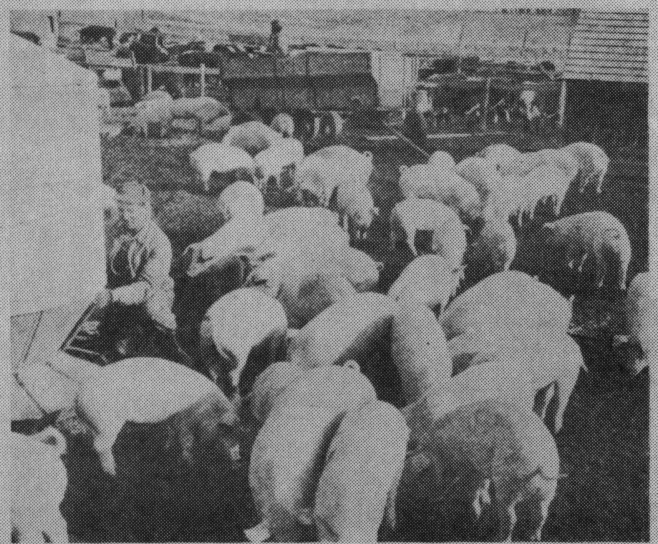

Corn programs to help hogs

\section{Men $\mathbf{9 0 \%}$}

\section{Women $\mathbf{7 5 \%}$}

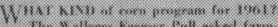

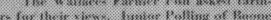

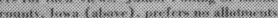
insi s, inithe lism

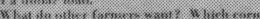

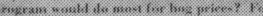

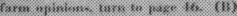

in this is:use

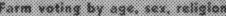

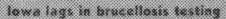

Thunksgiving on a turkey farm

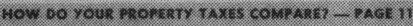

B has one claim to superiority. There were fewer nonreaders in the $\mathbf{B}$ group than in the A group. Perhaps the hog picture had some value here in converting possible non-readers into readers.

Both A and B scores were good. You can't lose in an Iowa farm paper by putting hogs on the cover - with or without a farmer.

Wallaces Farmer, November 19, 1960 
Figure 4.8

A

\section{No Cuts}

\author{
Read Most
}

Men 54\%

\section{Thumbnails Help}

What happens to readership when you add thumbnail cuts to a two-column story? The

A version, in this split, used the standard text but with no illustrations.

The $\mathbf{B}$ version, on the next page, inserts

\section{This corn crop is a problem!}

\section{A lot of corn is still standing: and some may spoil in the crib}

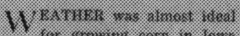

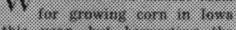

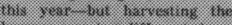

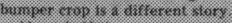

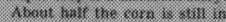

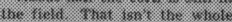

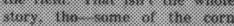

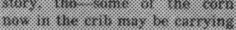

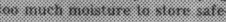
3.:

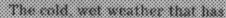

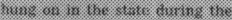
(2.) :

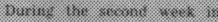

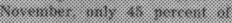
in:

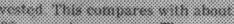

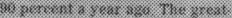

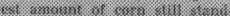

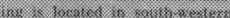

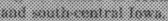

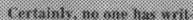

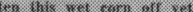

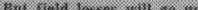

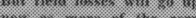

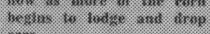

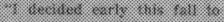

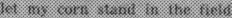

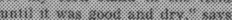

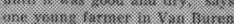

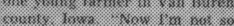

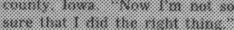

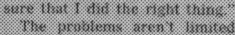

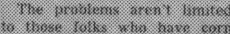

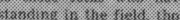

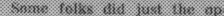

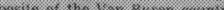

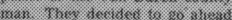

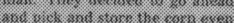

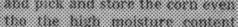

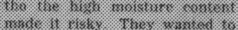

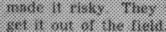

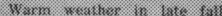
:

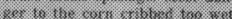

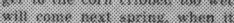

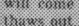

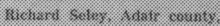

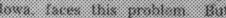

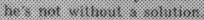

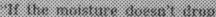

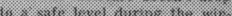

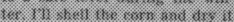

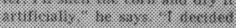
*1: :

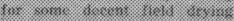
:xwat:m:

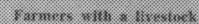

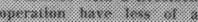

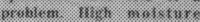

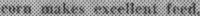

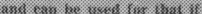
13:tr: is: 80:3:

i.

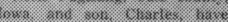

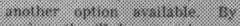

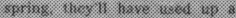
int is ti:

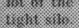

1.:

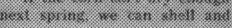
: $: x^{\prime:}$

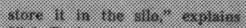

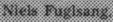

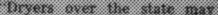

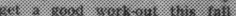

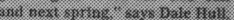

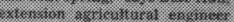

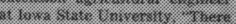

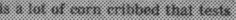

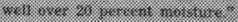

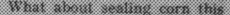
in: $1: 2:$

in: in:

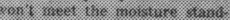

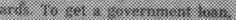

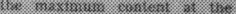

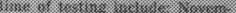

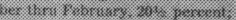
3.: i: i:

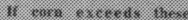

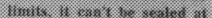

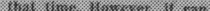

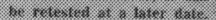

(3.1:

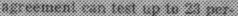

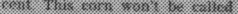

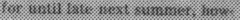

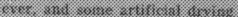
inas:

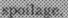

1. :

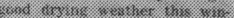

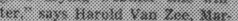

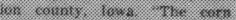

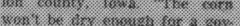
(10,

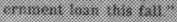

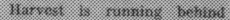

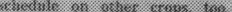
7x:

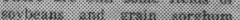

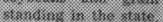

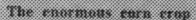

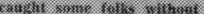

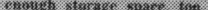

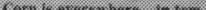
(1): $1: 50$ i. in prit if

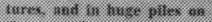

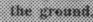

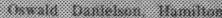

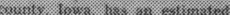

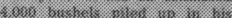

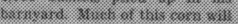

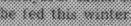

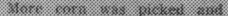
3:

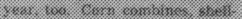
3.

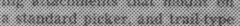
8:

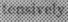

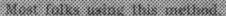
:

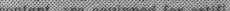

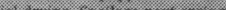

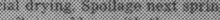

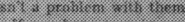

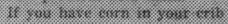

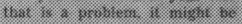

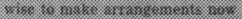

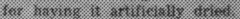

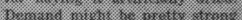

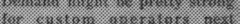
(2):

$x:$ 


\section{This corn crop}

\section{is a problem!}

\section{A lot of corn is still standing: and some may spoil in the crib}

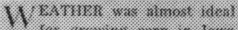

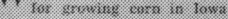

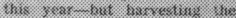

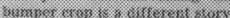

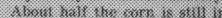

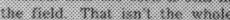

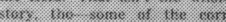

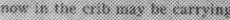

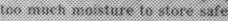

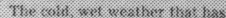

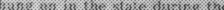
25: (1)

$136.4 \times 13: 13$

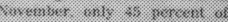

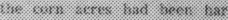

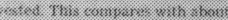

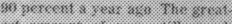

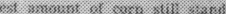

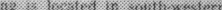

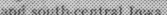

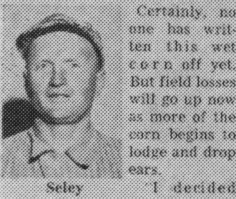

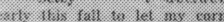

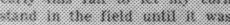
sond mi sty." smye wne youn: tminnor in Visn immen connty.

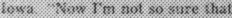

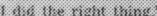

Ther mathens: arent limitad

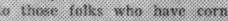

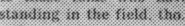

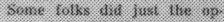

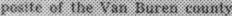

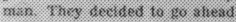

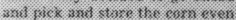

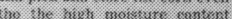

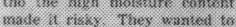

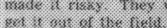

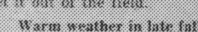
4anser to the vara cribled tras wer mill vimms next

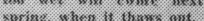

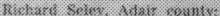

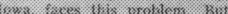

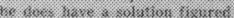

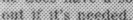

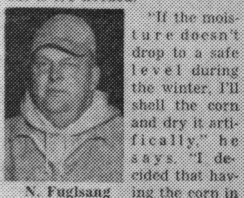

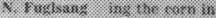

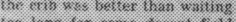

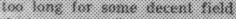
invisis nemint"

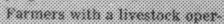

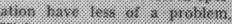
Wish mosture snin miakes ex.

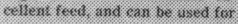
$x \times x \times x x=$

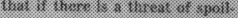

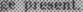

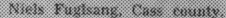

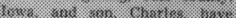

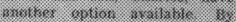

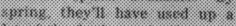

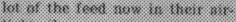
i: $: 1:: 10:$

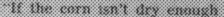

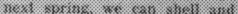

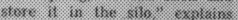

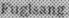

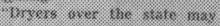
(3) :

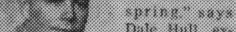

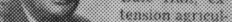

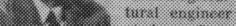

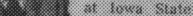

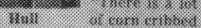

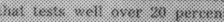

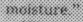

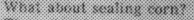

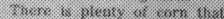

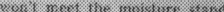

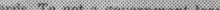

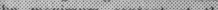
19: (1) 13ris

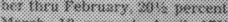

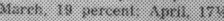

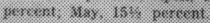

11 virn exrodis these timits, it exnit hit seated at that time, iforrwer, it cat be retested at a later date

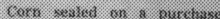

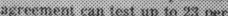

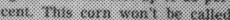

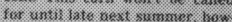
exex, and some nxtukwial trying

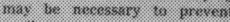
spousis:

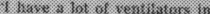

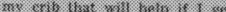

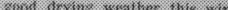
1: $*: 3 n$ (1)

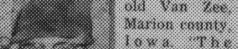
i: $0: 48:$ : in: is:

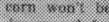
4iny :moniny 103

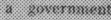

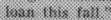
$12: 0 x=4: 2$ is minisus: 1:x

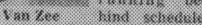

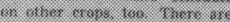

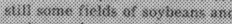
(⿻7丷: $3: 2: x:$

The ntwomers: exteist some forks withori

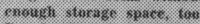
forro is every wherk: in then pirary erths at snaw fence in nw promadient strus

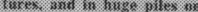
the srounit

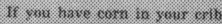
that ix a problem it mish be

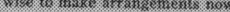

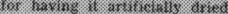

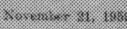

Figure 4.9

B

\section{Thumbnails}

Read Most

Men $\mathbf{7 2} \%$

\section{four thumbnail cuts of men mentioned in the article. \\ Results of the split, for men, follow:}

\section{(No cuts) (Thumbnail)<smiles>[10BH]C1CC1</smiles>

$\begin{array}{lll}\text { Read Some } & 63 \% & 82 \% \\ \text { Read Most } & 54 & 72\end{array}$

(Wallaces Farmer, Nov. 21, 1959) 


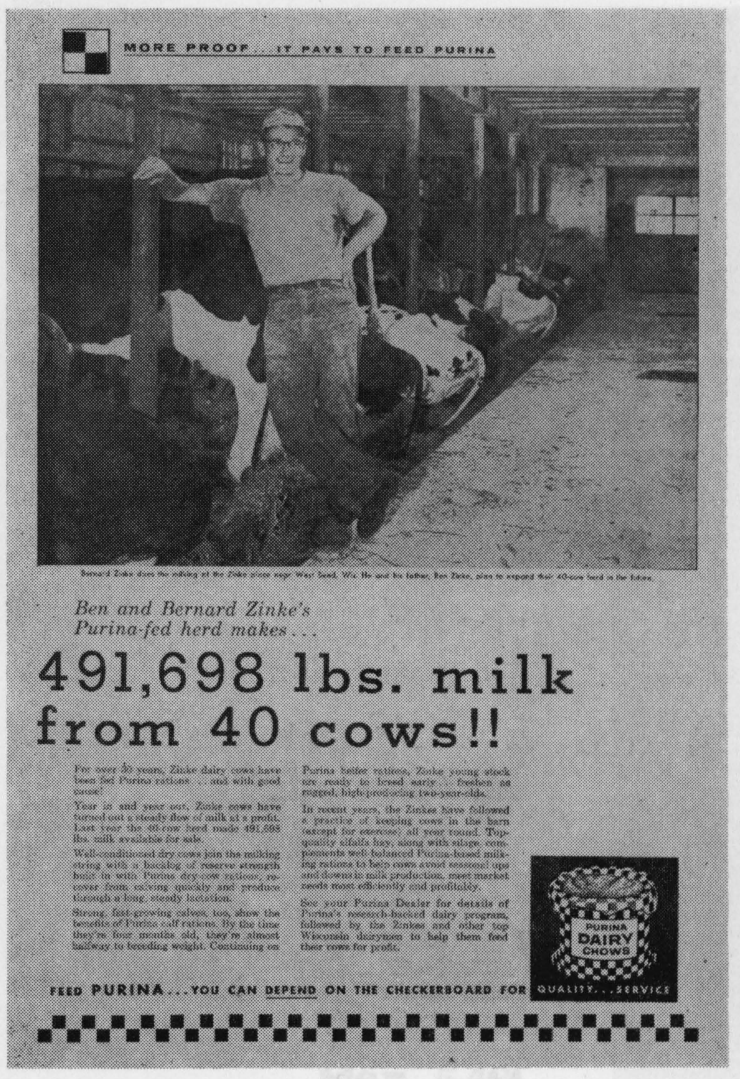

Figure 4.10

\section{Split Page A}

Page Score

Men 61\%

\section{Women $26 \%$}

\section{Square Cut Versus Cutout}

Does it pay to cut away background on a photograph and play up the central figure?

But what is the central figure? Would it be better to play up a cow instead of the farmer?

While the picture in A outscored the cutout in B, the sales copy in B pulled up a little ahead of A.

Sales Copy

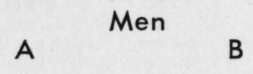

Read Some . . . . . . . . . $24 \% \quad 27 \%$ 
Figure 4.11

\title{
Split Page B
}

\author{
Page Score
}

\section{Men $47 \%$}

\section{Women $18 \%$}

\section{1,698 lbs. milk from 40 cows!!}

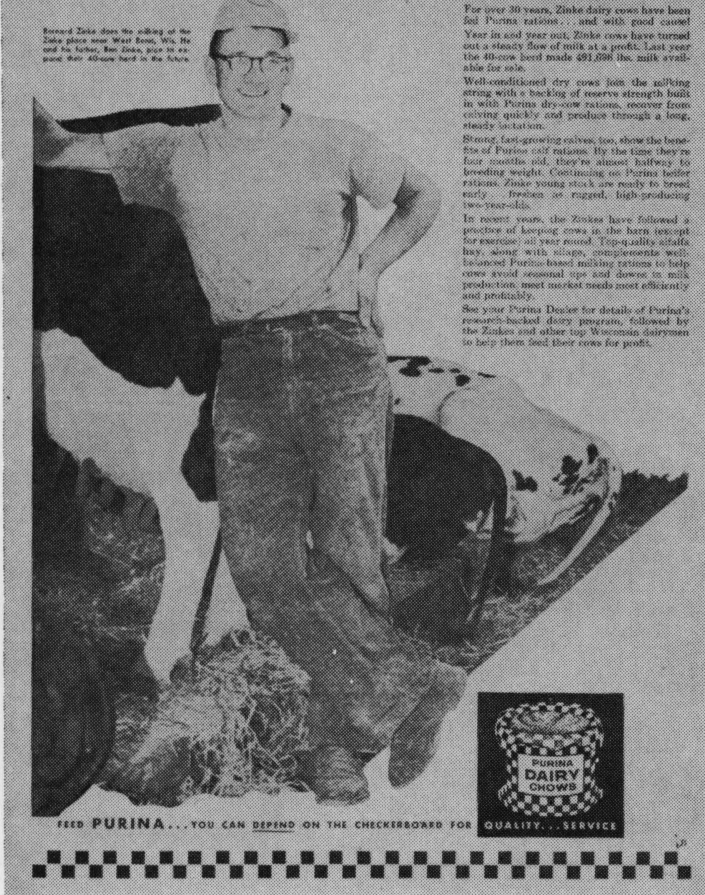

What kind of farmers read A and B? This may be more important than the total score.

Farmers with 30 cows and up:

A

Read Some Sales Copy . $31.6 \%$
B

$14.3 \%$

Farmers who sold Grade A milk gave A a Read Some score twice as good (42.4 per cent to $\mathbf{2 0 . 8}$ per cent) as B.

Wisconsin Agriculturist, October 3, 1959 


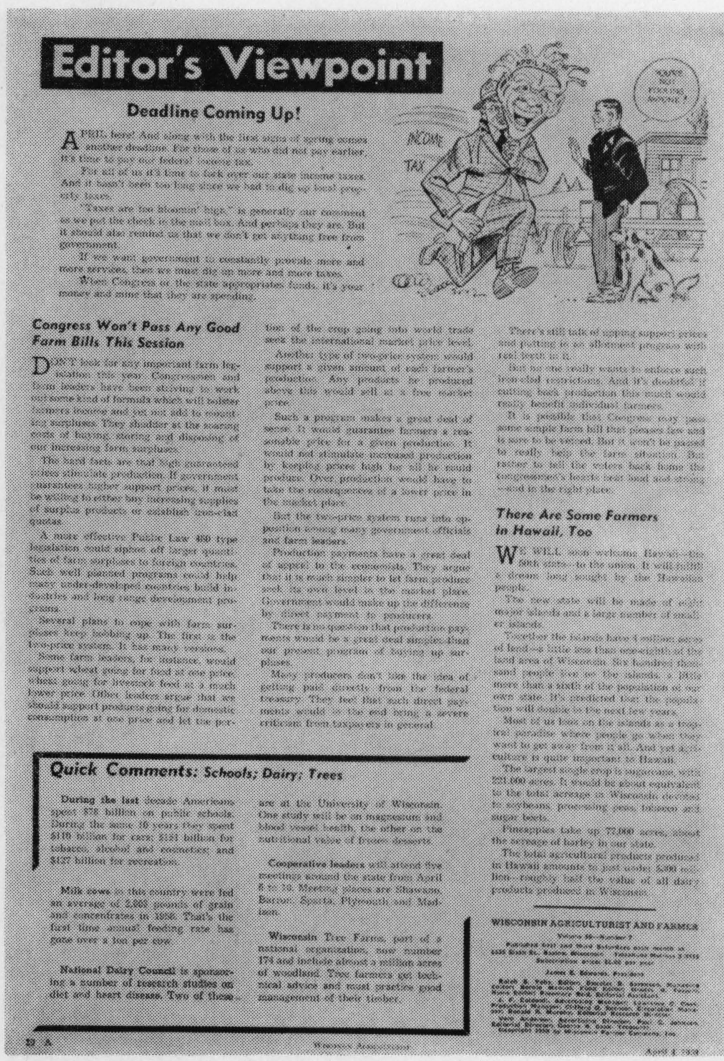

Figure 4.12

\section{Split Page A}

Cartoon Score

Men $46 \%$

\section{Women $\mathbf{4 0} \%$}

\section{Cartoon Versus Photo}

Photographs usually outscore cartoons on our papers, but not on the editorial page of Wisconsin Agriculturist. The cartoon shown above in A outpulled a B page in which a photograph was used in place of the cartoon.

Did the higher score for the cartoon pull up readership on the editorials? Editorials near the cartoon scored 5-10 points higher than the same editorials on the page with the photograph. Short items at the bottom of the page (farthest from the cartoon) showed less difference. 
Figure 4.13

\section{Split Page B}

Photograph Score

Men 27\%

\section{Women $24 \%$}

\section{Editor's Viewpoint}

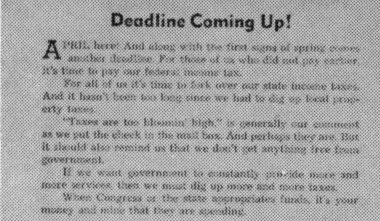

\section{Congress Wan't Pass Any Caod} Form Bills This Sexsion

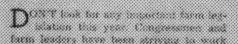

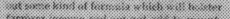

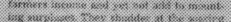

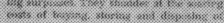

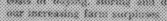

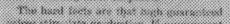
in:

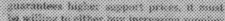

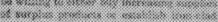
sist:

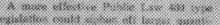

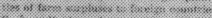

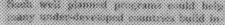

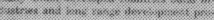

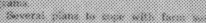
: $1:: 1: 1: 0: 1: 0$

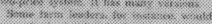
34:2:

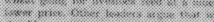

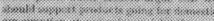

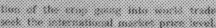

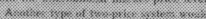

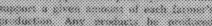

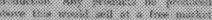

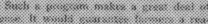

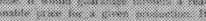

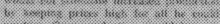

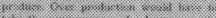

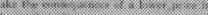
(:)

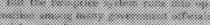

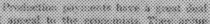
. (2.1:

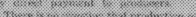

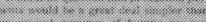

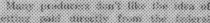
:2:3:

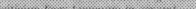
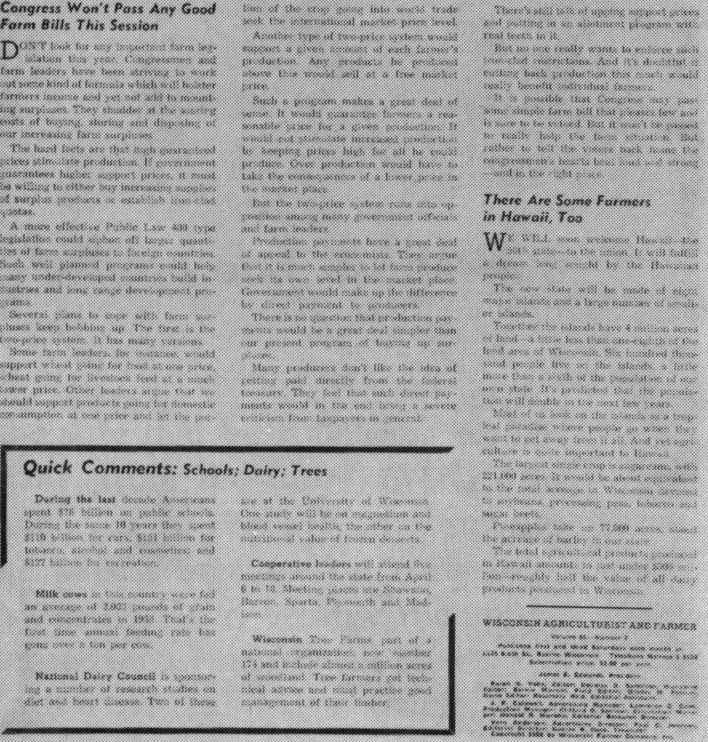

The main value of the cartoon was in its appeal to younger readers and particularly to younger men.

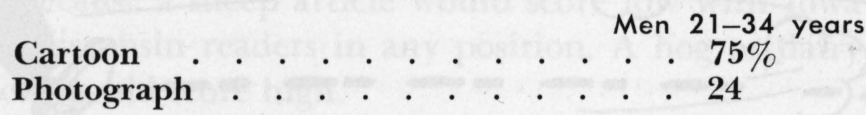

An earlier split showed a similar advantage for the editorial page cartoon with younger readers.

Wisconsin Agriculturist, April 4, 1959 


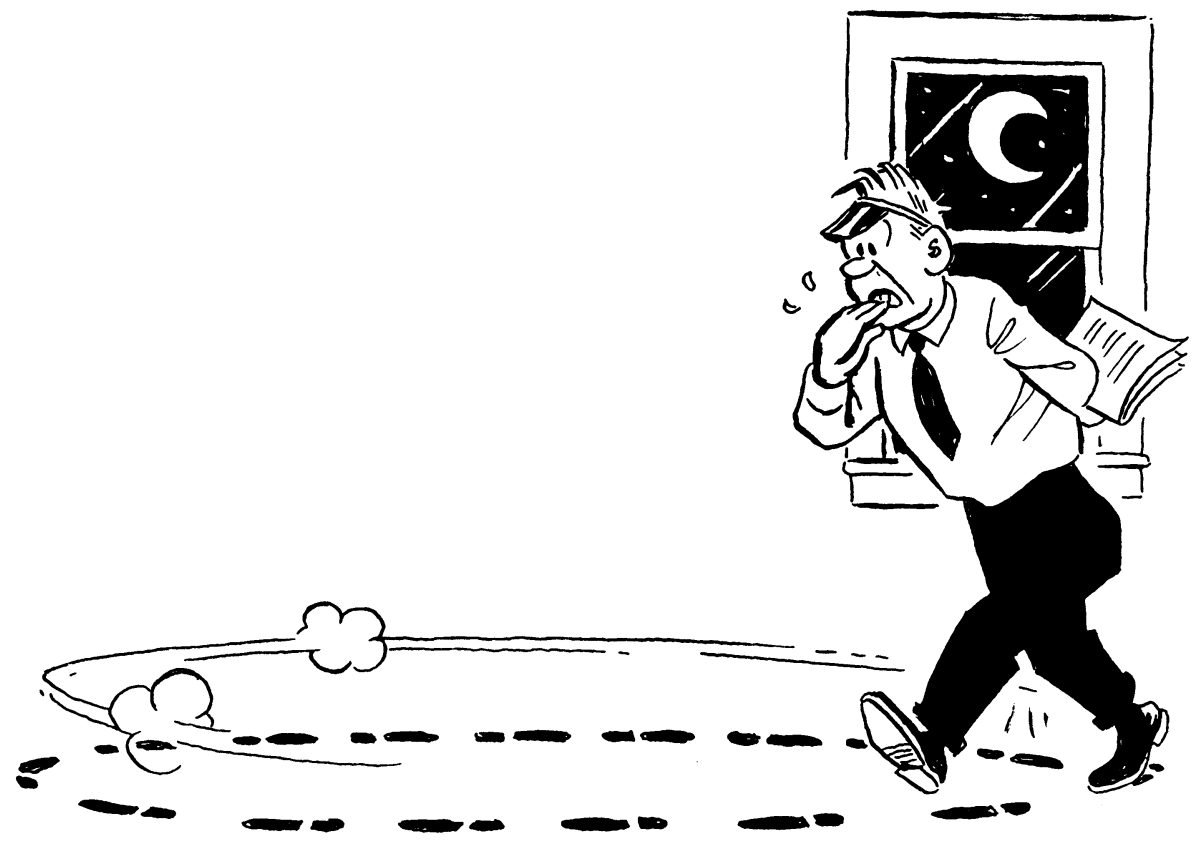

Harry E. Walsh cartoon. By permission from How To Write Columns, by Olin Hinkle and John Henry, (1) 1952, Iowa State University Press. 


\section{5.}

\section{Page Position and Readership}

HOW CAN AN EDITOR be sure that he is holding readers throughout the magazine, from the front cover to the back? One way, of course, is to check readership surveys and see what the page scores are on each page. This is not a final answer, however, because the appeal of different articles and advertisements will vary.

Suppose that an attractive full page article on a subject of interest to the reader (possibly hogs in Iowa, dairying in Wisconsin) appears on page 13. The page scores 81 per cent for men. On page 79 , there is a twocolumn article on sheep (not so important) with no illustration. It scores 30 per cent for men. Does this prove that readership in the back of the book is low? No, because a sheep article would score low with Iowa and Wisconsin readers in any position. A hog or dairy article would score high.

To find out whether the edtiorial matter is pulling readers through the book from front to back, use the split run. Print Article 1 on page 17 for half the run and see that it reaches half the sample of farm people 
interviewed. Then shift Article 1 to page 66 for the second half of the run. Get a readership score for Article 1 in each position.

In the same issue, print Article 2 on page 66 for half the run. Then shift to page 17 . Get a score for Article 2 in each position.

If all the interviewers were to start from the front of the book, reader fatigue will almost automatically give the copy on page 17 a better score than the copy on page 66 . What we do, therefore, in all readership surveys, is to start half the respondents in the middle of the book, go through to the last page, come back to page one and go through to the middle. The other half of the respondents are taken straight from page one to the last page. This device presumably equalizes reader fatigue. Unless this device were used, we couldn't learn much from the tests described in this chapter.

Our first test in transposing articles was in Wallaces Farmer (November 5, 1949). We switched two-column articles on page 12 and page 27 . In each case, the article suffered when moved to page 27.

This test was repeated November 4, 1950. This time the shift was from page 12 to page 50 in a 64-page issue. We found we lost readership in the shift from page 12 to page 50 . (1)

Faced by this evidence of weakness in the back of the book, the editors began to make changes. More and stronger copy was used in the back of the book. Two popular departments were given a permanent position on the inside back cover and the facing page.

We checked again in Wallaces Farmer (March 19, 1955). This time we switched picture pages - one on 
page 17 and one on 81 in an issue of 100 pages. This time page 81 lost a little but not more than the expected experimental error.

On October 1, 1955, a similar split was tried out in an 80-page issue. Two articles - each two columns in length - were transposed. Their titles were "Apply Nitrogen in Fall" and "Fertilizer Helps Stop Erosion."

Following are Read Most scores for men. The sample had 68 men and 100 women in $\mathrm{A}$; 100 men and 100 women in $\mathrm{B}$.

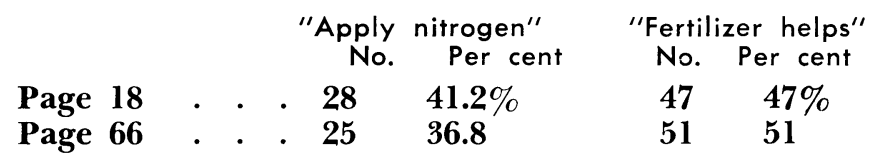

Scores for women - much smaller - showed about the same variation.

In the 92-page March 16, 1957 issue (Wallaces Farmer) a similar split was tried. Again two articles each two columns in length - were transposed. Each dealt with some aspect of cattle feeding.

Read Most scores for men on the two articles follow. The sample has 100 men and 100 women in A: the same in B. Since the sub-sample in each case is 100 . the number and the percentage are the same.

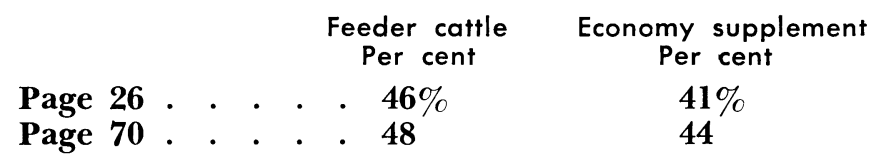

Later surveys were designed to see if these gains had been held. For instance, in the January 16, 1960 issue 
(Wallaces Farmer) a corn silage article was run on page 18 in the A section and on page 60 in the $B$ section. The "Service Bureau" was run on page 60 in A and on page 18 in B. Read Most scores for men are:

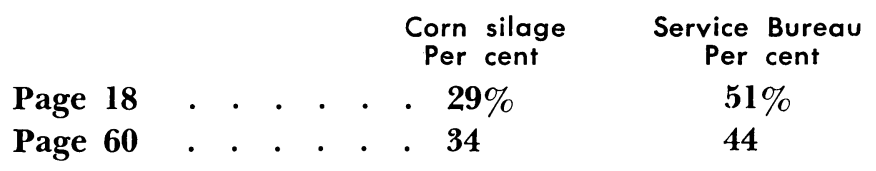

A shift from page 24 to page 71 showed similar results. Read Most scores for men follow:

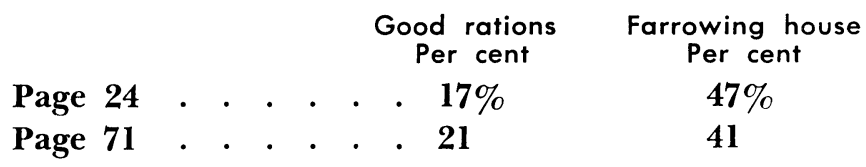

Women had lower scores on these articles which were aimed primarily at men. The pattern of response was the same, however.

All of these reports, except the picture page split in 1955, dealt with two-column articles. Wisconsin $\mathrm{Ag}$ riculturist (April 2, 1960) tried a shift with page articles.

Here are the scores for the two pages. The switch was from page nine to page 74 . The article was "How Thick Should You Plant Corn?"

\begin{tabular}{|c|c|c|c|c|c|}
\hline \multirow[b]{3}{*}{ Any This Page } & & \multicolumn{2}{|c|}{ Men } & \multicolumn{2}{|c|}{ Women } \\
\hline & & Page & Page 74 & Page & lage 74 \\
\hline & . & . $66 \%$ & $\mathbf{5 9 \%}$ & $24 \%$ & $21 \%$ \\
\hline Read Some . & . & . 64 & 51 & 12 & 11 \\
\hline Read Most . & . & 44 & 36 & 11 & 6 \\
\hline Picture and cap & ion & 52 & 47 & 22 & 18 \\
\hline
\end{tabular}


There is a slight edge for page nine, especially with the Read Most score for men. The other differences are minor.

Here are the results of another article, "The Farmer's Job in Civil Defense:"

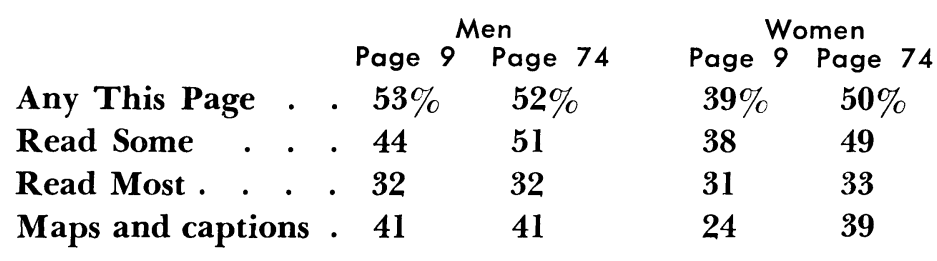

This comes out even, except that page 74 has the edge with women. This has happened in other splits. Apparently some women start to read with the homemaking department and go on through to the back. This sometimes gives a stronger women's score in the back of the book than one might expect. The best spot for dual purpose ads or editorial matter may be in the area in back of the homemaking department.

If scores for both pages are combined, we get the following:

\begin{tabular}{|c|c|c|c|c|}
\hline & \multicolumn{2}{|c|}{ Men } & \multicolumn{2}{|c|}{ Women } \\
\hline & rage & & rage & \\
\hline Any This Page & $\mathbf{5 9 . 9} \%$ & $55.5 \%$ & $31.5 \%$ & $35.5 \%$ \\
\hline Read Some . & 54.0 & 51.0 & 25.0 & 30.0 \\
\hline Read Most & 38.0 & 34.0 & 21 & 19.5 \\
\hline $\begin{array}{c}\text { Picture (maps) } \\
\text { captions }\end{array}$ & 46.5 & 44.0 & 23 & 28.5 \\
\hline
\end{tabular}

These combined scores make it clear that there is no significant difference between the two positions so far as reader interest is concerned. 
The custom on Wisconsin Agriculturist and Wallaces Farmer has been to run tests like this every year to see whether readers are reading all the way through the magazine. These results are of great interest to advertisers. A good ad on page 80 presumably would have just as good a chance for readership as one in the front of the book. 


\section{Corn silage fits ration for sows}

Some research indicates that silage can increase litter size

If Vou an alresuly feedins norn allanse to your cattie, you may provit by feeding your soms silaxe, 100.

"I ve fed my sows shase sine ing gestiation for 3 or 1 yesirs. says Maurice Deaker, Wepelle counity, lowa tit's easy to put sume extra rorn stase in the auser wayon each disy.

He ferds the sonss at the sambe tims lie fowds his ratte

Sonvi ted proporly sapples mented forn silage pitine pris. duse at lesast as mans pigs per lither in kewes on puose connmons pations some rescarch prex show there tian be an inerriase 13: liktors siane.

Wher reswareh will indi. cate that pigs farrowed from swos fed a corn silage ration mas outdo pigs from sous fed some of the nore ensm.

mon rations.

Yound lise nost apt io protie from fereding a corn singe ra. tion if you are presimitly seil foreding grain and supplement

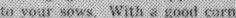
4hese yation. fru can cut your per wow foed sond 6 shownd is conts past bisy.

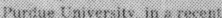

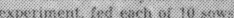

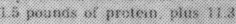

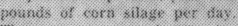

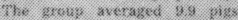

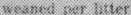

With protein at 6 sonts per

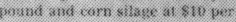

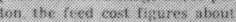

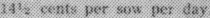

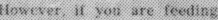

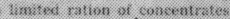

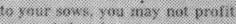
3x inswis by chwnyting to a corn

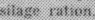

Somo lowa formers hase bum silus for ther sow horde bat if is not a common praction: firly sows of more are uswally required to justity a silo for your sow herd alone.

only choice-vuality shase makdes pood sow leed finely cwi siluge is best sows whil som a coarsely cut silage And they a coarsely cut silage And they have a strong preference for it reacties the hard dent stise.

lowa state linverkity workin: thisk it's lis th is stant feeting silase 8 to it weeks ketore the sans are irnd. Otherwise, don't stant them on the corn silage wnil afles breeding is ower. Clesnosing leed tor dose to brectiong lime may wat your in. wer is:

reod the nork shlase tree twoice on a watform or in frounh bavin sow noed of 8 10 powmls of silage.

120 vercent protein balancer is useri bs lowa state linversity (1) supplement the corn vilase ration. The batances can be makle either from we at the chiversits formulas of by mix

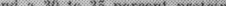

Foed the 20 perwant batinerer wrex wach day in the following imusints

Gitts

Flusking portiad 4 to 3 pounds firtit 10 wheks:

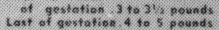
Sows

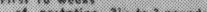
Lat of gestatian 2 , to 3 pound

Whin your are startins the

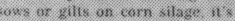

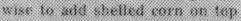

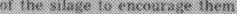
$20.20 \% 210$

vorn silitive in not alwins the ame yosi stier year thes

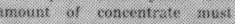
anciscionilly be adjusted to the anount of corn in the slines

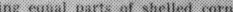

Fiusting geriad 4 to 5 paunds
Figure 5.1

Read Most

Men

Page 18, $\mathbf{2 9} \%$

Page 60, $34 \%$

\section{Page 18 Versus Page 60}

To see whether readership stays high all the way through the issue, articles are switched from front to back. In this case, the corn silage article ran on page 18 in the A version and on page 60 in the $\mathbf{B}$ version. Read Most scores are given above.

Page 60 (in an issue of 76 pages) is as good a position as page 18 .

Wallaces Farmer, November 21, 1959 


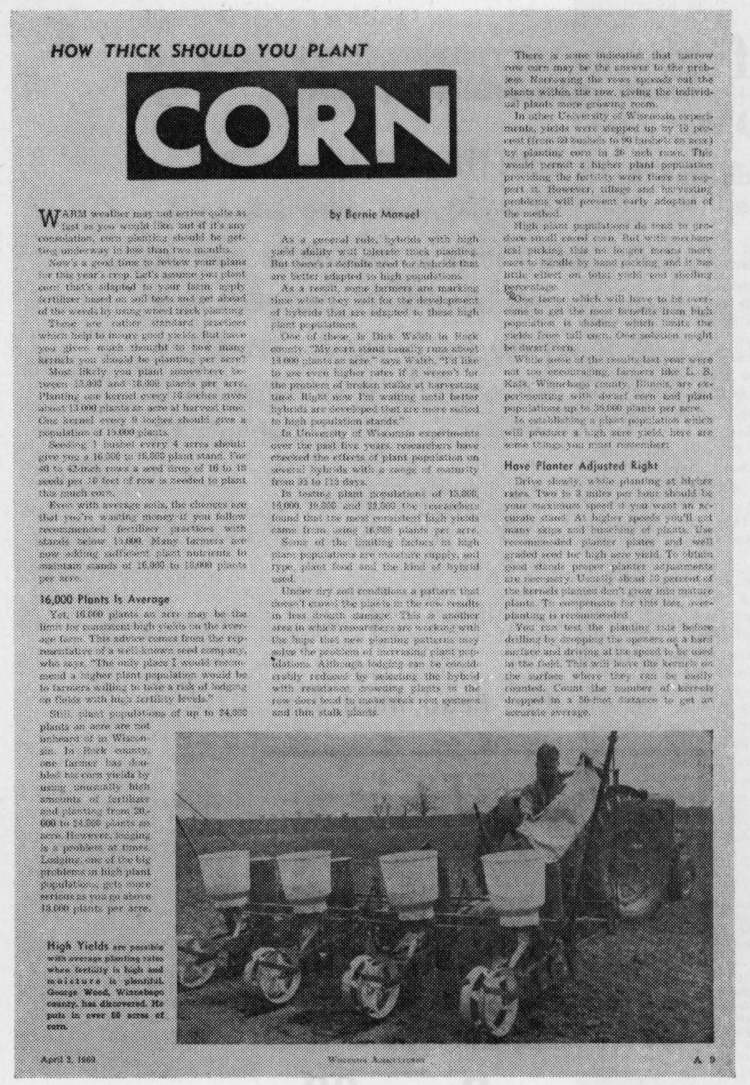

Figure 5.2

\section{Corn Page}

Page Scores

Page 9

Men 66\%

Women 24\%

Page 74

Men 59\%

Women 21\%

\section{Page 9 Versus Page 74}

This is another example of transposing pages in order to measure the flow of readership through the issue. In this case, the corn article appeared on page 9 of the A section and on page 74 of the B section. The defense article was on page 9 of the B section and on page 74 of the A section. This issue had a total of 84 pages.

Differences are not significant except in the case of wo- 
Figure 5.3

\section{The Farmer's Job in Civil Defense}

\section{Defense Page}

Page Scores

Page 9

Men 53\%

Women 39\%

\section{Page 74 \\ Men 52\% \\ Women 50\%}
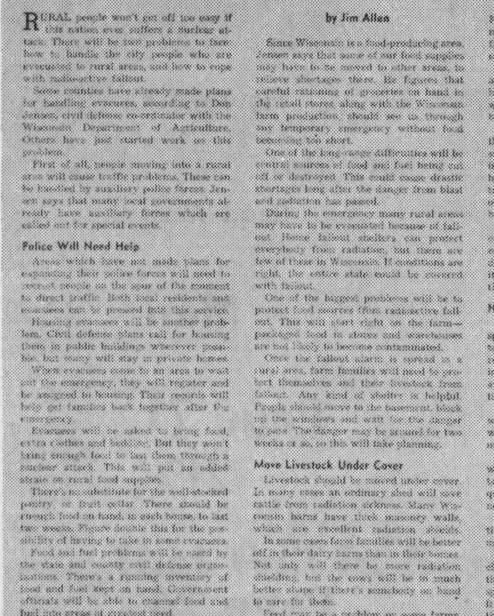

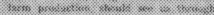

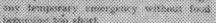

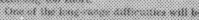

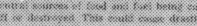
(3.:5i:

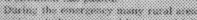
(19)

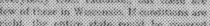
(3): : : (1) (in)

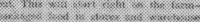

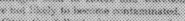

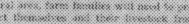
(i.

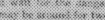

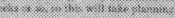

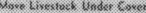

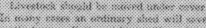
(3:.

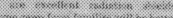

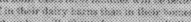

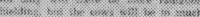
*⿻:

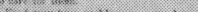
TARGET AREA

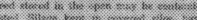

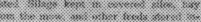

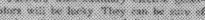

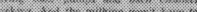

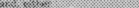
4is (i)

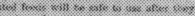

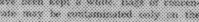
(in)

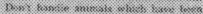

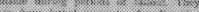

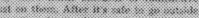

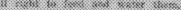

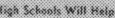
$x$ :

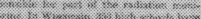

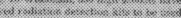
(4) 4.

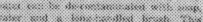
is

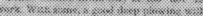

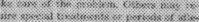

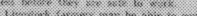

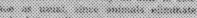
1.

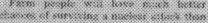

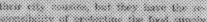

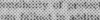

FALLOUT ZONES

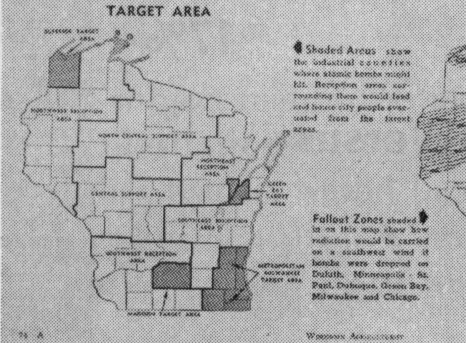

. 
Figure 5.4

Read Most

Men

\section{Page 71 \\ $21 \%$}

Page 24

$17 \%$

\section{Page 24 Versus}

\section{Page 71}

This is another test of the kind described in Chapter 5 . Good Rations ran on page 24 in the A version of the split and on page 71 in the $B$ version. An article on farrowing houses (not shown) was also transposed.

Adding up scores on each article in each position, we get a Read Most score of 31 per cent for men on page 71 and a Read Most of 32 per cent on page 24 . In other words, an article would apparently do as well on page 71 as on page 24. This issue had a total of 88 pages.

Wallaces Farmer, January 16, 1960

\section{Good ration can boost milk output}

- Good roughage gets most emphasis

- Feed grain according to production

- Balance ration with good protein

Tor PRoDUCrnoN from your I dairy herd is limited by two thines the suherited ability of your cows to convert feed into milh. and the gualtry and quan wity of that feent

This assumes you' ate atresty froviding sood hord manage inent.

There: d miling you can da Fistit now about the inseritarice af cows in your miliking line but you can natee sure they ane geven thil opportanity to yieti a profitabie amount at nutio

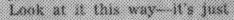

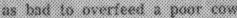
3. it is is be stingy with a nonc proviuces.

lowa State extension diviryman loob Fincham to plains "romly the fend left wer after all other nowis are net ean be used by th cow to prodice milk.

Vnaterfexthas a heasy pro ducer may not immediately shows ap in lowered production. A cow will temporanily rob he body of food malerials to pro dwe nilk. But eventually, mill output sutters

The lowi state folks stagsect, A lew coms adequintely fed may be more profitable than any ad. ditional number that must be restrictiod to make tems swail? able fir the entire berd

What are boxisy's requirements before the fend she eits can be usnd for milk procisction?

- Nody maintenamese is the bis one

An average nalstelin noed: 20 porinds wi hay lor his equis. alent danly juat to keep herself alive. In lint, from two-thinds to three-fourths of the roukhage a cow kats is neat for neiniten. ance only.

- The developing fetus is mother inoportant wser of bossy \& ration:

A cow exrmes a call doring most of her lactation. She has to 'skare' her ration with this unborn sall before the can use it to prouluce milk. This support is especially hesvy during the is especially beavy during the later stages of promsancy when
the fetus makes its most rapid growt

- A third outlet for leed nut trients is for growth.

A heifer salving at 24 to 26 months of ase should continue to prow for another two years or more. This additionst growsth is going to be vital for high life time production. So be sure your fending adjusts for 11

Where do you start? Best at? vice is to feed liberalty but not wastefulty

Current prices make good hay your cheapest source of nutr

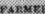

Nos, So pushing roughase cons. sumbtion should pay oft. An remember: the more rountsape a cars cats the more there is aysulable for milk production

Fincham suggests, "feed between 20 and 30 pounds af hay of taxy eftuivaleat daity ies to 90 ins of cers silage) for each 1,0ed pound eww in the hert."

readins three or four tumes per day, ratker tlase just once. "mill hoosi conatmpition," he $a d d s$

Rernember il take, only alwout 20 pownds of sood quality 168 mae hisy to satisty maintenance

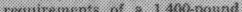

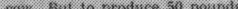
1.

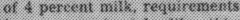
jumy approximately like this: enerny, is tures as mumb; pro. tein. 4 limes is muck; phos: phanows, if limes as much, sind calcinm, 6 inmes is much.

Wiry to to pounds of tay roulu, meat these divmanets. But coss mant ext that much. Her flomach iust isnt large etrough. Hay pelleting may semn remove this plyysical lasrier?

Here' \& where your hame-grown rrains and purchased suppto. ments fill the gaty.

"Balance your grain mixture accorting to the qual. ity of the resughane you feedt: *i: advises pincham "Then teed this srain ae. cording to the production of each eow:"

For examole, with sond gual. trencharse a che producing - prisnds of 4 percent mile needs about is pounds of cons centrate reod. Feeding medium quality hay boosts this amount to 11 paunds.

Whany dairymen wse this rule of thumb ciood nuality hay, 1 16. srain per 4 llas, milk prov duced: medium quality lay, 1 16. grain per 3 thes nulk; poor quality bay, 1 the grain per $2^{3 / 2}$ llos: mitk

How about protein? With top geality hay fed thesratly, add (ion of in mane a balanded ration. Dor over rate your hay, tho-anly leaky, sun-cured, legume forage rates top quality.

If hay is medium or low qual. ty your shontd atid some pro tein concentrate to the ur tein concestrate to the gran. percent digestibie protein ration is suggested for these roughages.

Vitamins and minerals are important, too. Be certain your cows are getting enough by sup. plementing your grein mix and

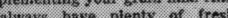
water available.

Jnatary 16,1000 


\section{6.}

\section{Heads That Pull in Readers}

WE FOUND OUT EARLY that subject matter was more important than layout, style, illustrations or anything else. If an editor could guess what readers would be excited about at the time the paper hit the mail box and could deal with that subject, the readership score would be high.

On a head, then, the first thing is to make sure that it indicates what the copy is about. This sounds easier than it is. For one thing, it means using terms that are well-known.

One horrible example came in the Starch survey of Wallaces Farmer (October 15, 1960.) The poll article dealt with methods of getting cropland out of production, but the head played up the technical term "cross-compliance." One result was that the Read Most score for men was only 26 per cent, one of the lowest ever scored on a poll story.

This was an error in editorial judgment. I had thought "cross-compliance" had been talked about enough so that farmers knew what it was. I was wrong. 
If the article is about hogs, get the word "hog" in the head. If it is about fertilizer, say "fertilizer." The label has value.

You want more than a label, of course. One stock head that always registers is "What Price for Hogs Next Fall?" For a human interest story, there is a wider range. "What Happened to Mary Jones" was the head of an article tracing graduates of a rural high school.

An early head about retired farmers said "To Town, to California or to Heaven." This off-beat head probably did better than a label "Retired Farmers," but we didn't try a split on it. There is danger in trying to be too bright and original at the cost of making the reader guess as to what you are talking about.

In the early years of the poll, we didn't score heads by themselves. We figured that if the Read Some score was good, that proved the head was all right. Since then, we have tried scoring heads from time to time and find once in a while that a good scoring head is not necessarily followed by a good score on the following copy. The important thing still is whether the head pulls the reader into the article. If only the head is read, it isn't much good even if it does seem to score high.

Actually I have some doubts about the accuracy of these head scores. It is harder for a respondent to remember noticing a head than to remember actually reading some of an article.

Should the head use a question or a command?

A double split was tried out in Wisconsin Agriculturist (November 2, 1957). Heads were as follows (Figure 6.1) : 
A - "New Concentrates Will Sell More Milk"

B - "Will New Concentrates Sell More Milk?"

A - "Will New Hormones Change Crops?"

B - "New Hormone Could Change Crops"

Combining the two splits for Read Some, the statement got 52 per cent with men and the question 48.5. Young men readers especially seemed to prefer the statement to the question. Women leaned slightly toward the question.

In Wallaces Farmer (November 5, 1949) the following heads were tested:

"Don't Plan Too Many Spring Pigs"

"Are You Planning More Pigs?"

Here the statement scored higher than the question. Apparently the readers were looking for advice, and the positive statement had more appeal.

One thing we are more sure of is this: Don't limit the size of your audience by your head. In Wallaces Farmer (March 4, 1944) a head, "Dairy Association Hears Report" scored 20.8 Read Some for men. "Reports Fight on Oleo" or its equivalent might have done better.

Similar disadvantages come from putting the name of a country in a head, from using " $4-\mathrm{H}$ " in a head or the label of any minority group. Farm Bureau, because of its large membership, can be used in Iowa.

Minority groups should not be ignored. We are entitled to use a 4-H story occasionally, a sheep story, even a bee-keeper's story. But the scores are bound to be low. 
If there is any way to handle the head or copy to get the majority interested in the minority theme, use it. "These Boys Build Beef Herds" is better than "4-H Boys Build Beef Herds." On the first, you'll get the 4-H readers and some others. On the second, your audience may be limited to 4-H'ers.

Do decks (sub-titles) help a head? We have been using two lines of 18-point Bodoni and have run a number of splits to see whether this addition or others to a 36-point or 42-point head increased readership.

Here is one typical split from Wallaces Farmer (January 18, 1948) :

A - Head: "More Profit From Early Beef Calves" (No deck)

B - Same head as A plus deck: "Early Calves Make Better Use of Pasture; Weigh More at Market Time"

Men had 57 per cent Read Some for $A$ and 49 per cent for B.

Another split in same issue on the same subject was:

A - Head: "Soil Insect Control"

Deck: "Deep Placement of Starter Fertilizer Calls for Shift in Soil Insecticide Application"

B - Same head, no deck

On this A had 56 per cent for Read Some for men and the same for B. Combining scores, 52.5 Read Some for men on head and deck; 56.5 for head without deck. Apparently this kind of deck did no good. Similar 
tests on other types of decks indicated the same answer. Apparently the standard two-column head does well by itself.

Some experiments with lead-ins - a short line leads into the head - indicate this way of supplementing the head may have some value.

In Wisconsin Agriculturist (February 18, 1956) we tried a lead-in to a one-line head "When Does It Pay To Add More Land" as against conventional two-line head and two-line deck. Read Some for men was 75 per cent for the lead-in and 65 per cent for the regular head.

Although the differences are not significant, the edge is certainly toward the lead-in.

A two-line head was run against a one-line head in Wallaces Farmer (November 21, 1959). The one line did a little better, 27 to 22 for Read Some with men; 57 to 49 with women.

Another test of heads came in Wallaces Farmer (January 18, 1959). A used the head "Collect Dividends with Farm Records" and B "Need a Fulltime Secretary Soon?" No change in type was made.

Read Some favored A with men (52 to 43); women favored B (32 to 26). Perhaps "secretary" pulled the women in.

Advertisers have experimented with head splits. Starcross Alfalfa in Wallaces Farmer (January 17, 1959), ran a big head on the left-hand page of a split in $\mathrm{A}$ and switched the head to the right-hand page in B. The head scored better on the left-hand page (40 to 27 for men) and Read Some on copy was also strong (23 to 10$)$. 
Allied Chemical tried a split on heads in Wallaces Farmer (March 17, 1956), as follows:

$$
\begin{aligned}
& \text { A - "Crops Make Money with Arcadian" } \\
& \text { B - "I Like Arcadian 12-12-12" }
\end{aligned}
$$

There was no significant difference, except for a slight edge to A (Read Some, men 22 to 19). Other splits indicate that "profits," "make money" etc. may sometimes be good labels for ads.

Another test of headlines was made in Wisconsin Agriculturist (April 5, 1958) with a fertilizer ad. Here the competition was between "Get 74 Bushel Increase from 'Tired' Cornland" and the head "Plow Down Nitrogen for Corn? Sure" (Figures 6.3, 6.4) .

On this, the second head came out better, with a score of 33 per cent against 23.2. The stronger headline pulled up copy scores. The Read Some score on sales copy was 24 for the "plow down" head and 15.9 for "74 bushel increase."

Why did farmers apparently prefer the second head? One guess is that the first head claimed too much. A 74 bushel increase may have simply looked too big. A Wisconsin farmer who averaged 50 bushels might add the 74 to 50 , whistle and say, "It can't be done."

The second head, incidentally, scored where it counted, among larger corn growers and among those who said they used nitrogen on corn.

Wisconsin Agriculturist, working with Herman Felstenhausen of the Department of Agricultural Journalism, University of Wisconsin, checked the influence of using the profit motive in the head. In the issue of April 2 , 1960, in eight splits, one head played up profits and 
the other head workmanship, interest in conservation or some other non-profit motive (Figure 6.4). Here are two examples. The scores are the percentage of men readers of the issue who read some or most of the article:

\begin{tabular}{|c|c|c|}
\hline $\begin{array}{c}\text { Build Corn Profit } \\
\text { With Weed Killers } \\
46 \%\end{array}$ & vs. & $\begin{array}{c}\text { Keep Corn Clean } \\
\text { With Weed Killers } \\
52 \%\end{array}$ \\
\hline $\begin{array}{c}\text { Build Better Herd } \\
\text { With DHIA Testing } \\
\qquad 5 \%\end{array}$ & vs & $\begin{array}{c}\text { Boost Herd Income } \\
\text { With DHIA Testing } \\
46 \%\end{array}$ \\
\hline
\end{tabular}

When all the results were considered, Felstenhausen concluded, "The results showed no preference for one motivation headline over another." (1)

You can put "dollars" in the headline, but it may not work. Heads stressing conservation, the pleasure of doing a good job or other motives may get just as good a response.

It seems plain that a good deal more work should be done with heads. In case after case, we find instances where a good head has pulled up a mediocre story; a poor head has lowered the score on a good story.

What should a good head have?

1. The good head should have plenty of white space around it. The jammed up head suffers.

2. The old two-line deck doesn't seem to have much value. Try more lead-ins. 
3. Put a label on the story. Is it about hogs, or dairy cattle, or fertilizer, or what? Sometimes this can be handled as a Tead-in.

4. After labelling the story, try to get some color into the rest of the head. Quotes can have value.

5. Perhaps it would pay to have the writer of an article submit four or five heads. Let the desk try to work up a few more. Sort for the best.

6. Don't use words that the reader can't understand. Technical language, in ads or editorial copy, will not get across.

7. If you want to attract a minority group - tobacco growers, honey producers, maple sugar makers - a head so labelled is useful in pulling in these particular folks. But it may repel the rest of your audience. Playing to minorities makes sense at times, but know what you are likely to gain and what you are likely to lose. 
Figure 6.1

Question Head

Read Some

Men 53\%

\section{Women $16 \%$}

\section{Question vs.}

Statement

The only change in the articles reprinted here is the shift from question to statement in the head. A second split on "Keeping Corn Clean" also showed little difference in response to the two kinds of heads.

An earlier split on "Planning More Spring Pigs" gave the edge to the statement in preference to the question. Sometimes folks want positive advice.

Wisconsin Agriculturist, November 2, 1957

\section{Statement Head}

Read Some

Men 50\%

Women 14\%

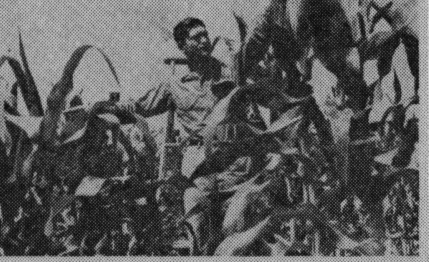

Gibberellic Acid caused corn at right to grow taster and sassle slightiy earlies than corn at lest. At haswest time there was no ditteronee in might of riold horever.

\section{Will New Hormone Change Crops?}

\begin{tabular}{|c|c|}
\hline 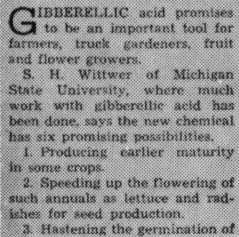 & 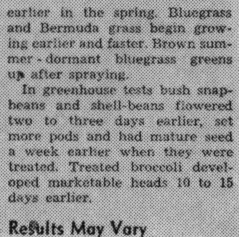 \\
\hline
\end{tabular}

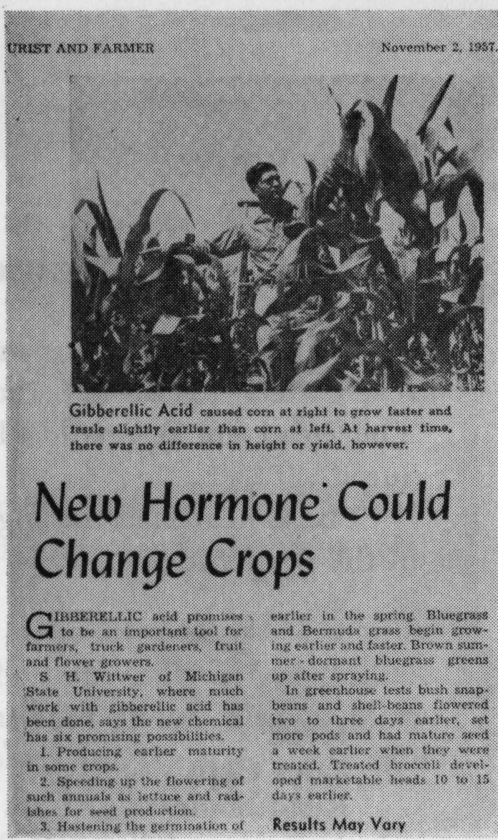




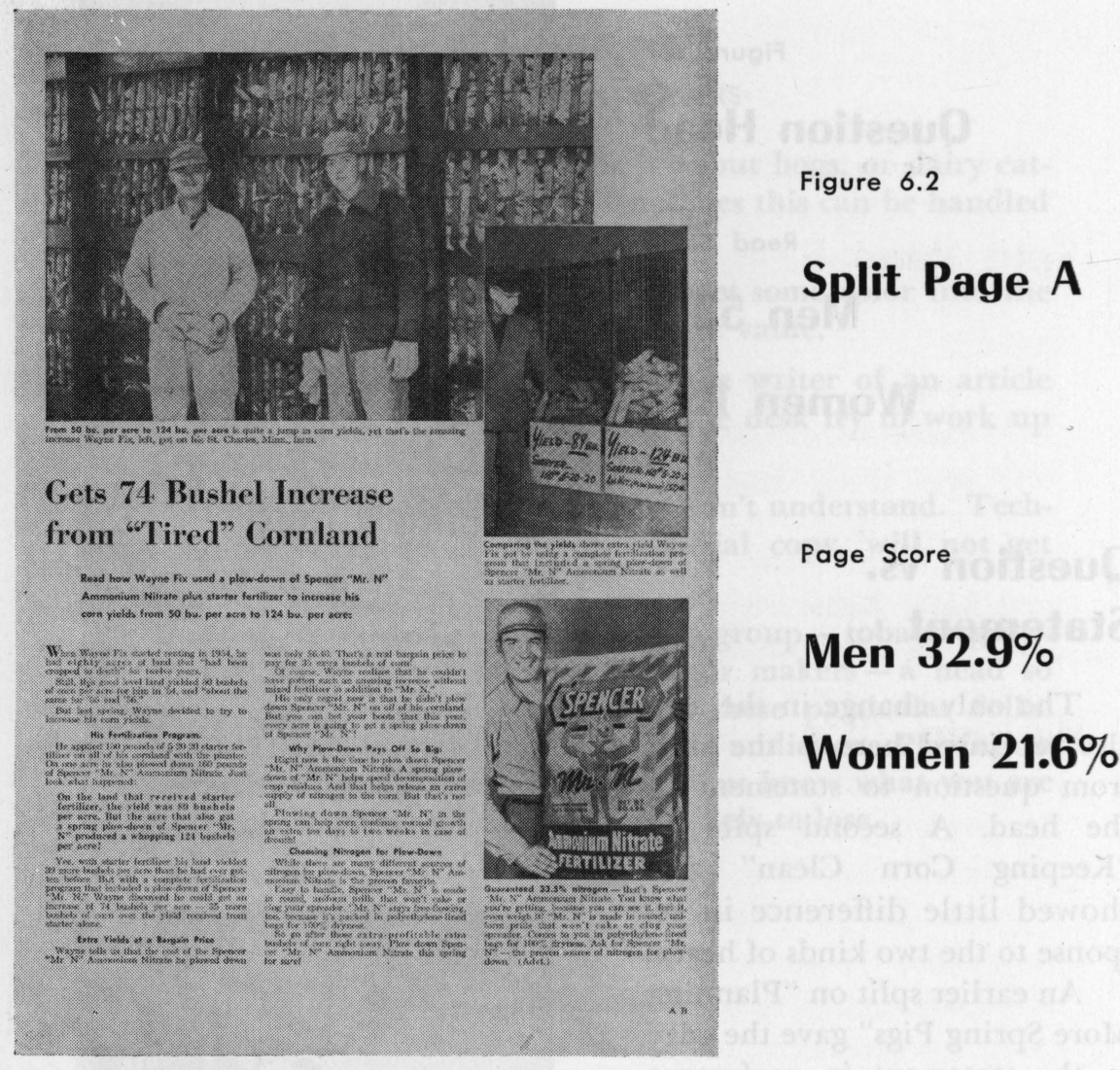

\section{Strong Head Helped This Ad}

Only one change was made in this split. The head in A read "Gets 70 Bushel Increase from 'Tired' Cornland." The head in B read "Plow-Down Nitrogen For Corn? Sure!"

The $\mathbf{B}$ head had the higher score and pulled up the rest of the $\mathrm{B}$ ad with it.

Men

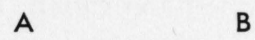

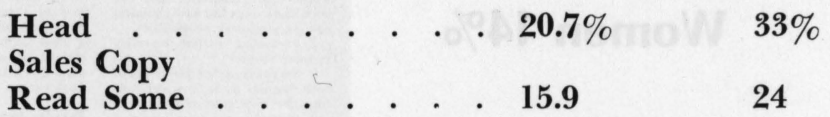


Figure 6.3

Split Page B

Page Score

Men $49 \%$

\section{Women $26 \%$}

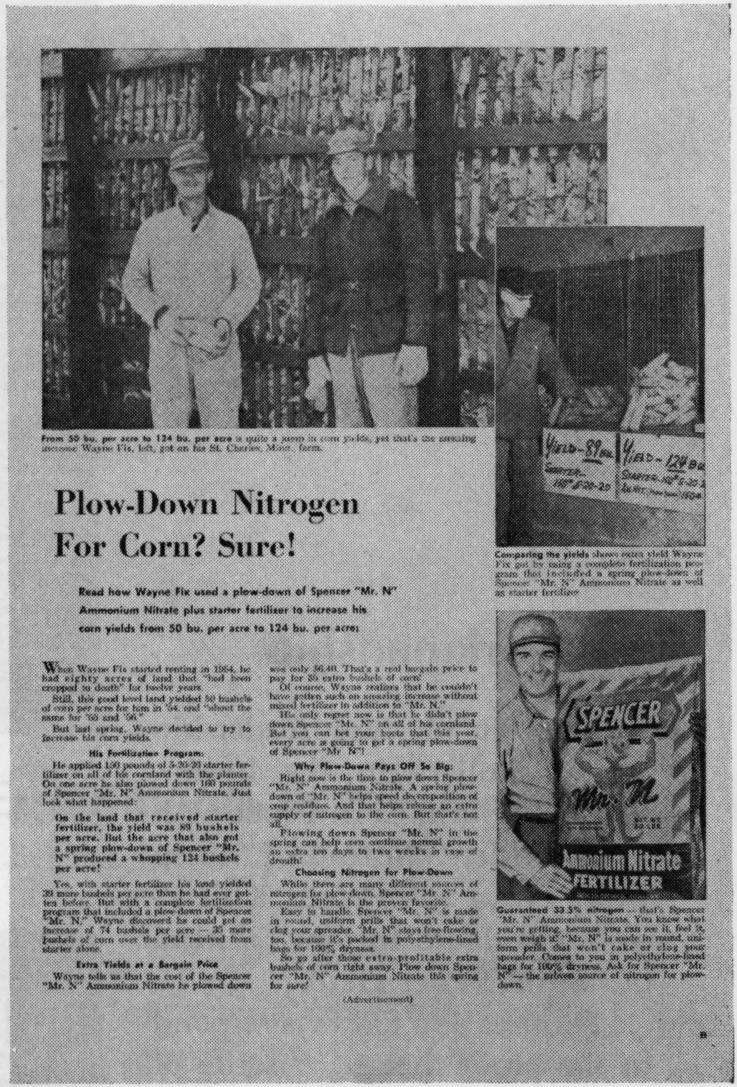

Farmers who used nitrogen on corn gave $\mathrm{B}$ the advantage.

\begin{tabular}{|c|c|c|c|c|}
\hline Any Thi & is $\mathrm{Ad}$ & Use & nitrogen on corn & Don't use \\
\hline $\begin{array}{l}\mathbf{A} \cdot . \\
\mathbf{B}\end{array}$ & & & $\begin{array}{l}22.7 \% \\
34.0\end{array}$ & $25.0 \%$ \\
\hline
\end{tabular}

Farmers with larger corn acreages also preferred B - as did farmers who generally used some kind of commercial fertilizer.

Why did the B head win? One possibility is that A claimed too much. A farmer, who habitually got 50 bushels of corn to the acre, might be dubious about the possibility of increasing the yield 70 bushels, up to a total of 120 bushels. 
Figure 6.4

Heads

Read Some

\section{"Corn clean"}

Men 52\%

\section{Profit}

\section{vs. Workmanship}

Does it increase readership to put dollars in the head such as, "Build Corn Profit with Weed Killers" instead of "Keep Corn Clean with Weed Killers" or "Boost Herd Income" instead of "Build Better Herd."

Farmers don't always respond to the profit theme. A series of splits found that putting "dollars" or "profit" in the head was not a sure way to high scores.

Wisconsin Agriculturist, April 2, 1960

Read Some

\section{"Corn profit"}

Men 46\%

\section{Keep Corn Clean with Weed Killers}

TUST haw eood wre those new $\int$ chemicals for weed control in orx:

Chemicale-simazine and atrasine have producod some stak thing rosults. They' ve also caused disnppoviniment.

The desision whether ox not to wse them this sprine will weed to be wade

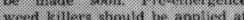
ring 1. up.

There's no doubt that the diem iests provide a majer break hroum in com weed control-i conditions are nisht kot theis use but Uredes the wrons condtion. they ean be an expernetve mistake

Cost is High

vour choine between the two smancine and atrasise: is noarly 3 tossup. So says Kemeth Busch

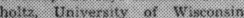

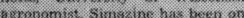
the market three yean Alravine came out lask yesi Atraxine ap prass a little better is rescare to dat

heir toain drawhonk so far

The sprayins sticuid be done at pianting time or within the next three disys Farly application inscerases the chances of eftling ahesi of spring xeins

Equis your sprayer with 20.

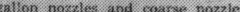

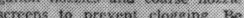
sure the sprist the tore

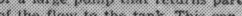
(1) a.

Avoid excessive over-dosige Hesvy application may leave a residue which could atfect prain crops the following year. Oats ase especially senst:se

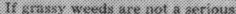
probily and is the curt tow

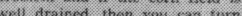
to

Alter broad leat werds carne up. 2.4. D wanks well. Apply it befone the corrs is 10 inches tall. Linter lieatruent nisy damage the corn uniess drop nozzies ane uxed to kapp the spray off the corn leatrie

Perennial wheds require sperial trowtnient Dout newhert theen in planning your weed control gro-

\section{Build Corn Profit with Weed Killers}

TUst haw gond are thoule nexse

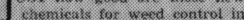

metmiculis-simadine and aura. timn hate prodtuced some tax thing nesults. They'te also eausech disopposintinsent

The dicision whether or not to ase there this sprowy will need to

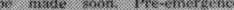

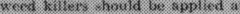
conn plantise time. They dont work entintively atter wend: come

There's no dowbt that the chetsmalis provide a major linerke (1)

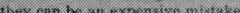

Cost is High

Your shwhe betswent the two

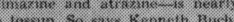

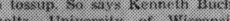
(nx)

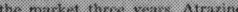
(2.

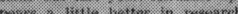
pe

Their mann drawback in tar is
The sprassny should be done at planting lime or within the rext throe detys Es crisses fhe thandes of eetting aheat of sprins rams

Equip your spratyer with 20 . galton nosster and coszse nozale

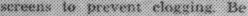
suns the sprasyer has an anitator or a likree pumse that returns part of the bow in the twenk this conts

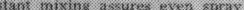
distrimution.

Arwid excensive norr domane: Heney application may leave a

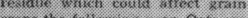

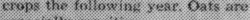
especially sensitive.

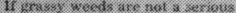
problem and if the entrn freid is Well drained then yox can tume

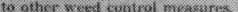

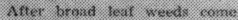

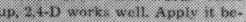
forse the corn is 10 vaches tall. tater trumatent may damase the otrn unte: diop aomitins are wioed

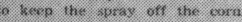
lwave:

Fextenniml werd: nequixe sncial trettmani Dant nestedt them in

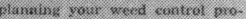




\section{7.}

\section{More Experiments in Readership}

What Good has this testing done the two papers? If you put readership scores on a long chart, you find a lot of zig-zags but no impressive gains over the years. Like another famous character, by running as fast as we could, we have managed to stay in the same place. For a brief illustration, look at the readership scores for Wallaces Farmer in March 9, 1940 and January 16, 1960.

How many non-readers then and now?

$$
\begin{aligned}
& \text { Men Women } \\
& 1940 \text {. . . . . . . . . } 23 \% \quad 20.7 \% \\
& 1960 \text {. . . . . . . . . } 18 \quad 24.5
\end{aligned}
$$

A look at the 20 year report on non-readers indicates a little change. Allow for bad weather, rush seasons, etc., and you come out in about the same place. 
What about readership scores? Another small sample shows.

Lead editorial

Read Most - Men

1940 "Sell More Lard" . . . . . . . 53.3\%

1960 "What Do Price

Supports Do" . . . . . . . . . 54.5

"Country Air," for women, in 1960 scored within a few points of the 1940 figure. Copy on hogs ran a little higher in 1960.

If you look at the long chart, it seems that the war period brought an increase in readership. It brought more important news on farm programs, ceilings, etc. There was also less chance to get away from home on account of gas rationing.

Crises bring more readership. We don't know what the AAA period in the 'thirties would have scored since we didn't survey then. A guess is that scores would have been high. When everything is going smoothly, readership drops. When there is an early frost, a drop in the price of hogs or a new farm program, readership picks up.

It should be remembered that since 1940, television has come into its own. Farmers are getting more magazines. The competition for attention is greater. Perhaps it is something for a farm paper to have held its own.

We guess that reading habits have changed even though scores have not. Today, for instance, we are fairly sure that a good many readers pick up the paper for a few minutes, lay it down, then pick it up again later. The ideal reader who settles down in his chair and reads the paper for two hours is getting scarcer.

Actually we have no early figures on this, because we 
didn't start asking this question until a few years ago. But in Wallaces Farmer (October 18, 1958), Starch found this:

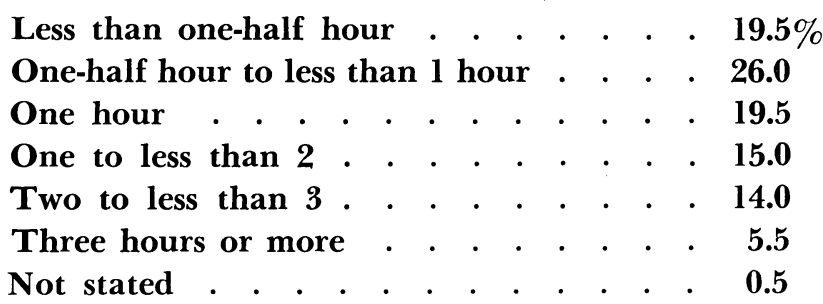

Another change probably has come in what is called "reading days." If you pick up the paper to read it on Monday, that's one day; if you repeat on Tuesday, that gives you two days, etc. We have checked this and find the average is close to three reading days.

If you look at a 1940 issue, you may be inclined to say that 1960 issues look more readable. For one thing, type is larger.

When we began our surveys in Iowa we were using 8-point Bodoni on a 9-point slug for narrow measure copy - 121/2 picas - and 10-point on a 12-point slug for full page, 17 pica columns.

We have stayed by 10 on 12 for the full page copy or for any place where we can use a wide line -17 to 22 picas. On narrow measure, however, we have moved up to 9 on 11.

The face has changed. In Iowa we shifted from Bodoni to Paragon for body type, but found it a little weak. A heavier, blacker face seemed desirable. Experiments by other people confirmed this view. So we moved over to Corona; wide measure, 10 on 12; narrow. 9 on 11. 
Wisconsin Agriculturist moved to Excelsior with 8 on 10 for narrow measure, 10 on 12 for wide, and recently shifted to Times Roman with 10-point for narrow and 12-point for wide measure.

Why are we using larger type? The Minnesota Poll (Minneapolis Tribune) reports that of its readers, seven out of 10 adults wear eyeglasses. In our Iowa sample, 62 per cent wear glasses. Some of these glasses, moreover, may be the dime store variety. Lighting is bad in some farm homes. Thus, it seems that large, clear type has an advantage.

For the most part, we have taken the word of other experimenters in this field. We ran one split in Wisconsin which threw some light on the use of leading.

On the editorial page, we ran one version in 10 point solid and the other in 8-point on a 10-point slug. It was interesting to note that several people said, "Why test the obvious? Of course the bigger type will get more readers."

It didn't. The extra leading made up for the difference in type size. The 8-point came out a little better than the 10-point.

As noted elsewhere, we have run wide (22 picas) 10-point against narrow (12 picas) 9-point and couldn't find much difference. In a slightly different split, however, we ran 10-point ( $161 / 2$ picas) against 9-point (12 picas) in a half-page space (Figure 7.1).

In this split in Wallaces Farmer (January 16, 1960) women came out even but men scored as follows:

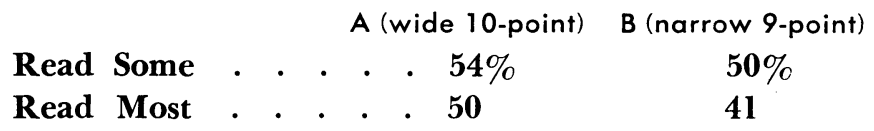


An unchanged ad on the same page gave an edge to A (32 to 26) but the Read Some on the sales copy was in B's favor -13 to 17 . A breakdown by age on the article showed more difference:

\section{A (wide 10-point) B (narrow 9-point) \\ Men of 50 and up . . $62.2 \%$ \\ $41.9 \%$}

The size of the sub-sample was 37 for $\mathrm{A}$ and 43 for B.

Women, 50 and over, showed the same preference for larger type. There was a similar approval from women who had only been to school from one to eight years.

We are inclined to think that the larger type (with plenty of white space) may be a help to older people. It is possible that younger folks, educated to big type in magazines, may also show the same preference. It would take more experiments, however, to be sure of this.

One continual argument on the staff is about the way dirt copy is to be handled. Is it enough to say, "Do this and that for your hogs," quote experiment station results and stop?

Or should we go in the field, interview several farmers, quote them and then add experiment station results?

The second method costs more. Presumably it makes the reader feel that the paper is thinking in terms of farm people like himself. But is it worth the expense and trouble?

This is a vital issue, but a hard thing to test. As 
noted in the chapter on illustrations, it seems that readers do look for pictures and quotes of people they know. But this may be a long time effect. Measuring one article, written in different ways, may not be enough.

We have attempted this experiment several times. Wisconsin Agriculturist in splits has not been able to find that the farm visit and quote method pulled in any more readers than the desk copy.

Wallaces Farmer tried a split (September 20, 1958) with personalized dirt copy against desk copy with a few quotes and had somewhat different results.

Heads and leads of the two versions follow:

A-(Head) "I got my bellyfull of the stuff."

So says one Iowa farmer. But grain sorghum still looks like a good crop.

(Lead) "I swore last fall that I'd never raise grain sorghum again," said . . .

B-(Head) Harvest sorghum early. Better count on using a crop dryer too. Sorghum lodges easily soon after frost.

(Lead) Combine your grain sorghum early and dry it, etc.

In the body of the article $\mathrm{A}$, a few personal touches were added to the description of the men interviewed. A quoted two farmers not quoted in B. A had 46 lines of quotes; B had 27 lines of quotes.

It should be noted that B wasn't pure desk copy. Interviews were used, but not to the same extent as in A.

Men

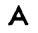

B

Read Some . . . . . . . $54 \%$

$27 \%$

Read Mos

47

22 
Women also had a two to one margin ratio for $\mathrm{A}$.

Sorghum raisers presumably would be more interested than non-raisers. A had 66.7 per cent Read Most for raisers against 50 per cent for B. For non-raisers, A had 44 per cent and B 13.7 per cent.

As usual, the frills counted more with readers who were not greatly interested. Sorghum raisers were apparently ready to read the article whether or not it had quotes and people.

Space is a problem here, of course. It takes more room to get in these personal descriptions, colorful quotes, etc. Yet the local angle and the personal angle are important. But to work these angles takes staff, expense money and time.

One series of experiments dealt with the use of boxes - whether to put a rule around a box or let white space set it off. For example, a box on corn supply with an article on the same theme, Wallaces Farmer (November 5, 1949) used a sample of 98 men in $\mathrm{A}$ and 97 in $\mathrm{B}$.

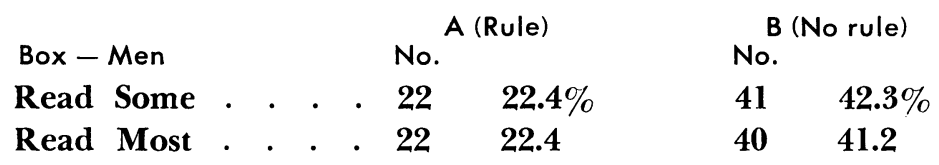

The unchanged article copy gave $\mathrm{B}$ a 4.5 point advantage on Read Most. The changed box gave B (no rule) an advantage of 18.8 points. Allowing for this 4.5 shift in scores on unchanged A and B copy, we have a net advantage of 14.3 percentage points for the box without the rule (Figures 7.2, 7.3) .

This was a characteristic response, where the box 
was closely related to the article and was run at the bottom of the page. We found, however, that when the box was blown up to a large size with a cut it took on the nature of a separate article and the rule made no difference.

Later tests in Wisconsin Agriculturist indicated that a box above the head on a two-column article scored equally well with or without the rule.

White space is probably as good as a rule and sometimes better since the rule may check the movement of the eye. However the unexpected result of the series of tests was something else.

We kept finding out that the box, no matter how handled, usually scored lower than the copy it accompanied and always lower than a good photograph. For example, in Wallaces Farmer (March 16, 1957) the article in A scored 67 Read Most while the boxed chart (more dramatic than the usual box) scored 47 Read Most. In B the article scored 69 Read Most and the boxed chart 44 Read Most. The box, with or without the rule, was no great help to the article. A photograph would have done much more.

Another experiment in Wisconsin Agriculturist (November 5, 1955) had the same moral. There was a men's score of 80 per cent on the copy and a score of 56 per cent on the box. Stated in another way, of the 129 men who read some of the copy, only 87 also looked at the box.

This was a high scoring article (on Secretary of Agriculture Ezra Benson and his policies), and the box may have suffered on this account. Yet the purpose of the box is to stop the straying eye and coax it into the copy. This didn't happen. 
Our tentative conclusion, therefore, is that the box, in any form, isn't likely to do what it is supposed to do; namely, draw attention to itself and the article. Putting a rule around the box - if at the bottom of the page - probably hurts it.

Today, we rarely use boxes except in the case of poll articles where the results are summarized. We even have some doubts about this.

Is it worth while running a table of contents near the front of the magazine? Wallaces Farmer tried to check on this (March 16, 1957).

The A section ran an article; the $\mathrm{B}$ ran a table of contents. Both were two columns (Figure 7.4).

More people read the article than looked at Contents. (Read Some, 65 to 50 for men; 56 to 27 for women). But did Contents help the articles it plugged?

Seventeen plugged articles-Read Some-were matched with 17 non-plugged articles.

Where the articles were not plugged in either $\mathrm{A}$ or $\mathrm{B}$, the A sample had an advantage of 14.1 percentage points. Apparently the A and B samples were not wellmatched in this experiment. The plugged articles in $\mathrm{A}$ had only an 11.5 percentage point advantage over the unplugged articles in $\mathrm{B}$. The corrected difference was 2.6 points. As far as this experiment shows, the plugs in the Table of Contents did not help the respective articles.

Other experiments with plugs on the cover show much the same thing. The cover plug may help to pull the respondent into the magazine; it apparently does not help the score of the particular article plugged.

There is one big exception to this. When the cover 
picture, the head and the caption are linked together to plug one article inside, there is evidence that the plugged article does gain.

A curious (to an editor) complaint comes up once in a while. An advertiser may say that editorial copy is too interesting; it diverts attention from the advertising.

Actually any advertiser wants an interesting magazine. Otherwise he'd have no readers. But an advertiser on page 31 may think that pages one to 29 and pages 32 to 100 should be exciting. Only the editorial copy on page 30 , facing his ad on page 31 , should be dull. (1)

To any editor, this seems nonsense. But the notion pops up once in a while. Roy Eastman in Printers' Ink (1951) said, "When you get your ad next to particularly absorbing 'reading matter' you just buy yourself a handicap, for even your 'visibility' is decreased."

It doesn't work that way for a state farm paper. We used a split on this. Scores are Read Most for editorial copy and Any This Ad for the ad. Men's scores are:

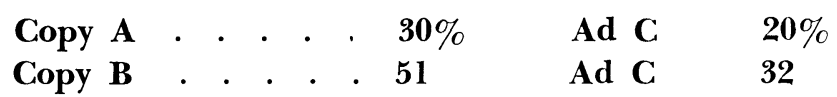

Now Ad C was the same in each case; only the editorial matter was changed. The editorial copy in $B$ happened to be more interesting than that in $\mathrm{A}$. The more interesting editorial copy pulled up the ad scores.

We ran seven splits of this kind, with scores for both men and women. Since the copy in each case was aimed at men, the men's scores were higher and the results probably more useful. 
Of the seven men splits, an increase in the score of the editorial matter facing the ad was accompanied by an increase in the score of the ad in five cases. In two cases, a slight increase in the editorial score was accompanied by a drop in the ad score.

With women, the result was the same - five out of seven.

So far as we can tell, therefore, the chances are that an interesting article will help the ad next to it. (2)

My own hunch is that Eastman may have been thinking of fiction running from one page to the next. If a reader got bound up in the fortunes of Jack and Jill, he might overlook the accompanying ad. However, when no article is carried beyond the spread on which it starts, a reader must lift his eyes and the ad, if attractive, has a chance. 


\section{Bigger Type for Old Folks}

The articles on the next page are the same except for type size and column width. The upper article is set in 9-point Corona on an 11-point slug and the columns are $121 / 2$ picas wide. The lower article is set in 10-point Corona on $12,161 / 2$ picas wide.

For men, the bigger type seemed to help readership. It apparently made little difference with women.

Age break-downs for men showed a considerable edge for the larger type with older men.
Read Most
Wide, 10-point
Narrow, 9-point
Men of 50 and up . . $62.2 \%$
$41.9 \%$

A number of splits in this field give a slight but not decisive margin to somewhat larger type.

Wallaces Farmer, January 16, 1960 
Figure 7.1

Read Most

9-point type

Men 41\%

Read Most

10-point type

Men 50\%

\section{When did you last \\ Smell a skunk?}

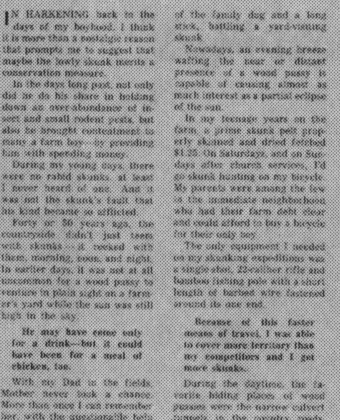

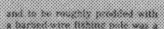

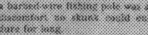

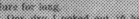

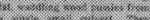

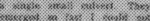

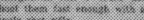

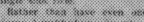

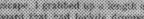

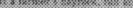

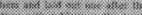

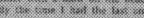

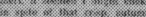

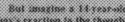

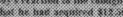
सा:3 का : $: 3:$ :

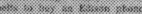

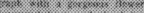
3.

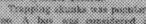

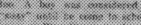

When did you last.

\section{Smell a skunk?}

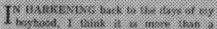

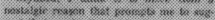

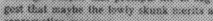

(2) atcosis:

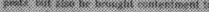
की

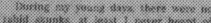

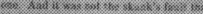

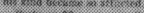

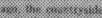

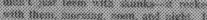
(25) 40. : :

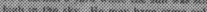

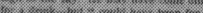

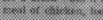

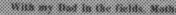

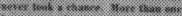

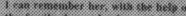

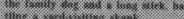

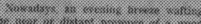
200: |31: (in)

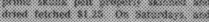

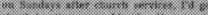

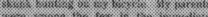
.

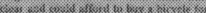

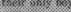

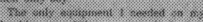
स: (2.

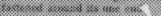

: i:

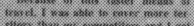

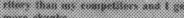
manc:

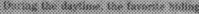
(2.

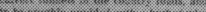
(ix: i: (1:0. an:

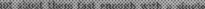
si: sine

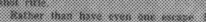
(2: (3.) (i:i:i:i:

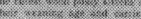

$x^{-10}$

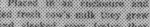

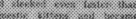

(202)

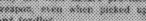

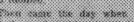

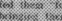
(25)

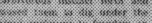

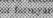

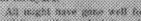

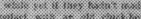

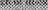

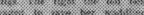
(⿻一;: :

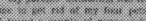

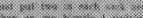

:

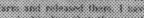

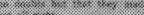

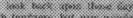

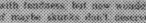

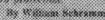

\section{[ 119$]$

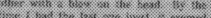

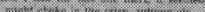

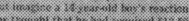

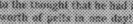

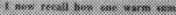

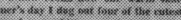

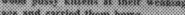
i:

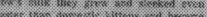

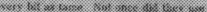

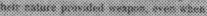

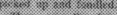
(1.7. (2)

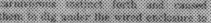

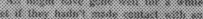

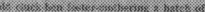

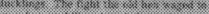

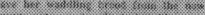

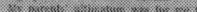

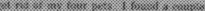
(2. is: :

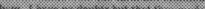

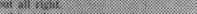

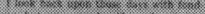

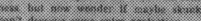
(1) 
Figure 7.2

\section{Washington Wire}

\section{Copy Split A}

Read Some, Box

\section{Men $\mathbf{2 2 . 4 \%}$}

\section{Rule Versus White Space}

If you run a box with an article, do you put a rule around the text or let white space divide the box from the rest of the copy?

A series of experiments indicates that on copy like that in Figure 7.2 and Figure 7.3, white space does better than a rule.

\section{Will New Farm Law} Help You?

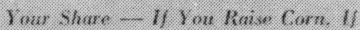

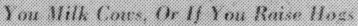

11: :3.:

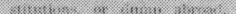

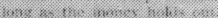

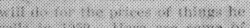
(1.8:

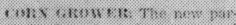

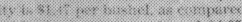

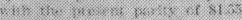

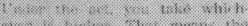

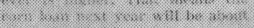

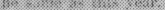

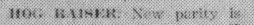
4. (1.

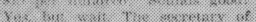
s.

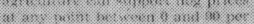

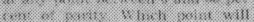

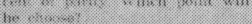

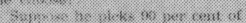
min:

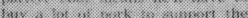

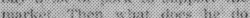

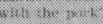

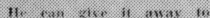

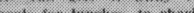
(3) (15)

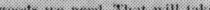

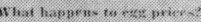

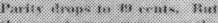

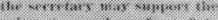

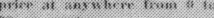
$3 n \pi m: n: m$.

सा:

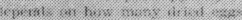

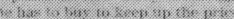
(in)

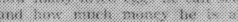
:

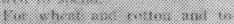

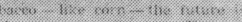
(x)

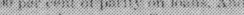

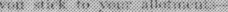

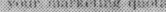

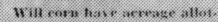

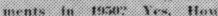

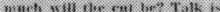

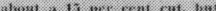

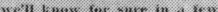

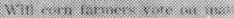

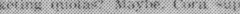

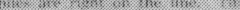
(2:

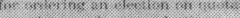
(3:

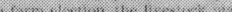
:

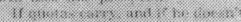

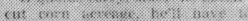

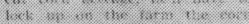

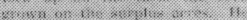
i:

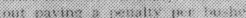

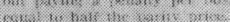

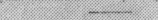

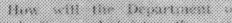

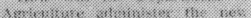

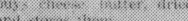

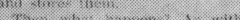

You Never Had

\section{So Much Old Corn}

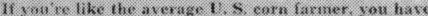

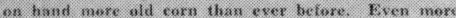
thisn in $104 \%$.

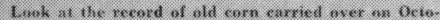
ber i of moinus yearx:

\begin{tabular}{|c|c|c|}
\hline Yrar & Bushels & Carry-Aver \\
\hline $13: 3,3$ & & 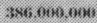 \\
\hline 13:2 & & (6) 8060.0146 \\
\hline $19: 2 x$ & & 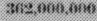 \\
\hline $1941 \%$ & & 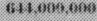 \\
\hline 1347 & & 17.4. \\
\hline $114 \mathrm{k}$ & & 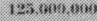 \\
\hline 11414 & & 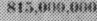 \\
\hline
\end{tabular}

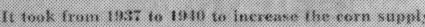

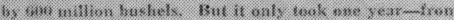

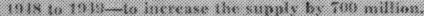

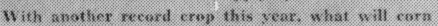

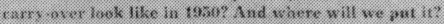




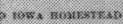

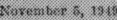

Washington Wire

\section{Will New Farm Law}

\section{Help You?}

Your Share - If Y ou Raise Corn, II

You Will. Conse, Or If Y ou Raike Hogs

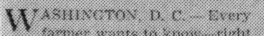

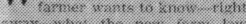

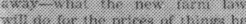

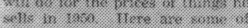
the : in:

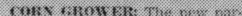

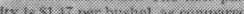
ห)

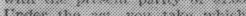

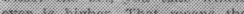

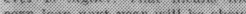

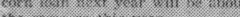
the

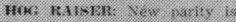

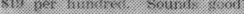

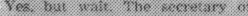

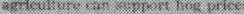

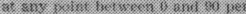

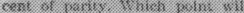
he silos:

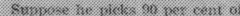

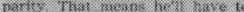

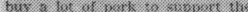

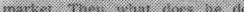
with the in:

11. c⿻is givi it awsy to

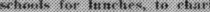

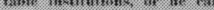

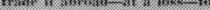
gomit we mod. That will take a tert of manst.

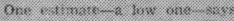

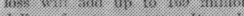

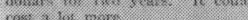

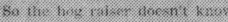

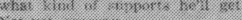

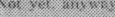

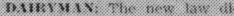

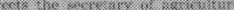
tw :MTMm: : in:

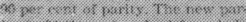

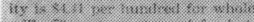
mink. 10 : knk: th:

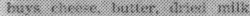

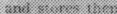

Th: $=1$ :

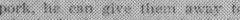

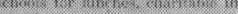

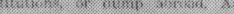

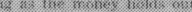

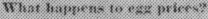

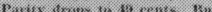

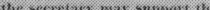
(19)

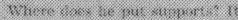

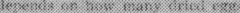

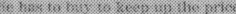

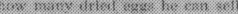

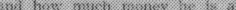

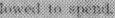

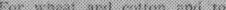

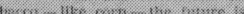

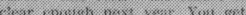

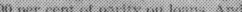
(2.1: (1.

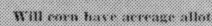
ment: in twas: Tes, Hew

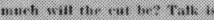

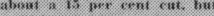

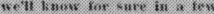
work:

11:40.

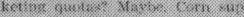

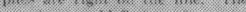
:

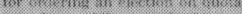
-

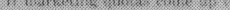

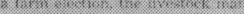

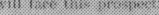

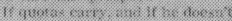

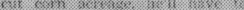

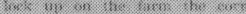

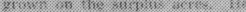

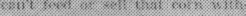

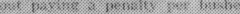

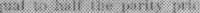

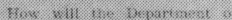

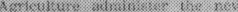

\section{You Never Had}

\section{So Much Old Corn}

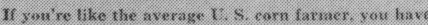

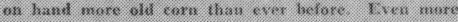
thase in 1640.

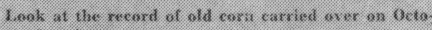
ber i of inxious neares

\begin{tabular}{|c|c|c|}
\hline$x=3 x$ & Brishek & 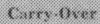 \\
\hline $1: 1: 2: 8$ & & 2X16, . \\
\hline $11 \times 87$ & & 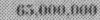 \\
\hline $10 \times 38$ & & : \\
\hline $14: 4$ & & 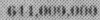 \\
\hline 19:4\% & & 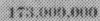 \\
\hline 1018 & & 12: : . : \\
\hline 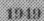 & & $815,01010.6010$ \\
\hline
\end{tabular}

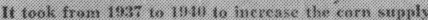

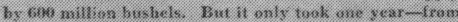

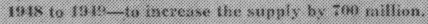

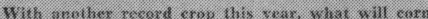

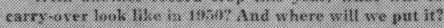

Figure 7.3

\section{Copy Split B}

Read Some, Box

\section{Men $\mathbf{4 2 . 3 \%}$}

On other types of box, there seems little difference between the rule and no rule.

Most important is the fact that in almost all of the splits, the box, no matter how treated, scored lower than the accompanying article. A photograph apparently did more to get readers for the article than a box.

Wallaces Farmer, November 5, 1949 
Figure 7.4

Read Some

\section{Men 50\%}

\section{Women 27\%}

\section{Does a Table of Contents Help Readership?}

In this split, B carried a Table of Contents and A ran an article on school reorganization. The article got more readers than the Table of Contents.

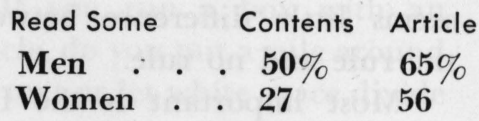

More important than the score is this question: Did the plugged articles in Contents do better than the unplugged articles? The answer is: No real difference.

Wallaces Farmer, March 16, 1957

\section{In this Issue}

March 16, 1957

\section{New Features}

\section{Livestock}

Are you weaning pigs early? ............16, 68 llog raisers tell of their experiences with early weaning in these iwo stories. Pase is is on prestarter ferus, 68 on carly-weaming manasernent.

How to creep feed your lambs.............. 56

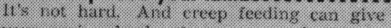
your spring lambis that extra puih toward early marketing.

\section{Marketing and Management}

Extra beet caused the meat oversupply.....76 However catule mimilers have started to decline. hog raisers may benefit as treat supplies drop.

What's Ahead 2.21

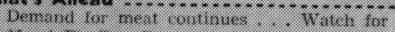
March Pig Crop Fepont. Dairy prosperta ... Feeder cattil supplicer. Meat production re. cords and what they mean

\section{Crops and Machinery}

Your tractor system system ................ 59 Heré: how to dedust your own tractor's sys: tem in get easicr stcering and longer lire servies:

Save more water for crops.................82 Subsoil moistive is short again. Here are ways to kate the trin you get.

\section{For Everybody}

Let's spread our school tax load...............48 Farmers bear loo great a share of present school taxes, argues an lowa farmer. Here are his reasons for at hift of the hasd

How they kept their church...............87 When perple leave a community, they often leave curnmanity problems. llores how the stay-athome kept their chumh and held a community tonkethex.

\section{For the Home}

When you plan special desserts...............60

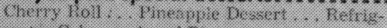
cratur Calis: Annel po.

Patterns . ................

Cookery Corner $\ldots \ldots \ldots \ldots \ldots \ldots \ldots \ldots \ldots .62$

Cher Sunburat kith Stick Duns ... Tuna Salad Chew Fininkfurtur livin:

Household Helps .............................63

\section{Old Friends}

Visits With Your Vet.....................42, 43

Service Bureau .......................... 54

Voice of the Farm ................... 58,59

Outside Stuff ...............................72

Rural Route Ramblings..................... 74 
What do we think we have found out in the experiments reported in this chapter? Here are some tentative conclusions:

1. It pays to check back once in a while and see if your articles on a particular subject are scoring as well as they did last year, five years ago and 10 years ago. Don't feel too badly if you haven't gained. Competition is getting tougher. If you fall short in any particular area, start finding out why.

2. It costs more to interview and photograph many farm people in building up experience articles. We think it pays, but it is hard to get adequate evidence.

3. Personalized copy - details about Jim Smith - probably goes over a little better than copy without quotes and case histories. But, remember that the hero of every article should be the reader; he should say, "This fits my case."

4. Putting a rule around a box sometimes hurts and sometimes makes no difference. The important point here is that a box almost never scores as high as a photograph. To break up a page, a photograph makes more sense than a box.

5. An advertisement that runs next to a good article is likely to benefit. But when readership is high and continuous throughout the magazine, an ad anyplace will get readership in accordance with its merits. 


\section{8.}

\section{What Kind of Folks}

\section{Read Your Ad or Article?}

Suppose An AdVERtisement for hog feed finds 80 readers out of a sample of 200. That looks like a good score.

But also suppose that 60 of these readers aren't raising hogs. That leaves only 20 readers who are the kind of prospects the advertiser wants to reach.

This happens more often than you might think. A flashy photograph may pull in some casual readers. It may not pull in and hold the prospects the advertiser wants.

To measure the effectiveness of an ad we need to know more than just how many folks noticed it and how many read the sales copy. We also need to know what kind of folks did the noticing and the reading.

Wallaces Farmer and Wisconsin Agriculturist call this kind of investigation "market analysis." It is probably the most helpful thing a farm paper can do for its advertisers.

The same kind of "market analysis" is also useful with articles prepared by the editors. Did an article 
prepared for young renters really reach them? Did an article aimed at women with big families get read by that kind of subscriber?

Starting in 1951, we prepared market analyses of this kind on a number of articles and ads. In many cases, the analysis showed the ad to be stronger or weaker than you would guess from the score of the whole sample.

For instance, how well did an ad aimed at cattle feeders reach its mark? (Schering Corporation - Trilafon - September 20, 1958, Wallaces Farmer) .

The ad scored 26.5 per cent with men. That is, 53 men out of the 200 in the sample looked at the ad. But what kind of folks were these 53?

The Poll asked whether farmers were feeding or planning to feed cattle. Here is the response:

Any This Ad No. of
interviews

Plan to feed

82

Do not plan to feed . . . 105 Undecided about feeding

9

No. of ad readers Per cent

29

23 $35.3 \%$ 21.9

11.1

This ad reached a fair share of the possible prospects.

An Oliver ad for field shelling of corn in Wallaces Farmer (September 20, 1958) needed to define its prospects in a little different way. The Poll asked:

"What do you think about the future of field shelling corn?"

“1) I'm doing it or thinking seriously about doing it.

“2) Looks interesting, but don't know whether it will work well.

“3) It isn't practical."

The three groups scored as follows: 


$\begin{array}{ccc}\begin{array}{c}\text { No. of } \\ \text { interviews }\end{array} & \begin{array}{c}\text { No. of } \\ \text { Anny This } \\ \text { Ad" readers }\end{array} & \begin{array}{c}\text { Per cent of } \\ \text { ad readers }\end{array} \\ \text { - } 26 & 8 & 30.8 \% \\ \text { - } 120 & 47 & 39.2 \\ \text { - } \quad 44 & 22 & 50.0\end{array}$

Note that the men who said, "It isn't practical" were still the best readers. For the long pull, the ad's major service may have been to shake the convictions of this hostile group.

Another way to check on this ad was by corn acres. In this case, the farmers with 75 acres or more in corn had a 43.4 per cent score. This was the largest group, in terms of acres, and the ad scored better with these folks than with smaller farmers.

How does this method work with articles by the editors? Take the department "What's Ahead," a discussion of market prospects. In the same issue of Wallaces Farmer (September 20, 1958), the Poll tried to find out how this outlook copy was getting across to farmers who took one, two or three farm papers.

If a farmer took three farm papers, would this competition make him less interested in "What's Ahead?"

To find out, the Poll checked farmers who had Read Most of the copy in "What's Ahead."

Farm papers

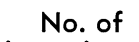

interviews

\section{Take Wallaces Farmer}

only . . . . . . . . 12

Take two farm papers . . 46

Take three farm papers $\quad$. 136

$$
\text { No. of }
$$

readers

\section{Per cent}

$33.3 \%$

34.8

56.6

The big and important group was made up of those who took three farm papers. In this group, we found a higher percentage of readers of the department than in the other two groups. 
A Purina ad for hog feed in Wallaces Farmer (September 20, 1958) raised the usual question: Did the ad get read by hog farmers who were good prospects? Any This Ad scores were used.

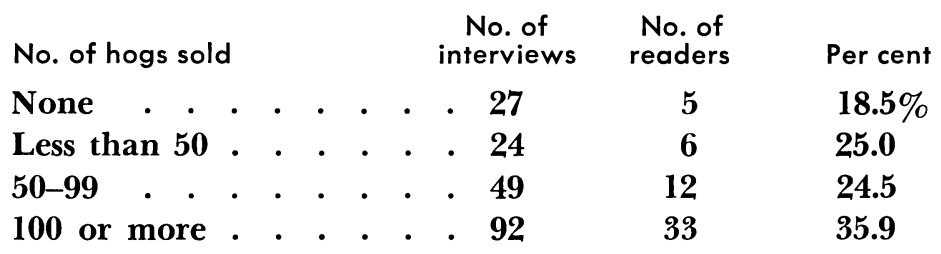

Here the biggest group and the most important to the advertiser also made the highest score.

In some advertisements, the age of the prospect, whether he is an owner or renter, or whether he is in the upper third of income returns may be the important factor.

In a Purina hog feed ad in Wallaces Farmer (November 21, 1959) market analysis showed the following:

1. Younger farmers (21-34) were better readers than older ones.

2. Farmers with gross incomes of $\$ 10,000$ or more were better readers than farmers with smaller incomes.

3. Farmers with fewer than 50 hogs sold during the year were the poorest readers.

In a Starcross Alfalfa ad in Wallaces Farmer (January 17,1959$)$ several breakdowns were used. The critical one probably was "Are you planning to sow alfalfa in 1959?" Any This Ad scores follow:

$$
\begin{array}{ccc}
\text { No. of } & \text { No. of } & \\
\text { interviews } & \text { ad readers } & \text { Percent }
\end{array}
$$

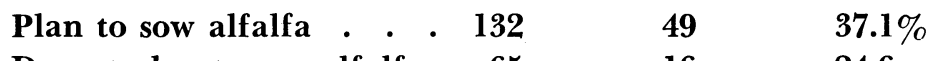

$\begin{array}{llll}\text { Do not plan to sow alfalfa } & 65 & 16 & 24.6\end{array}$ 
Apparently the ad reached its target in a fair number of cases. But suppose the scores had been reversed and there had been 16 ad readers among those who planned to sow alfalfa and 49 among those who did not so plan?

The over-all score of 33 per cent would have been exactly the same, but the effectiveness of the ad would have been quite different.

A John Deere ad in Wallaces Farmer (January 17, 1959) checked corn acreage, income, total crop acreage and number of tractors owned (Figure 8.7). On the basis of corn acreage, the Poll found:

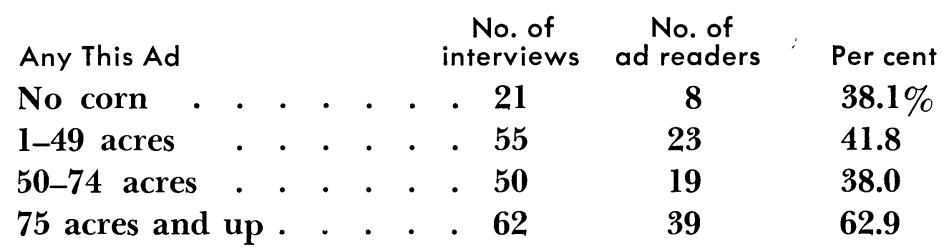

The appeal of the ad was broad, but the bigger corn growers showed the most interest.

Another ad, Protein Blenders, Wallaces Farmer (January 17, 1959) was aimed at both hog and cattle feeders but did better with hog feeders than with cattlemen. With hog feeders the ad scored almost twice as high with those who sold 100 hogs or more as with those who sold less than 50. But with cattle, the feeders and the folks who didn't plan to feed came out almost the same (Figure 8.5).

The market analysis may throw additional light on split runs. A Bovitrin (Merck) ad on treatment for mastitis, Wisconsin Agriculturist (October 3, 1959), found the A ad scoring 20 per cent Any This Ad and the B ad, 32 per cent. Different illustrations were used - a test tube in $\mathrm{A}$ and a cow in $\mathrm{B}$ (Figures 4.4, 4.5). 
These were men's scores for whole samples. But what kind of folks were the real prospects? Probably those who were having trouble with mastitis. A question on this found that 87 (55.4 per cent) of the sample were having trouble and the balance were not - or, at least, didn't admit it.

How did the ad appeal to those two groups? Scores follow for men:

$$
\text { Had trouble }
$$

A B

Any This Ad . . $16.7 \% \quad 47.0 \%$

Read Some . . . $11.1 \quad 41.2$
$A^{\text {No trouble }}$ B

$\mathbf{2 0 . 0} \% \quad \mathbf{2 0 . 0} \%$

$8.9 \quad 12.0$

This indicated that the superiority of B over A was considerably greater in terms of prospects than was shown by the total score.

Market analysis of food ads brought out some useful facts. In Wisconsin Agriculturist (April 4, 1959) a check of the King Midas flour ad showed that families of four or more made up 59.5 per cent of the whole sample. But this part of the sample actually provided four-fifths of the persons in the households reached by the ad. A household with four eaters was worth twice as much as a household with two eaters. So the score of the flour ad with women in families of four or more was the vital item in the analysis (Figure 8.3). This group scored as follows:

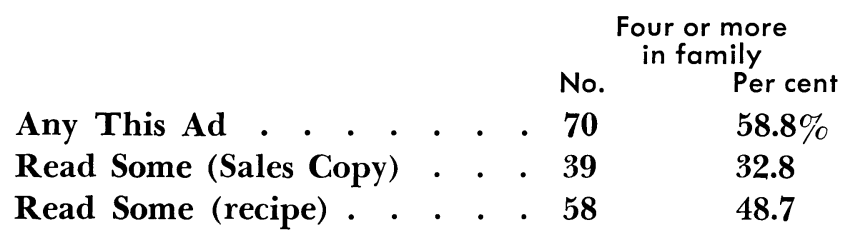


The Poll asked, "Have you done any baking in the last three days?" And 89.4 per cent of the sample said "Yes." These bakers paid more attention to the ad than the non-bakers.

This point was checked again with a Robin Hood ad in Wisconsin Agriculturist (April 5, 1958) (Figure $8.6)$.

$$
\begin{aligned}
& \text { Baking - Yes Baking - No } \\
& \text { Any This Ad . . . . . . . } \mathbf{5 4 . 7 \%} \quad \mathbf{3 7 . 9} \% \\
& \text { Read Most (Sales Copy) • • 18.0 } 6.9
\end{aligned}
$$

Another use of the market analysis shows up in a Ford Tractor ad in Wallaces Farmer (January 16, 1960) . Here, among other things, the Poll asked the brand of the last tractor bought and then checked this reply against readership.

Any This Ad

$$
\text { No. of }
$$
interviews ad readers

Allis Chalmers . . . . . 15

Ford . . . . . . . . 27

5

International . . . . 62

Per cent

John Deere . . . . . . 51

Massey Ferguson . . . . 8

Other . . . . . . . . 32

Of the 27 who had bought a Ford at last purchase, 13 looked at the ad. Of the 168 who had NOT bought a Ford at last purchase, 47 looked at the ad.

Ordinarily you expect that a user of a product will be more attracted to the ad than a non-user. The ad has two jobs at least: to renew the faith of the old customer and to attract a new customer. This Ford ad did well on both counts.

The critical point in using market analysis in ad- 
vertising is this: What kind of breakdown will really throw light on the effectiveness of the ad? With feed ads, one question is obvious. Does the farmer who reads the ad have any hogs, or cattle or poultry or any other kind of livestock aimed at by the advertiser?

In some new products, age may be a factor. Young men will respond better than older ones. In some cases, income is important. A costly product won't stand much chance with a farmer of low income.

There is a temptation sometimes to use this kind of Poll as just another census. Since the number of questions that can be asked is limited (respondents run out of patience), the only questions used should be those that throw light on the specific ad being measured.

To get full value out of market analysis of advertisements demands study and cooperation between the advertiser and our research department. Properly handled, it can be one of the most useful of research tools.

Do young people read articles - and advertisements - as eagerly as older people? This is a vital question. The young farmers will be around for a good while. The older ones are getting close to retirement.

Suppose we had two articles, A and B. Each scored 45 per cent Read Most, which is good. But A had a 60 per cent Read Most score with young farmers and a 30 per cent score with farmers age 50 and over. Then suppose $\mathrm{B}$ had a 30 per cent score with young farmers and a 60 per cent score with farmers of 50 and over.

Which article would an editor prefer? Often the one which scored high with young farmers. (1)

Actually, most articles score fairly well with all age groups. This may be the result of editorial concern over the problem. Some reminiscent articles, like Bill 
Groves' department in the Wisconsin Agriculturist or an article on bang-boards in Wallaces Farmer, are bound to score higher with older folks than with younger. But these are balanced by other articles and departments.

One of our surprises on age breakdowns is the high score made by younger people on social security articles. Apparently younger farmers valued the insurance features for widows and young children. They also seemed to think that social security for older farmers might lead to retirement and help younger men to farms.

Young men, in a weaker financial position than older, have been responding lately (1960) to articles that seemed to give hope for some improvement in income. A Washington report in Wisconsin Agriculturist (September, 1960), which told of plans for new farm programs, scored well for younger readers.

Wallaces Farmer checked on the effect of age on readership in the issue of February 4, 1961. Here are Read Most figures:

$$
21-34 \text { yrs. }
$$

$35-49$ yrs.

50 and up

Men (20 items) . . $35.1 \%$

$39.1 \%$

Women (13 items) 36.2

41.4

$36.4 \%$

41.1

This shows a fair score for people 21-34, but nothing to brag about. Editors would be happier if young people scored higher than older groups.

What about education? On this point too, the farm papers have been fairly successful in attracting both those with a grade school education and those who stayed in school longer. There are some differences. For instance in Wallaces Farmer (November 19, 1960) a somewhat technical livestock article showed a slight but not significant margin for farmers with more education. 
A surprise came in a tax article in Wisconsin Agriculturist (September 3, 1960) where the men who attended grade school only did significantly better than the other group. This may be a tribute to unusually clear exposition of a difficult but vital subject.

In the issue of Wallaces Farmer for February 4, 1961, articles and departments for men and women produced a mean Read Most as follows:

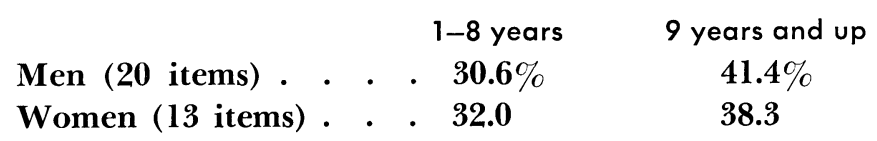

This seems to indicate that one of our problems is getting hold of the subscriber who has not gone beyond eighth grade.

How many of these folks are there? Of our Iowa subscribers less than half of the men and only about one-fifth of the women have stopped at eighth grade. In Wisconsin, around half of the men and two-fifths of the women are in this class.

This group shrinks every year. But for several years, at least, it is an important bloc. Are we shooting over the heads of those whose education stopped in the grades? What can be done to pull them in?

Do part-time farmers read different copy than fulltime farmers? In one case in Wisconsin Agriculturist (September 3, 1960) an article on part-time farming did what you might expect. It drew a heavy vote from part-time farmers (64 per cent Read Most for men). Outlook copy (Agri-Vision) drew only 32 per cent Read Most for this group. On other items, part-time response was much like full-time. 
These are points to remember:

1. The total score on an ad or article may not mean much. If a hog feed ad is read mostly by farmers without hogs, what good is it?

2. Market analysis can show whether the ad or article reached the folks at whom the copy was aimed.

3. Split runs may yield more meaning if we can find out how many real prospects read $A$ and how many real prospects read $B$.

4. Watch the readership of young farm people. They are the subscribers of the future.

5. Subscribers who had only eight grades or less in school are not usually as good readers as those with more education. This is an editorial point that should be kept in mind in copy preparation and copy editing. 
Page Score

\section{Grain Belt}

feeding demonstrations prove it pays to feed Purina

Men 35\%

Women $17 \%$

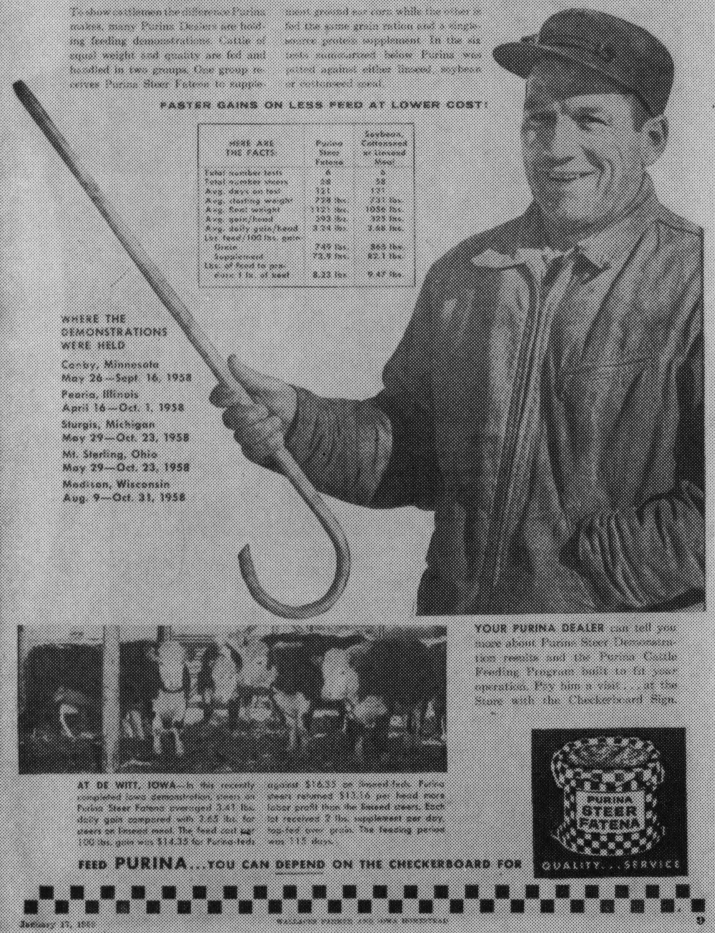

\section{Did Cattle Feeders Read?}

This page advertisement had a fair score for all readers. The important point, however, is: How many farmers who were feeding or who expected to feed cattle looked at the ad?

Of the men readers of the issue, 39.3 per cent were feeding or planning to feed, 55.6 per cent were not feeding or planning to feed.

These two groups scored as follows:

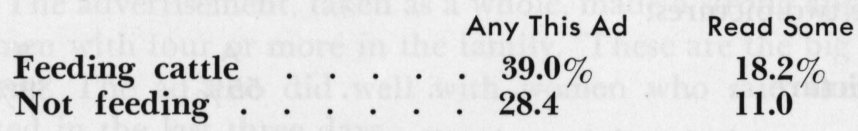

The cattle feeders showed more interest than the nonfeeders. 


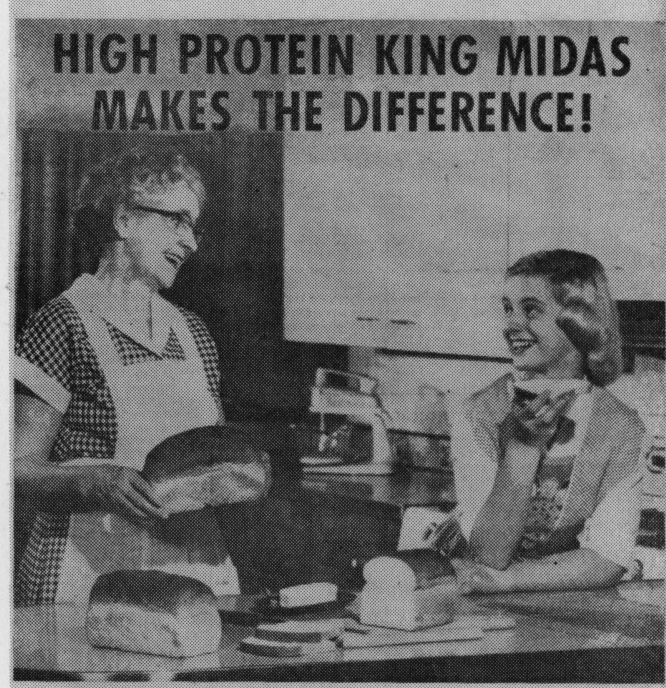

Figure 8.2

Split A

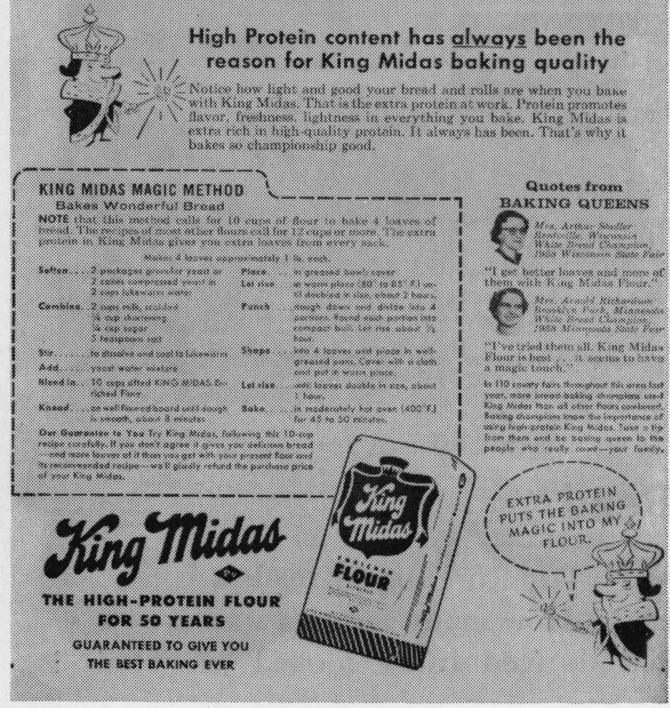

\section{Ad Score}

Women 64\%

\section{The Balloon Went Down}

In this three-column ad, the B picture with the balloon (to show a quotation) didn't do well. Here are the scores for women on the two pictures:

$$
\text { Picture . . . . . . . . . . . . } \begin{array}{ccc}
\text { A } & \mathbf{5 5 \%} & \mathbf{3} \% \\
\mathbf{3 9} \%
\end{array}
$$

The superiority of A on the illustration carried over into the copy. On the recipe at left, the Read Some scores were: 
Figure 8.3

\section{Split B}

\section{Ad Score}

\section{Women $49 \%$}
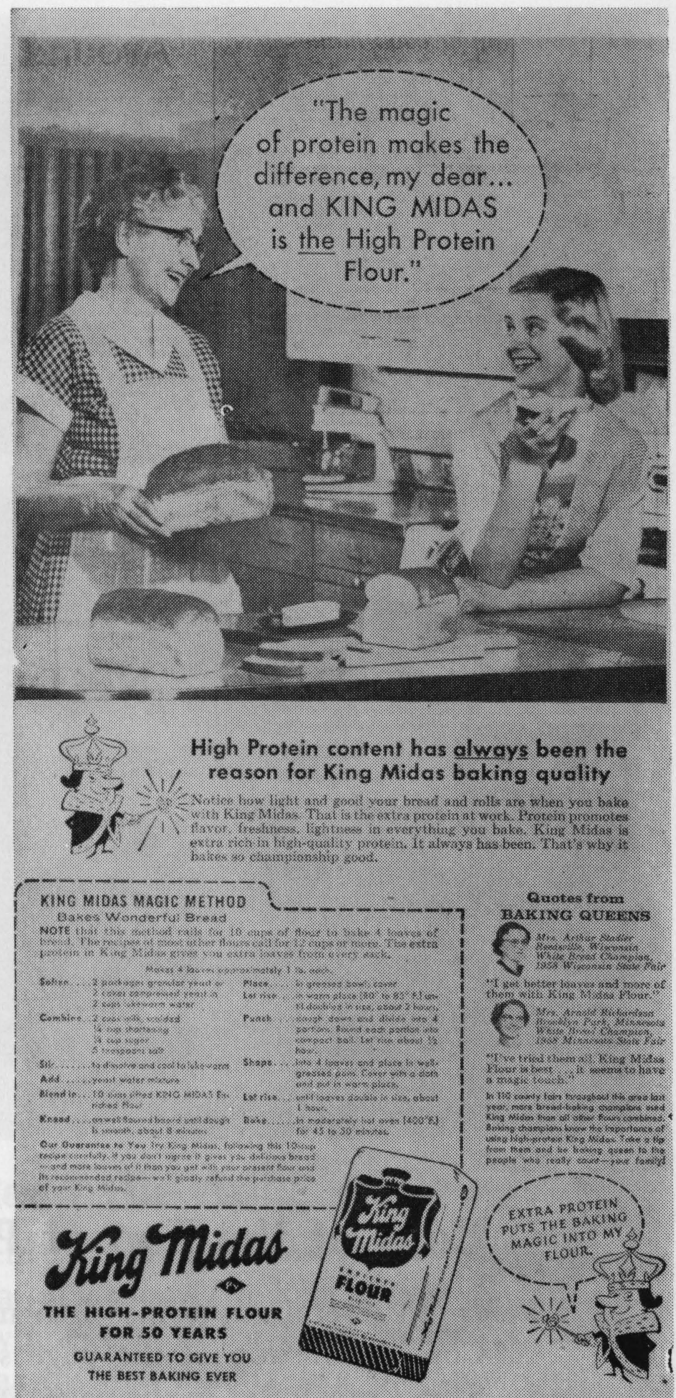

This test does not, of course, prove that the balloon is worse or better than the ordinary head. It does seem to show, however, that a good picture is weakened by cutting down space or introducing extraneous material. Don't mutilate a good cut!

The advertisement, taken as a whole, made a strong appeal to women with four or more in the family. These are the big bread eaters. The ad also did well with women who said they had baked in the last three days. 


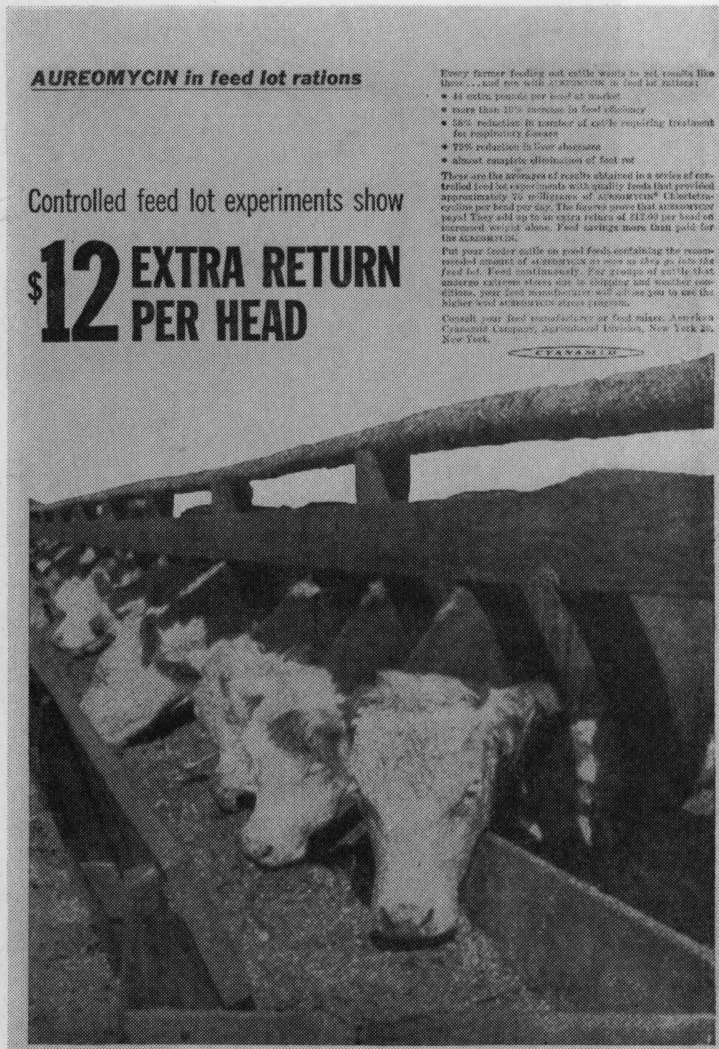

Figure 8.4

Page Score

Men $\mathbf{4 7 . 5 \%}$

Women $\mathbf{1 7 . 5} \%$

\section{Copy at the Top of Page}

In several ads (some of them splits) we found that Sales Copy at the top of the page seemed to score better than Sales Copy lower in the page. What does this page ad show?

Score of the Sales Copy is good, but not outstanding:

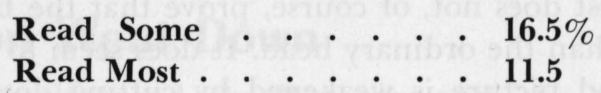

Question: Is the type too small to get full advantage from this position?

Cattle feeders paid more attention to the ad than nonfeeders. Feeders gave an "Any This Ad" score of 63.4 per cent; non-feeders a score of 36.2 per cent. 
Figure 8.5

Page Score

\section{Men 37\%}

\section{Women 8\%}

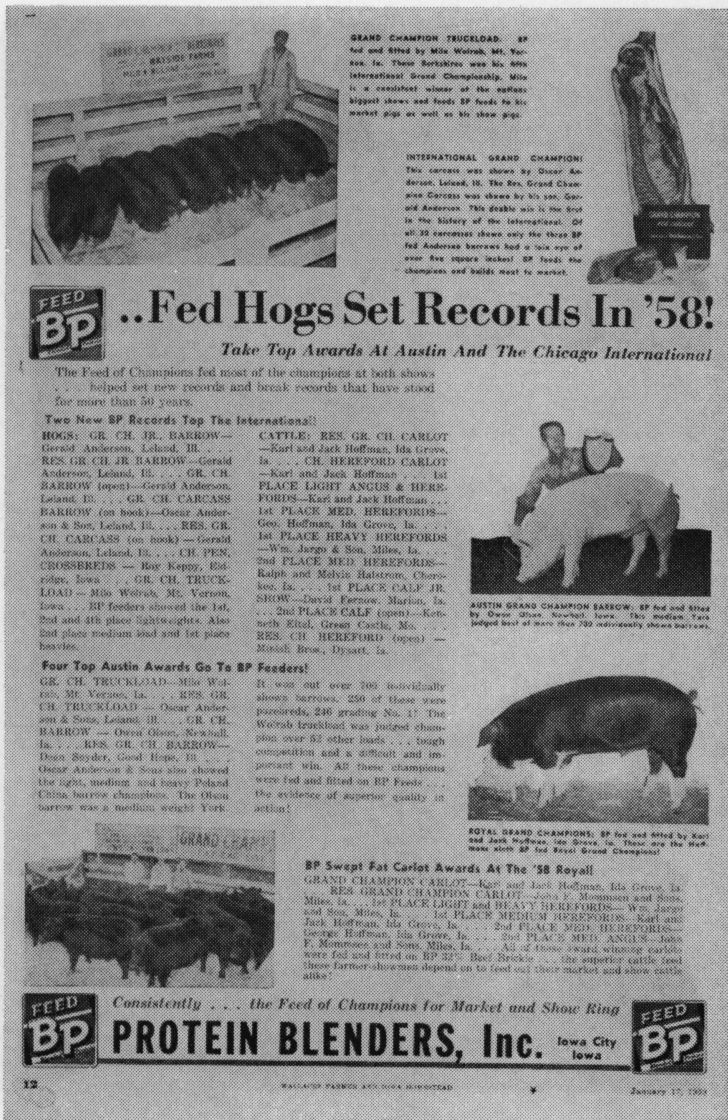

\section{Big Hog Raisers Read the Ad}

This page advertisement was aimed mainly at hog raisers, with a side shot at cattle feeders. The long sales copy (mainly a report of show winners) pulled a Read Some of 20 per cent. Attention was divided among five pictures. None scored very high.

The copy did hit the big hog raisers. Read Some scores follow for hog raisers who sold differing numbers of hogs during the year.

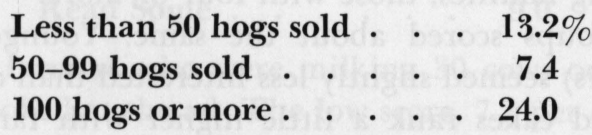

Cattle feeders and non-feeders did about the same amount of reading. 


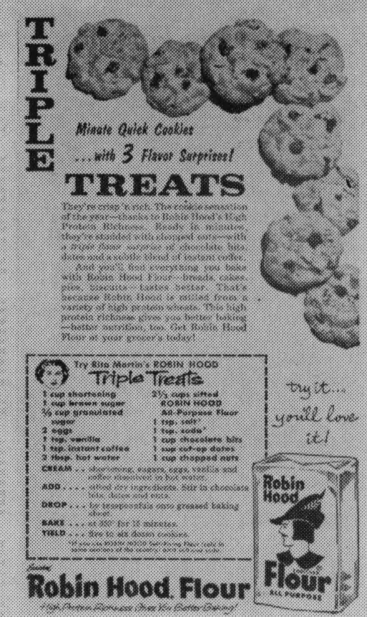

Figure 8.6

Ad Score

\section{Women 60\%}

\section{Cookies Score High}

This ad (only 230 lines) scored as well as some much larger ads. Here are the Read Some scores for women on the Sales Copy and the recipe copy.

$$
\begin{aligned}
& \text { Sales Copy . . . . . . . } 43.0 \% \\
& \text { Recipe copy . . . . . . } 57.5
\end{aligned}
$$

The ad pulled well with all sizes of families. The critical point here, of course, is that a food ad must do well with the big families, those with four or more.

Age groups scored about the same. Younger women (21-34 years) seemed slightly less interested than older ones.

Pies and cakes rank a little higher with farm women than do cookies. But still over 40 per cent of Wisconsin farm women bake 4 dozen cookies or more in a week.

Wisconsin Agriculturist, October 3, 1959 
Figure 8.7

Page Score

\section{Men 39\%}

\section{Women 26\%}

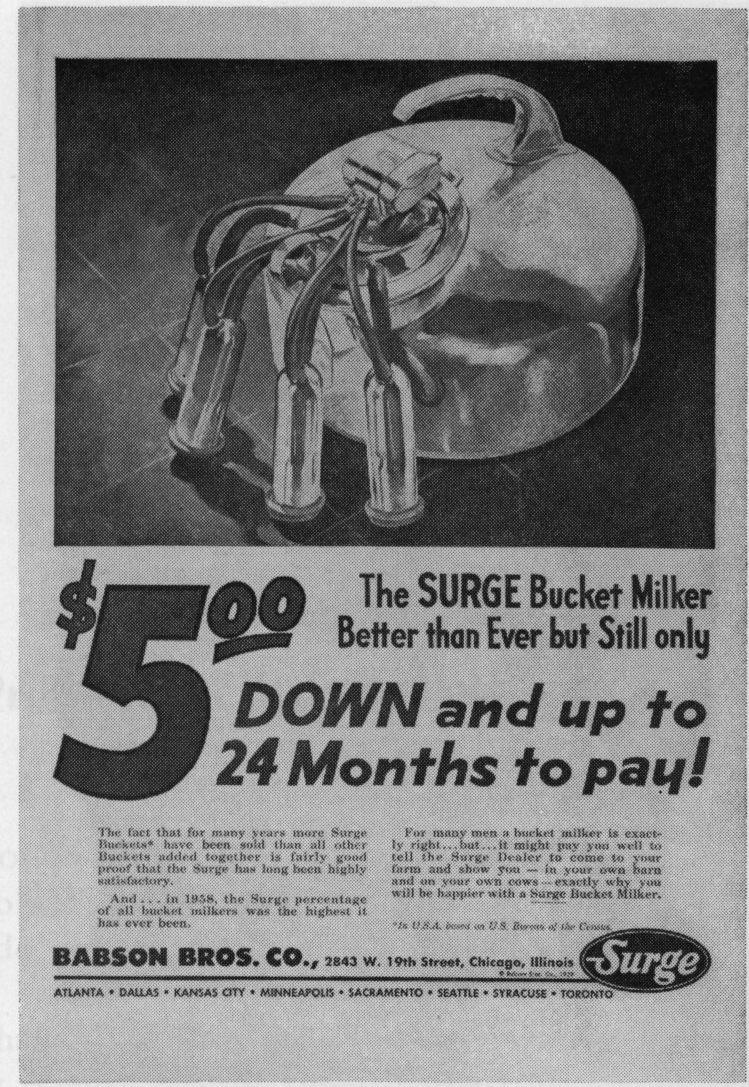

\section{Big Dairymen Read the Ad}

Men gave the following scores to different parts of the $\mathrm{ad}$, but the main interest lies in the response of the better prospects, the men with the big herds.

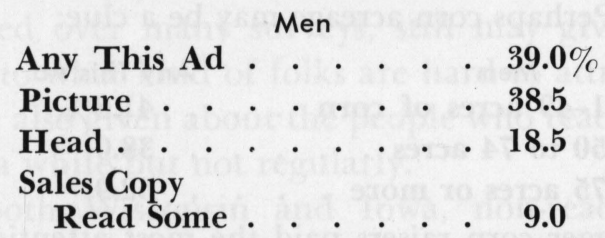

Of the farmers who were milking 30 cows or more, 56 per cent looked at the ad. The low score, 7.7 per cent, came appropriately from farmers who had no dairy cows. Farmers with gross incomes of $\$ 10,000$ or more showed more interest in the ad than farmers with smaller incomes. 


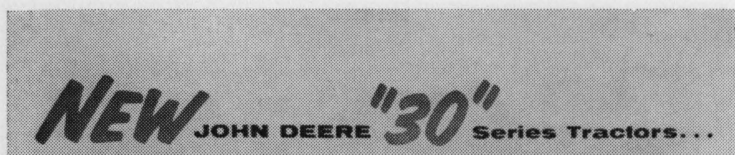

Squeeze More Out of Each Man-Hour ...Take Less Out of Each Man!

Figure 8.8
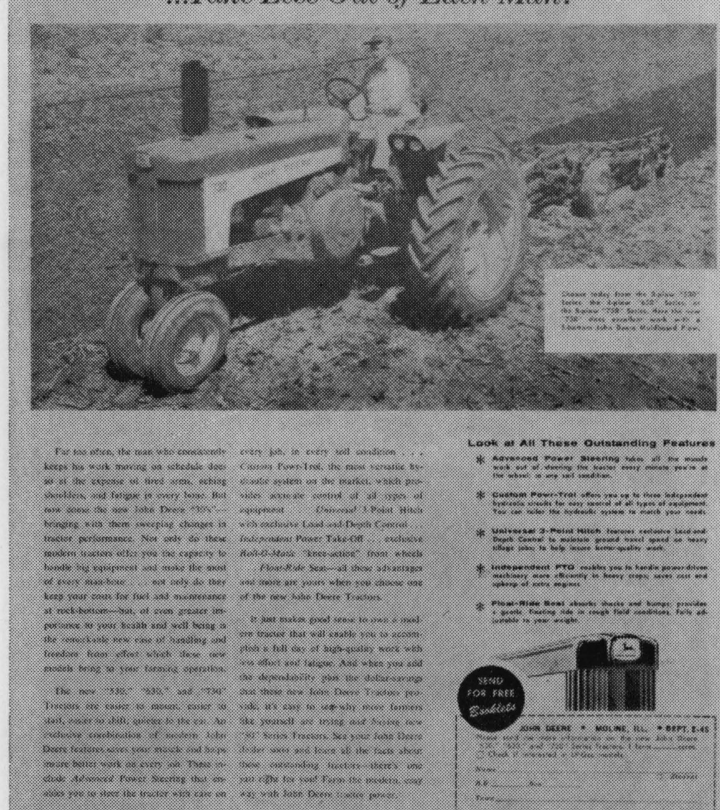

Leot at all these outatanding Fentures

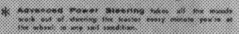
*

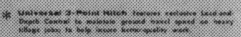
* *

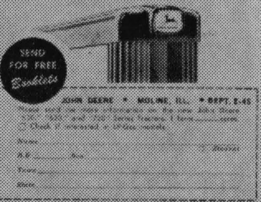

Page Score

Men 46\%

\section{Women $14.5 \%$}

\section{Bigger Farmers Read This Ad}

What kind of farmers are the best prospects for an ad like this? Perhaps corn acreage may be a clue:

\begin{tabular}{|c|c|c|}
\hline Men & & Any This Ad \\
\hline $1-49$ acres of corn & & . $41.8 \%$ \\
\hline 50 to 74 acres. & & . $\quad 38.0$ \\
\hline 75 acres or more. & & 62.9 \\
\hline
\end{tabular}

The bigger corn raisers paid the most attention to the ad as did the farmers with the biggest gross income and the farmers with the biggest acreage in all crops.

Sales Copy, with all farmers, scored 19 per cent. The illustration drew 43 per cent. 


\section{9.}

\section{The Problem of the Non-Reader}

A NON-READER, IN OUR LANGUAGE, IS SOMEBODY who was exposed to the publication but didn't read it. He may, of course, be a reader for one issue and a non-reader for the next.

One man may have read every issue but the one that arrived at the peak of corn-picking time. If that issue is the one we survey, then he is a non-reader. Thus, the non-reader sample contains folks who never read the paper, some who read it once in a while and some who are good readers but just happened to miss this once.

Unsatisfactory as this is, the non-reader sample, accumulated over many surveys, still may give us some clues as to what kind of folks are hard to attract. Some clues are also given about the people who read the paper once in a while but not regularly.

In both Wisconsin and Iowa, non-reader figures have been assembled for several years. Older men and women showed a slightly greater tendency to be readers as contrasted with younger folks. More time to read may be more important than failing eye sight. 
Years in school did make a difference. Scores (Wallaces Farmer) follow for 1958-60:

\begin{tabular}{|c|c|c|c|c|c|c|c|}
\hline Education, men & & & & \multicolumn{2}{|c|}{ Readers } & \multicolumn{2}{|c|}{ Non-readers } \\
\hline 1-8 grades & . & • & $\bullet$ & 358 & $38.5 \%$ & 130 & $53.1 \%$ \\
\hline 9 grades up & - & - & - & 571 & 61.5 & 115 & 46.9 \\
\hline & & & & 929 & 100.0 & 245 & 100.0 \\
\hline Education, wor & ien & & & No. & Per cent & No. & Percent \\
\hline 1-8 grades & - & - & • & 193 & $21.3 \%$ & 96 & $28.8 \%$ \\
\hline 9 grades up & & & & 713 & 78.7 & 237 & 71.2 \\
\hline & & & & $\overline{906}$ & $\overline{100.0}$ & 333 & 100.0 \\
\hline
\end{tabular}

Non-readers were more likely to be found among men and women with from one to eight years of schooling.

In Wisconsin there is a similar picture. With women, the differences in schooling are not significant. Men, however, with from one to eight years of schooling are more apt to be non-readers.

These results can be looked at in two ways. If we are thinking about the subscriber of 1970 , we want to be sure we are reaching farm people with high school education or better. These are the kind of folks we'll have in the future. But now and for some time to come, we'll continue to have readers who have only been to grade school. Can we reach them with simpler language, more pictures, etc. and still not lose readers with more education?

Mail boxes are flooded with newspapers, farm publications and general magazines. Is a non-reader one who is overwhelmed by a full mail box?

In Wisconsin, men taking three or more farm publications are more apt to fall in the reader than the nonreader class. The difference is significant. 


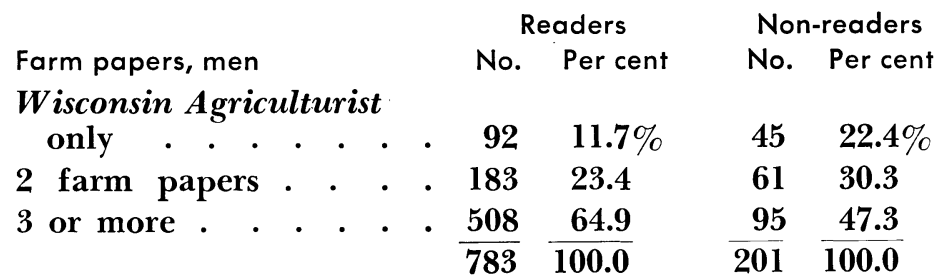

Women showed little difference, though the slight edge was in the same direction as with men.

In Iowa there was little difference with men, but women with three or more farm publications were more apt to be readers than non-readers.

Farm papers are not the only class of publications to compete for attention. The average farm family sees two or more general magazines. Does a farmer who sees Reader's Digest, or Look or Time stop reading a state farm paper? Does a farm wife who sees McCalls, Better Homes and Gardens or Ladies Home Journal stop reading Wallaces Farmer or Wisconsin Agriculturist?

We can't match the readers of General Magazine A against readers of Wallaces Farmer. The sample of readers of General Magazine $\mathrm{A}$ is too small. But we can sort out farm people who take one general magazine; those who take two and those who take three or more.

In Iowa we find that both men and women who see three or more general magazines are more apt to be readers than non-readers of Wallaces Farmer. Here is the women's score:

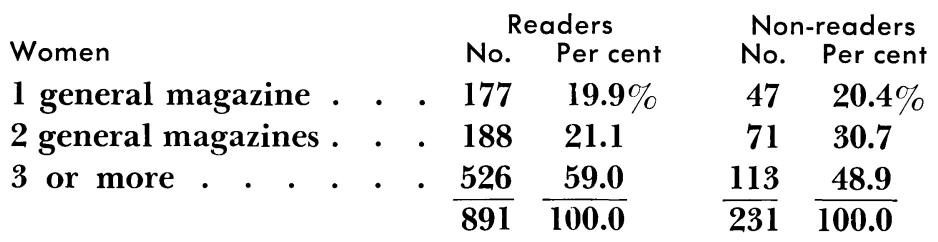


In Wisconsin, men showed a slight but not significant margin in the same direction. Wisconsin women are apparently more likely to read general magazines. Those who took three or more general magazines are as apt to be non-readers as readers.

Three surveys in Wisconsin checked the effect of a second language on readers and non-readers. In general, a second language seemed to make no difference.

\begin{tabular}{|c|c|c|c|c|c|c|c|}
\hline \multirow{2}{*}{\multicolumn{2}{|c|}{ Men, second language }} & & & \multicolumn{2}{|c|}{ Readers } & \multicolumn{2}{|c|}{ Non-readers } \\
\hline & & & & No. & Per cent & & \\
\hline Germanic & & & & 127 & $\mathbf{5 8 . 0} \%$ & 26 & $65.0 \%$ \\
\hline Scandinavian & . & & • & 48 & 21.9 & 5 & 12.5 \\
\hline Other . & . & & • & 44 & 20.1 & 9 & 22.5 \\
\hline & & & & 219 & 100.0 & 40 & 100.0 \\
\hline
\end{tabular}

It should be noted here that of the whole sample about one-third had a second language. The table above has a small sub-sample for non-readers and any conclusion drawn therefore must be tentative. Women showed no difference between language groups.

Wisconsin Agriculturist ran another test on readers and non-readers. We asked each farmer to check the farm enterprise (hogs, dairy, poultry, etc.) from which he got 10 per cent or more of his income. On dairy products, beef and poultry, there was no difference. Farm men and women, however, who had 10 per cent of their income from hogs seemed to have more nonreaders than one would expect.

Hogs, Men

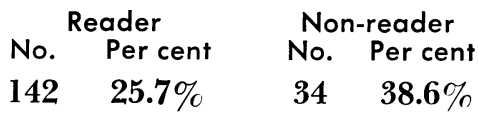


This is a small sample and should be observed with caution. Yet it seems possible that hog raisers may feel they are under-represented in the Wisconsin Agriculturist.

What do all these figures (details in editorial research files) show?

Both papers seem to be doing fairly well in a competitive situation with farmers who take many farm papers and many general magazines.

Wisconsin Agriculturist does a little better than Wallaces Farmer in keeping folks with from one to eight years of schooling. Yet the main need may be for both papers to be sure they hang on to farm people with a high school education or better.

On age groups, the important struggle is to hold those from 21 to 34 years of age. This is being done fairly well, but needs constant checking. 
Figure 9.1

Copy Score

Read Some

Men $\mathbf{7 7 . 5 \%}$

\section{Women 46.5\%}

\section{Converting Non-Readers}

Farm people who have been to school for only eight years or less are more likely to become non-readers than those who have gone to school longer.

Copy with strong appeal, especially to those who finished from one to eight grades, may attract some of these non-readers.

"What's Ahead" a department on market outlook in Wisconsin Agriculturist, had the following scores for men by education:

$\begin{array}{ccc} & \begin{array}{c}1-8 \\ \text { grades }\end{array} & 9 \\ \text { Read Most up } & 64.2 \% & 72.5 \%\end{array}$

The average Read Most score for two-column articles in this issue was 32.1 per cent. So the 64.2 per cent score for those who finished one to eight grades is well above the average for this group.

Wisconsin Agriculturist, September 3, 1960
What's Ahead

\section{Fall milk prices up}

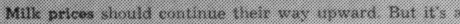

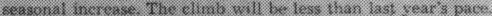

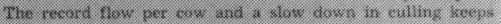

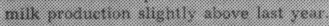

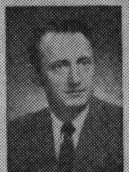

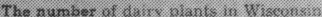

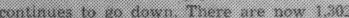

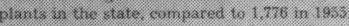

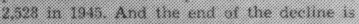

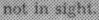

Ne: income part larmi in Winconsin ntond

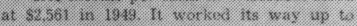

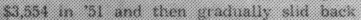
to a low of 52147 in thi sines that time it

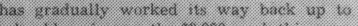

Ratiph Yohe

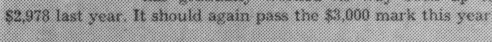

it loaks is it bromlet prines will work their way downmwand

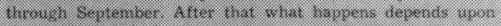
the numbert of ehieks noins sut.

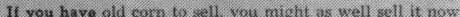
it looks now as if there s a bis corn crop coming up. Phices at harvest time will probabily rum about 3 to 4 cents betow last year's averagat:

Contracting ford feedier cattle is wav downt this year. Thenell be plenty of eattie avantable to buyers this fall And buyers should be in a stromker barkaining position

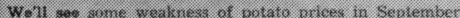
That's when the dignind of the late crop pets underway Cret the late summer spluds owt of the ground and on the mutket befone the fall crop hat vest starts.

Tha first phase of the beet estile eydle that at bunding up numbers sems to be drawing to a close Alneady the number

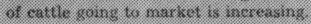

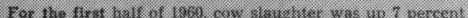

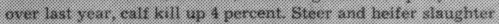
has been ruming about 10 to 12 percent ahead ot 1959

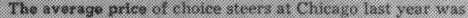
about \$28 it il be arownd \$25.75 to \$26 this year Cinesses ane that it will so aroumd 824 . give or take a dallar-next year

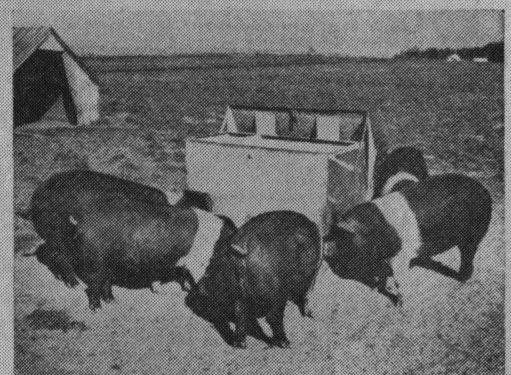

Outlook is still good far hogs wrex 225 poundi. But do every. thing rou ean to encourage tant gains over the nexpl fen wreks on lings nataring natket weight

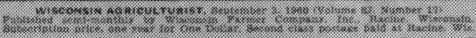




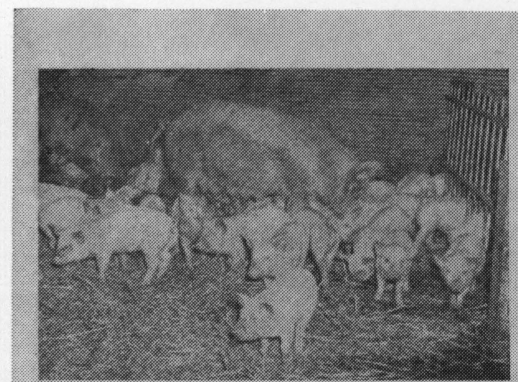

Take good eare of haby pizs and panti likely lave larger.

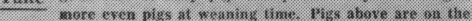

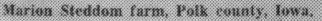

\section{Baby pig care -it PAYS}

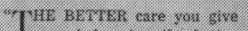
1 your baby pigs the better. Whe mass youll have at 7.8 wowk:

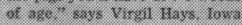
stal: University swine nutritwins. is:

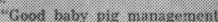

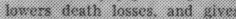

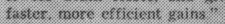

Herce aro some prints to int

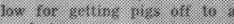
grood start.

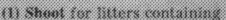

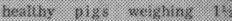

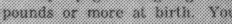

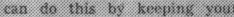

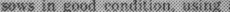
recommindend ratisi:

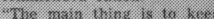
the sonss in tomititions in thes

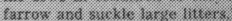

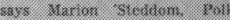

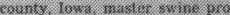
dweer "And see that thexy tom? cet: $.000 .13 t^{2}$

(2) Clema your smms of mis mis bring them into the farroning house a convile of darss indore

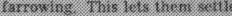
domn and get accustomind io 1.5 surroundins:

(3) start sonss on a sooni luxis. tion ration containing about percent protein after they fist

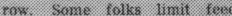
to sows noht atter farrowin: nhers let sows eat all the fect they want It seems to work: eittier way.

(4) See that prigs get a chance. to murse as soon as they wre born. Tentil nhow that pies ean take anivantage of the anti. bodies in colostral nall for anly 6 to 9 howns alter birth.

(6) Do your ear-notching alinot: ly afler farrowithy it hurts oils: less then. And it gitea you a chance to diech anch pie

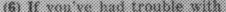

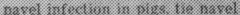

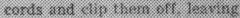

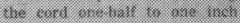
long. Then tily il: 4.

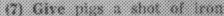

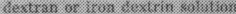

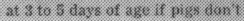

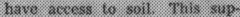

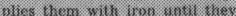

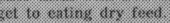

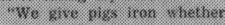
we move tham to pastints at

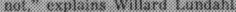

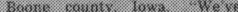
inon thoso getting trai so the 3.xt.

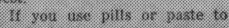

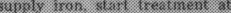

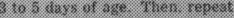

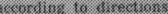

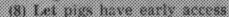

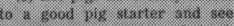

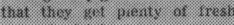
swater to inimis.

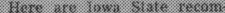
inendint:

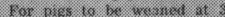
weaks. it \& 84:

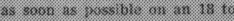

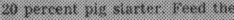

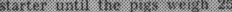

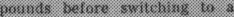
innoer ration

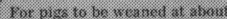
5. wentis, it: sursusted you stan

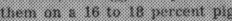
stimter at 10 dis:s lo is wernis on

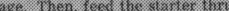

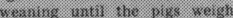
minut ni posinds

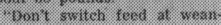

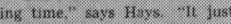
causes unnecessiry struss:

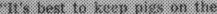
tartint for a week or sis atter

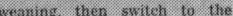
sroswins kationt?"

(9) Dont combins instration wits vassmation or you mis haxe trombie.

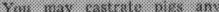

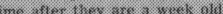

The yumiget the butict it sets then: wincis leas:

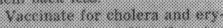

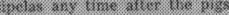

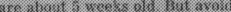

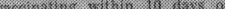

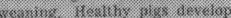
this $18 \div 8$ in:

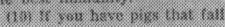

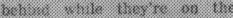

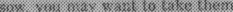

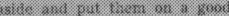

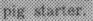

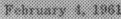

Figure 9.2

Copy Score

Read Some

Men 60.5\%

Women $\mathbf{2 0 . 0 \%}$

\section{Hogs May Pull in Non-Readers}

In Iowa, copy on hogs usually scores high. This baby pig article, for instance, had a Read Most score of 52 per cent for men. The average Read Most score for 20 articles and departments in the issue was 36 per cent for men.

Since those with from one to eight years of schooling are more apt to become non-readers than folks with more education, it is worth noting that men with one to eight years of schooling scored 45.2 per cent Read Most on this article. Copy with this appeal may help to make a regular reader of the subscriber who is inclined to look at the paper only now and then.

Wallaces Farmer, February 4, 1961 


\section{0.}

\section{Opinion Polls and Readership}

Opinion POLLs, conducted by Wallaces Farmer and Wisconsin Agriculturist since 1938, have one obvious value for a farm paper. They provide timely articles with a local angle - "This is what Iowa farmers think about issue $\mathrm{X}$; this is what Wisconsin farmers think about issue $\mathrm{Y} . "$

The polls can do much more than this. They give the editors insight into farm attitudes. They replace guesses on farm opinion with facts.

For instance, most of the editors on Wallaces Farmer assumed that Iowa farmers were "dry" in the sense of being opposed to state legislation for "liquor by the drink." Actually two polls showed a slight edge for such legislation; a third poll, a slight edge against.

Many students of political science recommend that the governor, like the president, be permitted to name his cabinet instead of having them elected. The same students recommend a four-year term for state officers.

What do farmers think? To date, farm opposition to these measures is strong, as measured by the polls. 
This does not mean that the editors should drop the subjects. But it does mean that editorial discussion designed to favor these projects will have to do more than say, "This reform is a good thing."

The most important editorial use of the polls may be to measure areas of ignorance and indifference. We often use a screening question which asks, "Have you ever heard about Issue X?" Then we ask of those who have, "Do you approve or disapprove Issue X?" (1)

The original purpose of the screening question was to get rid of those who obviously had no right to an opinion. As it has turned out, the screening question does something more important. It indicates the area of ignorance.

In every poll, there is an "undecided" group. We used to be impatient with this response and tried to cut it down. Now we are inclined to think it has great value.

For example, in February 1960, the Wallaces Farmer Poll asked: "In the election this fall, Iowans will have a chance to vote on holding a constitutional convention in 1961. Have you heard or read anything about this proposal?"

Only 31 per cent said "Yes." The same question in August got a "Yes" vote of 27 per cent.

Plainly this was an area of ignorance. The polls indicated that there was a gap to be filled. Actually, while Wallaces Farmer did discuss the question, the effective work was done by the Iowa Farm Bureau Federation which conducted a vigorous campaign against the convention and carried farm districts in the election.

Contract farming began to get into the news in a 
big way in 1958. It has already gone far in the broiler districts of the South, but hadn't affected the Corn Belt. In 1958, however, the Wallaces Farmer Poll described contract (integrated) farming as follows: "This is where a farmer signs with some company or cooperative to get help on feed, equipment, marketing, etc. and agrees in return to produce and sell much as the company or cooperative directs."

In July, 1958, men answered as follows:

1. $43 \%$ had heard or read a great deal about it.

2. $30 \%$ had heard some talk about it.

3. $37 \%$ hadn't heard it discussed.

This gave some support to the policy of using several articles in this field. While the issue wasn't as red-hot as we had supposed, a sizable majority had some information on the subject (Figure 10.1)

A larger area of indifference showed up in an August, 1959 poll on respirators: "Some farmers are using respirators to keep dust, chaff, etc. out of their lungs on especially dirty jobs. Did you make use of a respirator during the past year?"

Only 11 per cent said "Yes." Plainly, if the use of respirators is a good thing for farm health, it would take a lot of educational work to increase their use.

Another question in the field of health in Wallaces Farmer (February, 1958) was: "Have you been vaccinated for tetanus (lockjaw) ?"

Over half -54.5 per cent - said, "No." But even this result looked better than it actually was. Of the less than half who said, "Yes," most were vaccinated in the armed services and half of the "Yes" group were 
vaccinated 10 or more years ago. Apparently only about one-fourth or less of the total were effectively protected.

We run articles on fertilizer and get fairly good reader-interest scores. But how many farmers are prospects for such copy? In October 1958, we found that 37 per cent hadn't bought any commercial fertilizer that year. So an article on fertilizer, which assumed the use of fertilizer, was talking to only 63 per cent of our farmers. In 1958 some copy was still needed for farmers who hadn't bought fertilizer and who could only be reached by a different type of article.

In 1960 in Wisconsin milk quotas were being discussed. One of the issues was whether quotas could be transferred or had to stay with the farm. This was a fairly new and somewhat complicated issue. The poll asked:

"There has been some discussion of whether to make milk quotas transferable so that a farmer could sell his quotas to somebody else who wanted to keep a larger herd. Have you heard or read anything about this plan?"

Only 28 per cent said, "Yes, have heard something about it." The rest, 72 per cent said, "No, haven't heard."

Plainly the important news here (reported in Wisconsin Agriculturist February 4, 1961) was not how the informed farmers voted (almost half said quotas should stay with the farm) but that the majority hadn't heard about the proposal.

If transferable quotas were to be one of the farm policy issues, more discussion in the paper and elsewhere was needed before farmers could vote intelligently. 
In 1958 in Wisconsin, there was much talk about dairymen changing over to the use of bulk tanks. Sometimes it seemed that everybody was changing over. To check, in October, 1958, the Poll asked: "How do you handle the milk pick up on your farm?"

Only 19.5 per cent said they used bulk tanks; 66.2 per cent still used milk cans. The rest (14.3 per cent) said they had no dairy cows.

Checkups of this kind show changes over time. On this bulk tank issue, a Starch survey in Wisconsin Agriculturist (November 5, 1960) found that 40.9 per cent had bulk tanks then. This can be contrasted with 7 per cent in September, 1955.

Somewhat the same question arose concerning the number of farms with milking parlors. Only 3.8 per cent of the sample reported using them in 1958. Apparently the popularity of this device had been overestimated at that time.

Integrated farming was also the theme of a Wisconsin question. In August, 1958, the poll reported 21 per cent had heard or read a good deal about it; 42 per cent had heard some talk about it; 37 per cent hadn't heard it discussed.

Apparently Wisconsin farmers were less interested in the subject than those in Iowa.

Trends were shown in political affairs. In July, 1953, 72 per cent of the Wisconsin sample said that Ezra Taft Benson was doing a good or fair job as Secretary of Agriculture. In August, 1958, 23 per cent voted this way. Iowa farmers showed a similar shift in the same years.

Questions on knowledge of foreign affairs were asked from time to time. Quemoy and Matsu were the 
subject of queries in both states before the 1960 presidential campaign. In 1958, 26 per cent of Iowa farmers "had been following the news closely"; Wisconsin had 33 per cent in this class.

Lebanon was a sore spot overseas in late 1958. Wisconsin Agriculturist asked: "Have you paid any attention to what's been going on in Lebanon, Jordan, and the Middle East?"

"Yes, keeping up closely" pulled 35 per cent; and 18 per cent said, "Haven't had time to keep up with it at all." The rest (47 per cent) were in the class: "Have followed it somewhat but have been too busy to keep up closely."

These examples show what editors can learn from the polls about the state of information of their readers. The surveys usually underline the old saying, "Never overestimate the information of your reader; never underestimate his intelligence."

The pre-test of subject matter also has a place in the editor's kit of tools. This is a device which uses a mail questionnaire to try to find out in advance how readers will respond to a given type of article.

This permits an editor to try off-beat subjects on a sample. Perhaps he has been timid about subjects in which people are really interested. At little expense, he can give such subjects a dry run and then - if the response is good-check further by an actual article printed in a survey issue.

We use a sample of 1,000 names. Returns run around 50 per cent. A white ballot "For the man of the house"; a pink ballot (same questions) "For the woman of the house."

Plainly, the 50 per cent who didn't answer were less 
interested than the 50 per cent who did reply. We expected and usually got, higher scores on the pre-test than we could expect on a reader-interest survey.

As a rule of thumb, we said that the pre-test usually ran 20 per cent higher than the survey article. To be specific, when 80 per cent checked, "I'm sure I'd read this article," we expected a Read Most of 60 per cent.

This was a rough estimate and didn't always work out. Yet the pre-test did give some indication of probable results, and was helpful.

Sometimes it looked as if changes in the head (from pre-test to reader-interest) made a substantial difference. Here was a 1960 pre-test question:

"Hazards of going steady. Are young people who start dating early and settle down to going steady in high school more apt to get into trouble and find themselves pushed into marriage at 17 or less? Here are some case histories."

This had a pre-test score of 41 for men and 56 for women.

This subject was approached again, in the same pretest as follows:

"Should we have 'shot-gun' marriages? When an unmarried girl becomes pregnant, often the family insists on getting her married in a hurry. But sometimes this merely loads the girl up with two or three more children and a bad marriage. What family experts say."

This, in essence like the first, pulled 44 for men and 76 for women. No change with men but a much higher score for women. The hotter head of the two pre-tests apparently made a difference.

An article in January, 1960, with the head, "High School Marriages" pulled 56 Read Some for men and 
74 per cent for women. Read Most scores were 50 and 68 . In this case, the pre-test came close to an accurate prediction of the readership score.

Since we have found that choice of subject matter is more important than any other factor, it seems that the pre-test might well be used more often. It gives insights as to reader response that can open up new fields to the editor.

Layout, style, illustrations and all the rest of the editor's tools mean little compared to picking the right subject. The reader-interest survey helps on this. So does the opinion poll. One rough test in the opinion poll is to see how many comments were volunteered by respondents on a given subject. If a question brings out 30 or 40 comments, as reported by interviewers, the chances are that the subject has more reader appeal than one that only brings out a dozen comments.

But the pre-test still does the best job in helping the editor check on the interests of his subscribers that he might otherwise ignore. Often he will find that a subject to which he hadn't given much thought will rank high.

What the pre-test can't show is what will interest farmers five or 10 years from now. This is the subject of Chapter 13.

The opinion poll and the pre-test, of course, should not be used to scare editors away from subjects in which only a few farmers are interested. The paper should always be a few jumps ahead of its readers - but not too many.

In 1918, Wallaces Farmer ran a good deal of copy on hybrid corn. Probably only a few farmers were interested. But the hybrid corn copy - continued until hy- 
brid corn was on the market - undoubtedly played a part in preparing for the boom in hybrid corn in the 'thirties.

Again, in 1922, Wallaces Farmer began to pound hard on the theme that overproduction was hurting farm income. Suggestions were made on ways to adjust production to demand. Again the editor was considerably ahead of farm opinion and of farm organization leaders. But the early discussion of the issue made for more general acceptance of the AAA later.

One great editorial danger is that the editor, up to his ears in a subject, may think everybody has the same interest and the same background he has. This is rarely true and this assumption may lead to articles and editorials that leave out data important to the understanding of the issue by the average subscriber.

The opinion poll helps to keep the editor conscious of this hazard.

Advertisers run into the same problem. An ad may play up a theme that a farmer has heard too often. It may play up a theme of which he has never heard. Both kinds of ads may lose.

Here are some points to keep in mind:

1. An opinion poll tells the editor what farmers think about current issues.

2. It also tells him which issues they haven't heard about or in which they aren't interested.

3. The pre-test of subject matter helps the editor on his most important job, the selection of subjects that interest his subscribers. 
Figure 10.1

Page Score

\section{Men $\mathbf{7 2} \%$}

\section{Women $46 \%$}

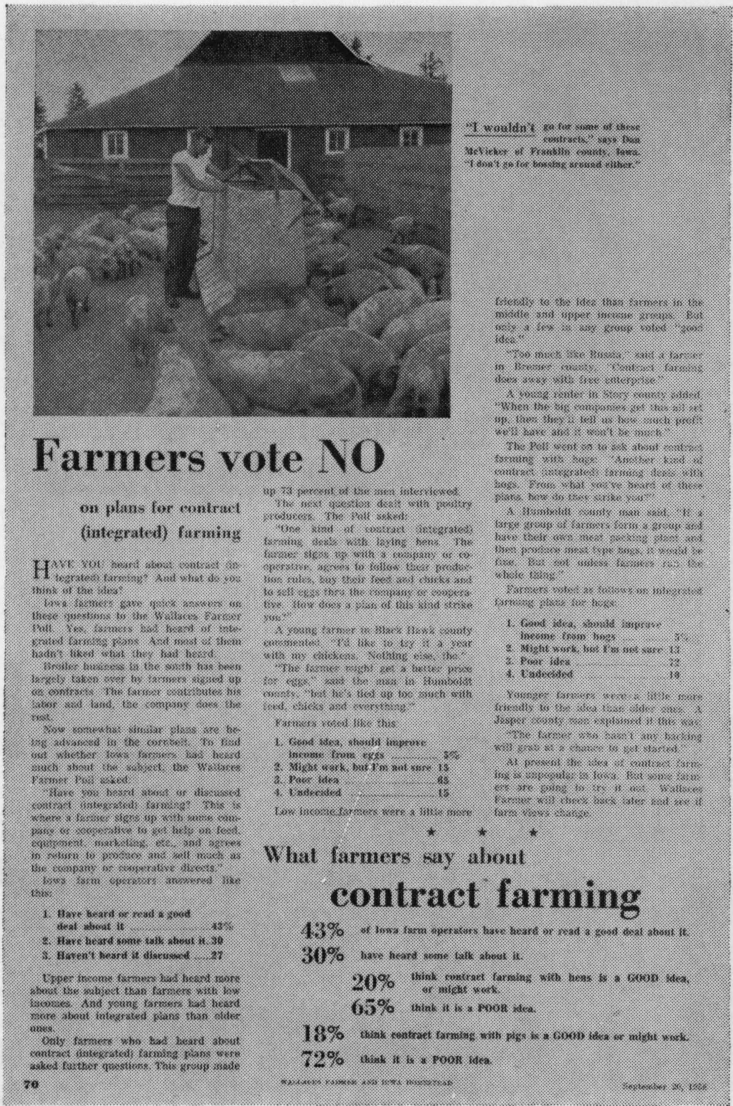

\section{Photo, Box, Article}

Did readers look at the box, ignore the photograph and the article and turn to the next page? Or did they look at the photograph only and ignore the box and the article?

Men No. Percent

Saw picture only . . . . . . 8 . 8 .

Saw picture and article . . . . $102 \quad 51.0$

Saw box only . . . . . . . . $\quad 2 \quad 1.0$

Saw box and article . . . . $104 \quad 52.0$

At this time, 27 per cent of the men hadn't heard about contract (integrated) farming. So the article started with the handicap of trying to attract some readers who were unfamiliar with the subject. 


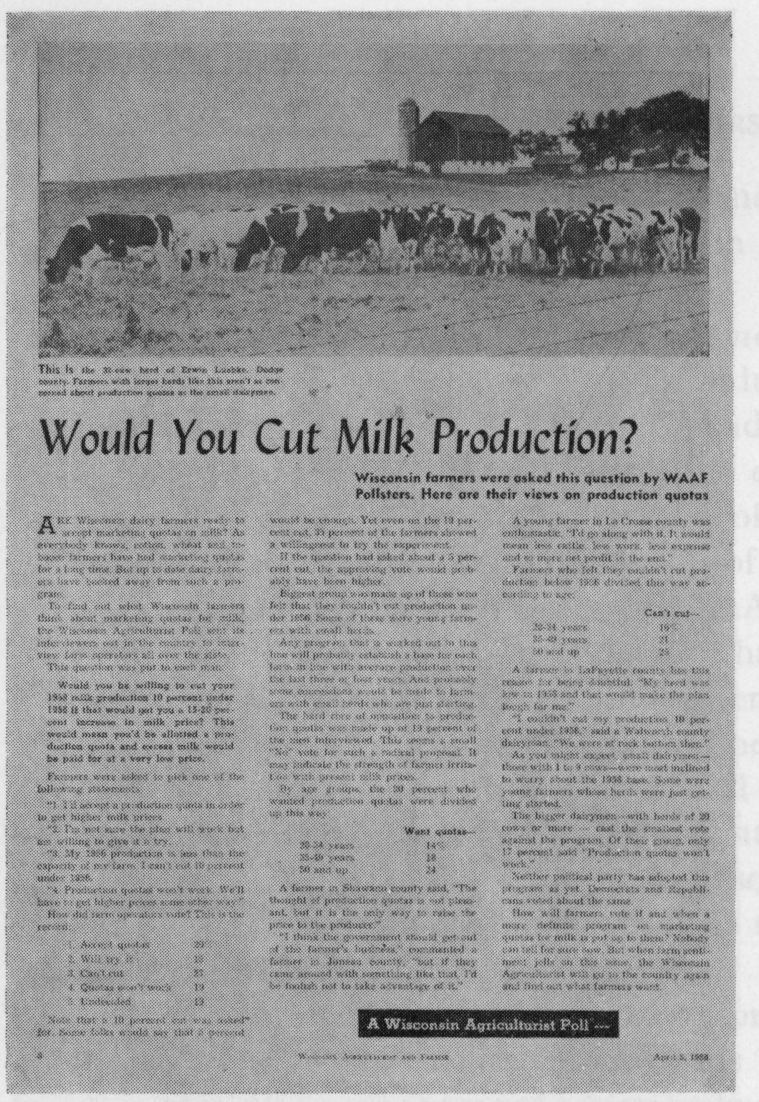

Figure 10.2

Page Score

Men 80.2\%

Women $42.0 \%$

\section{Poll Articles Rank High}

This is the report of a Wisconsin Agriculturist Poll on a proposed change in dairy policy. The article was given a high score by men and a fair score by women. Both wanted to know what other farmers thought about production quotas.

$$
\begin{aligned}
& \text { Men Women } \\
& \text { Read Most . . . . . . . . } 59.9 \% \quad 19.1 \%
\end{aligned}
$$

The article appealed to men of all ages:

$$
\begin{array}{cccc}
\text { Read Most } & 21-34 \text { years } & 35-49 \text { years } & 50 \text { up } \\
& 63.6 \% & 54.5 \% & 63.0 \%
\end{array}
$$

Education seemed to make no difference in the response. Farmers who had quit school at eighth grade and those who had gone to high school and beyond scored about the same. 


\section{1.}

\section{Subjects That Appeal}

WE HAVE NOTED that selecting subject matter is the major task of the editor. If the reader is excited about a subject, he'll endure bad writing, small type and unattractive layout.

To discover the most attractive subject matter, the editor can pre-test themes, as suggested in Chapter 10.

He can also, within limits, rely on past experience with readership tests. It is always necessary to remember that a subject exciting in 1960 may not be exciting in 1961, and that a subject full of attraction in November may be old and dull the following April.

One of the most complete studies on subject matter was conducted by the Statistical Laboratory of Iowa State University in three editions of "InFARMation Please" (1947, 1951 and 1955). (1) In each of these surveys around 600 farmers and 600 farm women were used in a probability sample of Iowa farm operators and homemakers.

The study was designed to find out where farm people go to get information. It also showed the kind 
of farming and homemaking information in which farm people were interested.

In the first study (1947) farm operators were given a card listing 11 subjects. Each was asked to "read off the five things for which you most often need and use information."

The subjects and the number of farm operators choosing each are shown in the summary below:

Farm operators choosing

Subject

No. subject

Handling and feeding livestock . . . 387

Per cent

Market prospects a year or more

in the future . . . . . . . . . 334

$69.48 \%$

Advice on present livestock and

grain markets . . . . . . . 303

59.96

Corn and other field crops . . . . . 252

Care and use of farm machinery . . . 239

Contouring, terracing, drainage, etc. . 201

Repairing and constructing barns . . 176

Farm accident prevention . . . . . 155

Keeping poultry . . . . . . . . 126

54.40

45.24

42.91

Corn loans and other federal

farm programs . . . . . . . 82

36.09

31.60

27.83

22.62

Field work was done in the fall of 1947. This was a year farm prices and income were good. Probably for that reason the interest in "corn loans and other federal farm programs" was low. The editor, thinking of the high interest in such programs in the 'thirties, was inclined to overestimate farm interest in the subjects in 1947.

Market outlook ranked high and resulted in some changes in copy and in editorial emphasis. Although Wallaces Farmer had always given special weight to 
these subjects, it seemed possible that we should do even more in that field.

At the same time, farm women were asked similar questions:

Farm homemakers choosing
subject No.

Per cent

Recipes and meal planning . . . 370 $69.42 \%$

Canning and preserving food . . . . 361 67.73 Patterns, sewing and fashions . . . . . $\quad 322 \quad 60.41$

Home improvement . . . . . . . $294 \quad 55.16$ Keeping poultry . . . . . . . . . . $275 \quad 51.59$ Health and medicine . . . . . . . . . $247 \quad 46.34$

Kitchen and home equipment . . . . 23243.58

Gardening . . . . . . . . . . 225442.21

Child care . . . . . . . . . . . . $172 \quad 32.27$ Beauty care . . . . . . . . . . $52 \quad 9.76$

There were few surprises here. It looked as if the usual concentration on food in Wallaces Farmer was justified. We did wonder why the low score on "beauty care." Did farm women think it unwomanly to admit an interest?

The next survey of this kind was in November, 1951. Had times changed? Did farmers and farm women have different interests?

Four choices were given to each farmer. Note the top four in the men's list:

Farm operators choosing subject

No.

Per cent

Marked prospects in months ahead . . $316 \quad 53.5 \%$

Fertilizers and rotations . . . . . . . . $312 \quad 52.8$

Handling and feeding livestock . . . $286 \quad 48.4$

Weed and insect control . . . . . . . 2584 
Fertilizer was coming to the front. The chemical revolution in weed and pest control was on the way. Corn this time was down to 9th in a list of 12 .

Women had changed less. The top four were the same. But "health and medicine" had come up a notch. A vote was not taken on "beauty care."

In November, 1955, another survey was made. The top subjects for men were as follows:

\section{Farm operators choosing subject}

No. Per cent

Market prospects in the months ahead . $360 \quad 54.9 \%$

Current livestock and grain markets . . $296 \quad 45.1$

Handling and feeding livestock . . . . $294 \quad 44.8$

Price supports, farm legislation,

social security, etc. . . . . . . $275 \quad 41.9$

"Fertilizers and rotations" was in fifth place and "weed-insect pest control" in seventh. Observe the steady appeal of market information and the rise of "price supports, farm legislation, etc."

Farm income in 1955 in Iowa was still good, but it was starting down from the peak. Hogs in Iowa, in November, 1955, were down to $\$ 11.60$. This was quite a change from the May price of $\$ 17.00$ and the peak price in April 1954 of $\$ 26.40$.

Women's choices stayed about the same with one striking exception. "Health and medicine" came up to third place. There were 326 women, or 52.4 per cent of the total who selected this subject.

It looked as if Wallaces Farmer was justified in running more copy on price supports and more on health and medicine than in 1947 or 1951 .

A readership survey supported this view. In October 1, 1955, the readership survey checked a page article 
entitled "Ask \$17 Support for Hogs." The page as a whole pulled 87.5 per cent with men. The article had a 64.9 Read Most score for men. It also drew a fair number of women readers, 28.5 per cent Read Most. Women, on this and other occasions, indicated that they knew where the money for their new washer was coming from - or if it was not coming.

Readership scores in survey issues underline the same points. In Wallaces Farmer (February 4, 1961) a page of discussion of market trends and of management problems pulled 84.5 per cent of the men, with a Read Most of 66.5.

A three-column article on page 72, "Insurance for Hospital Bills" got Read Most scores of 28.5 per cent with men and 44.0 per cent with women. This article was outside the Home Department, aimed at women, but also drew some men.

The importance of timely news was shown in Wallaces Farmer (November 19, 1960) when a two-column Washington Letter, headed "What Will Farmers Get From Kennedy" pulled 64 per cent Read Most for men and 33 per cent for women. A post-election analysis of the farm vote in the same issue got 56 per cent Read Most for men and 39.5 for women. (Incidentally, this proves again that farm women do a lot of reading outside the Home Department.)

The same issue illustrates treatment of a subject of interest only to a minority. A two-column turkey article got a Read Most for men of 15.0 per cent and 14.5 for women. This was a deliberate play to a small group.

Another example of outlook copy registering high came in Wisconsin Agriculturist (April 15, 1961). The two-column department "What's Ahead" got a Read Most of 68.5 for men and 30.0 for women. 
A page article appealing to smaller farmers, in the same issue, was, "He Farms 60 Acres." This had a page score for men of 72.5 and for women of 62.5 , with a Read Most of 59 per cent and 43 per cent. This article was a mixture of farm management and human interest. Its main appeal probably was to farmers who were uncertain about the ability of a man farming 60 acres to make a living.

Another Wisconsin Agriculturist (April 2, 1960) shows the usual response by farm women to a food article. The page score was 92 per cent for women and Read Most 71 per cent. A few men, as usual, gave a quick glance at the illustration (pancakes) and went on hastily. We can get women to read men's articles but have a hard time getting men to read women's articles. The exception is when the Home Department lead deals with family problems and is illustrated by photographs in which men appear.

Dairymen are a minority in Iowa, just as hog farmers are a minority in Wisconsin. So when Wallaces Farmer (January 16, 1960) devotes a page to dairy farming, a high score is not expected. In this case the market was further narrowed by the title, "Stanchions and Pipeline Milking” which didn't apply to all dairymen. But the page score still was 43.5 per cent for men and 34.5 for women. Read Most was 22.5 for men and 14 for women.

Outlook copy scored high on both papers. An example is "What's Ahead" in Wallaces Farmer (January 16, 1960) where the two-column department pulled 76 per cent of the men and earned a Read Most of 66 per cent. Some women, 28 per cent, were also interested. 
Figure 11.1

Page Score

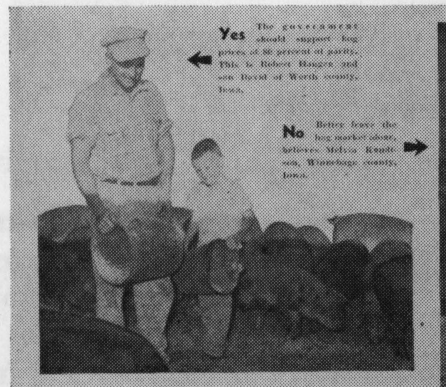

\section{Ask $\$ 17$ support}

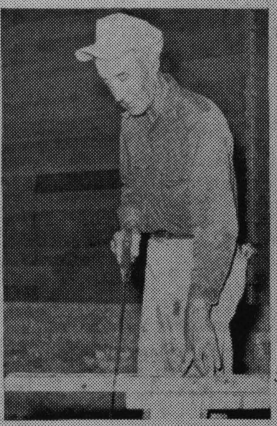

\section{for hogs}

lona tarns provple

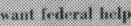

har liws maxher

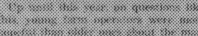

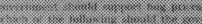

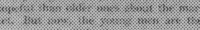

(:

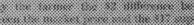
:

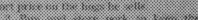

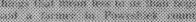

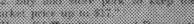

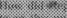

i. 1 i:
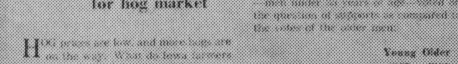

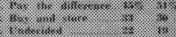

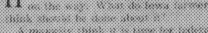
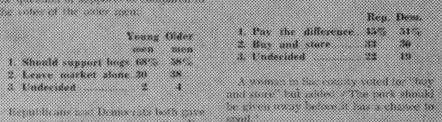

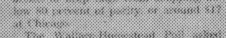

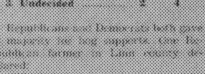

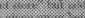

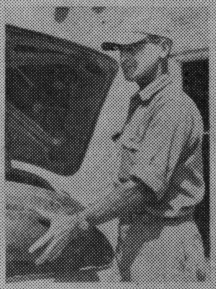

Not nur:

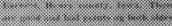

\section{When Hog Prices Hurt}

A timely subject will bring the readers in. In 1955, there was a sharp drop in hog prices. The Wallaces Farmer Poll asked farmers about federal action on hog supports.

The resulting article was read by both men and women:

Read Most

$$
\begin{aligned}
& \text { Men . . . . . . . . . } 64.9 \% \\
& \text { Women . . . . . . . } 28.5
\end{aligned}
$$

The top pictures scored 78.6 per cent with men and 42 per cent with women. The bottom picture scored 54.8 with men and 26.5 with women.

Wallaces Farmer, October 1, 1955 


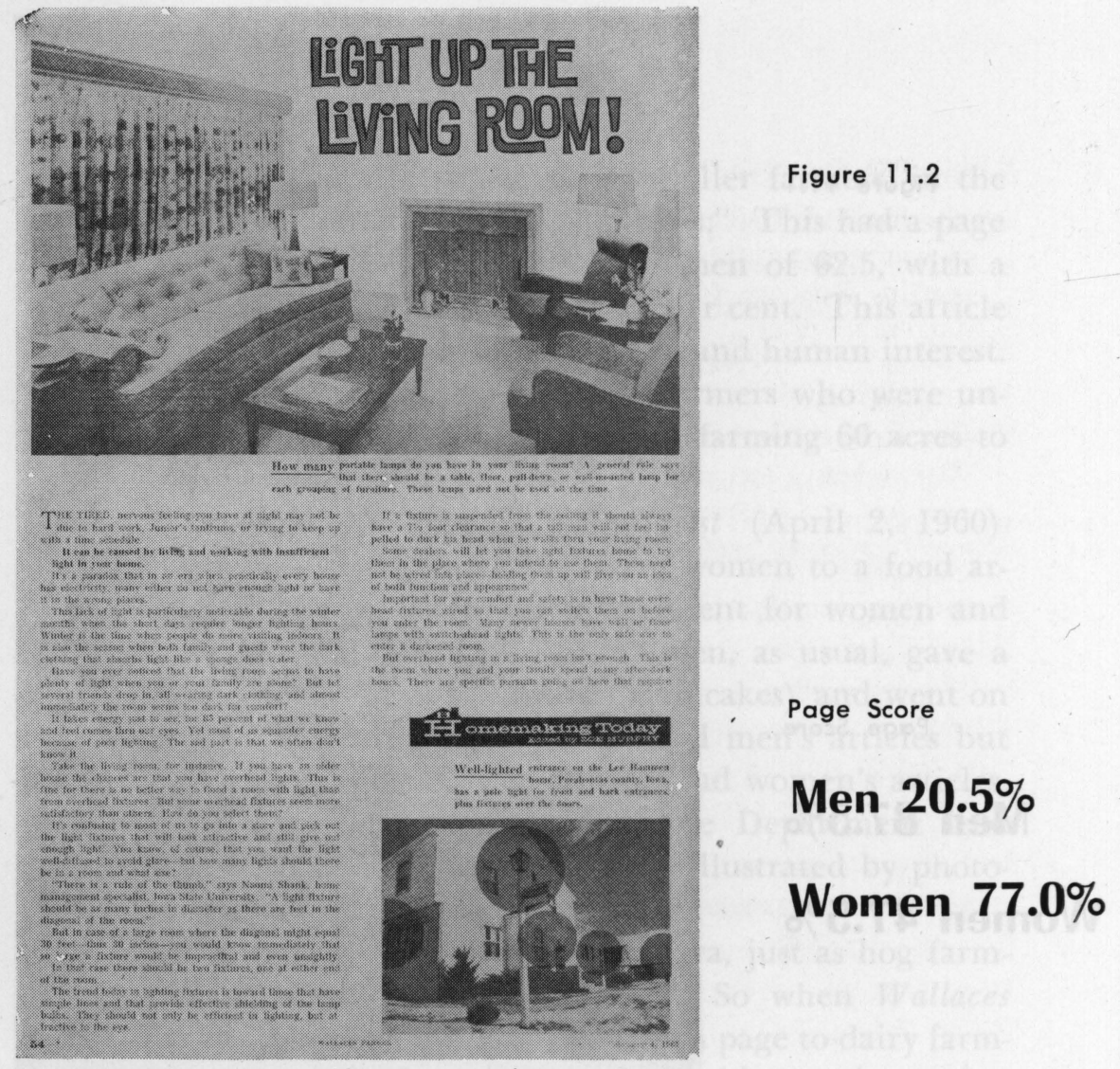

\section{Better Light in the Home}

Food copy always scores high with women, but so do articles built around home improvement. Here is an article about lighting the farm home. Women responded well; a number of men also read it.

Read Most score for women was 60.5 per cent. Also important was the fact that women of different ages responded about the same way.

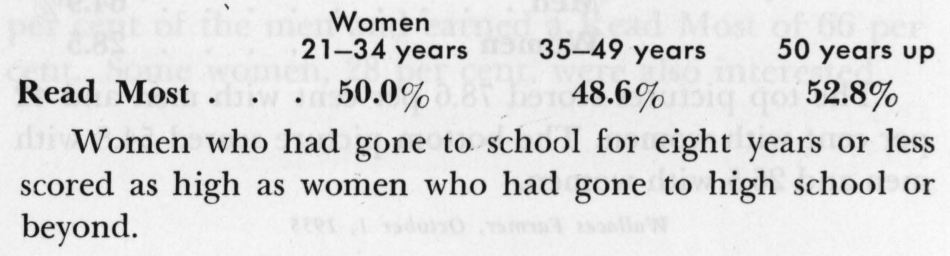

Wallaces Farmer, February 4, 1961 
What does our experience with subject matter add up to?

1. Hit hard on the major interests of your audience. This means hogs and corn in Iowa and dairy cattle in Wisconsin. But try for new material and new angles. A dairyman doesn't want to read about cows every issue unless the material is timely, fresh and loaded with human interest.

2. Keep checking on the interests of readers. You know that when hog prices drop sharply, interest in hog outlook and hog supports will pick up. But other angles are harder to figure out. Why, for instance, did women's interest in "health and medicine" pick up? For information on some points, you have to dig, use opinion polls and pre-tests of subject matter.

3. Don't forget minorities. In a hog state, you can't give as much space to sheep as to hogs, but sheep still are entitled to some attention.

4. Farm people are human. Articles on family problems score well. And even a dirt copy article gains when the problems are stated in terms of Henry Brown of Black Hawk County and Jim Jones of Keokuk County. 


\section{2.}

\section{Just Getting Read Isn't Enough}

When Wallaces Farmer BEGAN its first readership studies in 1938, we could say that a certain number of readers of the issue had actually read some or most or none of the article on page six or the advertisement on page 21. But presently it dawned on us, as on many others, that this kind of readership figure wasn't enough.

Fortunately, the readership survey can be handled so as to tell us much more. We can find out how readership is affected by age, education and other factors. We can even approach a more vital question: What do our subscribers think of what they read?

A reader may go through an article and still wind up with a poor opinion of the article and of the magazine. High readership may be associated with either favorable or unfavorable response. How can we find out which it is?

We are using on Wallaces Farmer and Wisconsin Agriculturist some simple devices that may give us some clues as to what farm readers think of what they read. 
We started out with the most obvious of tests. In repeated surveys, conducted both by ourselves and by the Statistical Laboratory of Iowa State, we have found that farmers want practical information on timely production problems. The perfect tribute to us comes from the farmer who says, "I was just going to write you. But when I got your paper out of the mailbox, I found you had answered the question I had in mind."

So in the reader-interest survey of the January 18, 1958 issue of Wallaces Farmer, we prepared a card that asked these questions:

If you read most of the story, "Wet Corn Makes Top Feed," on page nine how would you rate this article on the points below?

1. Real practical help for me.

2. A few things here I can use.

3. Nothing practical here for me.

1. Article told about something new to me.

2. I'd heard about it before, but not as much.

3. Nothing new in this article.

In this test, we hoped to find out whether the article was of practical help, and also whether some of the information was new. These points, in our minds, weren't the same. A farmer could be reminded of standard information and still get practical help.

Interviewers waited until they got to page nine and listened to the report of the respondent on that page. If he said he had read most of the wet corn article, he was handed the card. 
Here is the response:

$\begin{array}{ll} & \text { No. Percent }\end{array}$

Real practical help for me . . $32 \quad 24.1$

A few things in it I can use . . $70 \quad 60.1$

Nothing practical here for me $\quad \frac{21}{123} \quad \underline{15.8}$

Article told about something new to me . . . . . . . . . 2923.6

I'd heard about it before, but not as much . . . . . . 80

Nothing new in this article. . 7

No comment . . . . . . . 7

$\overline{123}$

100.0

Since this was the first attempt, we weren't sure what it meant. What is par for the course? Our guess was that the article did pretty well.

To check again, we took the reader-interest survey of Wisconsin Agriculturist (April, 1958). When the interviewer got to page 76 and the respondent indicated he had read most of the article, "Spray Yellow Rocket in Hay Fields," he was given a card which asked him to rate the article. Scores for men follow:

\begin{tabular}{|c|c|c|}
\hline Real practical help for me & $\begin{array}{l}\text { No. } \\
20\end{array}$ & $\begin{array}{c}\text { Per cent } \\
23.0\end{array}$ \\
\hline few things in it $I$ can use . & 40 & 46.0 \\
\hline Nothing practical here for me & 18 & 20.7 \\
\hline o comment $\cdot$. $\cdot$. $\cdot$. $\cdot$. & $\frac{9}{87}$ & $\frac{10.3}{100.0}$ \\
\hline
\end{tabular}

Article told about something new to me . . . . . . . . . $25 \quad 28.7$

I'd heard about it before, but not so much . . . . . . . $41 \quad 47.1$

Nothing new in this article . $\quad 5 \quad 5 \quad 5.8$

No comment . . . . . . . . $16 \quad 18.4$

$\overline{87} \quad \overline{100.0}$


To get a little more light on what to expect from a "practical help" vote on a dirt copy theme, we asked the same questions about three articles in Wallaces Farmer (January 17, 1959). The three scored an average vote on "real practical help" of around 38 per cent among the men who read some or most of the copy. If we measure these enthusiastic readers against the whole sample, they made up 25 per cent of the total.

What kind of men were these enthusiastic readers? There were 77 men out of the sample of 200 who voted "real practical help" on one or more of the three articles. These enthusiastic readers had slightly more education, more income, took more farm papers and had bigger farms than the non-enthusiasts.

We had another problem allied to this one. On it, we used a similar device. We were running two departments about whose merits we were doubtful. For the test, we added a third department whose long-time record was excellent and on which we had no doubts at all.

To the folks - both men and women - who read some or most of the three departments, the interviewers handed out a card which said:

The editors of Wallaces Farmer are wondering whether to drop this department. They'd like your advice. Which of the statements below comes nearest to representing your views:

1. Don't take the department out. I like it very much.

2. I usually read it, but I could get along without it.

3. Take it out if you want to. I won't care.

4. No opinion. 
We had interviewer trouble on this one. Some interviewers didn't present the card to all the Read Somes and Read Mosts. But the main disappointment was the general amiability of the comments. Very few wanted to get rid of any of the departments. The following scores list those who said, "Don't take it out."
Men
Women
No. Per cent
No. Per cent
Workday Pointers
86.5
6380.1
(This was the strong department, according to other tests.) $\begin{array}{llllll}\text { Rural Route Ramblings . } & \text { - } & 93 & 77.5 & 82 & 78.8\end{array}$
(This was the department, humorous in intent, on which we had doubts.)

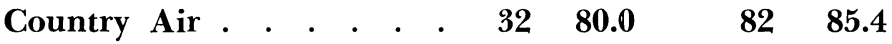

On this test, all three departments earned the right to stay in. However, I'm not satisfied with the answer. Maybe our respondents were too amiable. A less brutal third choice than "Take it out" might have showed us more about farm attitudes.

We had another problem with the department dealing with recipes. Readership scores don't show much about recipe reading. Scores are always high. But surely there are differences between one set of recipes and another. Yet you wouldn't think so from the usual scores.

In the reader-interest survey of Wallaces Farmer (January 17, 1959) (Figure 12.6), we had interviewers find women who said they had read some or most of the recipe column. Then each respondent who had read the department was given a card which said: 
Since you read some or most of this Cookery Corner department.

I'd like to know a little more about your use of the recipes:

1. Have you tried out any of the recipes on this page?
1. Yes
2. No

2. If Yes, how did the family like the recipe?
1. Liked it
2. Didn't like it
3. No comment

3. Are you planning to use in the future any of the recipes on this page?
1. Yes
2. No
3. Undecided

A similar study was made in Wisconsin Agriculturist (April 4, 1959). Here are the results for both papers:

Wallaces Farmer

No. Per cent
Wisconsin Ag

No. Per cent

1. Have you tried out any

of the recipes on this page?

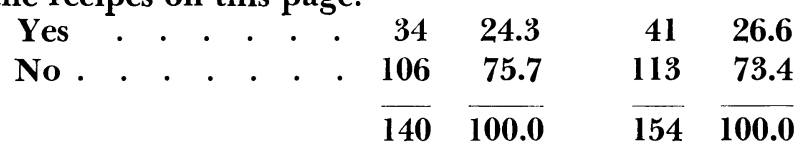

2. If Yes, how did the family

like the recipe?

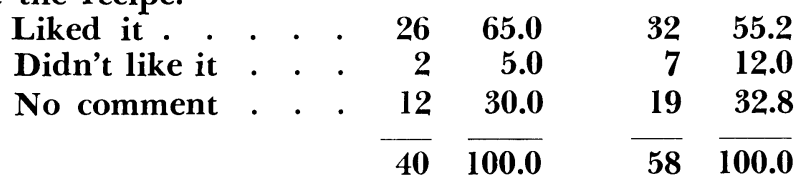

3. Are you planning to use in the future any of the recipes on this page?

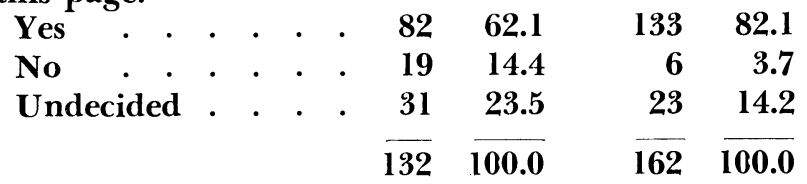


The main value of the experiment was to establish a base line that would mean more than the standard one: "Every recipe column should get a Read Most score from 60 to 65 per cent." Now we are inclined to say, "If less than 20 per cent of the recipe readers have tried out a recipe in the column, we're slipping."

Another study of women's readership came in Wallaces Farmer (January 16, 1960). We ran an article about selecting, cooking and serving a prime rib roast (Figure 12.5) .

The Poll asked: "Have you ever cooked and served a beef roast in the way described?

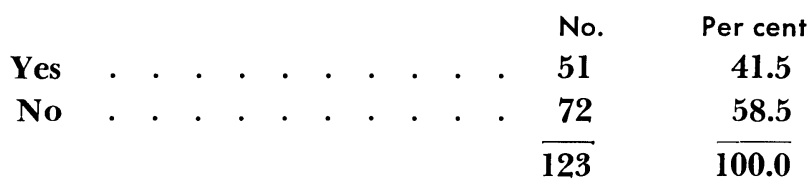

We found here that our farm women were less familiar with this kind of meat cookery than we had guessed.

We also asked: "If No, did the article make you want to try it some time?"

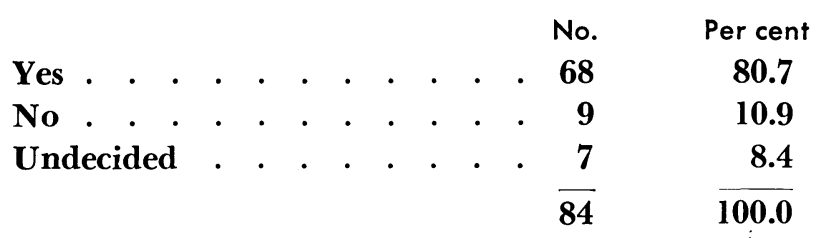

Apparently a large number were interested in trying out what, for them, was a new method in cooking meat. 
The Poll also asked: "Would you like to see more articles of this type in Wallaces Farmer?"

\begin{tabular}{|c|c|}
\hline & No. \\
\hline Yes & 121 \\
\hline No & 2 \\
\hline Undecided & 4 \\
\hline
\end{tabular}

The editors learned that there was a demand for this kind of copy and that for many women, it was a fairly new field. We had not expected as many to be unfamiliar with the subject; neither had we expected so much interest in more articles.

The over-all score (Read Most 56.5 per cent) was good, but it did not convey any of the information secured through the questions above.

Advertisers are even more anxious than editors to find out whether farmers believe what they read. In a reader interest survey of Wisconsin Agriculturist in 1959 one advertiser asked us to find out whether farmers believed the claims in copy about the efficiency of the feed being advertised.

We found 47 men in the sample who had read some or most of the ad copy, and who expressed an opinion on the ad. These men were given a card which restated the claim in the ad. We then asked the respondent to check one of the following:

1. Sounds reasonable to me.

2. Might be possible, but I'm not sure.

3. Don't think you could do it.

4. Undecided. 
Of the 47 men who checked an answer to the question, 19 had serious doubts about the claim. The scores follow:

No. Per cent

1. Sounds reasonable to me $\quad$. . . . . . $\quad$. $7 \quad 14.9$

2. Might be possible, but I'm not sure . . $17 \quad 36.2$

3. Don't think you could do it . . . . . 19

4. Undecided . . . . . . . . . . . . . 4

$\overline{47} \quad \overline{100.0}$

This seemed to show that the claim in the ad wasn't getting across. A change in copy was indicated.

Another advertiser wanted to find out whether a testimonial, using the picture and name of a farmer, was believed. This MoorMan's ad appeared in the Wallaces Farmer (September 20, 1958) (Figure 12.2). The card asked whether an average farmer could be as successful in feeding hogs as was the man in the testimonial. There were 42 men who read some or most of this copy. They expressed themselves as follows:

No. Percent

1. Yes, seems likely . . . . . . $22 \quad 52.4$

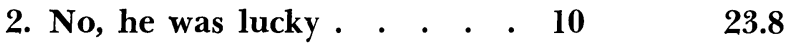

3. I didn't pay much attention

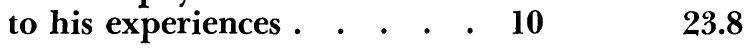

$\overline{42} \quad \overline{100.0}$

While the sample is smaller than we like, the testimonial does seem to get a fair vote of confidence. Of the 42 farmers who read this copy, 20 were large hog raisers who had marketed 100 hogs or more in the past 
year. Of these 20 prospective buyers of hog feed, 14 accepted the testimonial and only two rejected it. This approval by men who were presumably the better prospective buyers of hog feed gave additional weight to the results.

Another advertisement also ran testimonial copy on a feed ad. Farmers who read the ad were asked, "You've read the report of the experience of John Doe in feeding livestock. Do you think it likely that he could really do this well?"

The farmer readers of the ad answered:

"Yes, I think he could probably do that well" . . . $43 \%$ "Seems like the ad claims a little too much" . . . 35 "It claims a lot too much" . . . . . . . . . . . . 8 "No opinion" . . . . . . . . . . . . . . . . . . . 14

This advertisement had a good readership score. But was the believability score high enough? The advertiser had some doubts. The copy is getting another look.

In the three feed ads discussed above, much the same kind of sales argument was used.

In all three ads, layouts were of almost equal merit. All three had good readership scores. What made the difference in believability?

One of the lower ranking ads ordered the farmer to buy the product and shouted in large type what the benefits would be. The better ad tackled the theme with this head:

"Good results - as reported by Marvin Gesell, Howard County, Iowa."

The copy following gave a detailed report of what happened on the Gesell farm. The conclusion- 
reached in the twentieth short line under the headpresented a feed cost about the same as that reported in one of the less successful ads.

Questions can throw more light on reader response to articles. Two articles may have the same readership score. Yet one may be enthusiastically received and the other cast aside with the bored remark, "That's old stuff."

Tests like these have the great merit of being fairly easy to handle in connection with a standard readerinterest survey. They answer, easily and inexpensively, one of the major questions every editor asks about readership. (1) 
Figure 12.1

Page Score

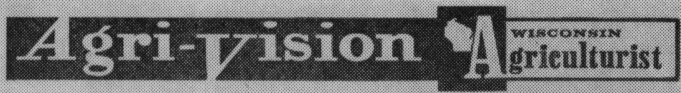

To help you meke the right decision

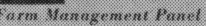

Daing IIn

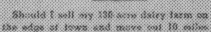

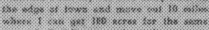

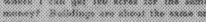

thes

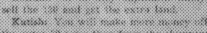

:

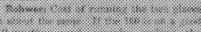

146:3: $: 3:$

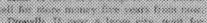

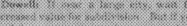

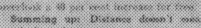

Hogs $7=$

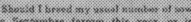

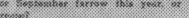

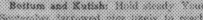

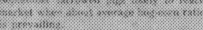

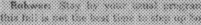

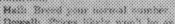

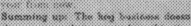

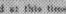

\section{$6 \cos$}

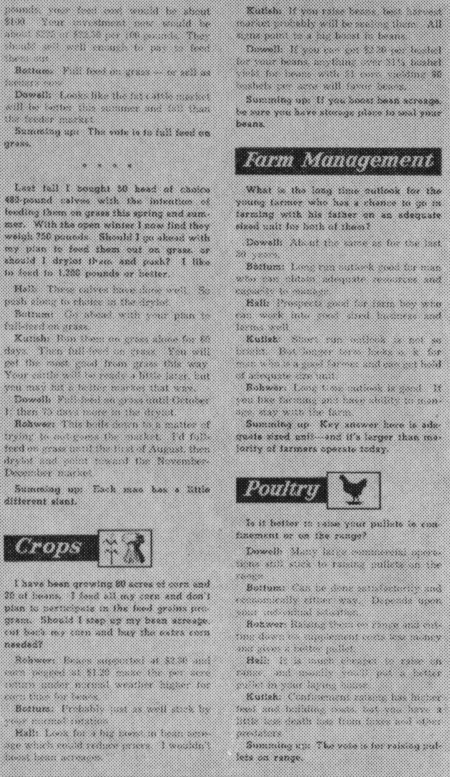

Men $\mathbf{7 2 . 5 \%}$

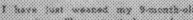

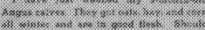

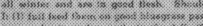

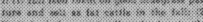

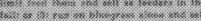

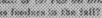

Women $44.0 \%$

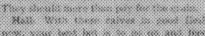

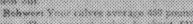
3.:

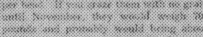

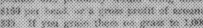

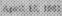

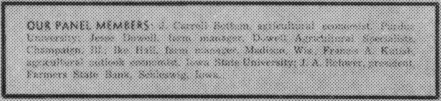

\section{"Help" and "Enjoyment"}

Men who read this department were asked, "What did you think of it?"

"The article made suggestions that will be of practical help to me" . . . . $42.3 \%$

"It has a few points I can use" . . . . . 32.4

Men readers were also asked whether they enjoyed reading the article-thus, "enjoyment" as contrasted with "help." And 92.8 per cent of readers of the department reported they "enjoyed" the copy.

Farmers may find it harder to admit "help" than "enjoyment." Both sets of questions throw some light on the meaning of the readership score. 


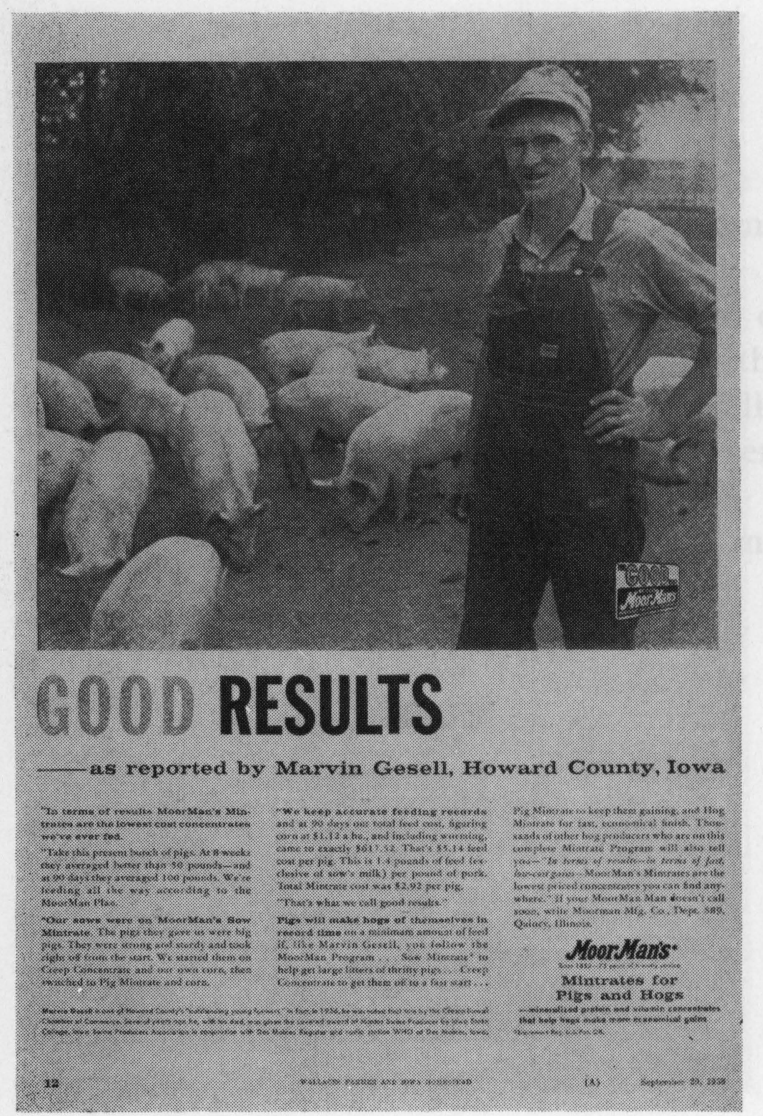

Figure 12.2

\section{Page Split A}

Page Score

Men 42\%

Women 26\%

\section{“Did You Believe Gesell?"}

These two pages came out almost even in scores, with one marked exception. The sales copy in B, pushed up to the top of the page, did better with men (Read Some 27 per cent to 16 per cent) than the sales copy in A.

Readers of the page were also asked, "Do you think an average farmer could be as successful in feeding hogs as Mr. Gesell was in the case reported here?"

Over half (52.3 per cent) answered, "Yes, seems likely." Other experiments on the believability of testimonials indicate that a 50 per cent approval is an unusually strong vote of confidence. 
Figure 12.3

\section{Page Split B}

Page Score

Men $\mathbf{4 8} \%$

Women 24\%

\section{GOOD RESULTS}

-as reported by Marvin Cresell, IXoward Connty, Iowa
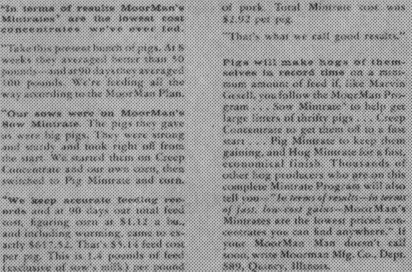

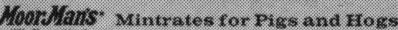

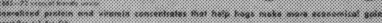
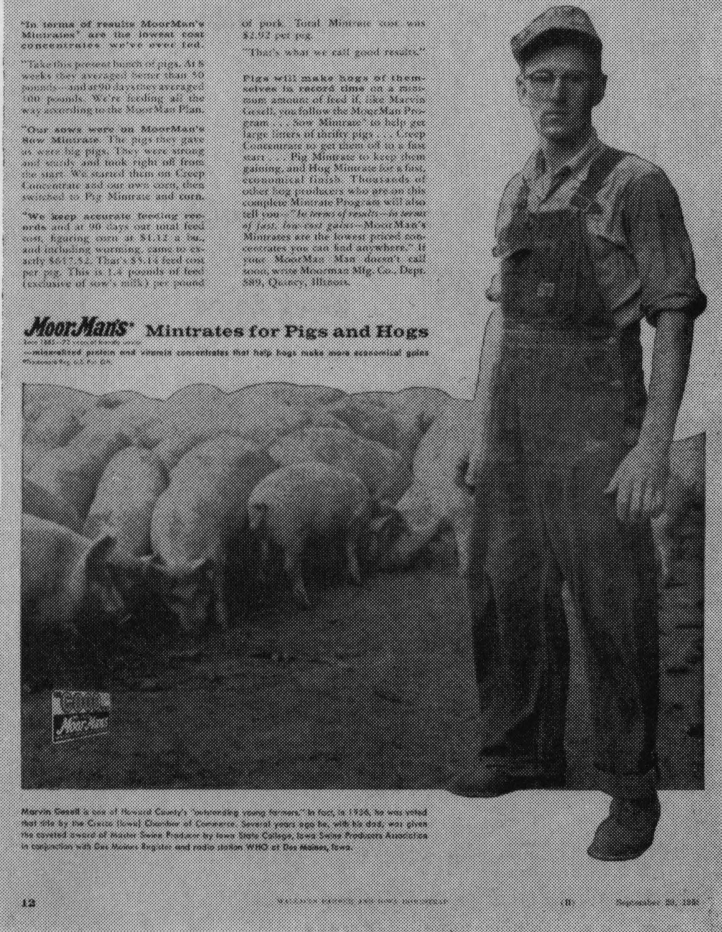

Women showed less interest in the ad, more skepticism about the testimonial. Only one-third of the women readers of the ad said, "Yes, seems likely."

The A reader may note that this cutout did about as well as the square photograph. This is contrary to the result in Figures 4.10, 4.11. In that case, the square photograph out pulled the cutout. One explanation may be that in 12.3, no damage was done to the hogs; in 4.11 the cows were badly chopped up. The mutilated cut in 4.11 destroyed the appeal of one part of the photograph; in 12.3, the hogs were allowed to make their usual appeal. 
Figure 12.4

Copy Score

Read Some

Men $65.5 \%$

\section{Women 33.5\%}

\section{"Will These}

\section{Methods Work?"}

Men who read this article on dairying were asked if they thought "the methods reported would work on my farm."

Of the men readers of the article, 43.7 per cent said "Yes." And another 22.2 per cent checked, "These methods might work on my farm." Only 6.3 per cent said, "They wouldn't work on my farm."

Wisconsin Agriculturist, October 3, 1959

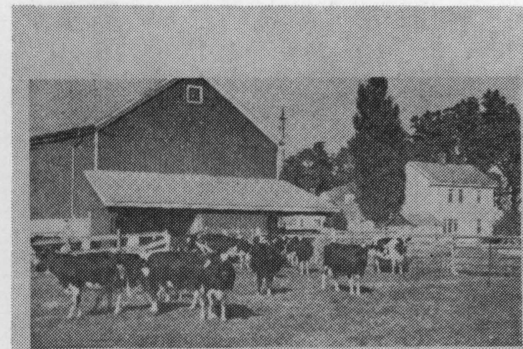

High Production is the rule in this herd ourned by john and

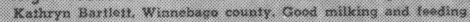

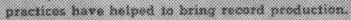

\section{Good Management Means More Milk}

Feeding and milking practices have big influence on dairy production

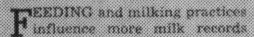
If intlownici more milik rectind:

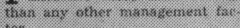
tor:

That the report tmon linver: sity of Wisconsin disiry specialist: whe print out thes the difterenos betwrisn poor sad extellont milk: fins practices atone is arturnd 100

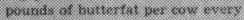
Yese: Trust amrosmas to 8.000 pounds far a 30 - 0 w herd.

"production rumands ane now bes. ing broken becaluse of bottior theds and botter mansinement: points

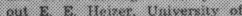
Wreconsin darry snceiatist "tis

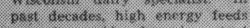
werenti considernd as important and cons lisit werent produense

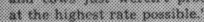

Regularity is Important to Good Management

some damminen likne oliver Prowst, Dadge comnty: somider temularity ane of the most uswor tent matraksment poirsts

"Chores come frost on mo trim,"

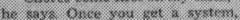
suddon chandes axe hand on the

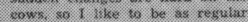
with mikiking as possibles"

The Propst herd was one of 4 .

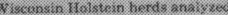
by ireseurchers to pin dork the drenes to which mills and the pros. duction are inthareneed by im vixomanestal factor:

soncralists rated exth of these

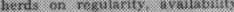
ot lest. vacusm levels on the milking lirt: sanitation: udde: stimulation, milking mashine time and mastitis comtrol. Rkesult: were combined with other feeting wind manissoment mactices

Takiny sare of diry cows wisk one of the imoartiant proutuotian

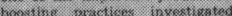
within rossoniabie limits any the

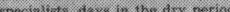

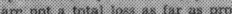

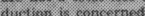

"I like to kire mis masso shout (90) 3. ne din

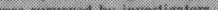
In the stivity corin 1. t) exyori me 4.5.

the mext millking yoms than thas

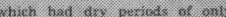

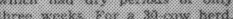

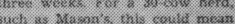

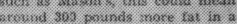

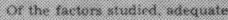
fowdirse and tistikins practsen seensied to be the mosit imaportant If vou underteed curns by ant

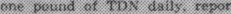

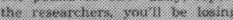
ansund 12 powntes of fat per cose

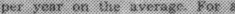

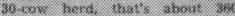
pounds of tht gach yets

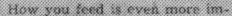

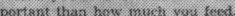
cours in the promitis in

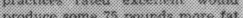

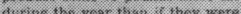
ante the

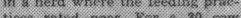

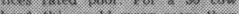

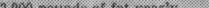

The stivity $\mathrm{kis}$ uniterseonnd the adxantiage of lares conss and consa with a lone prodinctive life in the hard Seven conse in the John and Kathrya Bartlest hord in Whane. knsed coumty proved that point in fanusary when their total litetime broductian veat exer a million pound: of mitik:

Takes 40 Average Cows to Equal 7 High Ones

Dairy experts Doint out that it

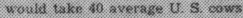
to equal tivin million pound lite. time mark of the sewen baxt3ett Noristoins

it strould be remembered that cowss don't reath theid hichent \{evel af prodiction tratil thas are

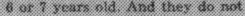

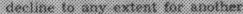
tive veari

This pains: us the palue of

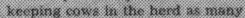
ywars as wass bot:

Buzi for nost daimynam what connts is the combinied intisunce

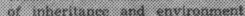

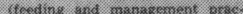
(4:00:s)

The ksow that's poing to make you the most moind is ong that: frocus fior hish prodtuction then

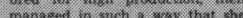

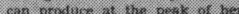
inherited atility.

Octwotser 2.1959 


\section{Cookery Corner}

Cottage Checse Salad

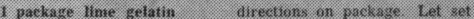
a paps cottase cheser

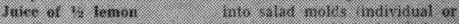

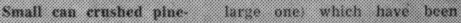

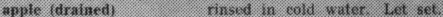

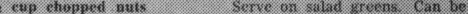

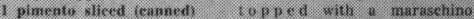

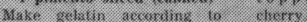

\section{Baked Stuffed Pork Chops}

4 rih park chops leat i inch thich

1 takicoponn chuppost anion

4. eap aleed cetern

2 tsbitespeori: tat

2 cups ary bread erumbs

1. teaspoon satt

Dasil of pepper

3., teaspous sage

14. can water

Sill and pepper

stit a packet alosid the bone

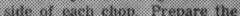
sluting by brownins the onion and coleng in thet and then coms. binink with crumbs, salt, sage and water stuft each chap

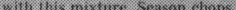
plade in a haking pasi Cover pan and bake in a 350 decres

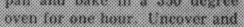
continue haking 30 minutes to browi:

\section{Stutfed Cabbage}

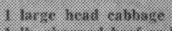

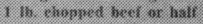
kect ind bill samisinge

$1,8 \times 8$

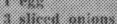

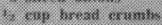

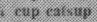

sait atad peppory in tastis

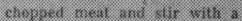

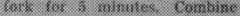

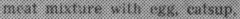

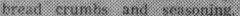

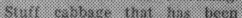

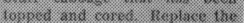

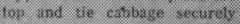

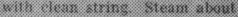

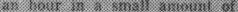

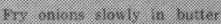
(3.)

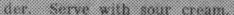

Figure 12.5

\section{Department}

Score

Women 88.5\%

\section{They Tried}

\section{Out Recipes}

This department "Cookery Corner" always has a high score. But what does the score mean?

One way to find out is to ask, "Have you tried out any of the recipes on this page?" The women were interviewed from 10 days to two weeks after they received the paper. Of the women readers of the department, 24.3 per cent answered "Yes."

And 62 per cent said they planned to use one or more of the recipes in the future.

Wallaces Farmer, January 17, 1959

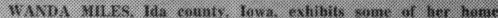

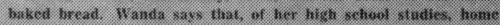
economics is her lawonte.

inimiary 10,1000 


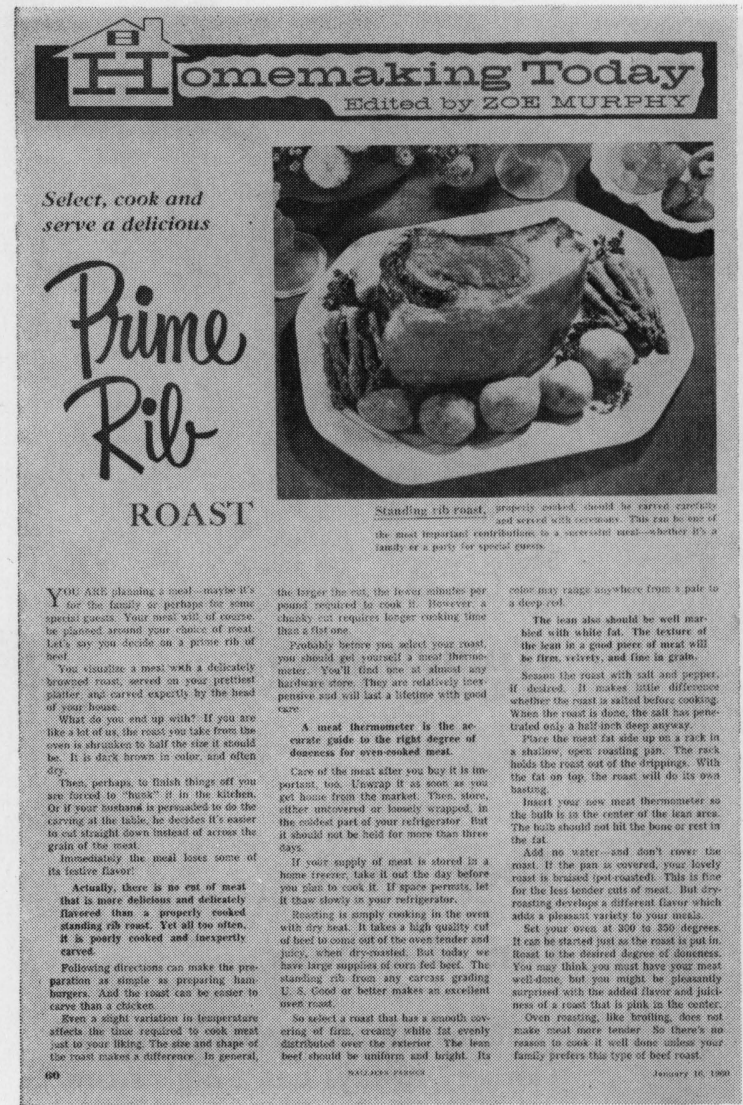

Figure 12.6

Page Score

\section{Men $11.5 \%$}

\section{Women 85.0\%}

\section{“Do You Want To Try This?”}

Women readers on this page were told about selecting and cooking a prime rib roast. Then they were asked, "Have you ever cooked and served a beef roast in the way described?"

Less than half (41.5 per cent) said, "Yes."

We also asked, "If No, did the article make you want to try it some time?" Of this group, 80.6 per cent said they'd like to try it. And of the whole number of readers of the article, 95.7 per cent said they'd like to see more articles like it in the paper.

Farm women were less familiar with this kind of cookery than we had guessed. They were also more eager than we had expected for more copy of this kind.

Wallaces Farmer, January 16, 1960 
From this series of ads and from similar studies, is it possible to draw any conclusions that will help copy writers to anticipate trouble in this field? Plainly more data is needed, but the following suggestions may be helpful:

1. The best ad didn't claim too much and didn't shout too loud. An almost diffident approach, coupled with a conservative claim, seemed to help believability.

2. Testimonial copy apparently can be either good or bad. It is bad if it sounds like the farmer quoted was bragging. A farmer talking across the fence to his neighbor doesn't brag too openly. He is more apt to say, "I was lucky this year. Got a bigger crop than usual."

3. Easy reading of copy is important. In terms of a Flesch "reading ease" score, the copy lead in the top ranking ad had 13 words to the sentence and 132 syllables per 100 words. The copy lead in one of the other ads had an average sentence length of 20 words and a syllable count of 156 per 100 words.

4. If the advertiser's experiments show that he can, most of the time, cut feed costs 50 per cent under those shown by the average farm, this is good news for the product. Yet it may not pay to make so strong a claim - even if well documented - in the ad. Farmers discount big claims.

5. Copy that issues orders: "Buy this, etc.," is not likely to do as well as a more indirect approach that says, in effect, "John Doe is doing pretty good with this feed. Maybe you'll have the same experience." 


\section{3.}

\section{Research in the Future}

There has been a Revolution in farming since 1940. Bigger farms, new machinery and new methods have made enormous changes. A good farmer of 1940 who left Iowa, went to California and came back to Iowa to farm again in 1960 would be baffled by many of the things he would have to do.

In this period of rapid change on the farms, have farm publications changed? Critics insist that the farm paper of 1940 is almost the same as the farm paper of 1960.

We use larger type, more and bigger pictures, and grow breathless in pursuing the latest developments from college experiment stations and from the experimenters of commercial concerns. Have we changed enough?

The evidence is that farm publications still hold farm interest. The series of "InFARMation Please" reports, prepared by the Statistical Laboratory of Iowa State University, indicate that farmers still rely heavily on the state farm paper as a source of information. 
Other surveys show much the same thing. Glenn Johnson of Michigan State reports on sources of information by 1075 farmers in seven Midwest states. (1)

$$
\text { Information on Prices }
$$

No. of mentions

Farm magazines . . . . . . . . . . 856

Publications of farm organizations . . . . 160

Newspapers . . . . . . . . . . . . 664

Radio . . . . . . . . . . . . . . 635

Television . . . . . . . . . . . . 145

Information on Production

Farm magazines . . . . . . . . . . 513

Publications of farm organizations . . . . 75

Newspapers . . . . . . . . . . . . 195

Radio . . . . . . . . . . . . . . 196

Television . . . . . . . . . . . . .

Information on New Technology

Farm magazines . . . . . . . . . . . . 242

Publications of farm organizations . . . . 24

Newspapers . . . . . . . . . . . . . .

Radio . . . . . . . . . . . . . . 72

Television . . . . . . . . . . . . . .

In the opinion of these farmers, what are the "most important" subjects?

No. of

mentions

Prices . . . . . . . . . . . . . . 352

Production method . . . . . . . . . 325

New technology . . . . . . . . . . . 64

Human information . . . . . . . . . . 79

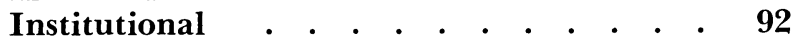

Couldn't rank first . . . . . . . . . . 8 
On production, the bread and butter of the content of farm publications, the high standing of the farm press seems clear. On prices - and price prospects newspapers and radio are pushing up. On new technology, the farm press leads. Yet it should be noted that new technology ranks low in prestige compared to production and prices.

Why are farm papers, even if relatively unchanged since 1940, still doing so well in their traditional role? It might be noted here that every editor will probably say that his farm paper has changed since 1940; it is the other papers that have not changed. Most outsiders looking at the issues of the two dates would say, "Yes, some changes. But a reader of 1940 would still feel at home with the paper of 1960."

One reason for the continued strength of the farm press is probably just habit. Probably every farmer in Illinois grew up in a home where Prairie Farmer came regularly. To a degree, the same is true of the Wisconsin Agriculturist in Wisconsin and Wallaces Farmer in Iowa.

The stock remark of an older subscriber is often, "I did my first reading in your paper. Looked at the livestock pictures and puzzled out the words alongside."

Over the years, too, each farm paper has been able to do something useful for most subscribers. Another stock remark: "You had a piece in the paper 10 years ago that I tried out and it worked. I figured it paid my subscription for 20 years."

A Starch report in Wallaces Farmer (March 5, 1960) asked the question: "Have you ever made use of farming or homemaking ideas (including recipes) reported in Wallaces Farmer?"' Of the men, 65 per cent 
said "Yes" about farming, and of the women, 68 per cent said "Yes" about homemaking.

The reverse is also true. A farmer who didn't buy an extra 80 in 1940 because of the paper's conservative warnings may calculate how much he lost by not gambling on a rise in prices during the war boom. A Republican farmer who voted for Hoover in 1932 might be critical of a paper's support of the New Deal's farm program.

On the whole, however, the farm publication is an old friend, or if not an old friend, at least an old and familiar enemy. There are always subscribers who open the paper eagerly to "see what this blankety-blankblank is going to say this week." And even one of these subscribers may add, "This guy is crazy on politics, but he does know something about corn and hogs."

But is familiarity with the product always an asset? Perhaps there are young farmers who think the familiar paper is too old-fashioned and "says the same thing over." The young farmer is geared to television, to more general magazines, to more farm papers, to more time on the road and in town and less time in a chair by a reading light. This is an additional reason for a continued check on the reading habits of young farmers.

Add to this the fact that there are more kinds of folks in the country than there used to be. There are residential farmers, who live on 10 acres and have a horse and a few chickens. There are retired farmers. There are part-time farmers who keep some stock and do a little farming on week ends but whose main income comes from a job in town. In the ranks of commercial farmers, there is a great difference in interests 
between the man with a gross income of $\$ 5,000$ a year and one with $\$ 40,000$ a year.

Farmers were more alike in the old days than they are now. The 1960 census raises the question of the nature of the farm audience. Will editorial copy that registers with the 6.7 per cent of Iowa farm operators who are part-time farmers also register with the 4.6 per cent who take in $\$ 40,000$ or more?

The census figures on economic class indicate how income groups line up in the two states:

$$
\begin{array}{ll}
\text { lowa } & \text { Wisconsin } \\
\text { No. Per cent } & \text { No. Per cent }
\end{array}
$$

Class I (sales of $\$ 40,000$ up) $\quad 8,110 \quad 4.6 \% \quad 1,010 \quad 0.7 \%$

Class II

\begin{tabular}{|c|c|c|c|c|}
\hline$(\$ 20,000$ to $\$ 39,999)$ & 21,579 & 12.4 & 4,221 & 3.2 \\
\hline Class III & 48045 & 975 & 93750 & 181 \\
\hline Class IV $(\$ 5,000$ to $\$ 9,999)$ & 47,408 & 27.1 & 43,523 & 33.2 \\
\hline Class V $(\$ 2,500$ to $\$ 4,999)$ & 23,537 & 13.5 & 28,324 & 21.6 \\
\hline Class VI $(\$ 50$ to $\$ 2,499)$ & 5,655 & 3.2 & 5,868 & 4.5 \\
\hline Part-time operators, etc. & 11,660 & 6.7 & 16,392 & 12.5 \\
\hline Retirement, etc. & 8,701 & 5.0 & 8,114 & 6.2 \\
\hline & 174605 & 00 & 31,202 & 00.0 \\
\hline
\end{tabular}

Do we want to put out a farm paper that appeals to all these folks? It is possible, but it has difficulties. The part-time farmer and the big commercial farmer are both interested in rural schools, in the social problems of country living, in flower gardens and lawns. But the description of an automatic feeding set-up wouldn't mean much - except as a curiosity - to farmers below the gross $\$ 10,000$ level. To include farmers above that level would mean an audience of around 44.5 per cent of the Iowa total. 
From the business angle, all of these people are a market for consumer goods - overalls, shoes, groceries, household gadgets, etc.

Would it make more sense to aim a farm paper at the better commercial farmers? If we aimed at the interests of those with $\$ 10,000$ or more, this would be 44.5 per cent of the census total in Iowa and 22.1 per cent in Wisconsin. If we stretched it to include those with an income of $\$ 5,000$ or more, this would be 71.6 per cent in Iowa and 55.3 per cent in Wisconsin.

There is another way to deal with this problem, of course. Shift to the vertical approach. Get out a farm paper devoted exclusively to dairying, or to hog raising or to poultry raising. Yet in the Middle West, most of the farmers have more than one major interest.

These are policy questions for the publishers and the editors. But the questions may get better answers if more research is carried out. Just how does our circulation now break up? How many are part-time farmers, how many are town people who own farms, etc?

What kind of copy are the bigger farmers reading? What kind is read by smaller farmers? So far our investigations show that production copy gets much the same kind of response from big and little farmers. But how many readers do we lose when we talk about a problem that affects only the top 10 per cent of our farmers? How many do we lose when we talk about a problem that means something only to the lower 10 per cent of our readers? We need to continue investigations in this field.

In checking on the appeal of vertical publications, we need to know the readership habits of farmers who sell 150 or more hogs a year and of farmers who milk 
30 or more cows. We have a good deal of information in this field, but it should be kept up to date.

Editorial style is related to these other policy decisions. Will it be useful to follow the lead of McCalls, Better Homes and Gardens, etc. and run less copy in very big type? How reconcile the interest of the man who wants a detailed technical article with the interest of the man who prefers only a 200 -word summary?

How important is the slick paper, four-color format to subscribers? (We know already that it is important to most ad agencies.) Our slick paper, four-color inserts give us a chance to compare the appeal of this kind of advertising copy with the appeal of run-of-the-book ads. We have no way at present to use splits to check editorial appeal of the two kinds of presentation. Experiments by others indicate that four-color layouts do not always help readership.

Another problem deals with the farm woman's interest in the paper. At present, we get fantastically high readership scores on Home Department copy and good scores for women on copy aimed primarily at men. Farming is, in many cases, a family affair. Women participate in decisions. With more education than men, they often point out to husbands articles they should read or ads they should notice.

Yet in the business field farm papers lose ground in advertising directed to farm women. Farm women use lipsticks, and only a fraction of the farm audience takes any one women's magazine, yet cosmetic advertising misses farm papers. Farm women buy groceries for hearty eaters in big families, yet food advertising is light. 
Is the answer to forget about farm women and aim copy only at farm men? Or is it to continue to appeal to farm women and hope that we can get more information on the farm women's market to the agencies? This question is also related to the question of dealing with commercial farmers only or with everybody living in the country. All women living in the country have similar problems - in gardening, in canning and freezing and in relation to rural schools.

Every publisher and editor should probably devote special time to a consideration of the death of Country Gentlemen, Cappers Farmer and a score of other farm publications. What killed them? Is there any chance that we have the same disease?

That is one good reason for more editorial research and for more thinking about the results of editorial research.

More emphasis should undoubtedly be given to pre-testing new subject matter and themes the publication has never used. To rely exclusively on earlier readership surveys is to be chained to the past.

Farm publications may be tied more to the past than other magazines. For them, the argument is even stronger for using pre-tests of subject matter as described in Chapter 10.

Something might be said here about the claim that "you can't edit a paper with a slide rule." Some folks worry about editors being influenced by experiments like ours to the extent that individual initiative, intuition, and possibly genius, will be stifled. (2)

There is some risk here, but I doubt if it adds up to much. A very few editors may decide that the results of 
a readership experiment (not always statistically significant) should be followed blindly. Far more will disregard such experiments and be guided, as usual by their own hunches, by habit, by the examples set by their contemporaries and by a few letters from subscribers.

Both extremes are foolish, of course. Anyone who has read this book this far will note how tentative many of our conclusions are. Many experiments do no more than provide the editor with a hunch. But a hunch of this origin may have value.

I remember the comment made by one eminent statistician when I was worrying over tests of significance. He said, "Let's suppose this experiment doesn't have results that turn out to be statistically significant. Still it is all the evidence you have to go on. If the cost of making the change indicated by the experiment is small, better go ahead and make it. And then run some more tests." 
Figure 13.1

Page Score

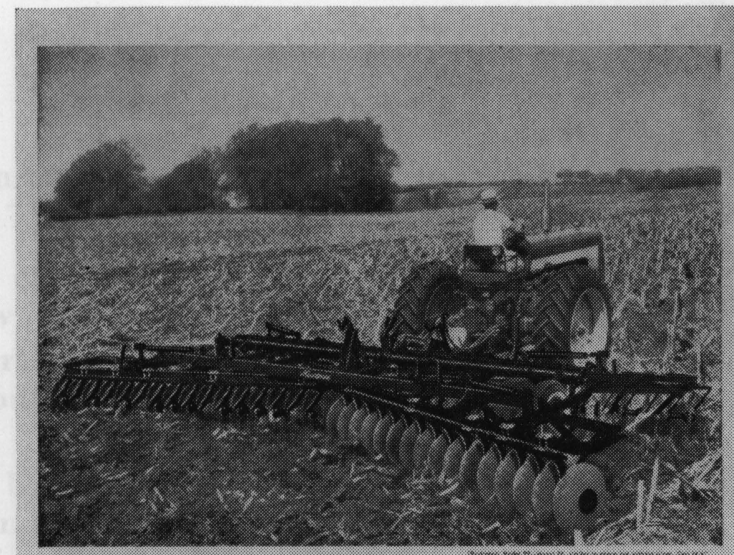

The New Jewrive 6 now Diskı

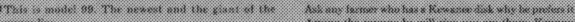

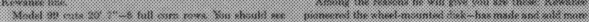

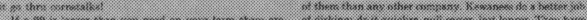

(i: i:

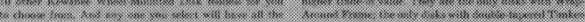

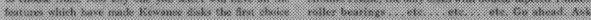

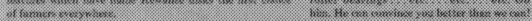

Men 54\%

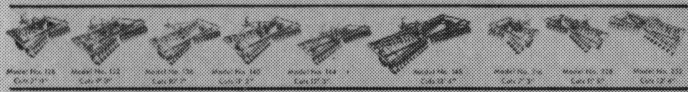

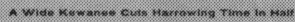

a

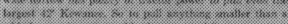

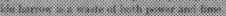

(1:

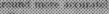

:

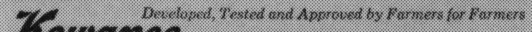

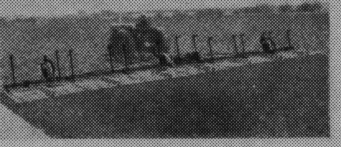

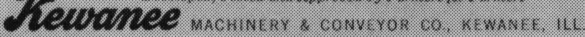

\section{Who Were the Best Prospects?}

This advertisement scored well. Its Read Some for men on sales copy was 27 per cent. Read Most was 19 per cent.

To which farm groups did the ad make the strongest appeal? Farmers who were young, with good incomes and on bigger farms showed the most interest.

Crop acres harvested

$$
\begin{array}{ccc}
1-49 \text { acres } & 50-74 \text { acres } & \text { and up } \\
38.1 \% & 46.9 \% & 64.3 \%
\end{array}
$$

Of the 98 farmers interviewed on this question, $63 \mathrm{had}$ 75 acres or more. This was the biggest as well as the best market. 


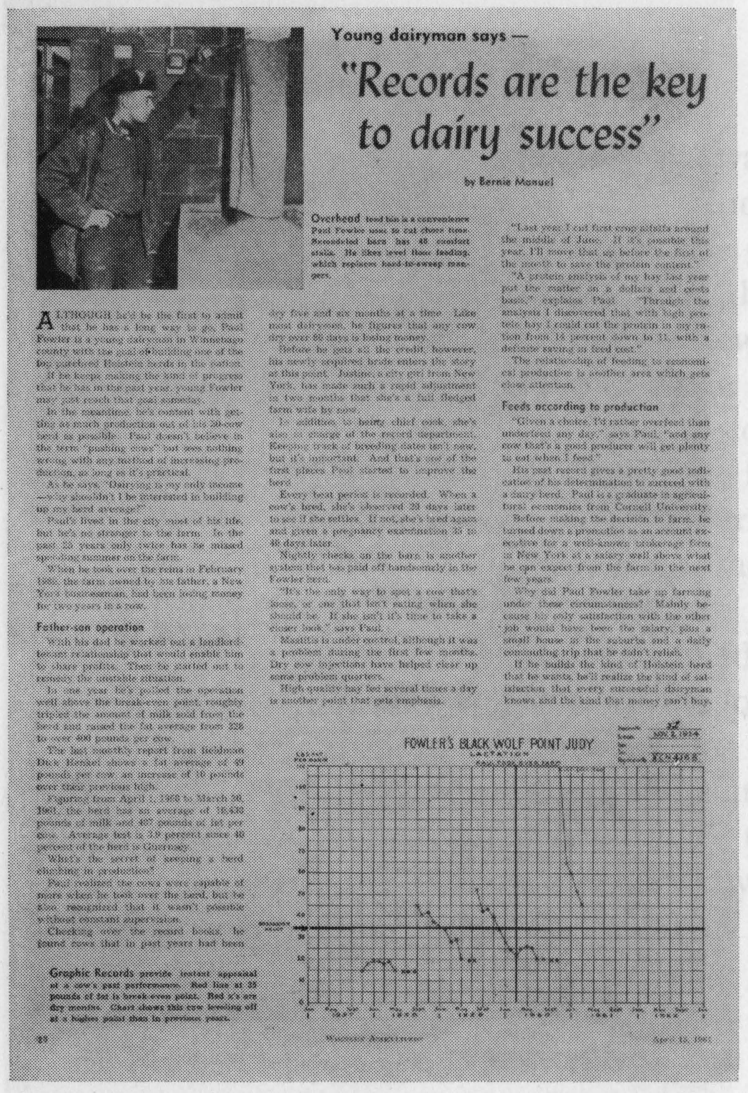

Figure 13.2

Page Score

Men $61.5 \%$

Women $34.5 \%$

\section{Who Reads About Farm Records?}

Younger farmers and farmers with larger incomes were more apt to read about farm record keeping than older and poorer farmers.

Read Some scores on men's age groups follow:

$$
\begin{array}{ccc}
21-34 \text { years } & 35-49 \text { years } & 50 \text { and up } \\
75 \% & 63 \% & 45.3 \%
\end{array}
$$

Here are Read Some scores on income groups:

$$
\begin{array}{ccc}
\text { Under } \$ 5,000 & \$ 5,000-\$ 9,999 & \$ 10,000 \text { and up } \\
44.7 \% & 69.6 \% & 70.7 \%
\end{array}
$$

Farmers who had gone beyond eighth grade in schooling were more interested than farmers whose education stopped earlier. 
The great danger in editing is not the blind following of experimental work. The great dangers may be these:

1. Doing this year exactly what you did last year and failing to test new ideas;

2. Imitating some drastic change made by a contemporary publication without testing its appeal to your particular audience;

3. Being influenced by a few letters, some from folks with an ax to grind and some by a few subscribers who are either radically for or radically against some proposal;

4. Failing to try to look five or ten years ahead, to try to see what audiences and publications may be like then;

5. Forgetting that sociology, anthropology, psychology and history are also fields in which farm editors need skills. Farm families are people as well as hog raisers and corn raisers.

Do readership surveys, pre-testing and opinion surveys help farm publication editors to avoid these dangers? I think they may. Every time a readership survey upsets a cherished belief, the editor is likely to profit.

"If I'm wrong about this," he may say to himself, "I may be wrong about something else." And he should be more able to take a fresh look at his job. 


\section{4.}

\section{What Kind of Editor?}

ANy DISCuSSION OF READERSHIP tests should close by repeating the usual warning. A readership test measures the past. An editor may in June of 1963 get out exactly the kind of publication that scored high in 1962. But 1963 is not 1962. There will be resemblances, but there will also be differences. How do you figure these out?

Before trying to answer this question, let us look for a moment at what I have called the "Joe Ratner Formula." Ratner was a talented editor who worked with Better Homes and Gardens and later with an advertising agency. He believed in research. He used it. But he also could laugh about its limitations.

"This is the way it works," Joe said. "You believe in readership research. So you check on the last issue. Food copy ranked high. OK, you throw out everything but food copy. Now in the next issue, you find that pie recipes outscore everything else. So you fill the next issue with pie recipes. But your readership survey shows that apple pie recipes score higher than others. The result is that the next issue, the climax of readership testing, includes nothing but apple pie recipes." 
This is ridiculous, but true. Every readership expert should repeat it to himself regularly.

What you need, of course, is balance in the issue. In a farm publication in Iowa, we are sure that corn and hog copy will score high. But that doesn't mean everybody wants to read only about corn and hogs. Minor interests play a part. So does variety.

But the major problem is still: What kind of new copy will attract your readers?

The pre-test of subject matter, already described in Chapter 10, is one way of estimating short-run changes. If the editor is bright enough, he can set up a number of possible subjects and have these checked by the reader.

But how does he know which subjects to ask about? Surveys on opinion and readership can give him some clues, but only clues. He needs to generate some ideas himself.

He can borrow ideas from other magazines. This is often a risky business since editors sometimes run together like sheep in what may be the wrong direction. The pre-test may help to show an editor that he is running the wrong way. This has value, even though it is negative value.

The editor can read widely, talk to people with different views, visit farmers and then think, "What can we say next issue that will do this fellow and his wife any good?" And he can use the pre-test to check his hunches.

So far we have been looking ahead in 1962 to what will be timely and useful in 1963. Now we come to a much harder task. How do we, in 1962, manage to look 
ahead to what will be timely and useful in 1965 or 1970 ?

My best example concerns Henry A. Wallace and his articles on hybrid corn. He began to write about hybrid corn in 1918. We had no readership tests then. If we had, my guess is that the score would have been low. Yet Wallace kept on writing on this subject which gradually became important. By 1934, when hybrid corn was first used, farmers knew much more about it and were quicker to use the new strains than if Wallace had waited 10 years to begin discussing the subject.

You can make the same point about economic issues. I'll use Wallace again as an example since he is the editor about whom I know the most. In 1922 he began to hammer on the need to adjust production to market demand. This program did not result in actual legislation until 1933.

Does it pay an editor, or his publication, to be five or ten years ahead of his times? Franklin D. Roosevelt, an expert in political affairs, used to say that a political leader should be a year or two ahead of the public, but no more.

An editor perhaps should follow the same rule. Yet I think there is an argument for letting readers know what is in the air, and what is likely to happen some years in the future. For this kind of copy, an audience will grow.

How can farm publications get the kind of editorial talent that can look ahead? If they get this kind of talent, can it be turned into circulation and into advertising lineage?

There are some doubts on this second point. I knew 
one man active in the business end of a farm publication who said flatly that the job of the editor is to fill in the white spaces left in the dummy after the ads are placed. He insisted that he saw no relation between editorial copy and circulation or between editorial copy and advertising appeal. (Perhaps he did see this relationship, but felt it better business to ignore it while arguing over editorial salaries.)

Circulation is not solely a matter of editorial appeal. It depends, to a great extent, on the skill and persistence of the circulation department. Editorial appeal does make renewals come easier. A paper that isn't read with interest cannot be boomed by even the most skillful circulation campaign.

Advertising readership, of course, is dependent on the ability of the editor to get readers to go through the issue and give an advertiser a chance. I can recall one "expert" who insisted that he wanted an ad placed opposite a dull article, so that the article wouldn't distract attention from his ad.

One constant question is: Are we getting out a paper for the readers or for the advertisers and the advertising agencies. Very often a layout that appeals to an agency falls flat when exposed to readers. And editors may be led into editorial blind corners by an agency's art director who has never checked his layouts against farm readership.

Finding first class editors is a problem and holding them is more difficult than it used to be. Editors are often persuaded into going with ad agencies, public relations firms, house organs and the like. This has been a good break for the journalists. They can bargain for 
pay and fringe benefits. But this situation has often lost farm papers the kind of editorial talent they can hardly afford to lose.

Pay in money isn't the only temptation. An editor is paid by prestige, by the feeling of power and by the satisfaction in making policy and influencing readers. Men - and women - who don't get this kind of pay are apt to move.

There are different kinds of editors, of course. One is the amiable kind, who knows everybody, whose editorials irritate no one, and who has the skill to introduce new ideas into the reader's head without the irritations that usually accompany that process.

Then there is the editor who fills up space, who goes through the motions and whose paper reads like everybody else's.

The most useful editor may, according to my biasc $d$ view, be the one who is able to look a few years ahead and to get his readers ready to accept the future or perhaps to modify it. He needs to know more than agriculture. He should know how United States agriculture fits into the affairs of the nation and of the world.

Here are two quotations that seem to me to indicate the kind of thinking that farm paper editors - and all editors - ought to be doing.

Lawrence E. Hinkle, Jr. said after describing the authoritarian way of life,

The point might well be made that the conflict between this way of ordering a human society and its opposite - the open system of thought, based upon observation, constantly tested against reality, allowing for great uncertainty, accepting a variety of points of view, not pretending to know the ultimate right or good and always keeping open the possibility that any judgment is incorrect - may be the basic conflict of our time. (1) 
I think a farm paper editor ought to be on the side of the "open system of thought." He should be thinking also about Kenneth E. Boulding's "traps for the future." Boulding of University of Michigan said,

The three traps are war, population and exhaustion. A nuclear war if it did not put an end to man, might easily remove from him any chance of perpetual affluence. Unlimited growth of population could do the same thing more slowly but just as effectively. The ghost of Malthus has been laid many times, but it won't lie down.

If science and technology give us death control, it must also give us birth control. We must eventually have a stable population and if we are all going to live to be 70 , the birth and death rate cannot be more than about 14 per thousand. This means an average of a little over two children per family and no nonsense.

The third trap might be our inability to develop a non-exhaustive high-level technology. Our existing technology is essentially suicidal so far as it is based upon geological capital which we are rapidly squandering. We cannot build permanent affluence on fossil fuels, not even uranium, and still less upon deposits of ores.

Permanent affluence must depend upon fusion as a source of energy, either in the sun or here on earth and it must depend upon the use of this energy to concentrate the diffuse elements of the sea and the atmosphere. Fortunately this high-level technology seems almost in sight. It is perfectly possible, however, that either nuclear or population explosions might prevent us from ever attaining it. (2)

I do not suggest that every editor should agree with Boulding's statement of the problems or of their treatment. I do suggest that these are the kinds of subjects on which a good editor should spend some time and thought.

It is not enough to know that 9-point type on an 11 point slug will get more readers than 9-point solid or 
that a picture six inches square will get more attention than a picture three inches square.

These - and their cousins and their brothers in research - are tools to be used by an editor who has something to report that may be useful to his readers, his nation and folks in other lands. While he must write with today in mind, it is hoped that he can also keep in mind the needs of 1970 and even the needs of the year 2000 . 


\section{Survey Methods and Reports}





\section{5.}

\section{Survey Methods}

SuRveY RESUlts are no better than the methods used. Many readers, therefore, will want a description of the methods used by Wallaces Farmer and Wisconsin Agriculturist.

I started in 1938 by getting advice from the Iowa State University staff. Ray Jessen, Arnold King and T. W. Schultz helped in laying out the program.

We began by taking the economic regions of the two states, as defined by the U. S. Department of Agriculture and by trying to give each region its proper representation in the sample. For instance, the dairy region of northeastern Iowa has 20.6 per cent of the farms. We aimed, therefore, to interview 20.6 per cent of the rural-farm adults in that region.

Within each economic region, we selected from six to eight counties to represent different soil types, ethnic groups, etc. Within each county, we told our interviewer (a farm woman) to work on one mail route (in reader-interest surveys) or on one road or in designated 
townships (in opinion surveys). The interviewer was instructed to begin interviewing outside town and suburban areas and to stop, without exception, at every other farm house along the route.

This sample, it will be noted, is not a strict probability sample. We did experiment with that kind of sample. The Statistical Laboratory at Iowa State drew up the design and we sent interviewers to the exact farms designated. Bad roads and call backs created problems, and finally we dropped back to the method described above.

We continually check our sample against census data and against U.S. Department of Agriculture crop and livestock reports. For the most part, they match. We have trouble from time to time with interviewers who pick the better farms. We alleviated this problem partially by emphasizing "every other farm" at training sessions. One complication comes up in bad weather. When a farm lane is filled with snow, the interviewer is likely to ignore the "every other farm" rule.

When we began the work, we asked interviewers to skip farms of 30 acres or less. In time, however, it seemed clear that this instruction had, at least, two errors. No interviewer can tell from the road how big the farm is. Our papers needed to know about small and residential farms as well as large ones. In recent years, therefore, the interviewer stops at all farms. We then sort for the small farmers, part-time farmers, fulltime farmers, etc.

An example of the check against census data is the report made for the reader-interest survey of March 17, 1956 in Iowa.

The sample was made up of 200 men and 200 
women on Iowa farms of 30 acres and over. The sample compares with census figures as follows:

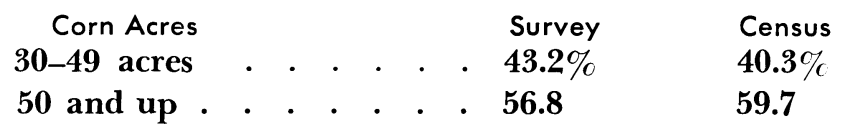

In owners and renters, the sample compares with the census as follows:

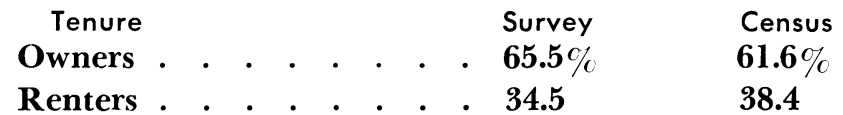

In crop acres planned for harvest in 1956, the sample compares with the census as follows:

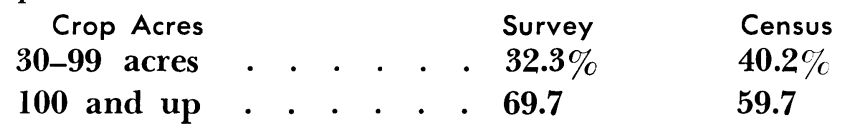

It should be noted that we continue to have trouble with farm size. It is possible, of course, that the sample has kept pace with the rapid shift toward larger farms and is more accurate than the outdated census figures we are forced to use. In 1961 our sample in Iowa had 72.4 per cent in the " 100 crop acres and up" class while the 1959 census had 64.5 per cent.

Comparisons with "intention to plant" and "pig survey" estimates by U.S. Department of Agriculture have helped us to check our sample. More difficult is the regular check on farm voting. To get the farm vote in the state, we use the 1950 report on rural-farm adults in townships. We assume that townships in Iowa with 85 per cent rural-farm adults are representative of the farm vote; in Wisconsin, we use 80 per cent rural-farm townships.

Since the 1960 census did not make a report on rural-farm adults by townships, we adjusted the town- 
ship figures by throwing out all townships which had population increases since 1950.

The problem in an election, of course, is not only to get a true sample of the rural-farm population but also to find how many and what kind of people are going to vote. This affects the size of the sample used. In order to be sure of interviewing around 500 voters, we must interview 700 people. In rural Iowa and Wisconsin, around 75 per cent of the eligible adults go to the polls.

After the election, we check back on the actual vote cast in the rural-farm townships. In 1960, for instance, we estimated that Nixon would get 56 per cent of the rural-farm vote in Iowa. He got 54.4 per cent. In Wisconsin, we estimated 50 per cent for Nixon. He got 52.4 per cent.

One result of the accurate pre-election polls is that we learn a good deal about the kind of people who vote for each candidate. How did young farm people vote? Catholics? Protestants? How many split their tickets?

We use, of course, two kinds of samples. One - for opinion surveys - deals with all farm people. The other - for reader-interest surveys-deals with subscribers only. Iowa and Wisconsin subscribers are so nearly representative of all farmers that there is little difference between a subscriber sample and a total farmer sample. A census investigation and breakdown some years ago in Iowa found our subscribers on slightly larger farms and with somewhat more livestock and income than Iowa farmers taken as a whole. (1)

Whether a survey is accurate depends to a great degree on the skill and the probity of the interviewer. From the beginning we have used farm women. They 
work for us only a few days a year, of course. We make two reader-interest surveys a year and from two to four opinion surveys. We select these interviewers on the basis of advice from farm friends and county extension people. WVe bring interviewers into Des Moines (in Iowa) and into Madison (in Wisconsin) for training sessions.

When a survey is completed, we send a letter of correction and approval with the check. There is some turnover. Some of the young women have babies. Some older ones find interviewing difficult in winter. A few are dropped because they cannot follow instructions. The kind of farm woman who is aggressive enough to enjoy knocking at strange doors must also listen and try not to convert the prospect. Some are incurable and leave us.

The farm woman interviewer has many advantages. She isn't turned down. By saying, "I'm Mrs. Smith; I live on a farm the other side of Blankville," she puts herself in a different class from the ordinary business caller. And she quickly adds, "I'm not selling anything." We forbid interviewers to accept any money for subscriptions.

In split runs we actually use two samples. Again, think of Iowa counties as a checkerboard. We send A copies to the black counties and B copies to the red counties. The interviewer must be warned to stick to a mail route originating in the county in which she is assigned.

We have changed methods since we started. At first we used a fresh copy of the paper for every interview. The interviewer marked with pencil the items noted. This method created problems in the office, for it was 
difficult to translate this kind of data onto IBM cards. We used homemade devices of various kinds, but finally shifted to a method outlined by Professor Robert Jones of the University of Minnesota in Journalism Quarterly.

Every part of every article or ad had a code number, and these code numbers were repeated on a score card which was marked by the interviewer. Then IBM punch operators took these score cards and put the data on IBM cards. This made it possible to get detailed breakdowns on our sorting equipment.

What difference did the change in methods make in scores on copy? It is difficult to be certain, but my impression is that the present method pushes up the Any This Page scores a little. The code numbers point to different parts of the article or ad and force the respondent to ask himself, "Did I look at that?"

In a split run, we try to match one kind of copy in the A version against a different kind (preferably with only one factor changed) in the $\mathrm{B}$ version. We use for split runs a sample of 100 men in $A$ and 100 women in $A$; an equal sample in $B$.

How can we tell if the difference between A and B scores means anything? Suppose, for example, that the $A$ version has a Read Most score of 45 and the $B$ version a Read Most score of 60 . Is that difference significant?

In statistical tests of this type, the hypothesis under consideration is that there is no difference between the copy used in the A and B samples. Differences between the A and B groups may be obtained owing to chance fluctuations arising from several sources.

The practical question we ask is: Is the difference 
between the A and B groups large enough so that it is unlikely to have arisen from chance fluctuations alone. We have used a 5 per cent level of significance as the cutting point for evaluating such a difference. Thus, if a difference is large enough so that it would be expected to occur only one time in 20 as the result of chance fluctuations, we are inclined to accept it as indicating a real difference in readership.

We also need to look at the scores on unchanged copy. Suppose the article tested is on marketing corn and is on page 14. Let's see how unchanged copy nearby with a similar theme compares.

\begin{tabular}{|c|c|c|c|}
\hline & & A & B \\
\hline Page & $10-$ Editorial on corn . & $40 \%$ & $45 \%$ \\
\hline Page & $12-$ Farm letter on corn & 30 & 35 \\
\hline Page & 16 - Ad on seed corn & 15 & 20 \\
\hline Page & $18-$ Hog rations using corn & 50 & 60 \\
\hline & $\begin{array}{l}\text { Total . } \\
\text { Average } \\
\end{array}$ & $\begin{array}{l}135 \\
33.75\end{array}$ & $\begin{array}{l}160 \\
40.0\end{array}$ \\
\hline
\end{tabular}

This difference in the scores of the controls should be taken into consideration in estimating the significance of the split itself.

Does the split run, in the example noted above, mean anything? Note the 15-point difference in favor of $\mathrm{B}$ in the split and the 6.25-point difference in favor of $\mathrm{B}$ in the controls.

The split-run difference here may still mean something, but we'd feel much better if we ran another split. If another split-and perhaps another-also shows a pattern with B ranking consistently ahead of A by 10 points or more, we are probably justified in accepting the result. 
Another way, when possible, is to duplicate the experiment. On page 14, we print Change $\mathrm{X}$ in $\mathrm{A}$; on page 54 , we use a similar article and a similar change, but run Change $\mathrm{X}$ in the $\mathrm{B}$ version. This - other things being equal - should wipe out the differences between $A$ and $B$ on unchanged copy.

This duplication of splits is possible with editorial copy. It is difficult to arrange with advertising copy. Yet even with editorial copy, one can't be sure of exact duplication.

If heads are being tested, are we sure that the head on a dairying article will have exactly the same relationship to copy as the head on a hog article? Dairymen may read one; hog farmers may read the other. These are different groups, and they may react to heads in ways related to their occupation. A difference in head scores may only prove that dairymen and hog farmers have different tastes, not that one head is better than another with all readers.

It is still possible to make a series of splits on a particular point with all the conditions as nearly alike as possible except for the tested factor. If, time after time, we get about the same answer, we can be fairly sure that, for our audience, the experiments indicate what we should be doing. An example is our series on a second color. Another is the earlier series on Flesch scores.

One colleague suggested I repeat a paragraph from Chapter 13. I wrote:

"I remember well the comment made by one eminent statistician when I was worrying over tests of significance. He said, 'Let's suppose this experiment 
doesn't have results that turn out to be statistically significant. Still it is all the evidence you have to go on. If the cost of making the change indicated by the experiment is small, better go ahead and make it. And then run some more tests.", 


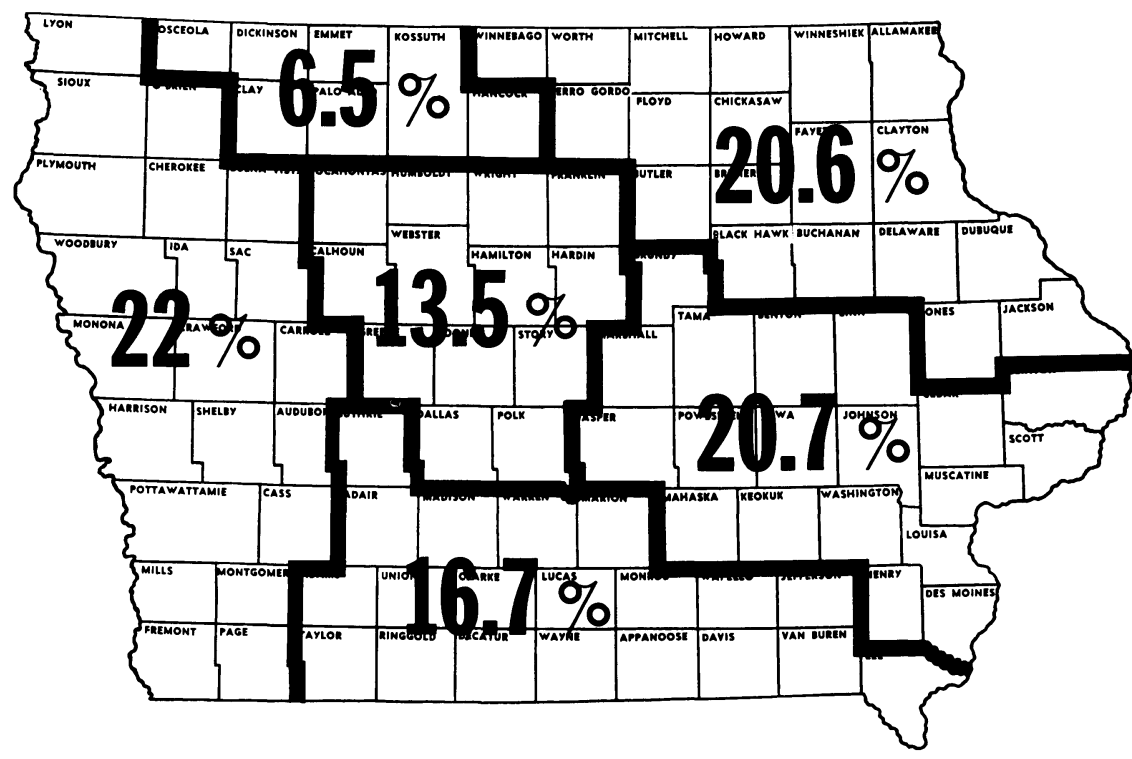

FARM ECONOMIC REGIONS (lowa)

Heavy black lines outline farm economic regions of Iowa as defined by the U.S. Department of Agriculture. Example: The northeast dairy region has 20.6 per cent of the farms and farm operators in the state. The Wallaces Farmer Poll therefore makes 20.6 per cent of its interviews in this region. 


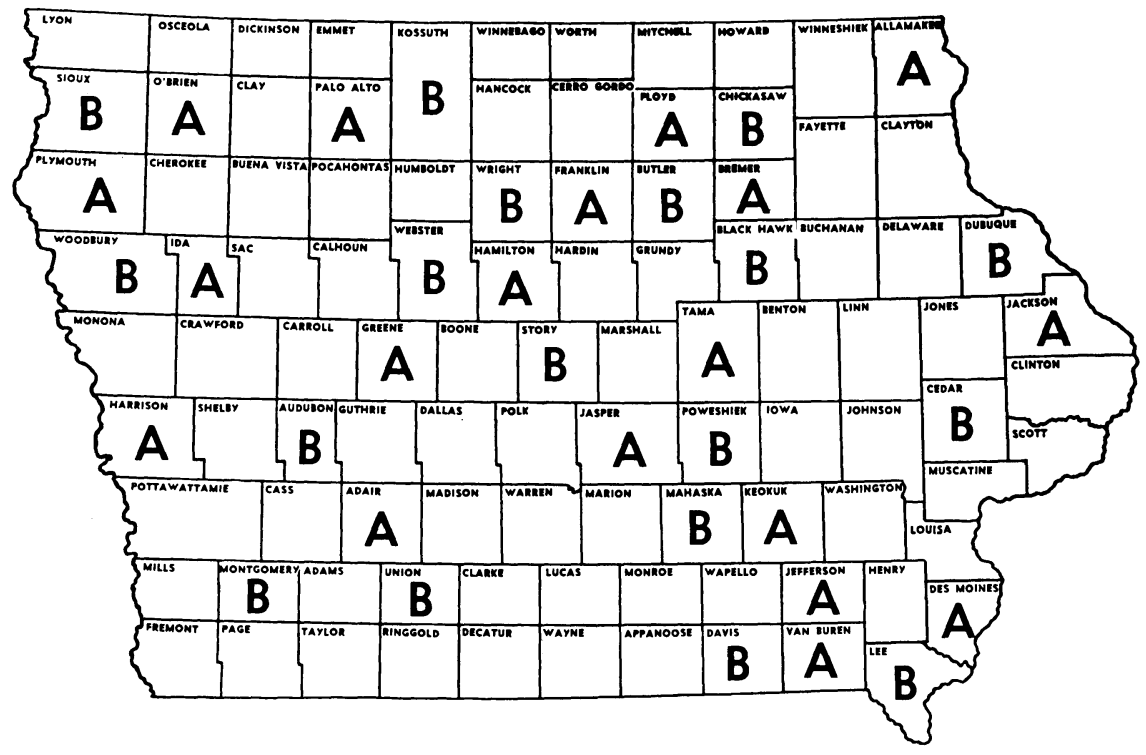

\section{WHERE INTERVIEWS WERE MADE}

Interviews were made in counties getting $A$ and $B$ copies as indicated above (for the issue of November 19, 1960). Assignments of A and B interviews are made with relation to the map showing economic regions. For example, interviews in the four A counties in the northeast section make up 20.6 per cent of the interviews in all the A counties. Likewise, interviews in the four B counties in the northeast also make up 20.6 per cent of the interviews in all the $\mathrm{B}$ counties. 


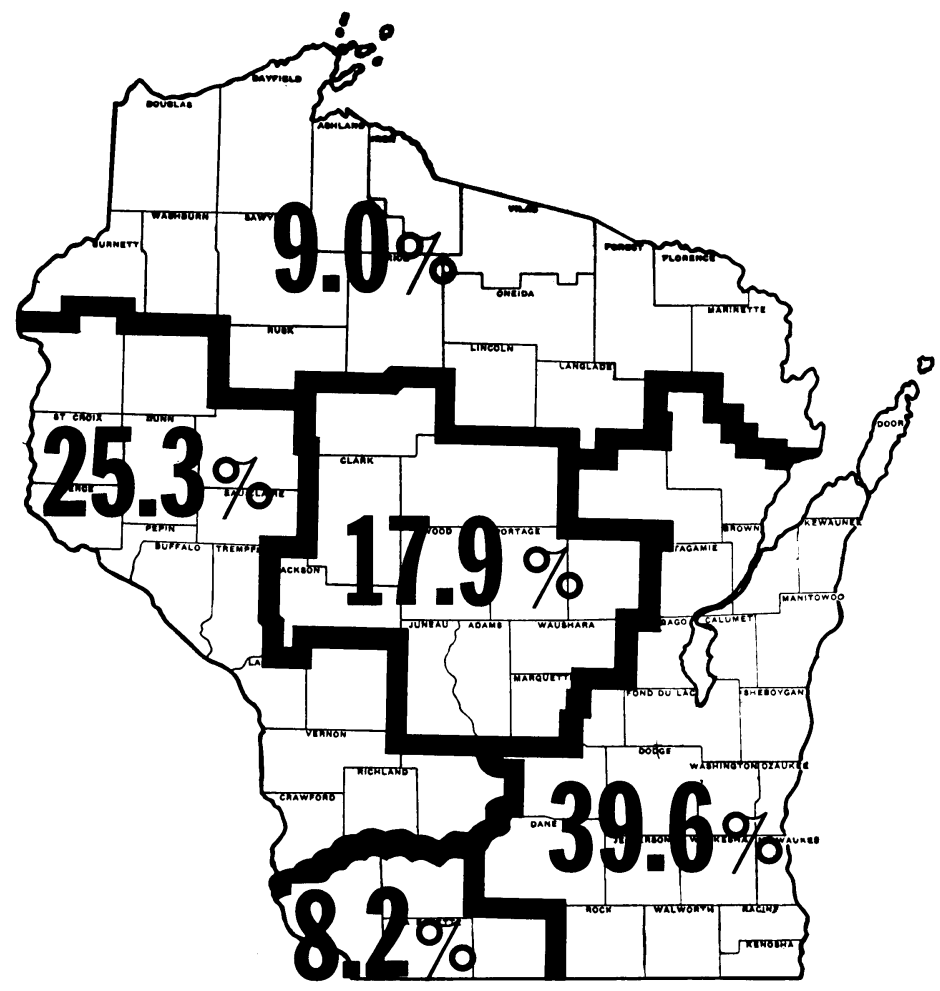

FARM ECONOMIC REGIONS (WISCONSIN)

Heavy black lines outline farm economic regions of Wisconsin as defined by the U.S. Department of Agriculture. Example: The southwest region has 8.2 per cent of the farms and farm operators in the state. Therefore the Wisconsin Agriculturist Poll interviews in this region were 8.2 per cent of the whole sample. 


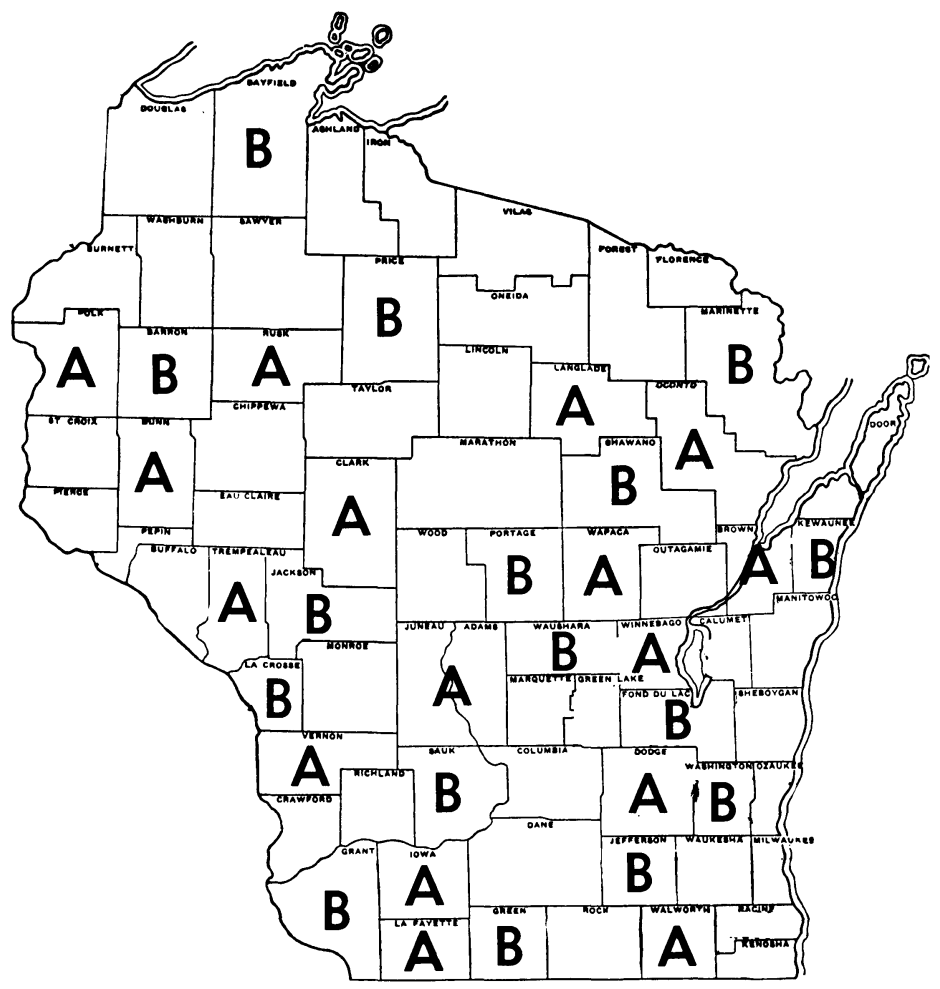

WHERE INTERVIEWS WERE MADE

Interviews were made in $\mathrm{A}$ and $\mathrm{B}$ counties (for the issue of October 7,1961$)$ as indicated above. Note that the southwest region has two A counties and two B counties. Interviews in the two A counties make up 8.2 per cent of the whole A sample. Interviews in the two B counties make up 8.2 per cent of the whole B sample. 


\section{6.}

\section{Reports on Split Runs and Market Analysis}

EXPERIMENTS LIKE THOSE DISGUSSED in this book are eventually summarized in the form of reports. Examples of two classes of the reports follow.

The first is the exact text of a report on a Bovitrin (Merck) advertisement which appeared in the October 3, 1959, issue of Wisconsin Agriculturist (See Figures $4.4,4.5)$. The second is the exact text of a report analyzing editorial research scores by reader characteristics in the February 4, 1961, issue of Wallaces Farmer.

Both reports were prepared by Richard J. Pommrehn, Director of Research for Wallaces Farmer, Wisconsin Agriculturist and Prairie Farmer. 


\section{Bovitrin (Merck) Advertisement \\ Page 26, October 3, 1959 issue \\ Wisconsin Agriculturist}

\section{PURPOSE OF SURVEY}

1. To measure readership of Ad A (test tube illustration) and Ad B (cow illustration).

2. To put questions to readers of the ad to determine sales appeals of different claims for the product.

\section{RESULTS}

A detailed report on the survey appears on the following pages. Below is a summary of the high points.

1. The B ad (cow picture) outscored the A ad (test tube picture). Bigger dairymen gave $B$ a marked advantage.

2. Strongest sales appeals were in "hits even remote and hidden pockets of infection," and "returns infected quarter to full production fast."

\section{SAMPLE}

The sample was made up of 200 men and 200 women interviewed on their Wisconsin farms. In distribution of interviews by economic sections of the state, the sample compares with census data as follows:

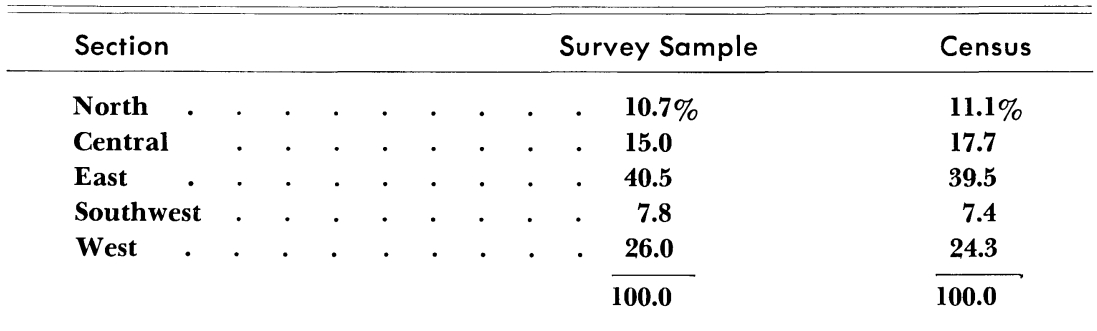

Interviews were made in the following 29 counties:

Barron, Bayfield, Brown, Buffalo, Crawford, Dodge, Dunn, Fond du Lac, Grant, Jackson, Jefferson, Juneau, Kewaunee, La Crosse, Langlade, Manitowoc, Marinette, Polk, Portage, Price, Sauk, Sawyer, St. Croix, Shawano, Taylor, Walworth, Waukesha, Winnebago, Wood. 
In distribution of owners and renters, the sample compares with the census as follows:

\begin{tabular}{lllllllllllll}
\hline \hline Tenure & & & & & & & Survey Sample & Census \\
\hline Owners & $\cdot$ & $\cdot$ & $\cdot$ & $\cdot$ & $\cdot$ & $\cdot$ & $\cdot$ & $\cdot$ & $\cdot$ & $86.7 \%$ & $85.5 \%$ \\
Renters $\cdot$ & $\cdot$ & $\cdot$ & $\cdot$ & $\cdot$ & $\cdot$ & $\cdot$ & $\cdot$ & $\cdot$ & $\frac{13.3}{100.0}$ & & 14.5 \\
\hline
\end{tabular}

Comparison of data on acreage of crops harvested follows:

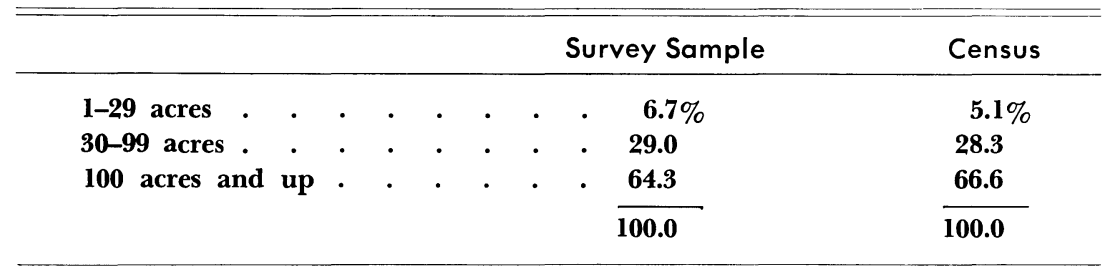

\section{METHOD}

Interviewers were sent to designated areas and called on farms where they conducted the usual reader-interest survey of the entire issue. The question asked was: "Did you HAPPEN to see or read anything on this page?" Information obtained by the interviewers was transferred to punch cards by IBM. 


\section{SPLIT RUN RESULTS}

Two ads were exposed to audiences of the same size and character. Ad A showed a picture of test tubes with this head, "New mastitis ointment employs remarkable drug to boost antibiotic efficiency." Ad B showed a picture of a man milking a cow with the head, "To reduce inflammation and let 3 antibiotics attack mastitis." Sales copy also differed.

$\mathrm{A}$ and $\mathrm{B}$ ads scored as follows:

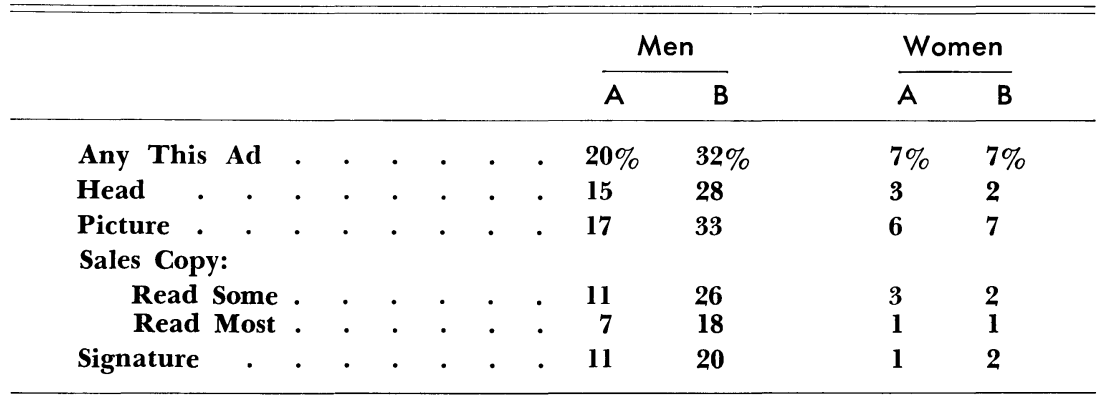

(Base is 100 interviews in each group - total of 400).

HOW TO READ: 17 per cent of all men readers of the $A$ issue looked at the picture in the $A$ ad. 33 per cent looked at the picture in the $B$ ad.

This looks as if the $B$ ad were making the best record. But further checks must be made. In the first place, do unchanged ads and copy in this issue in the dairy field score equally in $A$ and $B$ ? If unchanged copy scored higher in the $B$ version, then some doubt would be cast on the results above. Three dairy articles preceding the ad averaged scores of 51 Read Some for $A$ and 51 Read Some for B. A nearby dairy ad gave a slight advantage to $B$. The split, therefore, has passed this test on unchanged copy.

The next step is to see what readers were attracted by the ads. A man with no dairy cows may look at the ad, but this kind of readership will not increase sales.

Let's look first at how many farmers (men) had no cows, how many had from one to nine cows, etc.:

\begin{tabular}{|c|c|c|c|c|c|c|c|c|c|}
\hline \multicolumn{2}{|c|}{ No cows } & \multicolumn{2}{|c|}{$1-9$ cows } & \multicolumn{2}{|c|}{$10-19$ cows } & \multicolumn{2}{|c|}{$20-29$ cows } & \multicolumn{2}{|c|}{$\begin{array}{l}30 \text { cows } \\
\text { and up }\end{array}$} \\
\hline No. & $\%$ & No. & $\%$ & No. & $\%$ & No. & $\%$ & No. & $\%$ \\
\hline 37 & 18.8 & 20 & 10.1 & 52 & 26.4 & 55 & 27.9 & 33 & 16.8 \\
\hline
\end{tabular}


We will now see how the $\mathrm{A}$ and $\mathrm{B}$ ads appeal to farmers with different sizes of herds:

\begin{tabular}{|c|c|c|c|c|c|c|c|c|c|c|}
\hline & \multicolumn{2}{|c|}{ No cows } & \multicolumn{2}{|c|}{ 1-9 cows } & \multicolumn{2}{|c|}{$10-19$ cows } & \multicolumn{2}{|c|}{$20-29$ cows } & \multicolumn{2}{|c|}{30 and up } \\
\hline & $\mathrm{A}$ & B & $\mathrm{A}$ & B & A & B & $A$ & B & $A$ & B \\
\hline $\begin{array}{l}\text { Any } \\
\text { This }\end{array}$ & $\%$ & $\%$ & $\%$ & $\%$ & $\%$ & $\%$ & $\%$ & $\%$ & $\%$ & $\%$ \\
\hline Ad & 23.5 & 15.0 & 50.0 & 50.0 & 11.5 & 38.5 & 19.2 & 37.9 & 10.5 & 28.6 \\
\hline $\begin{array}{l}\text { Read } \\
\text { Some }\end{array}$ & 11.8 & 10.0 & 25.0 & 37.5 & 3.8 & 30.8 & 15.4 & 34.5 & 5.3 & 21.4 \\
\hline
\end{tabular}

HOW TO READ: Of farmers with 20-29 cows, 34.5 per cent Read Some of the B ad.

The $\mathrm{B}$ ad has a commanding lead in the sectors that count.

Another check sorts out farmers who have had mastitis in their herds from those who have had no trouble. The folks who had trouble are more likely to buy treatment for mastitis. This is the way the sample breaks down:

\begin{tabular}{|c|c|c|c|}
\hline \multicolumn{2}{|c|}{ Trouble with mastitis } & \multicolumn{2}{|c|}{ No trouble } \\
\hline No. & Per cent & No. & Per cent \\
\hline 87 & 55.4 & 70 & 44.6 \\
\hline
\end{tabular}

Over half of the farmers with dairy cows answered "Yes" to the question: "Have you had any trouble with mastitis in your dairy cattle in 1959?"

The farmers who answered "No trouble in 1959" may have had trouble before or may anticipate trouble in 1960. But the "Yes" group is, at the moment, more important to the advertiser. How did the two groups score?

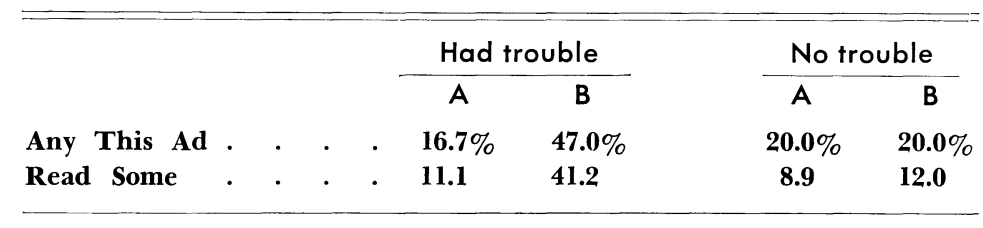

HOW TO READ: Of farmers who had trouble with mastitis in 1959, 41.2 per cent Read Some of the $B$ copy.

Again the B ad comes out ahead. 
Another check is on farmers who sell Grade A milk and those who do not. Here is the way farmers of each kind responded to the $A$ and $B$ ads.

\begin{tabular}{|c|c|c|c|c|c|c|c|c|}
\hline & & & & & \multicolumn{2}{|c|}{ Grade A sales } & \multicolumn{2}{|c|}{ Other } \\
\hline & & & & & $A$ & B & A & B \\
\hline Any This Ad & . & . & . & . & $4.2 \%$ & $42.4 \%$ & $25.0 \%$ & $30.6 \%$ \\
\hline Read Some . & . & . & . & . & 4.2 & 39.4 & 13.2 & 24.2 \\
\hline
\end{tabular}

This again puts $\mathrm{B}$ in the lead. Incidentally, 30.5 per cent of the whole sample sell Grade A milk.

What we don't know is which elements in the $\mathbf{B}$ ad made the difference. Since picture, head and copy were all changed, we can say no more than that the $B$ layout as a whole is superior to the A layout as a whole. We can guess, on the basis of past experience, that a test tube will attract fewer readers than a cow, but the experiment does not permit us to say how much weight should be given to this.

\section{TESTING SALES APPEAL OF DIFFERENT CLAIMS}

To each farmer who said he had looked at the ad, a question card was presented. This card said:

Since you looked at or read the Bovitrin ad on mastitis, we'd like to know which items (one or more) of the list below would be most likely to influence you to buy Bovitrin:

1. It contains a drug which boosts antibiotic action......... $9.6 \%$

2. It hits even the remote or hidden pockets of infection . . . . . 34.6

3. It returns infected quarter to full production fast . . . . . . . 36.5

4. It reduces udder inflammation and scar tissue ......... 5.8

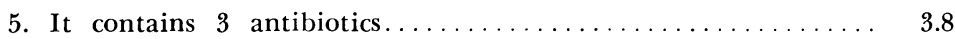

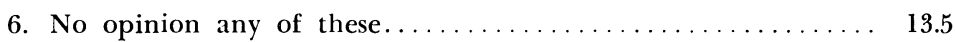

$A$ and $B$ readers voted alike. The items that got the biggest vote were 2 and 3 above. Since a few voted for more than one item, the total is over 100 per cent. 
Editorial Research Report, May 9, 1961

R. J. Pommrehn

Subject: February 4, 1961 issue, Wallaces Farmer

\section{EDITORIAL READERSHIP SCORES BY READER CHARACTERISTICS}

SCORES OF EDITORIAL ITEMS in the above issue have been broken down by reader characteristics in the usual attempt to determine the types of readers to whom we are appealing.

Both "Read Some" and "Read Most" scores have been used as the basis for cross-tabulations, but only one of these scores was used on any one article. The "Read Most" score was used on articles that seemed likely to receive high readership. "Read Some" scores were used on lower scoring articles. "Read Most" would certainly be the most important measurement, and it may be desirable to use "Read Most" scores as the basis for cross-tabulations on all future articles. However, this report seems to point up a slightly different pattern of readership between "Read Some" and "Read Most," and it indicates that "Read Some" scores cannot be completely overlooked.

Further analysis on this study and future studies might consider the reading habits of so-called "superior" farmers on the theory that we will be writing primarily for these people in the future. 


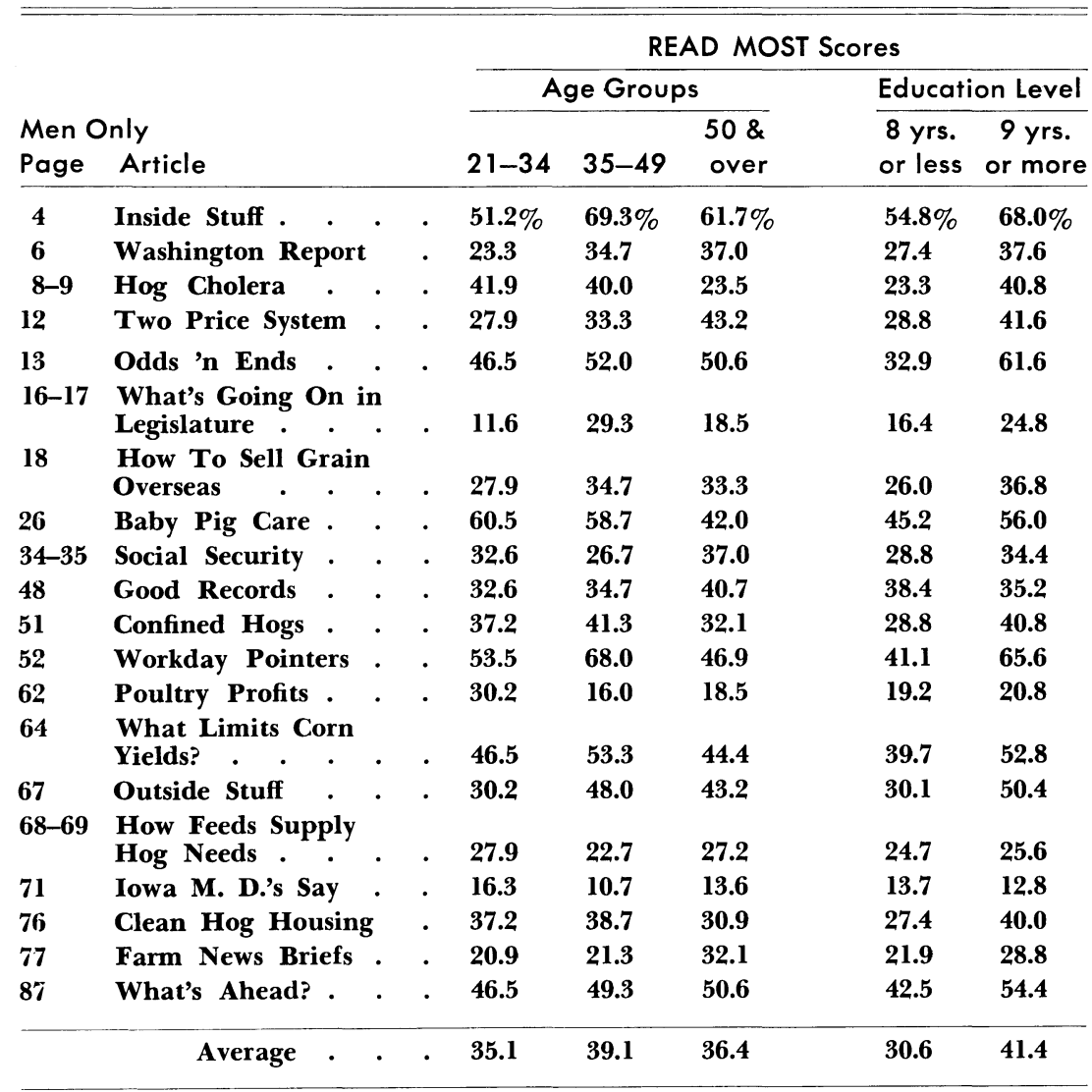

Average scores by age groups show little or no difference. Farmers with 9 or more years of education were better readers than those with less education. Another report being prepared on this study indicates that younger and middle-aged farmers are those who have been expanding their livestock and poultry operations and plan to continue. Articles on pages 26, 51, 62, and 76, which deal with hog and poultry operations, had their strongest appeal to younger and middle-aged farmers. More general articles appealed to older readers. 


\begin{tabular}{|c|c|c|c|c|c|c|c|}
\hline \multirow{3}{*}{\multicolumn{2}{|c|}{ Men Only }} & & \multicolumn{5}{|c|}{ READ SOME Scores } \\
\hline & & & \multicolumn{3}{|c|}{ Age Groups } & \multicolumn{2}{|c|}{ Education Level } \\
\hline & & & \multirow[b]{2}{*}{$21-34$} & \multirow{3}{*}{\multicolumn{2}{|c|}{\begin{tabular}{cc|}
$35-49$ & $\begin{array}{c}50 \& \\
\text { over }\end{array}$ \\
$69.3 \%$ & $60.5 \%$ \\
\end{tabular}}} & \multirow{3}{*}{$\begin{array}{c}8 \text { yrs. } \\
\text { or less } \\
54.8 \%\end{array}$} & \multirow{2}{*}{$\begin{array}{l}9 \text { yrs. } \\
\text { or more }\end{array}$} \\
\hline Page & Article & & & & & & \\
\hline 28 & Voice of the Farm & - & $39.5 \%$ & & & & $62.4 \%$ \\
\hline 30 & Passing of Passenger & . & 11.6 & 18.7 & 25.9 & $\ldots \ldots$ & $\ldots \ldots$ \\
\hline 36 & Safe Driving . & . & 32.6 & 38.7 & 48.1 & $\ldots \ldots$ & $\ldots$ \\
\hline 37 & Heat Lamps . . & . & 39.5 & 46.7 & 48.1 & $\ldots \ldots$ & $\ldots \ldots$ \\
\hline 38 & Voice of the Farm . & . & 51.2 & 69.3 & 55.6 & 52.1 & 64.0 \\
\hline 40 & Research Points . & . & 51.2 & 60.0 & $\mathbf{5 8 . 0}$ & 52.1 & 61.6 \\
\hline 42 & Water Storage & . & 30.2 & 36.0 & 46.9 & 37.0 & 40.0 \\
\hline 47 & Good Credit Risk . & . & 48.8 & 45.3 & 46.9 & 43.8 & 48.0 \\
\hline 50 & $\begin{array}{c}\text { Your Family's Good } \\
\text { Health }\end{array}$ & . & 23.3 & 28.0 & 21.0 & 21.9 & 26.4 \\
\hline 53 & Visits With Your Vet & . & 51.2 & 54.7 & 54.3 & $\ldots \ldots$ & $\ldots$ \\
\hline 58 & $\begin{array}{l}\text { Should School Size Be } \\
\text { Limited? }\end{array}$ & . & 39.5 & 52.0 & 54.3 & 42.5 & 55.0 \\
\hline 66 & $\begin{array}{l}\text { If Your Tax Gets } \\
\text { Checked }\end{array}$ & . & 37.2 & 53.3 & 56.8 & 54.8 & 48.8 \\
\hline 72 & $\begin{array}{l}\text { Insurance for } \\
\text { Hospital Bills }\end{array}$ & . & 25.6 & 33.3 & 49.4 & 39.7 & 36.8 \\
\hline 74 & Farm Business Report & . & 48.8 & 57.3 & 48.1 & 45.2 & 56.0 \\
\hline 86 & What's New? . . & . & 79.1 & 74.7 & 61.7 & 61.6 & 76.0 \\
\hline & Average & • & 40.6 & 49.2 & 49.0 & 46.0 & 52.3 \\
\hline
\end{tabular}

The articles, which may be somewhat marginal in reader interest, show on an average a higher appeal to middle-aged and older farmers than to younger farmers. Only "What's New?" showed a much stronger appeal to younger than to older farmers. This may be another indication of the importance of articles that will provide information on how to farm better and more efficiently to the younger group. In contrast with "Read Most" scores by education level which show higher reader interest by those with more education, "Read Some" scores on these articles show that education level made no difference in reader interest. To get a fair test, "Read Some" and "Read Most" scores should be analyzed on the same articles. This may be an indication that readers with less education "sample" an article, while those with more education are more likely to be thorough readers. 


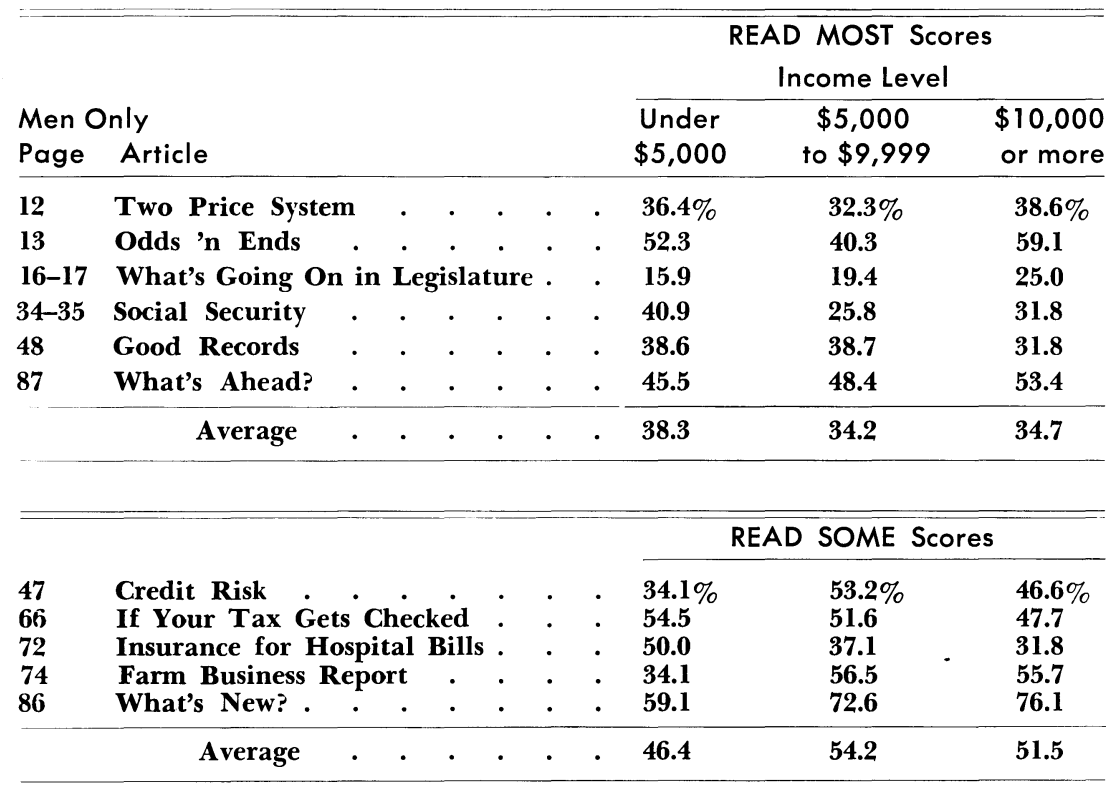

Neither "Read Most" nor "Read Some" scores show any striking differences by income level.

READ MOST Scores

Hogs Marketed in 1960

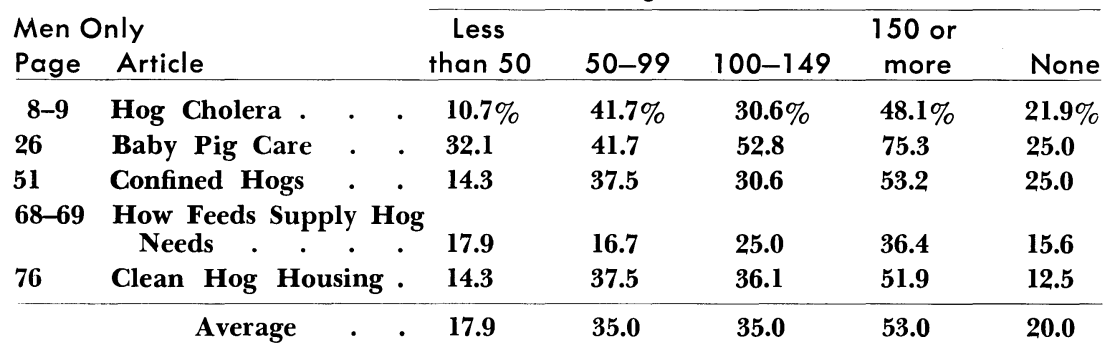

\section{READ SOME Scores}

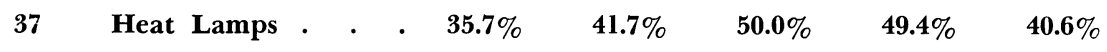




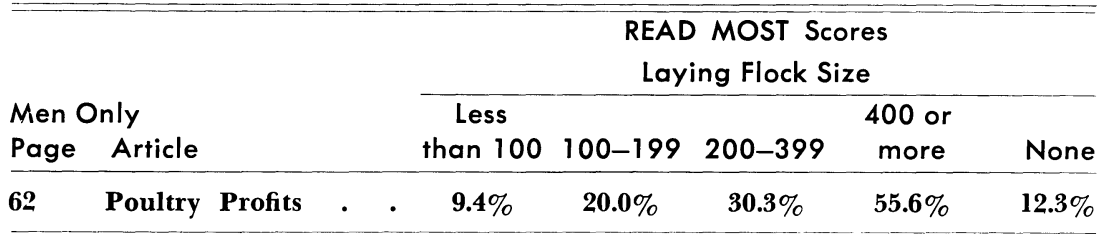

\begin{tabular}{|c|c|c|c|c|c|c|c|}
\hline \multirow{2}{*}{\multicolumn{2}{|c|}{ Men Only }} & & & \multicolumn{4}{|c|}{ READ MOST Scores } \\
\hline & & & & \multirow{2}{*}{$\begin{array}{l}1-49 \\
\text { Acres }\end{array}$} & \multirow{2}{*}{$\begin{array}{c}50-74 \\
\text { Acres }\end{array}$} & \multirow{2}{*}{$\begin{array}{l}75 \text { or } \\
\text { more }\end{array}$} & \multirow[b]{2}{*}{ None } \\
\hline Page & Article & & & & & & \\
\hline 64 & What Limits & Corn & Yields & $46.5 \%$ & $53.2 \%$ & $49.0 \%$ & $16.7 \%$ \\
\hline
\end{tabular}

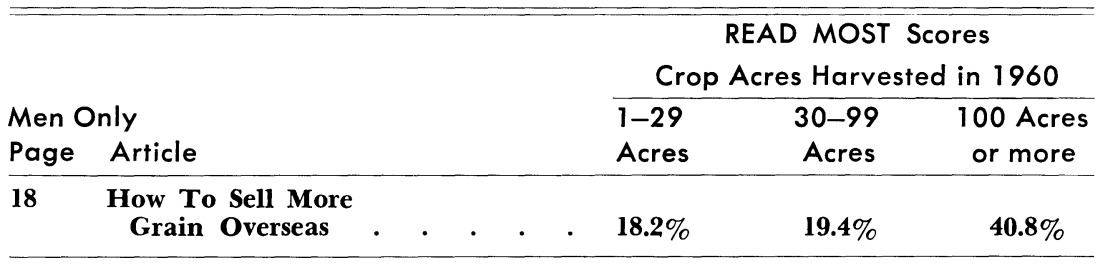

These scores indicate that the larger operators were the best readers.

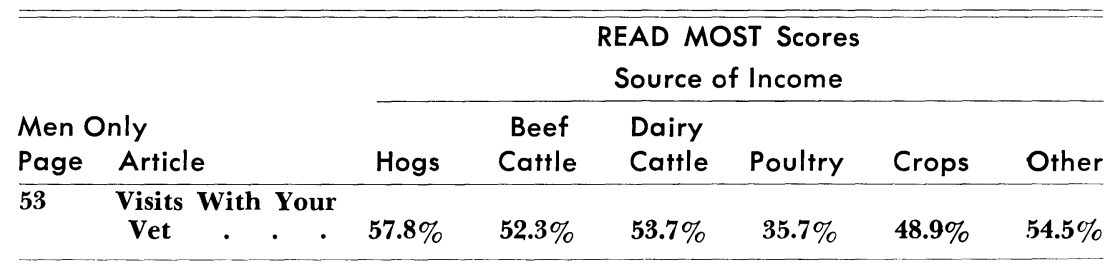




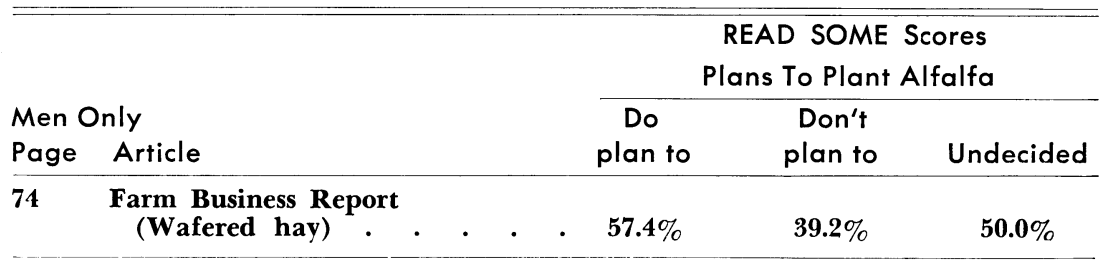

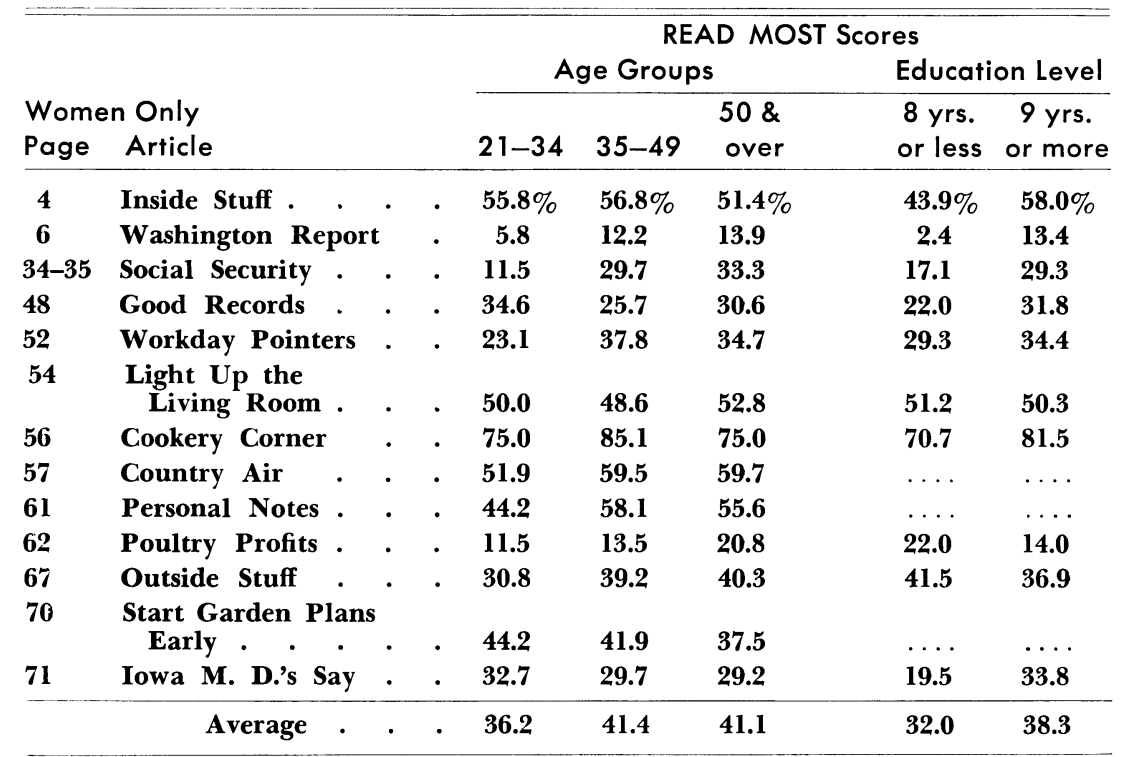




\begin{tabular}{|c|c|c|c|c|c|c|c|c|}
\hline & & & & & & D SON & res & \\
\hline & & & & & ge Group & & Educati & on Level \\
\hline $\begin{array}{l}\text { Wome } \\
\text { Page }\end{array}$ & $\begin{array}{l}\text { Only } \\
\text { Article }\end{array}$ & & & $21-34$ & $35-49$ & $\begin{array}{l}50 \& \\
\text { over }\end{array}$ & $\begin{array}{l}8 \text { yrs. } \\
\text { or less }\end{array}$ & $\begin{array}{l}9 \text { yrs. } \\
\text { or more }\end{array}$ \\
\hline 28 & Voice of the Farm & - & - & $32.7 \%$ & $\mathbf{5 0 . 0} \%$ & $45.8 \%$ & $29.3 \%$ & $48.4 \%$ \\
\hline 30 & Passing of Passenge & & - & 21.2 & 23.0 & 26.6 & $\ldots$ & $\ldots$ \\
\hline 36 & Safe Driving & - & - & 48.1 & 36.5 & 44.4 & $\ldots$ & $\ldots$ \\
\hline 38 & Voice of the Farm & - & . & 42.3 & 56.8 & 45.8 & 43.9 & 50.3 \\
\hline 40 & Research Points & - & . & 23.1 & 28.4 & 36.1 & 31.7 & 29.9 \\
\hline 42 & Water Storage . & . & . & 17.3 & 20.3 & 15.3 & 7.3 & 21.0 \\
\hline 47 & Credit Risk . . & • & - & 32.7 & 32.4 & 27.8 & 14.6 & 35.7 \\
\hline 50 & $\begin{array}{l}\text { Your Family's Good } \\
\text { Health } . \text {. }\end{array}$ & d & - & 42.3 & 47.3 & 45.8 & 26.8 & 50.3 \\
\hline 58 & $\begin{array}{l}\text { Should School Size } \\
\text { Limited? }\end{array}$ & $\begin{array}{l}\text { Be } \\
\text {. }\end{array}$ & - & 53.8 & 66.2 & 65.3 & 56.1 & 64.3 \\
\hline 66 & $\begin{array}{l}\text { If Your Tax Gets } \\
\text { Checked }\end{array}$ & . & - & 32.7 & 44.6 & 50.0 & 31.7 & 47.1 \\
\hline 72 & $\begin{array}{l}\text { Insurance for Hosp } \\
\text { Bills . }\end{array}$ & pital & . & 51.9 & 52.7 & 63.9 & 46.3 & 59.2 \\
\hline 86 & What's New? & . & . & 32.7 & 27.0 & 29.2 & 29.3 & 29.9 \\
\hline & Average & . & $e^{-}$ & 35.9 & 40.4 & 41.3 & 31.7 & 43.6 \\
\hline
\end{tabular}

Average "Read Some" and "Read Most" scores by age groups for women on selected items throughout the magazine show the same pattern - a fairly even level of interest with a possible slight advantage for middle-aged and older women. Women with the most education were the best readers.

\begin{tabular}{|c|c|c|c|c|c|c|c|c|}
\hline \multirow{2}{*}{\multicolumn{2}{|c|}{ Women Only }} & & & \multicolumn{5}{|c|}{$\begin{array}{l}\text { READ MOST Scores } \\
\text { Laying Flock Size }\end{array}$} \\
\hline & & & & \multicolumn{2}{|l|}{ Less } & \multicolumn{3}{|c|}{400} \\
\hline Page & Article & & & than 100 & $100-199$ & 200-399 & or more & None \\
\hline 62 & Poultry & Profits & . & $18.0 \%$ & $9.7 \%$ & $27.8 \%$ & $31.8 \%$ & $\mathbf{3 . 6} \%$ \\
\hline
\end{tabular}




\begin{tabular}{|c|c|c|c|c|c|c|c|c|c|c|}
\hline \multirow{2}{*}{\multicolumn{5}{|c|}{ Women Only }} & & & & \multicolumn{3}{|c|}{$\begin{array}{l}\text { READ MOST Scores } \\
\text { Income Level }\end{array}$} \\
\hline & & & & & & & & \multirow{2}{*}{$\begin{array}{l}\text { Under } \\
\$ 5,000\end{array}$} & \multirow{2}{*}{$\begin{array}{c}\$ 5,000 \\
\text { to } \$ 9,999\end{array}$} & \multirow{2}{*}{$\begin{array}{l}\$ 10,000 \\
\text { or more }\end{array}$} \\
\hline Page & Articl & & & & & & & & & \\
\hline 13 & Odds & 'n Ends & - & . & $\cdot$ & . & . & $17.1 \%$ & $22.2 \%$ & $25.3 \%$ \\
\hline $34-35$ & Social & 1 Security & . & . & . & . & . & 29.3 & 27.8 & 21.3 \\
\hline 48 & Good & Records & . & . & . & . & . & 29.3 & 31.9 & 28.0 \\
\hline \multirow[t]{2}{*}{54} & Light & Up the & Living & Room & . & . & . & 48.8 & 48.6 & 54.7 \\
\hline & & Average & . & . & $\cdot$ & . & . & 31.1 & 32.6 & 32.3 \\
\hline
\end{tabular}

\begin{tabular}{|c|c|c|c|c|c|c|c|c|c|c|}
\hline \multirow[b]{2}{*}{47} & \multirow[b]{2}{*}{ Credit Risk } & \multirow[b]{2}{*}{. } & \multirow[b]{2}{*}{. . } & \multirow[b]{2}{*}{. } & \multirow[b]{2}{*}{. } & \multirow[b]{2}{*}{. } & \multirow[b]{2}{*}{. } & \multicolumn{3}{|c|}{ READ SOME Scores } \\
\hline & & & & & & & & $24.4 \%$ & $38.9 \%$ & $\mathbf{2 6 . 7 \%}$ \\
\hline 66 & If Your Tax & Gets & s Chec & ked & . & . & . & 48.8 & 43.1 & 41.3 \\
\hline 72 & Insurance for & Ho & sspital & Bills & . & . & . & 48.8 & 55.6 & 60.0 \\
\hline \multirow[t]{2}{*}{86} & What's New? & . & .. & • & . & - & . & 34.1 & 27.8 & 33.3 \\
\hline & Averag & & . & . & . & . & . & 39.0 & 41.3 & 40.3 \\
\hline
\end{tabular}

Average scores by income levels were the same on these articles, but individual articles did not all follow the pattern.

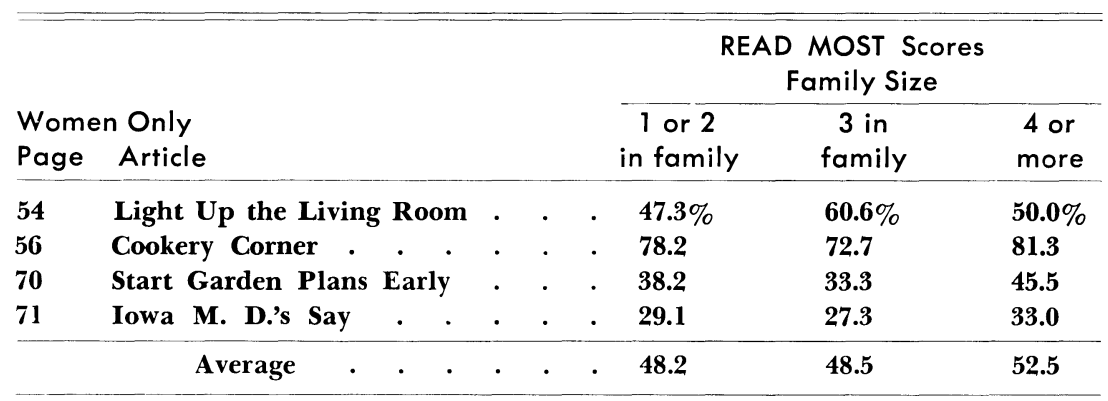

On an average, family size had little, if any, effect on reader interest in these articles. 


\section{Notes to Citations}

\section{CHAPTER 1}

(1) Advertising Research Foundation: Study No. 4, Wallaces Farmer and Iowa Homestead (Continuing Study of Farm Publications). September 20, 1947.

(2) Statistical Laboratory, Iowa State University: "InFARMation Please," No. 1, 1947; No. 2, 1951; No. 3, 1955. Wallaces Farmer, Des Moines, Iowa.

(3) Kearl, Bryant, "The Non-Reader in a Magazine Readership Survey." Journalism Quarterly, Fall, 1957.

(4) Lyman, Howard B., "Flesch Count and Readership of Articles." Journal of Applied Psychology, February, 1949.

(5) Ludwig, Merrit C., "Hard Words and Human Interest; Their Effects on Readership." Journalism Quarterly, June, 1949.

(6) Flesch, Rudolph, The Art of Readable Writing. Harpers, 1949.

\section{CHAPTER 2}

(1) Savage, Job K., Jr.: Effectiveness of the Midland Cooperator. Farmers Cooperative Service, U.S. Department of Agriculture; October 1, 1956.

(2) Advertising Research Foundation, loc. cit.

\section{CHAPTER 3}

(1) Pommrehn, Richard J., "Black and White Versus Color." Research Department Report, Wallaces Farmer, 1956.

(2) Freeman, Chester H.: Attention and Retention Value of Color. Communication Bulletin No. 1, Cornell University, October, 1960. 


\section{CHAPTER 4}

(1) For a helpful discussion of these and many other points in photography, see Fox and Kerns: Creative News Photography.

(2) Pommrehn, Richard J.: Split-run Readership Test as a Means of Increasing Ad Readership. MSS. M.A. thesis, Drake University, 1953.

(3) Research Department, Curtis Publishing Company: Magazine Editorial Research, Curtis Publishing Company, 1956.

(4) These and other statements at the end of chapters have too dogmatic and self-assured an air. Yet it is boring to say every time, "This conclusion is based on several experiments which seem to me to indicate a tendency in the direction of the statement here presented. I recognize that further experiments may change the picture. I also admit that subjective bias (often unrecognized as such) has probably played a part in the framing of this recommendation. In short, this is as much as I think I know today. It is not the last word on the subject, but it is probably a better word than I could produce if I hadn't run these tests."

\section{CHAPTER 5}

(1) Murphy, Donald R., "Page Position and Readership on a Farm Magazine.” Journalism Quarterly, Fall, 1957.

\section{CHAPTER 6}

(1) Felstenhausen, Herman: MSS. Department of Agricultural Journalism, University of Wisconsin, 1961.

\section{CHAPTER 7}

(1) Discussion of the relationship of editorial copy to advertisements is particularly sharp in the field of television. While most publications reserve for themselves the right to select all editorial copy, many television advertisers insist on controlling the programs in which their advertisements appear. Associated Press (September 27, 1961) reported a hearing before the Federal Communications Commission and noted that one director of advertising said his company "reviewed scripts for TV to make sure what we were doing and what we were saying were in the best interests of our corporation." Another advertiser took a different view and said that his company "had no voice in the subject matter, production techniques and casting of plays, but left those matters to the producers." This latter position is, of course, the point of view of most publishers and editors of magazines.

(2) Murphy, Donald R., "Position Next to Dull or Dandy Matter," Printers' Ink, August 24, 1951. 


\section{CHAPTER 8}

(1) For more discussion on this point, see Murphy, Donald R., "Farm Paper Study Goes Beyond Readership, Checks Ability To Reach Buyers." Advertising Age, May 29, 1961.

\section{CHAPTER 10}

(1) The need of measuring "areas of national ignorance" was pointed out by Elmo Roper, in Fortune, February, 1942. He said, "During my eight years of asking the common man questions about what he thinks and what he wants I have often been surprised and disappointed to discover that he has less information than we think he should have about some question we consider important. . . I believe the first duty (of public opinion research) is to explore the areas of public ignorance somewhat as we have tried to do in the survey on labor. . . . By experimenting further now in finding out what things people misunderstand or don't know, we shall be able to discount 'public opinion' that stands on a base of ignorance. And we shall be able to define in most specific terms the work to be done by our educators and thought leaders, now and in the future."

\section{CHAPTER 11}

(1) Statistical Laboratory, Iowa State University, loc. cit.

\section{CHAPTER 12}

(1) Murphy, Donald R., "Do Farmers Believe What They Read?" Journalism Quarterly, Winter, 1960.

\section{CHAPTER 13}

(1) Johnson, Glenn, "New Knowledge of Decision Making Process." Journal of Farm Economics, December, 1958.

(2) On this point, Charles K. Ramond, Technical Director, Advertising Research Foundation, commented in an address (January 26, 1960) before the Toronto chapter of the American Marketing Association. Raymond said that "fear of experimentation is a natural distaste for any approach which appears to reduce experienced cxecutive judgment to mathematical formulae. This is mainly due to a failure to understand the true function of the experimental method. It can never replace judgement; it can only narrow the range of uncertainty within which such judgment must always act. The question is not whether decisions can be better made by computers or by human beings. The question is whether human beings can make decisions better with or without the help of computers and experimentation." 


\section{CHAPTER 14}

(1) Hinkle, Lawrence E., Jr., "Communist Manipulation of Behavior." Science, June 16, 1961.

(2) Boulding, Kenneth E., "Reflections on Poverty." Address before National Conference on Social Welfare, Minneapolis, Minnesota, May 15, 1961.

\section{SURVEY METHODS}

(1) Light on the makeup of the subscription list of Wallaces Farmer came from three name-matching studies conducted by the U.S. Bureau of the Census. In the 1954 study, for instance, 1937 names of subscribers were matched with census data secured for these same names. The census study indicated that subscribers to Wallaces Farmer had slightly larger farms (190.0 acres to 176.5 acres) than the average Iowa farmer. The Iowa farm subscriber also had somewhat more valuable land and buildings $(\$ 39,738$ to $\$ 36,090)$.

(2) Jones, Robert L., "Methodological Improvements in Readership Data Gathering." Journalism Quarterly, Summer, 1953. 


\section{Books To Read}

BOOKS LISTED BELOW have been useful in our editorial research. Also useful have been articles in Advertising Age, American Journal of Sociology, Journal of Applied Psychology, Journal of Farm Economics, Journalism Quarterly, Public Opinion Quarterly and Printers' Ink.

Adorno, T. W.: Authoritarian Personality. Harpers, N. Y., 1950. Allport, Gordon W.: Nature of Prejudice. Doubleday, N.Y., 1954.

Allport, Gordon W., and Postman, Leo: The Psychology of Rumor. Henry Holt, N. Y., 1947.

Anderson, Harold H., and Anderson, Gladys L.: An Introduction to Projective Techniques. Prentice-Hall, N. Y., 1951.

Berelson, Bernard R., Lazarsfeld, Paul F., and McPhee, William N.: Voting: A Study of Opinion Formation in a Presidential Campaign. University of Chicago Press, Chicago, 1954.

Blankenship, Albert B.: How To Conduct Consumer and Opinion Research. Harper \& Brothers, N. Y., 1946.

Campbell, Angus, Gurin, Gerald, and Miller, Warren E.: The Voter Decides. Row, Peterson, White Plains, N. Y., 1954.

Cantril, Hadley: Gauging Public Opinion. Princeton University Press, Princeton, 1944.

Charnley, Mitchell V., and Converse, Blair: Magazine Writing and Editing. Gordon, N. Y., 1938.

Fox, Rodney, and Kerns, Robert: Creative News Photography. Iowa State University Press, Ames, 1961.

Hovland, Carl I., Janis, Irving L., and Kelley, Harold H.: Communication and Persuasion. Yale University Press, New Haven, 1953.

Hovland, Carl I., Mandell, Wallace, Campbell, Enid H., Brock, Timothy, Luchins, Abraham S., Cohen, Arthur R., McGuire, William J., Janis, Irving L., Feierabend, Rosalind L., and Anderson, Norman H.: The Order of Presentation in Persuasion. Yale University Press, New Haven, 1957.

Hyman, Herbert H.: Interviewing in Social Research. University of Chicago Press, Chicago, 1954.

Katz, Elihu, and Lazarsfeld, Paul F.: Personal Influence. Free Press, Glencoe, Ill., 1955. 
Klapper, Joseph T.: The Effects of Mass Communication. Free Press, Glencoe, Ill., 1960.

Klare, George R., and Buck, Byron: Know Your Reader. Hermitage House, N. Y., 1954.

Lasswell, Harold D., and Leites, Nathan: The Language of Politics. Stewart, N. Y., 1949.

Lazarsfeld, Paul F., Berelson, Bernard, and Gaudet, Hazel: The People's Choice. Duell, Sloan and Pearce, N. Y., 1944.

Lazarsfeld, Paul F., and Rosenberg, Morris: The Language of Social Research. Free Press, Glencoe, Ill., 1955.

Lazarsfeld, Paul F., and Stanton, Frank: Communications Research, 1948-1949. Harper \& Brothers, N. Y., 1949.

Lerner, Daniel, and Lasswell, Harold D.: Policy Sciences: Recent Development in Scope and Method. Stanford University Press, Stanford, Calif., 1951.

Lionberger, Herbert F.: Adoption of New Ideas and Practices. Iowa State University Press, Ames, 1962.

Mainland, Donald: Tables for Use With Binomial Samples. New York University, New York, 1956.

Mencken, H. L.: The American Language. Supplement One; Supplement Two. A. Knopf, N. Y., 1936, 1945, 1948.

Osgood, Charles E., Suci, George J., and Tannenbaum, Percy H.: The Measurement of Meaning. University of Illinois Press, Urbana, 1957.

Schramm, Wilbur: Communications in Modern Society. University of Illinois Press, Urbana, 1948.

Schramm, Wilbur: Mass Communications. University of Illinois Press, Urbana, 1949.

Schramm, Wilbur: The Process and Effects of Mass Communication. University of Illinois Press, Urbana, 1955.

Smith, M. Brewster, Bruner, Jerome S., and White, Robert W.: Opinions and Personality. John Wiley \& Sons, Inc., N. Y., 1956.

Smith, George Horsley: Motivation Research in Advertising and Marketing. McGraw-Hill Book Co., Inc., N. Y., 1954.

Stouffer, Samuel A.: The American Soldier, Vols. 1-4. Princeton University Press, Princeton, 1949.

Stouffer, Samuel A.: Communism, Conformity, and Civil Liberties. Doubleday \& Company, Inc., N. Y., 1955.

Waples, Douglas, Berelson, Bernard, and Bradshaw, Franklyn R.: What Reading Does to People. University of Chicago Press, Chicago, 1940. 


\section{Index}

Ad appeal to farmers with different sizes of dairy herds, 226

Adorno, T. W., 241

Advertisement for cattle feeders, 125, 138

cereal, 44

for corn shellers, 125

dairy feed, 135

farm machinery, 142

flour, 136, 140

hog feed, 49-51, 124

mastitis, 226

milker, 141

position, 123

possible scores, 13

scores related to editorial scores, 116,117

Advertising Age, 239

Advertising Research Foundation, $14,15,239$

Age groups

readership by, 131, 132, 198, 233, 234

response to articles, 229-30

Agri-Vision, score of, 181

Albrecht, Richard, 6

Allied Chemical, 100

Allport, Gordon W., 241

Anderson, Gladys L., 241

Anderson, Norman H., 242

“Any This Ad," defined, 13

"Any This Article," defined, 13

Art of Plain Talk, 19

Art of Readable Writing, scoring system, 21

Art work in color, 49
Articles

look alike, score differently, 26 plugged versus non-plugged, 115 poll, rank high, 160

readership scores in issue, 228-35

Aureomycin ad, 138

Babson Brothers ad, 141

Balloon, use of in ad, 137

Bean, Louis, 7

Beef, cooking of, 176, 186

Benson, Ezra Taft, farm opinion on, 114,154

Berelson, Bernard R., 241

Better Homes and Gardens, 194

Blankenship, Albert B., 241

Boulding, Kenneth E., 205, 240

Bovitrin (Merck) split, 74, 75, 128, 223-27

Boxes, 113, 114, 115, 120, 121, 159

Bradshaw, Franklyn R., 243

Brock, Timothy, 242

Bryant, David, 6

Buck, Byron, 242

Bruner, Jerome S., 243

Bucka, Clara, 7

Campbell, Angus, 241

Campbell, Enid H., 242

Cantril, Hadley, 242

Cappers Farmer, 195

Captions, type size for use on cover, 35

Cartoons, on editorial page, 82,83

Census, comparison with survey sample, 210, 211 
Certified Alfalfa Seed Council, 64

Charnley, Mitchell V., 242

Circulation of farm papers, 203

Cohen, Arthur R., 242

Color, 43-60

art decorations in red, 48, 58, 59

four color, 47

heads, 52-55

Murphy ad, 49, 50, 51

Nutrena ad, 44

overprint, 45,46

Quaker Oats ad, 44, 56, 57

red screen, 47

studies of 11 ad splits in color, 46

yellow screen, 47

Command or question heads, 97, 106

Contents, table of, 115, 122

Continuing Study of Farm Publications, 14, 15, 239

Contract or integrated farming, 152 page score on, 159

Control articles on split runs, 215, 225

Converse, Blair, 242

Cookies, in Robin Hood ad, 140

Cook's Corner, 68

Copy

easy reading important, 187

how to write, 21

personalized dirt vs. desk copy, 112

testimonial, 187

\section{Corn}

acres, response to ad by big corn farmers, 142

response of small and big corn growers to ad, 126

acres harvested, response by farm groups, 232

cover picture, picking, 35

hybrid, 157, 158, 202

overproduction, 158

response to John Deere ad, 128

silage, 91

thickness of planting, transposed article, 92, 93
Cornell University, 46, 237

Corona, type face, 109

Country Gentleman, 195

Covers, 29-42

corn picking picture, 35

importance of, 29, 31

material, 34,35

plugs, 115

pull readers, 36

scores, 32, 33, 37, 38, 39, 40, 41

split, 36, 38, 39, 40, 41, 76, 77

timely theme, 35

type size in caption, 35

women's scores on, 32

Crop acres harvested

readers by, 197, 224

response by farm groups, 232

Curtis Publishing Company, 69, 238

Cutlines, see captions

Dairy cows, size of herd, 141, 225

Dairy farmers, response to ad, 141, 225-26

Decorations and color, 58, 59

Deere, John, ad, 128, 142

Defense, civil, transposed article, :93

Dirt copy, treatment of, 111, 112, 113

Drake University, 238

Eastman, Roy, ad vs. reading matter, 116,117

Economic classes, by census, 192

Economic regions, 209

Jowa, 218

Wisconsin, 220

Editorial copy too interesting, 116, 117

Editorial page

survey on, 25

type size test, 110

Editorial research report, 228-35

Editors, 200-8 points for, 158

Education, readership by, 132, 133, $145,160,229,230$

Election, survey figures on, 71, 212

Enthusiastic readers, 173

Experiments in readership, 107-23 
Family size, response by groups, 129, 235

Farm Bureau, Iowa Federation, on constitutional convention, 151

Farm magazines, see farm papers

Farm papers changes in, 188 number taken, 126 sources of information, 189

Farm women, response to articles, $28,52,53,140,233-34$

Farmers, part-time and retired, reading by, 133, 191

Feiersbend, Rosalind L., 242

Felstenhausen, Herman, test of profit motive in splits, 100, 101, 238

Fertilizer, transposed articles on, 37, 153

Flesch, Rudolph, readability formula, 19, 20, 21, 22, 23, 24 easy reading copy, 187, 237

splits using Flesch formula, 19, 20

Folks who read your ad or article, 124-42

Ford tractor ad, 130

Fortune, 239

Fox, Rodney, 7, 238, 242 on photo composition, 66

Freeman, Chester H., 237

Gallup, George “Ted," readership surveys, 12

Gaudet, Hazel, 242

Giffin, Prof. Roscoe, 15

Ginsberg, Jean, 6

Gregory, Clifford, 6

Groves, Bill, 132

Gurin, Gerald, 241

Headline, in split run, 40, 41

Headlines, profit motive in, 106

Heads, 95-106

accuracy of scores, 96

in color, 49

command or statement, 97, 106

profit motive in, 100, 101, 106

question, 97, 103
Heath, Harry, 7

Hinkle, Lawrence E., Jr., 204, 240

Hog prices

editorial on, 25

low prices hurt, 169

may pull in non-readers, 149

Hogs

marketed, response by farm groups, 127, 139, 231

number sold, 127

supports asked, 165

Home Department, 28, 168, 176, 186

Hormones, in profit motive head, 103

Hovland, Carl I., 242

Hyman, Herbert H., 242

IBM, 224

Ignorance, areas of, 151-53, 239

Illustrations, $61-83$

cartoons, 63, 82, 83

cow vs. test tube, 74,75

cutout, 81,82

farm people in work clothes, 69

hog feed ad, 67

local angle, 63

man vs. hogs, 76,77

photograph vs. drawing, $64,72,73$

size of, 61,64

thumbnail cuts, 78,79

Income, effect on readership, 25, $131,141,198,231,235$

Indifference, areas of, 151-53, 239

InFARMation Please, report on, $161-64,188$

Information, sources of, 161-64, 189

Integrated farming, see contract farming, 152

"Intention-to-plant" surveys, 211

Interviewers

farm women for Wallaces Farmer Poll, 12, 213

use of questions, 224

Janis, Irving L., 242

Jessen, Raymond, 7

Johnson, Glenn, 189, 239

Jones, Robert L., 214, 240

Journal of Farm Economics, 239, 241 
Journalism Quarterly, 237, 238, McPhee, William N., 241 239,240

Jumps, why avoid, 16 splits on, 17

Katz, Elihu, 242

Kearl, Bryant, 3, 7 on non-readers, 16,237

Kelley, Harold H., 242

Kerns, Robert, 238, 242

Kewanee advertisement, 197

Khrushchev's visit, poll on, 34

King, Arnold, 7

King Midas ad, 129, 136, 137

Klapper, Joseph T., 242

Klare, George R., 242

Klinger, David, 6

Language, second, effect on readers, 147

Lasswell, Harold D., 242

Lazarsfeld, Paul F., 241, 242

Leites, Nathan, 242

Lerner, Daniel, 243

Letters to the editor, 12

Lighting in home, 168

Lionberger, Herbert F., 243

Luchins, Abraham S., 242

Ludwig, Merrit C., 237

Lyman, Howard B., 237

Magazines, general, number taken by farmers, 145 nonfarm, 29

Mail polls, on pre-test of subjects, 155

Mainland, Donald, 243

Mandell, Wallace, 242

Market analysis, defined, 24, 25, 124 shows whether ad or article reached folks at whom copy was aimed, 134

Marvin, Kenneth, 7

Mastitis

farmers having trouble with, 129 herds affected, 226 split on treatment, 74,75

McCall's magazine, 194

McGuire, William J., 242

Meat, cooking of, 177

Men

cover score, 37, 38, 39, 40, 41, 42

scores using color in ads, 50, 51, 116

young farmers, 131, 132

Mencken, H. L., 243

Merck (Bovitrin), 74, 75, 128, 22327

Methods, survey, 209-21

change in, 213

checking against census data, 211

control articles, 215

interviewer problems, 213

rural-farm adults, 212

split runs, 215

what kind of voters, 212

Midland Cooperator, non-readers of, 30

Milk output, transposed article, 94

Miller, Warren E., 241

Minneapolis Tribune poll, 110

Minnesota poll, 110

MoorMan's color split, 54,55

hog feed score, 178, 179, 182, 183

Murphy, D. B., 7

Murphy Products Company, color split, 49, 50, 51

Nafziger, Ralph O., 7

Nitrogen, in split on head, 104, 105

Non-readers, 143-49

converting, 148

defined, 16, 143

education of, 144

effect of second language, 146

hogs may pull in, 149

in 1940 and 1960,107

problems of, $29 \mathrm{ff}$., $143-49$

with three or more farm papers, 145

with three or more general magazines, 145

Nutrena, 44

Oliver ad, 125, 126

Opinion polls and readership, 15060 
Opinion surveys

Benson, 154

constitutional convention, 151

contract farming, 152, 154

election, 212

Lebanon, Jordan, and Middle East, 155

"liquor by the drink," 150

lockjaw, 152

milk quotas, 153

polls, 150-58

Quemoy and Matsu, 154

sample size, 14

Osgood, Charles E., 243

Overprint in color, 49

Owners and renters in survey sample, 224

Page one, see covers, front, 29-42

Paragon, type face, 109

Part-time farmers, 133

Photograph outpulls drawing, 72 cartoon vs. photo, 82,83 outpulls box, 123, 159

Pig, baby, 149

Plugs

to attract women, 35

effect on article plugged, 33

table of contents, 122

value of, $31,33,34,35$

Polls, see opinion surveys

Pommrehn, Richard J., 6, 7, 46, 222, 237, 238

Position, page, 85-94

transposed fertilizer articles, 87

weakness shown in back of magazine, 86

Postman, Leo, 241

Poultry flock size, response by, 232, 234

Prairie Farmer Experiment, 12

Pre-election polls, 71, 212

Pre-test of subjects, 155, 156, 157

helps editor check interests of subscribers, 157, 195, 201

Printers Ink, 116, 238

Production, information on, 161-61, 189
Profit motive, in heads, 100, 101, 106

Protein Blenders ad, 128, 138, 139

cattle feed ad, 135

hog feed ad, 127

photograph outscores drawing, $72-73$

square cut vs. cutout, 80,81

Quaker Oats, color split, 44, 56, 57

Question cards, use of, $171 \mathrm{ff}$.

Question heads, 97, 103

Quotas, poll on, 153

Ramond, Charles K., 239

Ratner, Joe, on readership, 200

"Read Most," defined, 13

scores, 227, 229, 231, 232, 233, 234, 235

scores compared, 15

"Read Some," defined, 13

scores, 226, 227, 230, 231, 233, 234,235

Reader, 11, 13, 16

Readers

per copy, 14, 15, 239

what kind, 124-42

Readership score, meaning, 13

key question, 13

Readership surveys

bigger type helped, 118

color splits, $45,47,48,58,59$

contract farming, 159

cover splits, 29-36

editorial page, 25

effect of crises, 108

farm records, 198

food page, 28

Gallup and Roper, 12

getting started, 11

high school marriages, 156

limits of usefulness, 161

milk quota article, 160

page position, 85-94

question cards, use of, 170-87

Ratner, Joe, on, 200

sales copy, top of page, 138

sample size, 14

scores, 1940 and 1960, 108 
Readership surveys (continued)

testing jumps, 17

Wallaces Farmer poll, 12 young people, 134

Reading, time spent in, 109

Reading days, 109

"Reading Ease," defined, 21 example, 22, 23

Recipes, read by farm women, 28

Records, farm, readership, 198

Reid, Rosemary, 6

Research, in farm publications, 1128

in the future, 188-99

survey methods, 209-17

Respirators, use of, 152

Respondent in surveys, 13

Robin Hood ad, 130, 140

Roper, Elmo, 239

Rosenberg, Morris, 242

Rule vs. white space, 120

Runovers, scores on, 17

Rural-farm adults, 211

Sales appeal testing, 227

Sales copy

beef cattle feed, 138

color, 56, 57, 58, 59

dairy feed, 135

farm machinery, 142

flour, 136, 140

hog feed, 139

mastitis, 75, 226

milker, 141

top of page, 73,138

Samples

opinion polls, 12, 71, 212

readership surveys, 210,211

split runs, 213

Savage, Job K., Jr., 237

Schering Corporation (Trilafon), 125

Schramm, Wilbur, 7, 243

Screening question, 151-53

Season, effect on readership, 31

"Seen," defined, 13
Sheep articles score low, 85

Significance, tests of, 214, 215

Silage, corn, transposed articles, 91

Smith, George Horsley, 243

Smith, M. Brewster, 243

Social security, articles on, 12, 132

Soil acidity, Flesch score on article, 22

Sorenson, Douglas, 6

Sources of farm information, 189

Soybean harvesting cover theme, 34 , 42

Spencer Fertilizer, 100, 104, 105

Split-run surveys

$A$ and B counties, 219, 221

$A$ and $B$ samples, 14, 18

attracting farm women, 36

Bovitrin split, 223-27

boxes with and without rule, 113, 120, 121

close-up cover, 36,37

color, $43 \mathrm{ff}$.

color in ads, 50,51

cow vs. test tubes, 74,75

cutout vs. square picture, 80,81

decorations and color, 58

defined, 18

first in 1946, 19

with Flesch formula, 19, 20

Flesch split, 1960, 22, 26, 27

head in color, 53

King Midas ad, 129, 136, 137

man vs. hog, 76,77

market analysis, 222

MoorMan hog feed, 178, 179, 182, 183

personalized dirt copy, 112

photograph vs. drawing, 72, 73

profit motive head, 106

prospects for ads, 134

quote in balloon, 136, 137

recipes with and without illustrations, 68

results, 224

table of contents, 122

thumbnails, 78, 79 
unchanged ads with differing editorial copy, 116, 117

Wallaces Farmer covers, 34, 35

Wisconsin Agriculturist covers, 34,36

Stanton, Frank, 242

Starch readership checks, 15, 62, $64,95,109,154,190$

Starcross Alfalfa, 99, 127

Statistical Laboratory, Iowa State University

study on subject matter, 161, 171, 239

surveys by, 15

Stouffer, Samuel A., 243

Strand, Norman, 7

Subject matter attractive, 161-66

experience with, 169

hog prices, 165,167

home lighting, 168

listing by InFARMation Please, 161-64

more important than layout, 21

than style, 24

Subjects, favorite

farm men, 162, 164

farm women, 163

Subscriptions not taken by inter. viewers, 213

Successful Farming, 46

Suci, George J., 243

Surge Milker, 141

Swanson, Charles, 7

Syllables, in "Reading Ease" formula, 23

in Flesch split, 26, 27

Table of contents, 115, 122

Tannenbaum, Percy H., 243

Taylor, Dorothy, 6

Technology, new, 189

Testimonials, testing by question cards, 177-79

Theme, 42

Thompson, Leon, 6
Thumbnail cuts, effect of, $67,78,79$

Transposed articles, 86-94

Type

appeal of larger type, 110, 111

bigger, for old folks, 118

changes in, 109

splits on width of line, 110

Voskuil, W. C., 6

Wallace, Henry A., 11, 202

Wallaces Farmer

age and education in readership, 132

baby pig article, 149

Benson poll, 154

caption type for cover, 35

comparison with Starch scores, 15

constitutional convention poll, 151

contract farming poll, 152

cover split, 35, 37, 38, 39

decorations and color split, 58, 59

department value, tests, 174

dirt copy split, 112

drawing vs. photograph, 64

editorial page scores, 25

high scoring covers, 33

hog price supports poll, 165, 167

home lighting, 168

hybrid corn, 157

InFARMation Please poll, 161, 162, 163

John Deere ad, 128, 142

"liquor by the drink" poll, 150

lockjaw poll, 152

mail pre-test on subjects, 156

meat cookery, 176, 186

mutilated cut, 67

non-readers and readers, 30, 31, 144-45

overprint test, 45

overproduction and farm income, 158

photographs in 1930, 1960, 61, 62 
Wallaces Farmer (continued) Poll started in 1938, 12 poor head lowers score, 95 Protein Blenders ad, 128, 138, 139 question cards, 171 second color test, 43, 44

Starch survey, heads, 97, 98, 99 testimonials, $177-79$ thumbnail cuts, $67,78,79$ timely theme score, 42 transposed articles, $86,87,88,91$, 94

trying out recipes, 185

"What's Ahead," 166 women's score on cover, 33

Waples, Douglas, 243

White, Robert W., 243

Wisconsin Agriculturist Agri-Vision score, 181 Benson, 154

Bovitrin ad, 128

bulk tanks, 154

color splits, $49,50,51,52-55,56-$ 57

cover splits, $36,40,41$

editorial cartoon, 63, 82, 83

Flesch splits, 20

food, 166

heads, 96-97, 99-101, 105

King Midas ad, 129

Lebanon, 155

market outlook, 165

mastitis ad split, 74-75 milk quotas, 153, 160

mutilated cut, 67

non-readers, 30-32

non-readers and readers with second language, 146

Poll comparison with Starch scores, 15

Quemoy, Matsu, 154

question cards, 172

readership by part-time farmers, 133

recipes with and without illustrations, 68

Robin Hood ad, 130, 140

small farm, 166

Surge ad, 141

transposed articles, 88-89, 92-93

type changes in, 110

"What's Ahead," 148

Women, farm

color in ads, 52-53

cover appeal, 36,38

food page, 28

readers of general magazines, 145

readership by, 28

recipe copy, 140

type size, 11

Wisconsin cover, 40-41

Workday Pointers, score on, 174

Words per sentence, 23, 26-27

Yohe, Ralph S., 6 